
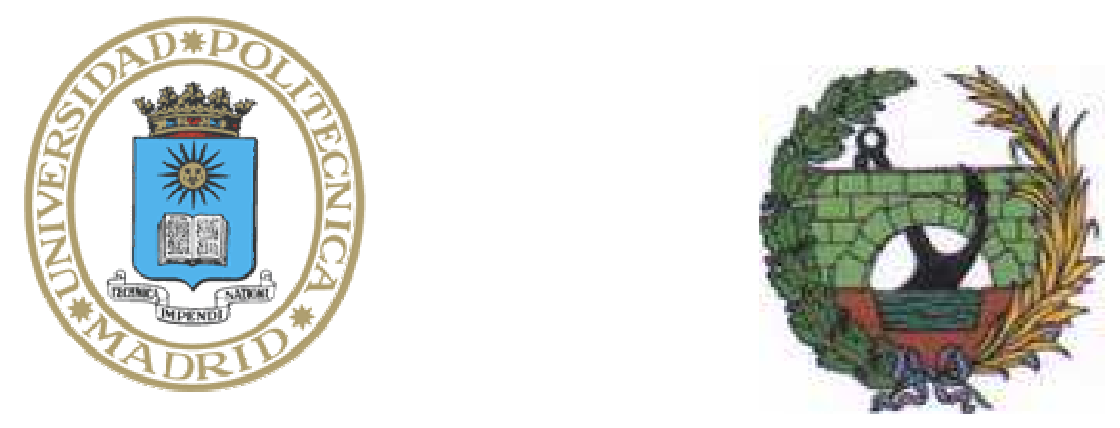

UNIVERSIDAD POLITÉCNICA DE MADRID

ESCUELA TÉCNICA SUPERIOR DE INGENIEROS DE CAMINOS, CANALES Y PUERTOS

TESIS DOCTORAL

\title{
ANÁLISIS TÉCNICO Y FINANCIERO DE LAS MÁQUINAS DE ELEVACIÓN
}

\author{
MIGUEL FLÓREZ DE LA COLINA \\ Ingeniero de Caminos, Canales y Puertos
}

Madrid, 2015 


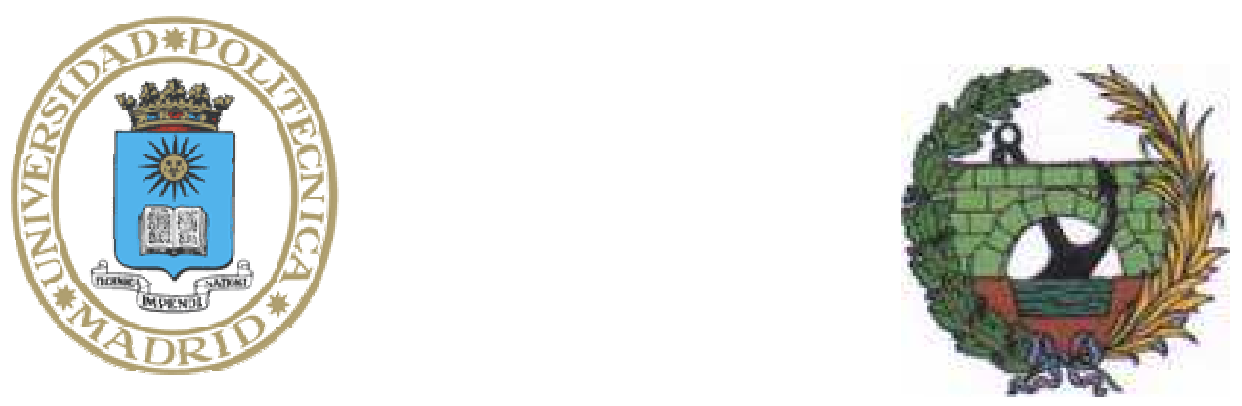

DEPARTAMENTO DE INGENIERÍA CIVIL: CONSTRUCCIÓN

ESCUELA TÉCNICA SUPERIOR DE INGENIEROS DE CAMINOS, CANALES Y PUERTOS

\author{
TESIS DOCTORAL
}

\title{
ANÁLISIS TÉCNICO Y FINANCIERO DE LAS MÁQUINAS DE ELEVACIÓN
}

Autor: Miguel Flórez de la Colina

Ingeniero de Caminos, Canales y Puertos

Director: Manuel Rivas Cervera

Doctor Ingeniero de Caminos Canales y Puertos

Madrid, 2015 


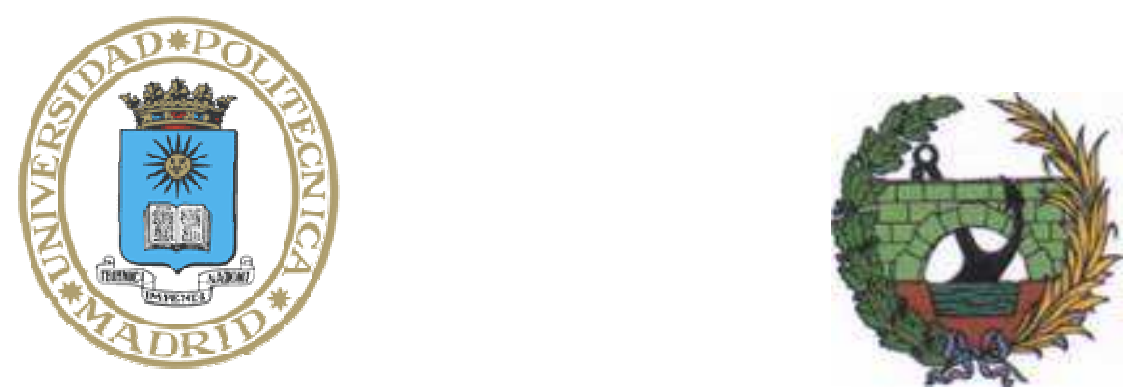

TESIS DOCTORAL

\section{ANÁLISIS TÉCNICO Y FINANCIERO DE LAS MÁQUINAS DE ELEVACIÓN}

Autor: Miguel Flórez de la Colina

Director de Tesis: Manuel Rivas Cervera

Tribunal nombrado por el Mgfco. y Excmo. Sr. Rector de la Universidad Politécnica de Madrid, el día de de 2015.

PRESIDENTE:

VOCAL:

VOCAL:

VOCAL:

VOCAL SECRETARIO:

Acuerda otorgarle la calificación de:

Madrid, de de 2015 



\section{RESUMEN}

Los nombres que se usan actualmente para las grúas los ponen las empresas fabricantes y muy frecuentemente no tienen relación con su tipología ni con su capacidad. Por otra parte, es de uso común en la construcción, llamar a las grúas usando su tonelaje nominal que coincide normalmente con su capacidad máxima que se obtiene a radio mínimo.

Existe una controversia por el uso de este valor ya que no suele definir bien la capacidad de las máquinas. En cuanto el radio de trabajo se aleja de sus valores mínimos, las grúas están limitadas por el momento de vuelco que no tiene porque comportarse de manera proporcional o ni siquiera relacionada con el valor de la capacidad nominal. Esto hace que comparar grúas mediante sus capacidades nominales (que son sus denominaciones) pueda inducir a errores importantes. Como alternativa, se pretende estudiar el uso de momento máximo de vuelco MLM por sus siglas en inglés (Maximum Load Moment) para intentar definir la capacidad real de las grúas.

Se procede a realizar un análisis técnico y financiero de grúas con respecto a ambos valores mencionados con objeto de poder determinar cuál de los dos parámetros es más fiable a la hora de definir la capacidad real de estas máquinas. Para ello, se seleccionan dentro de las tres tipologías más importantes por su presencia e importancia en la construcción (grúas de celosía sobre cadenas, grúas telescópicas sobre camión y grúas torre) nueve grúas de distintos tamaños y capacidades con objeto de analizar una serie de parámetros técnicos y sus costes. Se realizan de este modo diversas comparativas analizando los resultados en función de las tipologías y de los tamaños de las distintas máquinas.

Para cada máquina se obtienen las capacidades y los momentos de vuelco correspondientes a distintos radios de trabajo. Asimismo, se obtiene el MLM y el coste hora de cada grúa, este último como suma de la amortización de la máquina, intereses del capital invertido, consumos, mantenimiento y coste del operador.

Los resultados muestran las claras deficiencias del tonelaje nominal como valor de referencia para definir la capacidad de las grúas ya que grúas con el mismo tonelaje nominal pueden dar 
valores de capacidad de tres a uno (e incluso mayores) cuando los radios de trabajo son importantes.

A raíz de este análisis se propone el uso del MLM en lugar del tonelaje nominal para la denominación de las grúas ya que es un parámetro mucho más fiable. Siendo conscientes de la dificultad que supone un cambio de esta entidad al tratarse de un uso común a nivel mundial, se indican posibles actuaciones concretas que puedan ir avanzando en esa dirección como sería por ejemplo la nomenclatura oficial de los fabricantes usando el MLM dentro del nombre de la grúa que también podría incluir la tipología o al menos alguna actuación legislativa sencilla como obligar al fabricante a indicar este valor en las tablas y características de cada máquina.

El ratio analizado Coste horario de la grúa / MLM resulta ser de gran interés y permite llegar a la conclusión que en todas las tipologías de grúas, la eficiencia del coste por hora y por la capacidad (dada por el MLM) aumenta al aumentar la capacidad de la grúa. Cuando los tamaños de cada tipología se reducen, esta eficiencia disminuye y en algunos casos incluso drásticamente.

La tendencia del mundo de la construcción de prefabricación y modularización que conlleva pesos y dimensiones de cargas cada vez más grandes, demandan cada vez grúas de mayor capacidad y se podría pensar en un primer momento que ante un crecimiento de capacidades tan significativo, el coste de las grúas se podría disparar y por ello disminuir la eficiencia de estas maquinas. A la vista de los resultados obtenidos con este análisis, no sólo no ocurre este problema sino que se observa que dicho aumento de tamaños y capacidades de grúas redunda en un aumento de su eficiencia en cualquiera de las tipologías de estas máquinas que han sido estudiadas. 


\section{ABSTRACT}

The crane names that are actually used are given by crane manufacturers and, very frequently, they do not have any relationship with the crane type nor with its capacity. On the other hand, it is common in construction to use the nominal capacity (which corresponds in general to the capacity at minimum radius) as crane name.

The use of this figure is controversial since it does not really reflect the real crane capacity. When the working radius increases a certain amount from its minimum values, the crane capacity starts to be limited by the crane tipping load and the moment is not really related to the value of the nominal capacity. Therefore, comparing cranes by their nominal capacity (their names) can lead to important mistakes. As an alternative, the use of the maximum load moment (MLM) can be studied for a better definition of real crane capacity.

A technical and financial analysis of cranes is conducted using both parameters to determine which one is more reliable in order to define crane's real capacity. For this purpose, nine cranes with different sizes and capacities will be selected within the most relevant crane types (crawler lattice boom cranes, telescopic truck mounted cranes and tower cranes) in order to analyze several parameters. The technical and economic results will be compared according to the crane types and sizes of the machines.

For each machine, capacities and load moments are obtained for several working radius as well as MLM and hourly costs of cranes. Hourly cost is calculated adding up depreciation, interests of invested capital, consumables, maintenance and operator's cost.

The results show clear limitations for the use of nominal capacity as a reference value for crane definition since cranes with the same nominal capacity can have capacity differences of 3 to 1 (or even bigger) when working on important radius.

From this analysis, the use of MLM as crane name instead of nominal capacity is proposed since it is a much more reliable figure. Being aware of the difficulty of such change since nominal capacity is commonly used worldwide; specific actions are suggested to progress in that direction. One good example would be that manufacturers would include MLM in their 
official crane names which could also include the type as well. Even legal action can be taken by simply requiring to state this figure in the crane charts and characteristics of every machine.

The analyzed ratio: hourly cost / MLM is really interesting since it leads to the conclusion that for all crane types, the efficiency of the hourly cost divided by capacity (given by MLM) increases when the crane capacity is higher. When crane sizes are smaller, this efficiency is lower and can fall dramatically in certain cases.

The developments in the construction world regarding prefabrication and modularization mean bigger weights and dimensions, which create a demand for bigger crane capacities. On a first approach, it could be thought that crane costs could rise significantly because of this capacity hugh increase reducing in this way crane efficiency. From the results obtained here, it is clear that it is definitely not the case but the capacity increase of cranes will end up in higher efficiency levels for all crane types that have been studied. 


\section{AGRADECIMIENTOS}

Quiero dar la gracias en estas líneas a todas las personas que me han ayudado a realizar esta Tesis bien sea mediante su apoyo directo o bien por su paciencia, ánimos o información.

Sin ninguna duda, mi mayor agradecimiento va dirigido a mi director de tesis D. Manuel Rivas Cervera que me ha apoyado, guiado, dirigido y motivado para la realización de esta Tesis a lo largo de todo su proceso. Sin su enorme ayuda y su disponibilidad, no hubiera sido posible realizarlo.

También quiero dar las gracias a los profesionales del mundo de las grúas y maniobras especiales que me ha asesorado, facilitado información y datos y de los que tanto he aprendido, especialmente a: Dña. Consuelo Albarrán, D. Manuel Mato, D. Francisco Cruz, D. Juan Barranco, mis colegas de Wagenborg y muchos otros que tendría que citar aquí pero haría esta lista muy larga.

Y como no a mi familia por su apoyo y su paciencia. Muy en especial, a mi padre que siempre nos transmitió su pasión por la Ingeniería de Caminos y que tanto me animó a hacer la tesis. 


\section{INDICE}

RESUMEN

II

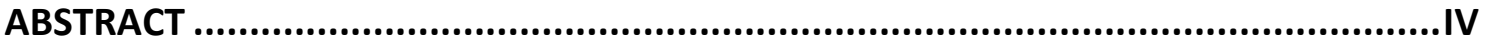

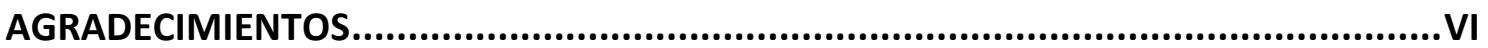

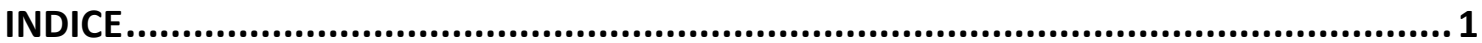

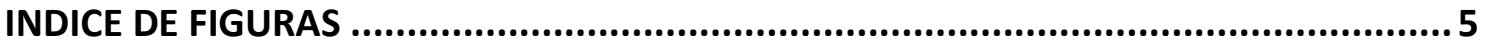

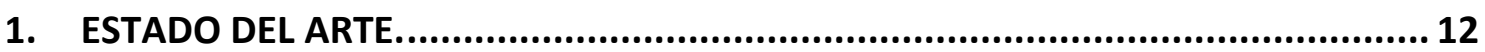

1.1.- SISTEMAS DE ELEVACIÓN / MÁQUINAS DE ELEVACIÓN ................................................ 12

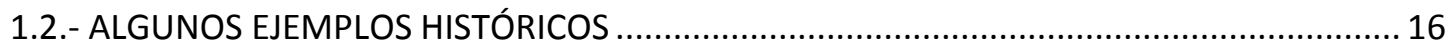

1.2.1. La antigüedad: desde la Cultura Clásica al Renacimiento ......................................... 16

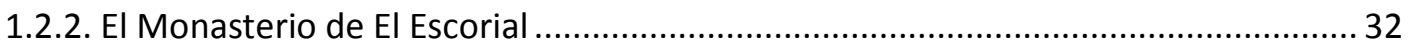

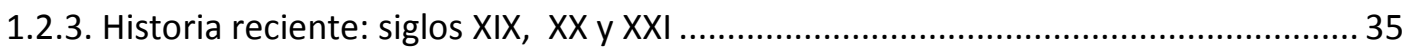

1.3.- RELACIÓN INDISOCIABLE CON EL SECTOR DE TRANSPORTES ESPECIALES ....................... 37

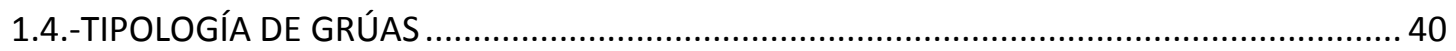

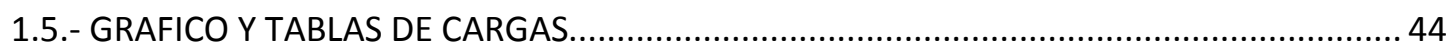

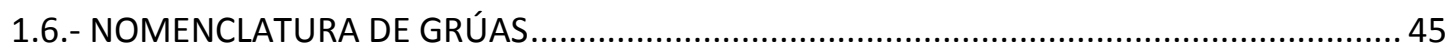

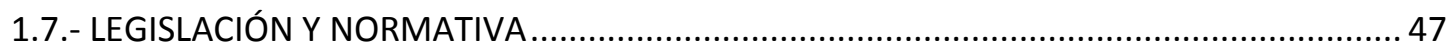

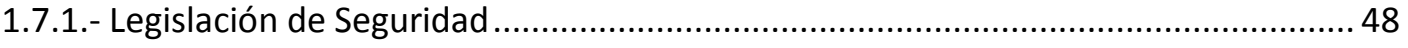

1.7.2.- Legislación sobre el carnet de Gruista .................................................................... 50

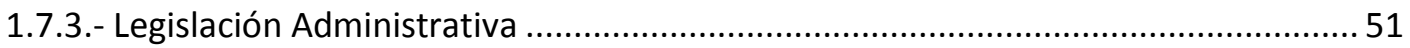

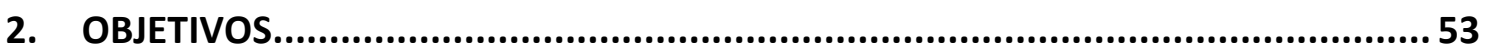

2.1.- OBJETIVOS RELACIONADOS CON LOS PARÁMETROS DE CAPACIDAD DE LAS GRÚAS.... 53

2.2.- OBJETIVOS RELACIONADOS CON LA COMPARATIVA DE LAS GRÚAS ESTUDIADAS........ 55

2.3.- OBJETIVOS RELACIONADOS CON EL ANÁLISIS DEL SECTOR DE LA ELEVACIÓN............... 57 


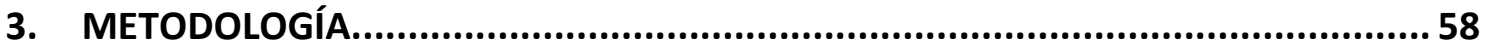

3.1.- ANÁLISIS DEL SECTOR DE GRÚAS Y SISTEMAS DE ELEVACIÓN …..................................58

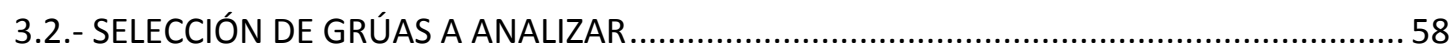

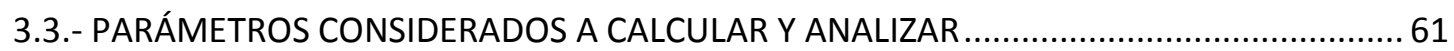

3.4.- METOdOLOGÍA PARA EL CÁLCULO DE COSTE POR HORA DE LAS GRÚAS........................ 62

4. ANÁLISIS DEL SECTOR DE GRÚAS Y SISTEMAS DE ELEVACIÓN. .........................65

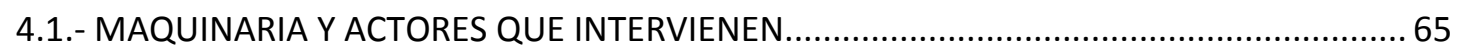

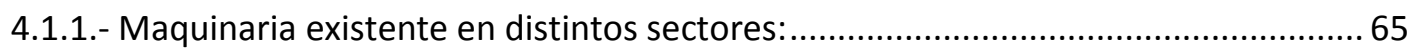

4.1.1.1.- Por tipología (Torre, telescópica, celosía, etc.) ................................................. 65

4.1.1.2.- Por sectores de actividad (Puertos, eólicos, cimentaciones, etc.) ..................... 68

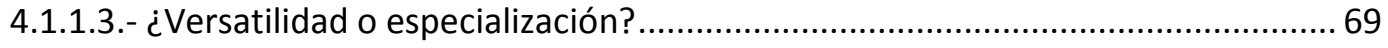

4.1.2.- Actores que intervienen en el sector de grúas....................................................... 71

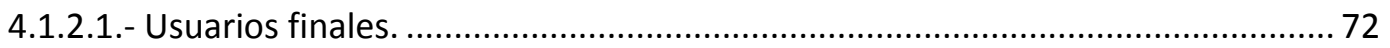

4.1.2.2.- Propietarios: empresas de grúas....................................................................... 73

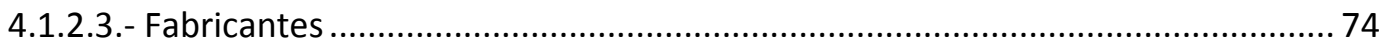

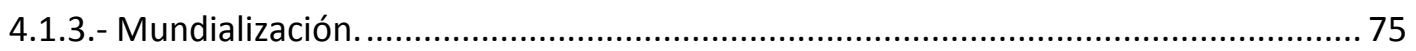

4.1.4.- Otros sistemas de elevación: de personas, pequeña maquinaria, etc. .................... 76

4.1.5.- Otros sistemas de elevación especiales: Pórticos, gatos de cable, gatos trepantes,

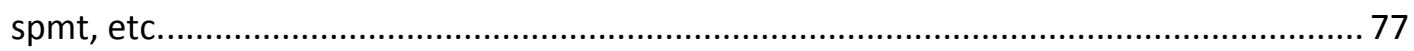

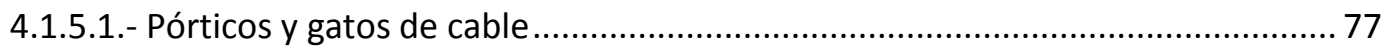

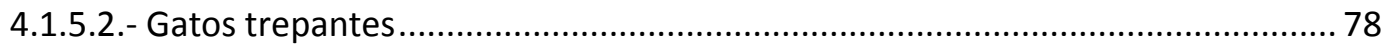

4.1.5.3.- Carretones SPMT (Self Propelled Modular Trailers) …...................................... 80

4.1.6.- Desarrollo en materiales auxiliares: material de izado, etc..................................... 81

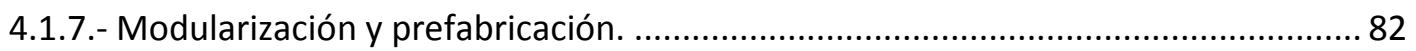

4.1.8.- Relación de las grúas con diversas variables de la construcción y la economía:...... 83

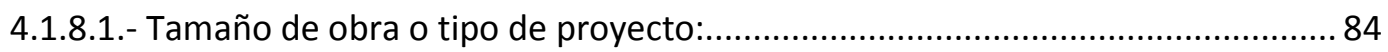

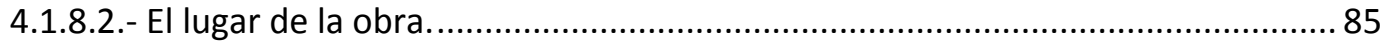

4.1.8.3.- Variable macroeconómicas: Incremento del PIB de un país / Inversión en

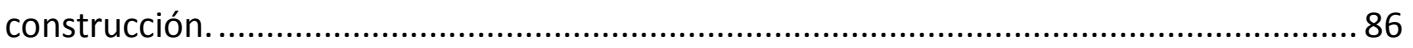

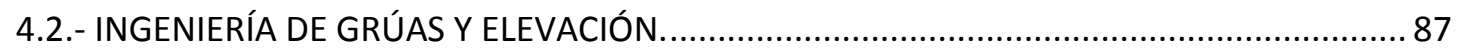

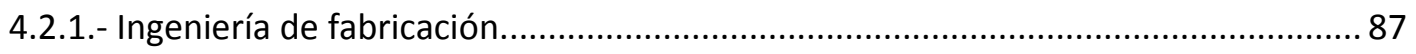

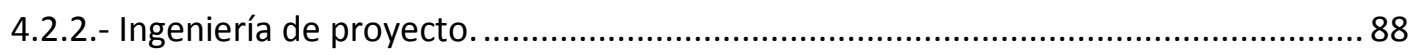

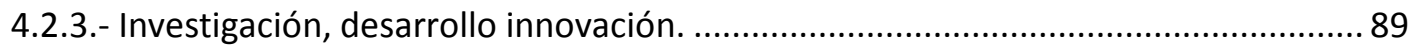




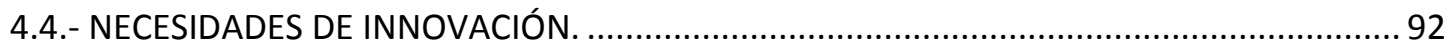

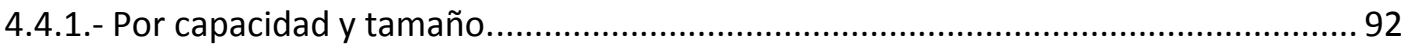

4.4.2.- Por especialización para el tipo de trabajo................................................................ 94

4.4.3.- Por evolución en la forma de ejecución de proyectos: Modularización.................... 95

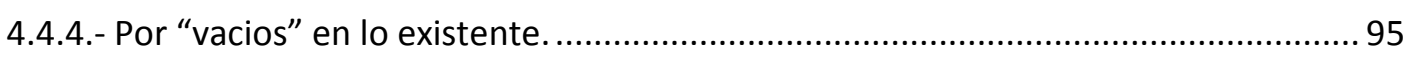

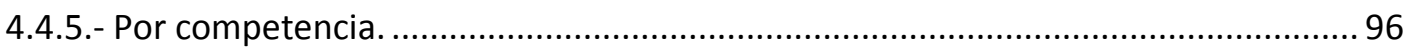

4.5.- ANÁLISIS DE CASOS CONCRETO DE NUEVOS DESARROLLOS......................................... 97

4.5.1.- Casos en los que una necesidad provoca una innovación........................................ 97

4.5.1.1.- Grúas portuarias o de buques de alta capacidad:............................................. 98

4.5.1.2.- Izado en el año 2001 del Submarino Kursk: ..................................................... 100

4.5.2.- Casos en los que una innovación provoca una necesidad.................................... 102

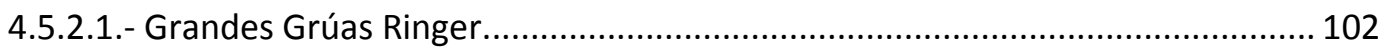

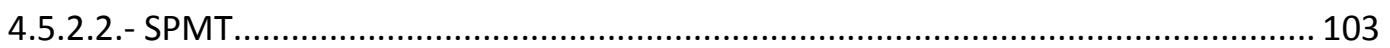

4.5.2.3.- Sistema de empuje vertical de grandes cargas............................................... 104

4.6.- MOTIVACIONES Y DESMOTIVACIONES ECONÓMICAS DE LAS INNOVACIONES. ........... 106

4.6.1.- Márgenes y riesgos comerciales de las innovaciones............................................. 106

4.6.2.- "Canibalizaciones" de productos existentes. Barreras de entrada......................... 107

4.6.3.- Cambio del "producto" ofrecido: del "alquiler" de una grúa a la "solución" de un proyecto.

5. ANÁLISIS COMPARATIVO TÉCNICO FINANCIERO ....................................... 108

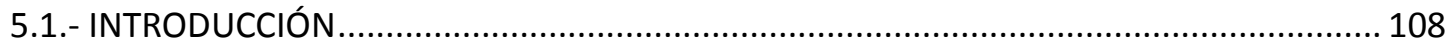

5.2.- ANALISIS TÉCNICO DE DIVERSAS GRÚAS............................................................... 112

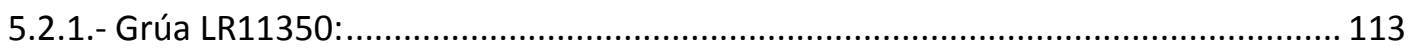

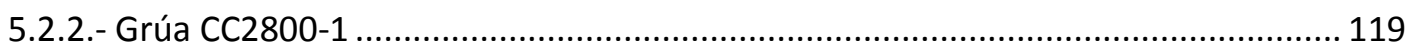

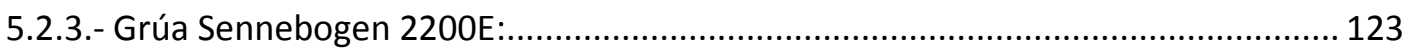

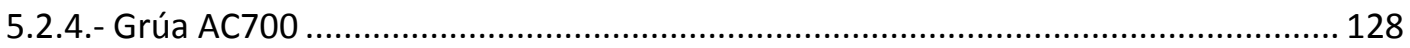

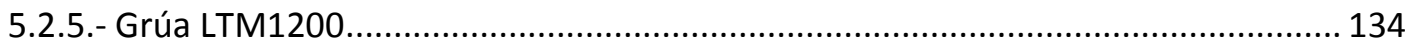

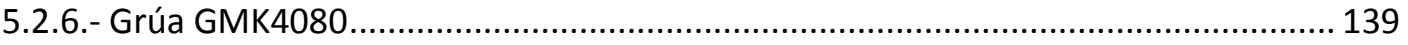

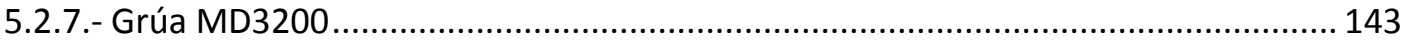

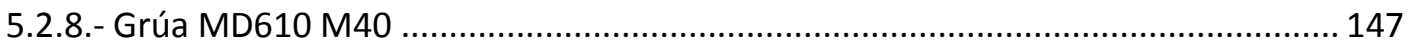

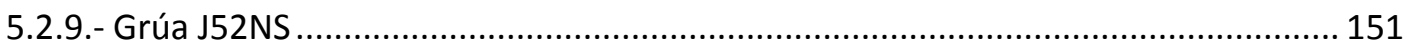


5.3.1.- Amortización

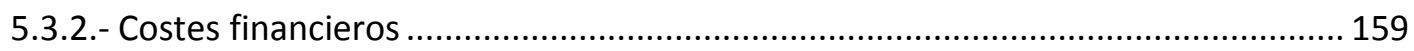

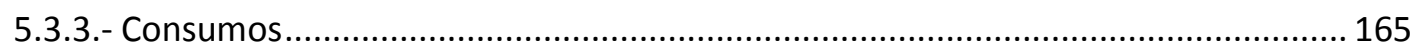

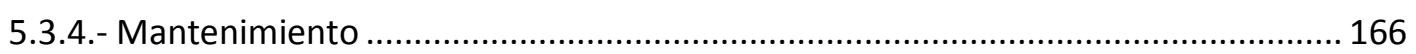

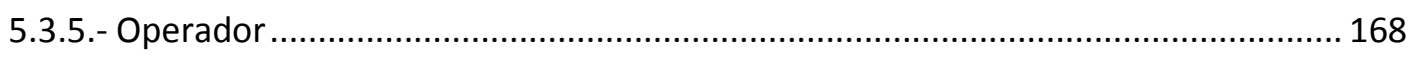

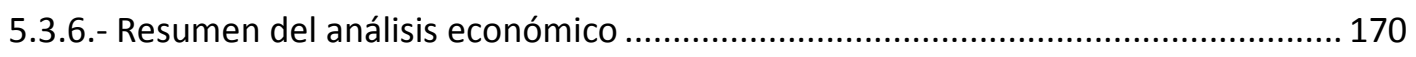

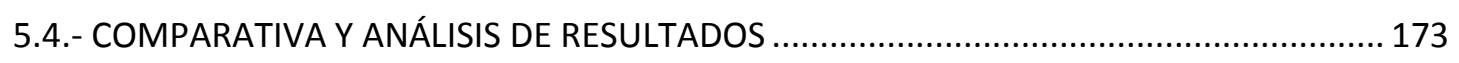

5.4.1.- Comparativa y análisis de los momentos de vuelco obtenidos y de las capacidades

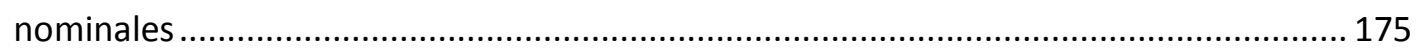

5.4.2.- Comparativa y análisis del coste horario de las grúas .......................................... 181

5.4.3.- Ratio Coste horario por tonelada nominal ........................................................... 182

5.4.4.- Ratio Coste horario por máximo momento de vuelco (MLM) .............................. 184

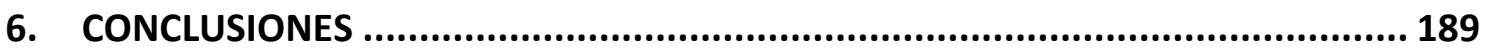

6.1.- CONCLUSIONES SOBRE EL MÁXIMO MOMENTO ADMISIBLE MLM Y EL TONELAJE

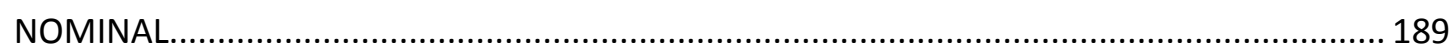

6.2.- CONCLUSIONES CON RESPECTO A LOS TAMAÑOS Y TIPOLOGÍAS DE LAS GRÚAS

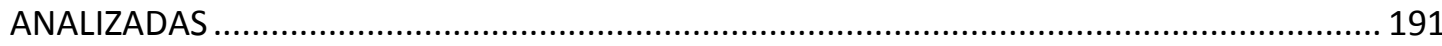

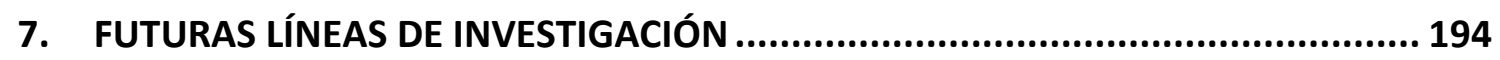

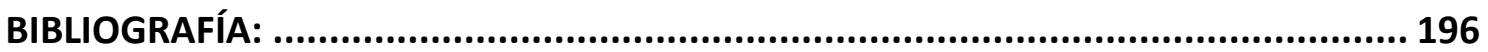

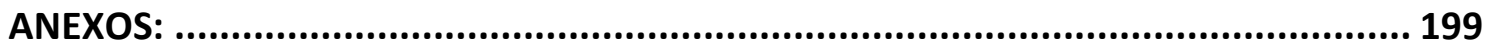

ANEXO №1: INSTRUCCIÓN TÉCNICA COMPLEMENTARIA (ITC) “MIE-AEM-2" del Reglamento de aparatos de elevación y manutención, referente a grúas torre para obras u otras aplicaciones. REAL DECRETO 836/2003 de 27 de Junio ........................................................... 200

ANEXO №2: INSTRUCCIÓN TÉCNICA COMPLEMENTARIA (ITC) “MIE-AEM-4" del Reglamento de aparatos de elevación y manutención, referente a grúas móviles autopropulsadas. REAL

DECRETO 837/2003 de 27 de Junio. 224 


\section{INDICE DE FIGURAS}

Figura 1.1: Plataformas elevadoras de personas: articulada, telescópica y tijera (fuente:

empresa GAM)

Figura 1.2: Foto del diario "El Mundo" del 30 de Marzo de 2008 ilustrando un artículo sobre la crisis de la Construcción.

Figura 1.3: Foto del diario "El País" del 29 de Octubre de 2006 mostrando la actividad de construcción en aquellos años.

Figura 1.4 y Figura 1.5: Construcción de la torre de Babel.

Figura 1.6: Llevar, empujar o tirar de pesos.

Figura 1.7: "Çigueña" 20

Figura 1.8: "Holivela"

Figura 1.9: "Sucula"

Figura 1.10: "Ergata-ae", o cabrestante

Figura 1.11: Cabria

Figura 1.12: Cabria con tenazas de hierro ("ferreus forfex")

Figura 1.13: Grúa con "polypaston" y con rueda ("maius tympanum")

Figura 1.14:"Construcción de un puente"

Figura 1.15: "Construcción de la torre de Babel"

Figura 1.16: Grúa en "Los veintiún libros de los ingenios y las máquinas"

Figura 1.17: Máquina para elevar materiales, basada en la que Filippo Brunelleschi empleó en Santa María de las Flores en Florencia (1420 - 1421). Tratado Taccola 30

Figura 1.18: "Castello" de Filippo Brunelleschi empleado en Santa María de las Flores en Florencia. Dibujo de Leonardo Da Vinci.

Figura 1.19: Detalle de la vista del monasterio del Escorial durante su construcción 32 
Figura 1.20: Maqueta de las grúas de Juan de Herrera del Museo de Construcción del Monasterio de El Escorial.

Figura 1.21: Tenazas de hierro ("ferreus forfex") para elevar piedras, Monasterio de El Escorial.

Figura 1.22: Polea para elevar piedras, Museo de Construcción del Monasterio de El Escorial.34

Figura 1.23: Detalle del cuadro "la torre de Babel" de Peter Bruegel', con una grúa de doble rueda

Figura 1.24: Grúa Fairbairn. (1875) Mánchester, del puerto de Sevilla, potencia 90 tn. 35

Figura 1.25: Grúa de vapor del puerto de Tenerife (1920). 36

Figura 1.26: Primera grúa Titán del puerto de Tenerife (1887)

Figura 1.27: Segunda grúa Titán del puerto de Tenerife (1893) 36

Figura 1.28: Carretones autopropulsados SPMT sin carga con los cilindros extendidos elevando su plataforma (max. 600 milímetros en cada carrera vertical).

Figura 1.29: Maniobra con dos grúas durante el transporte de las cámaras de coque de Petronor para pasar por encima de los racks de tuberías debido al gálibo insuficiente de los mismos (2009)

Figura 1.30: Cabria del Puerto de Bilbao (2005)

Figura 1.31: Grúa Celosía sobre cadenas (Central de ciclo Combinado de Castejón, Navarra, 2002)

Figura 1.32: Grúa telescópica sobre camión (Cajón del Adriatic LNG terminal, Algeciras 2006)

Figura 4.1: Izado de Cámara de Coque en la Refinería de Petronor en 2010 con dos grúas de celosía para verticalizarla: LR11350 y CC2500 de 1.350t y 500t respectivamente.

Figura 4.2: Grúa Portainer en el Puerto de Valencia mientras es transportada con carretones SPMT

Figura 4.3: Terex Demag CC2800 NT de ancho reducido de cadenas para desplazarse por parque eólico. 
Figura 4.4: Maniobra con torres, gatos de cable (dos de 900 toneladas) y patines de deslizamiento para el volteo de las columnas temporales de Puente Infante Dom Henrique (Oporto, año 2002)

Figura 4.5: Gateo de una Antena(INTA- NASA) en Robledo de Chavela para elevarla y poder introducir los SPMT debajo para su transporte.

Figura 4.6: Transporte de Cámaras de Coque de 480 toneladas a Petronor sobre SPMT 80

Figura 4.7: Izado en Dragados Offshore Cádiz con la Demag CC12600 de 1.600 toneladas usando tres niveles de balancines y multitud de eslingas y griletes de alta capacidad. El total del material de izado utilizado superaba las 100 toneladas de peso.

Figura 4.9: Grúa LR11350 (1.350 toneladas de capacidad nominal) con capacidad de "barrer" toda una planta para poder realizar con ella la práctica totalidad de las maniboras. Francia, 2013.

Figura 4.10: Grúa LR1350 colocando bloques de hormigón en la escollera del dique de la Esfinge, Gran Canaria 2008.

Figura 4.11: Transporte de puente mixto para su recolocación en la A42 a la altura de Toledo izándolo con SPMT y torres de celosía. Agosto de 2009.

Figura 4.12: Maniobra de verticalización combinando grúa CC6800 de 1.250t de capacidad con carretones SPMT que realizan la retenida de la maniobra usando una mesa de volteo. Refinería de Huelva, año 2008.

Figura 4.13: Grúa LR1350 de 350t de capacidad nominal colocándose sobre 3 capas de reparto de cargas (dos de madera y una de vigas cajón metálizas) para poder trabajar sobre forjado de hormigón postesado. Proyecto Adriatic Terminal LNG, Algeciras 2006. 90

Figura 4.14: Accidente de dos grandes telescópicas en Holanda en el verano de 2015 trabajando sobre barcazas.

Figura 4.16: Grúa de celosía descargando en tándem con una telescópica en el Puerto de Palma de Mallorca los módulos de la central de ciclo combinado de Son Reus.

Figura 4.17: Descarga de cámaras de coque de 480 toneladas en el Puerto de Bilbao desde buque con 2 grúas de 900 toneladas de capacidad cada una. 
Figura 4.18: Presentación de la propuesta de la maniobra para el izado del Submarino Ruso Kursk. 100

Figura 4.19: Barcaza Giant 4 con los gatos de cable para el izado del Kursk. 101

Figura 4.20: Segunda generación de PTC presentadas en Julio de 2011: PTC140 y PTC200.... 102

Figura 4.21: Transporte sobre SPMT de 14.000 toneladas, record sobre ruedas en su momento. 103

Figura 4.22: Sistema de torres con gatos de cable para izar el módulo de 7.000 toneladas en Brest en el año 2000. Fue record de este tipo de izado en su momento. 104

Figura 4.23: Sistema de empuje para izar una plataforma Offhore de 14.000 toneladas (aprox.) unos 12 metros de altura usando patines de deslizamiento. 105

Figura 4.24: Sistema MSG izando la Noria de Londres. 106

Figura 5.1: Extracto de la parte superior de la página no 33 de las tablas oficiales de la grúa LR11350 mostrando el gráfico de la misma

Figura 5.2: Extracto de la página no 34 de las tablas oficiales de la grúa LR11350.

Figura 5.3: Extracto de la página no 32 de las tablas oficiales de la grúa LR11350. 115

Figura 5.4: Extracto de la página no 25 de las tablas oficiales de la grúa LR11350. 116

Figura 5.5: Tabla resumen de resultados técnicos obtenidos para la grúa LR11350. 118

Figura 5.6: Extracto de la parte superior de la página no1 de las tablas oficiales de la grúa CC2800-1

Figura 5.7: Extracto de la página no 14 de las tablas oficiales de la grúa CC2800-1 120

Figura 5.8: Extracto de la página no 53 de las tablas oficiales de la grúa CC2800-1 120

Figura 5.9: Extracto de la página no 17 de las tablas oficiales de la grúa CC2800-1 121

Figura 5.10: Tabla resumen de resultados técnicos obtenidos para la grúa CC2800 122

Figura 5.11: Diagrama de la grúa Sennebogen 2200E de la página no4 de las tablas oficiales de la grúa. 123

Figura 5.12: Extracto de la página no 5 de las tablas oficiales de la grúa 2200E. 124 
Figura 5.13: Extracto de la página no 7 de las tablas oficiales de la grúa 2200E.

Figura 5.14: Tabla resumen de resultados técnicos obtenidos para la grúa $2200 E$.

Figura 5.15: Extracto de la página no5 de las tablas oficiales de la AC700 con sus dimensiones

Figura 5.16: Extracto de la página no 14 de las tablas oficiales de la AC700 con su diagrama con pluma principal 129

Figura 5.17: Extracto de la página no 15 de las tablas oficiales de la AC700. 131

Figura 5.18: Extracto de la página no 41 de las tablas oficiales de la grúa AC700 132

Figura 5.19: Tabla resumen de resultados técnicos obtenidos para la grúa AC700 133

Figura 5.20: Extracto de la página no1 de las tablas oficiales de la LTM1200 134

Figura 5.21: Extracto de la página no4 de las tablas oficiales de la LTM1200 135

Figura 5.22: Extracto de la página no 25 de las tablas oficiales de la grúa LTM1200 136

Figura 5.23: Tabla resumen de resultados técnicos obtenidos para la grúa LTM1200. 138

Figura 5.24: Diagrama de la GMK4080 de la página no13 de dicha grúa 139

Figura 5.25: Extracto de la página no14 de las tablas oficiales de la GMK4080. 140

Figura 5.26: Extracto de la página no 19 de las tablas oficiales de la grúa GMK4080. 141

Figura 5.27: Tabla resumen de resultados técnicos obtenidos para la grúa GMK4080. 142

Figura 5.28: Extracto de la página no1 de las tablas oficiales de la grúa MD3200. 143

Figura 5.29: Extracto de la página no 3 de las tablas oficiales de la grúa MD3200. 144

Figura 5.30: Tabla resumen de resultados técnicos obtenidos para la grúa MD3200 146

Figura 5.31: Extracto de la página no1 de las tablas oficiales de la grúa MD610 M40 147

Figura 5.32: Extracto de la página no 3 de las tablas oficiales de la grúa MD610 M40. 148

Figura 5.33: Tabla resumen de resultados técnicos obtenidos para la grúa MD610 40 150

Figura 5.34: Extracto de la página n¹ de las tablas oficiales de la grúa J52NS. 151 
Figura 5.36: Tabla resumen de resultados técnicos obtenidos para la grúa J52NS

Figura 5.37: Cálculo de intereses para la grúa LR11350

Figura 5.38: Cálculo de intereses para la grúa CC2800. 160

Figura 5.39: Cálculo de intereses para la grúa $2200 E$ 161

Figura 5.40: Cálculo de intereses para la grúa AC700. 161

Figura 5.41: Cálculo de intereses para la grúa LTM1200 162

Figura 5.42: Cálculo de intereses para la grúa GMK4080 162

Figura 5.43: Cálculo de intereses para la grúa MD3200 163

Figura 5.44: Cálculo de intereses para la grúa MD610 40 163

Figura 5.45 : Cálculo de intereses para la grúa J52NS 164

Figura 5.46: Tabla resumen de resultados económicos obtenidos para las grúas de celosía.. 170

Figura 5.47: Tabla resumen de resultados económicos obtenidos para las grúas telescópicas

Figura 5.48: Tabla resumen de resultados económicos obtenidos para las grúas torre......

Figura 5.49: Tabla resumen general de resultados obtenidos:

Figura 5.50: Comparativa de los momentos de vuelco obtenidos de las grúas 176

Figura 5.51: Porcentajes de los momentos Mom Rmin, Mon R30 y MomRmax con respecto al MLM (Maximum Load Moment)

Figura 5.52: Gráfico del ratio MLM / Toneladas nominales.

Figura 5.53: Comparativa gráfica de la importancia de los ratios MLM / T.Nom (Maximo momento por Tonelaje nominal de las grúas) según las distintas tipologías de máquinas. 180

Figura 5.54: Gráfico del coste horario en Euros 181

Figura 5.55: Gráfico del ratio coste horario en Euros / Toneladas nominales de la grúa 183 
Figura 5.56: Gráfico del ratio coste horario en Euros / MLM (Maximum Load Moment), momento máximo de la grúa.

Figura 5.57: Gráfico del ratio coste horario en Euros / MLM (Maximum Load Moment), medias por cada tipología de grúa analizada 188 


\section{ESTADO DEL ARTE.}

\section{1.- SISTEMAS DE ELEVACIÓN / MÁQUINAS DE ELEVACIÓN}

Al hablar de sistemas de elevación, incluimos un enorme abanico de medios y maquinaria de lo más variado ya que las necesidades de elevación son y han sido durante toda la historia básicas para la vida de las personas y especialmente para las actividades de construcción.

Las nomenclaturas y definiciones que se usan para estas máquinas y sistemas son muy a menudo confusas y con escaso rigor. Un claro ejemplo es la carretilla elevadora de obra en la que nos encontramos multitud de nombres según las obras o regiones. Se le llama: Carretilla elevadora o solamente carretilla, toro, forklift (usando la palabra inglesa), manitou (por la marca muy habitual en carretillas elevadoras telescópicas), etc.

Es por lo tanto fundamental clasificar correctamente toda esta variedad de medios tan diferentes entre sí ya que engloban desde un ascensor, a una grúa marítima capaz de elevar una plataforma offshore de varios miles de toneladas, pasando como veremos por equipos de transporte con cierta capacidad elevadora, por una simple grúa torre, por una cinta elevadora de material o por el blondín de una presa. Podríamos citar aquí un gran número de medios de elevación con enormes diferencias entre sí.

La primera distinción que se puede hacer para una clasificación de los sistemas de elevación sería la de la elevación de personas y de la elevación de materiales. Si bien es verdad que los medios se han utilizado tradicionalmente de forma no organizada, ni clasificada e incluso indistintamente, se puede decir que hoy en día, la diferenciación entre la elevación de personas y de materiales es cada vez más evidente y en ello ha influido sin duda alguna la conciencia de seguridad que tenemos en la actualidad y también la legislación derivada fundamentalmente de esta.

Es sin duda muy positivo que la diferenciación de la elevación de personas y materiales se haya hecho efectiva a nivel de los medios y maquinaria utilizados para cada cosa ya que permite mejorar la seguridad de las personas (diseño específico de las máquinas, coeficientes de seguridad para cada tipo de actividad, etc.) 
No hay mejor ilustración de lo anterior que la utilización y enorme auge a nivel mundial de las plataformas elevadoras de personas en obra (cestas telescópicas o tijeras) que ha sustituido en gran parte a los andamios, a los ascensores de obra pero especialmente a las cestas para personas colgadas de grúas telescópicas que hoy en día están prohibidas en muchas legislaciones.
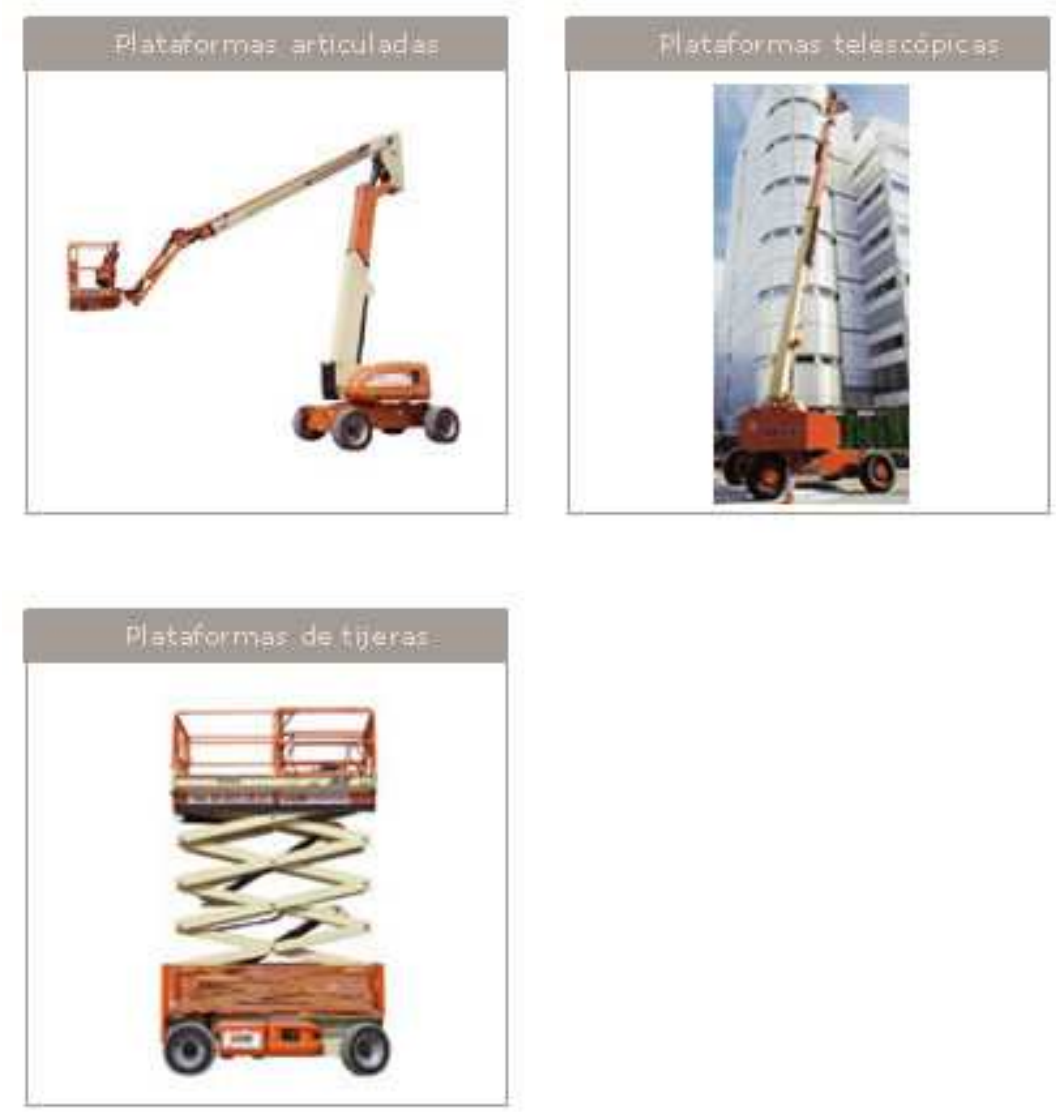

Figura 1.1: Plataformas elevadoras de personas: articulada, telescópica y tijera (fuente: empresa GAM)

Dentro de los sistemas de elevación de cargas, el abanico de medios sigue siendo enorme. Los medios más antiguos utilizados son sin duda la fuerza humana o animal combinándola o no con sistemas más o menos sofisticados de elevación (poleas, grúas primitivas, etc.).

La clasificación de los medios de elevación de cargas es compleja ya que depende de los criterios que se usen para realizarla. Hay sistemas de elevación que no se pueden considerar máquinas de elevación y también multitud de maquinaria que sirve para elevar cargas. Pero sin lugar a duda cuando nos referimos Máquinas de Elevación, a pesar de toda esta variedad e indefinición, "La Grúa" es sin duda La Maquina de Elevación por excelencia a nivel mundial. 
Tanto es así que la imagen de la grúa no es sólo un símbolo de los sistemas de elevación sino del propio sector de la construcción. Cuando se muestra una imagen o símbolo de la construcción en cualquier medio de comunicación o divulgación es frecuente, por no decir casi obligado, que se muestre una grúa. El caso de la grúa torre es especialmente simbólico para la construcción en general y no digamos para la edificación.

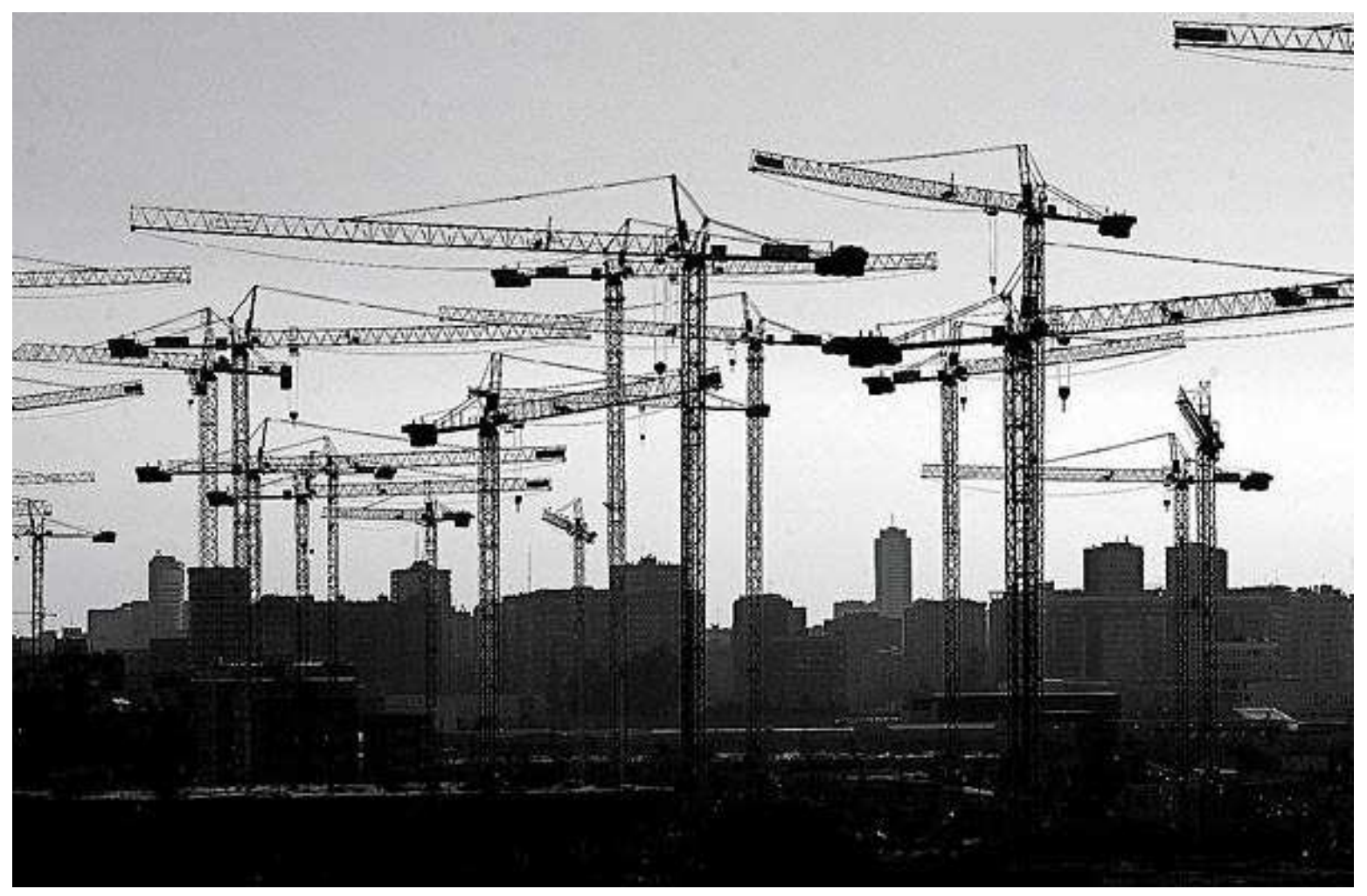

Figura 1.2: Foto del diario "El Mundo" del 30 de Marzo de 2008 ilustrando un artículo sobre la crisis de la Construcción. 


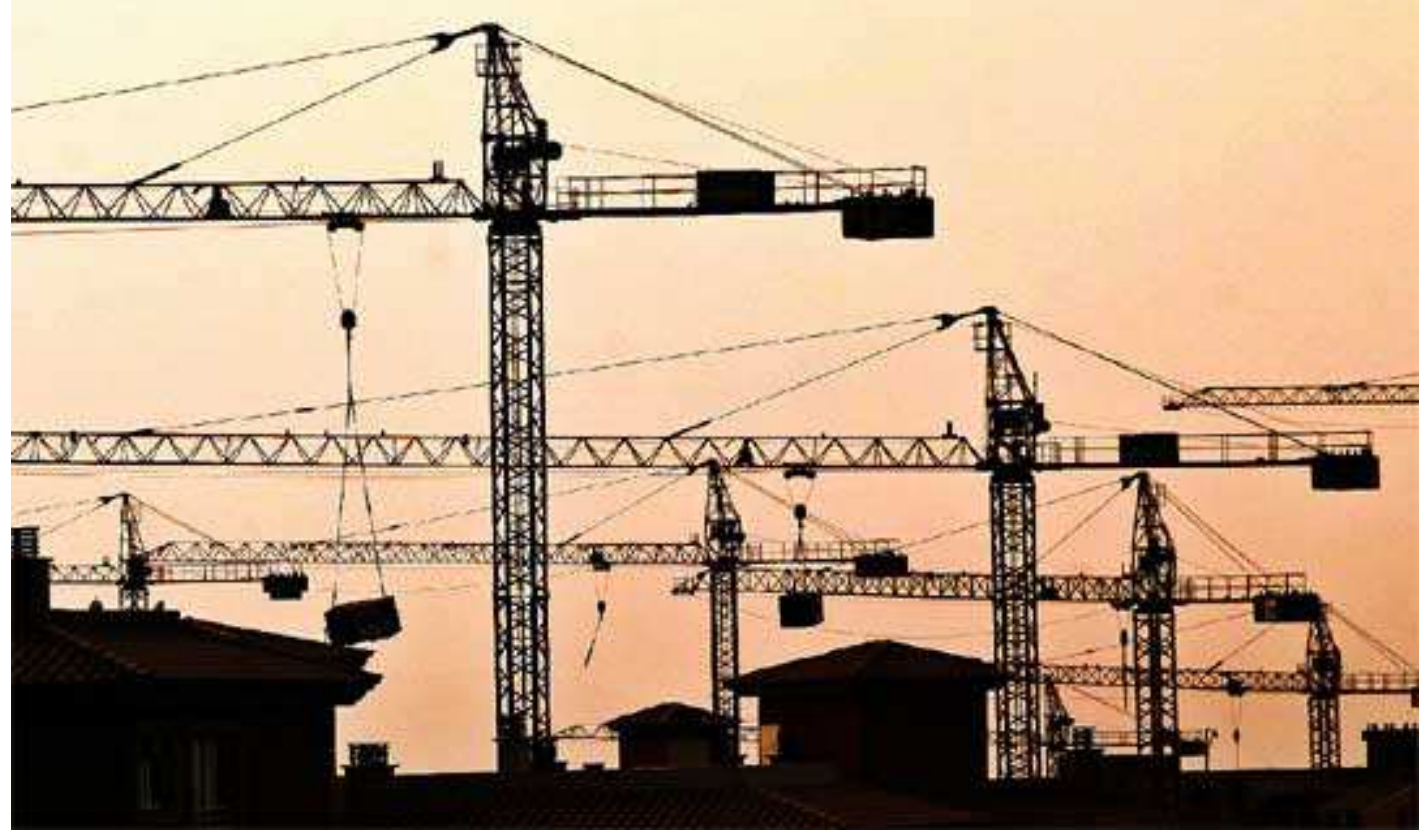

Figura 1.3: Foto del diario "El País" del 29 de Octubre de 2006 mostrando la actividad de construcción en aquellos años.

A pesar de ser una máquina tan conocida es difícil encontrar una buena definición y además el término grúa se utiliza también para otras acepciones similares como la grúa que remolca los coches en caso de avería...

Definición de grúa del BOE: “Aparato de elevación de funcionamiento discontinuo destinado a elevar y distribuir en el espacio las cargas suspendidas de un gancho o de cualquier otro accesorio de aprehensión."

La definición que aparece en el diccionario de la RAE (Real Academia Española, 1977) para "grúa” es: "(Del latín grus, gruis) f. Máquina compuesta por un aguilón montado sobre un eje vertical giratorio, y con una o varias poleas, que sirve para levantar pesos y llevarlos de un punto a otro, dentro del círculo que el brazo describe o del movimiento que pueda tener la grúa" 


\section{2.- ALGUNOS EJEMPLOS HISTÓRICOS}

\subsubsection{La antigüedad: desde la Cultura Clásica al Renacimiento}

Los restos más antiguos de las culturas humanas que han llegado hasta nosotros nos han dejado indicios de cómo han adaptado su entorno para adecuarlo a sus necesidades. Para esta transformación, han ido desarrollando sistemas cada vez más eficaces y, en un momento dado, han aparecido los medios auxiliares, herramientas y maquinaria que han facilitado este trabajo. Se ha realizado una selección de algunos casos concretos que han llegado hasta nosotros y que suponen momentos o soluciones esenciales, que han cambiado y mejorado estos procedimientos para resolver problemas relacionados con la elevación y transporte de materiales o con la elevación de personas para realizar trabajos en altura. La mayoría de los que se exponen estarán relacionados con la construcción, aunque otros, utilizando una maquinaria similar, podrían considerarse más vinculados a lo que hoy denominamos transporte. Soluciones que han ido aportando ideas para mejorar la economía de medios y de tiempo empleados para realizar este tipo de trabajos.

La forma de los edificios en altura más antiguos, así como determinadas trazas encontradas en sus materiales, nos permiten suponer que para la construcción de las pirámides egipcias o mejicanas, se emplearon rampas que permitieron colocar dichos materiales en su posición. Este procedimiento, requería una gran cantidad de mano de obra, tanto para ejecutar dichas rampas como para mover los materiales, grandes bloques de piedra tallada, hasta su lugar. Este problema de colocar estos materiales pesados (o en grandes cantidades) en puntos altos de una construcción, fue uno de los principales desafíos a los que se enfrentaron los constructores de la antigüedad. Y uno de los primeros textos que describe la construcción de un edificio, la torre de Babel, un pasaje de la biblia, nos habla de ello:

"1 Todo el mundo era de un mismo lenguaje e idénticas palabras. 2 Al desplazarse la humanidad desde Oriente, hallaron una vega en el país de Senaar y allí se establecieron. 3 Entonces se dijeron el uno al otro: «Vamos a fabricar ladrillos y cocerlos al fuego». Así el ladrillo les servía de piedra, y el betún de argamasa. 4 Después dijeron: «Vamos a edificar una ciudad y una torre con la cúspide en los cielos, y hagámonos famosos, por si nos dispersamos por toda la tierra». 5 Bajó Yahveh a ver la ciudad y la torre que habían edificado los humanos, 6 y dijo Yahveh: «He aquí que 
todos son un solo pueblo con un mismo lenguaje, y este es el comienzo de su obra. Ahora nada de cuanto se propongan les será imposible. 7 Bajemos entonces, y una vez allí confundamos su lenguaje, de modo que no entienda cada cual el de su prójimo». 8 Y desde aquel punto los desperdigó Yahveh por toda la tierra, y dejaron de edificar la ciudad. 9 Por eso se la llamó Babel, porque allí, embrolló Yahveh el lenguaje de todo el mundo y desde allí los dispersó Yahveh por toda la haz de la tierra." ${ }^{1}$

Este texto despertó la imaginación de constructores y artistas que nos han dejado sus interpretaciones de los procedimientos que pudieron emplearse, en muchos casos alejadas del texto y adaptadas a su época [Fig.1.4 y 1.5]. Como en las siguientes miniaturas de códices medievales, en las que se refleja como los sillares más pequeños, los ladrillos mencionados o el mortero o argamasa que los une, pueden ser transportados por un hombre que sube por la escalera o rampa (Fig. 1.4), mientras que para materiales más pesados necesitaríamos la ayuda de torno y poleas (Fig.1.5).

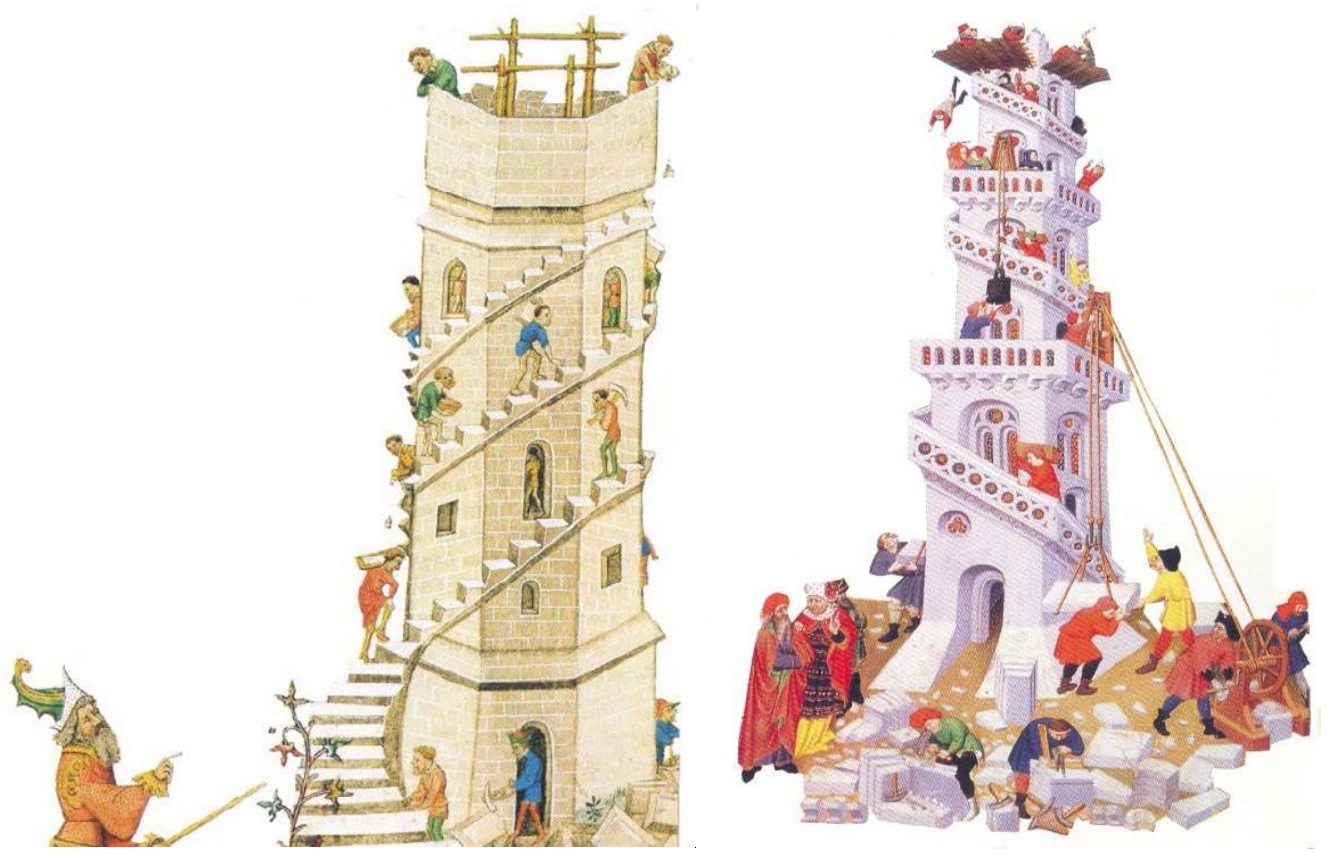

Figura 1.4 y Figura 1.5: Construcción de la torre de Babel.

\footnotetext{
${ }^{1}$ La Biblia, Génesis 11: 1-9. Biblia de Jerusalén (1975) Versión católica romana realizada por la Escuela Bíblica de Jerusalén. Ed. Editorial Española Desclée de Brouwer, S.A., Bilbao (nueva edición 1976; p15)
} 
En Europa y en el inicio de lo que denominamos "Cultura Clásica" se producen una serie de cambios científicos y tecnológicos que van a permitir transformar tanto la forma de los edificios como sus sistemas constructivos, mejorando los procedimientos conocidos por los egipcios y reduciendo de forma muy importante la mano de obra requerida. Permitieron a los Griegos construir unos templos que fueron y siguen siendo el "modelo de perfección constructiva" para muchos de los arquitectos de las generaciones posteriores; sistemas que evolucionan con las aportaciones técnicas romanas y medievales, pero que en lo esencial, se mantienen casi hasta la denominada "Revolución Industrial".

Los Griegos son los primeros en desarrollar y sistematizar los fundamentos de geometría y mecánica, de estudiar el movimiento y lo que denominaban "máquinas elementales", que como tales se fueron transmitiendo en los textos especializados hasta llegar a los tratados empleados en la enseñanza de ingenieros en el siglo XIX, como el "Ensayo sobre la composición de las máquinas" de Lanz y Betancourt $(1808)^{2}$ En todo este periodo los cambios e innovaciones están muy relacionados con combinaciones acertadas de estas "máquinas elementales" que permiten ir mejorando la eficacia de los medios de elevación de materiales y personas.

Los sistemas de elevación de cargas de la antigüedad empleaban la fuerza humana o la animal, no siendo muy diferentes de los que se explican en "Los veintiún libros de los ingenios y las máquinas" y de cómo se hacía en el siglo XVI en España: "El mover los pesos es en diversas maneras [...]: la una es llevándolas, y la otra manera es empuxandolas, y la tercera es quando las tiran" [Fig.1.6 $]^{3}$.

\footnotetext{
${ }^{2}$ LANZ Y BETANCOURT. "Ensayo sobre la composición de las máquinas" (1808) Ed. Colegio ingenieros de Caminos, Canales y Puertos, Demarcación de Madrid. Madrid, 1990.

3 PSEUDO JUANELO TURRIANO."Los veintiún libros de los ingenios y las máquinas" (1564- 1579). Manuscritos sig. 3372 a 3376 de la Biblioteca Nacional de Madrid. Ed. Colegio Oficial de Ingenieros de Caminos, Canales y Puertos de Madrid. Prólogo de Juan Antonio García-Diego (1983). Vol. II, p. 518.
} 


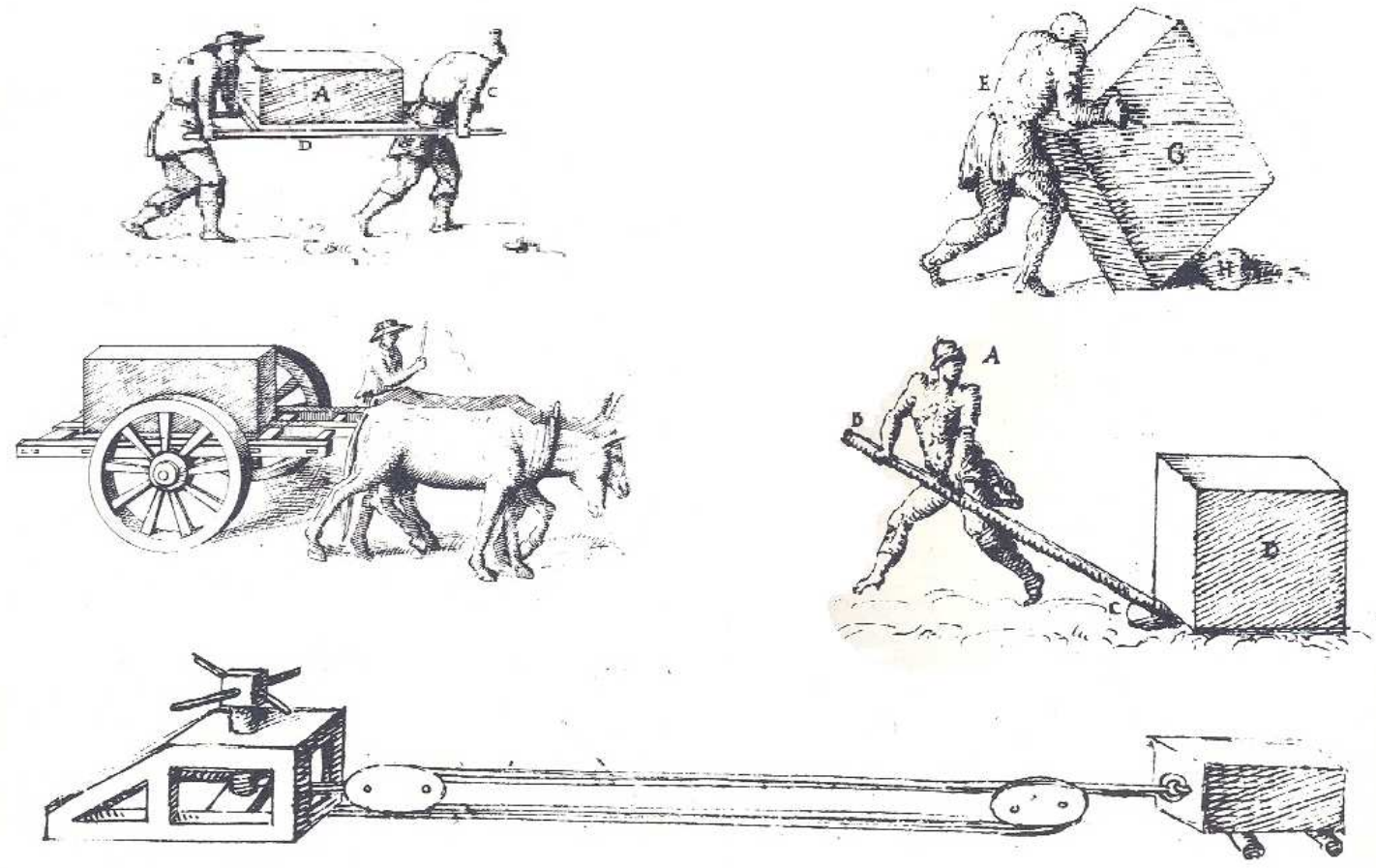

Figura 1.6: Llevar, empujar o tirar de pesos.

Para este tipo de movimientos de cargas, no han cambiado tanto los sistemas en los últimos siglos: se ha sustituido la fuerza humana o animal por motores, las sogas o cuerdas por cables y elementos de fijación de acero pero algunos de los fundamentos de geometría y mecánica que se desarrollaron en Grecia y Roma, así como el empleo de "máquinas elementales" como las palancas o las poleas, siguen estando presentes.

Los filósofos griegos en su análisis crítico y descripción de su entorno, encuentran que las palancas [Fig.1.6] pueden mover grandes pesos, sobre todo si tenemos un punto de apoyo, como se refleja en la popular frase atribuida a Arquímedes de Siracusa: "Dadme un punto de apoyo y moveré el mundo". Los mecanismos más sencillos para aplicar este principio en la construcción aparecen en las figuras de "Los veintiún libros de los ingenios y las máquinas" (fol.386 r. y 385r), que explica así el mecanismo que denomina "çigueña" [Fig.1.7], que aparece en la segunda figura: "Para levantar un peso y baxarlo de presto, no hay instrumento tan prompto como es el instrumento que llaman çigueña el qual tiene muy poco artificio. Es un tronco hincado derecho que es el E, el qual por la parte de arriba está abierto a modo de una horca ansi como se vehe pintado; y quando no se halla ansi hecho, hazese a mano y pasase una clavija de hierro, o, de madera en $B$, donde juega aquella antena $F$, y asesele un peso en $C, y$ 
tambien una cuerda para estirar pa abaxo y levantar el peso $E$, el qual esta colgado en $D$, de modo que ello es tan prestissimo al subir, como al baxar." 4

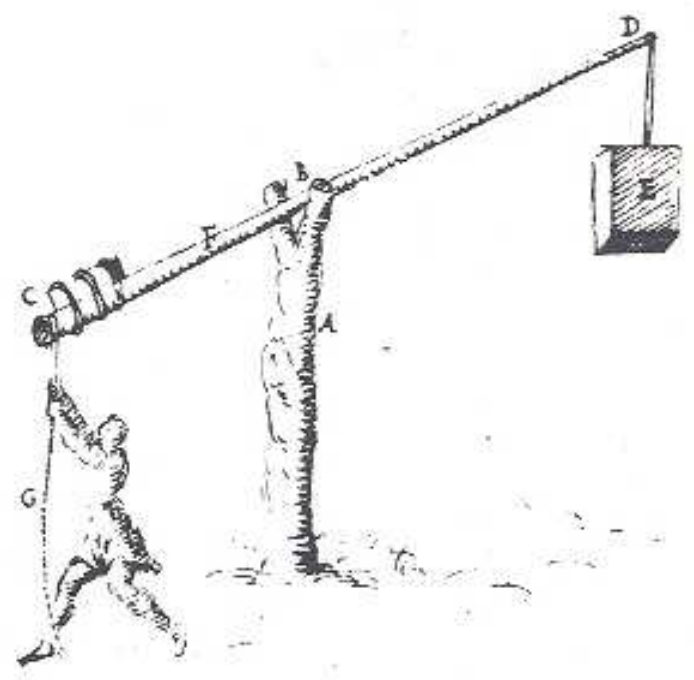

Figura 1.7: "Çigueña"

Pero que es mucho más sencillo si se emplean otros mecanismos como poleas o tornos ${ }^{5}$, que emplearon también los griegos, tanto para mover en horizontal como en vertical esos elementos pesados. Lo que unido a dispositivos de agarre en los grandes sillares de piedra como los "canes" o la "holivela" ${ }^{6}$ [Fig. 1.8], les permitieron construir las estructuras y edificaciones de sus "polis" (o ciudades-estado).

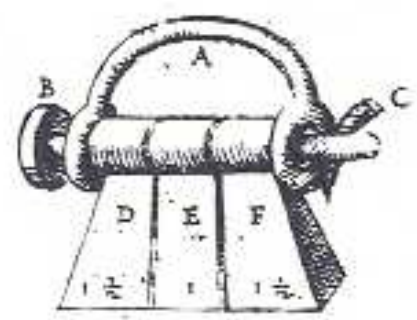

Figura 1.8: "Holivela"

\footnotetext{
4 PSEUdO JUANELO TURRIANO. “Los veintiún libros de los ingenios y las máquinas" (1564- 1579). Manuscritos sig. 3372 a 3376de la Biblioteca Nacional de Madrid. Ed. Colegio Oficial de Ingenieros de Caminos, Canales y Puertos de Madrid. Prólogo de Juan Antonio García-Diego (1983). Vol. II, p. 517.

${ }^{5}$ La primera descripción de un sistema de poleas aparece en los "Ejercicios mecánicos" (Mech. 18, $853 a 32$ - 853b13) atribuido a Aristóteles (384-322).

6 "canes" (salientes en dos de las caras opuestas del sillar para proporcionar puntos de sujeción para las sogas de izado) o la "holivela"(tres piezas de hierro o bronce con un pasador del mismo material, piezas que se colocaban dentro del bloque de piedra primero las laterales con forma de cuña y luego la central y el pasador, según se describe en "Los veintiún libros de los ingenios y las máquinas")
} 
El imperio romano transformó y cambio el espacio europeo, tanto en lo político y económico como en el espacio físico, a través de innumerables infraestructuras y edificios. El primer tratado de arquitectura e ingeniería que conocemos, el de Marco Vitruvio, nos explica algunos de los procedimientos y las máquinas que emplearon para ello. No nos han llegado las imágenes que acompañaban a este texto latino ${ }^{7}$, pero se han encontrado relieves o grabados de ese mismo periodo que coinciden con sus descripciones. Los romanos empleaban grúas muy distintas para elevar hasta su emplazamiento los materiales de construcción, con el nombre genérico de "machinae tractoriae". Jean Pierre-Adam (1984) e Ignacio González Tascón (2002) citan entre estas máquinas empleadas por los romanos: la súcula, el cabrestante o ergate, la cabria, los aparejos formados por varias poleas, las tenazas de hierro ("ferreus forfex" o "ferrei forfices"), las ruedas de gran diámetro con travesaños en el interior para que puedan accionarla varios hombres andando en su interior ("maius tympanum").

La "Sucula" o torno para levantar pesos, que se acciona haciendo palanca en unos palos (o"vectis") dispuestos radialmente y a escuadra respecto al eje horizontal sobre el que se enrola una cuerda o maroma, en unos huecos taladrados al efecto en dicho eje ${ }^{8}$ [Fig.1.9], En el otro extremo de la cuerda, se fija el peso que se quiere elevar. Se empleaba para elevar materiales no muy pesados como herramientas, ladrillos y la artesa (o "mortarium") que los albañiles empleaban para el mortero de cal necesario para las fábricas.

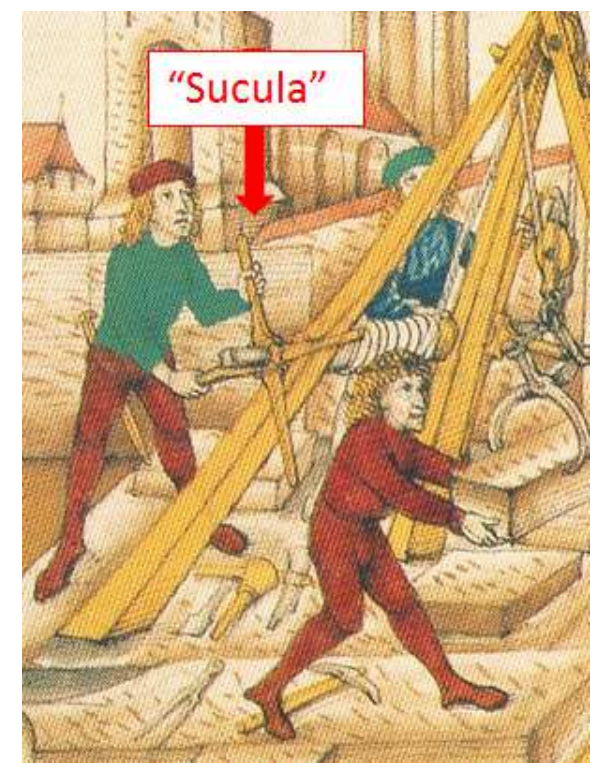

Figura 1.9: "Sucula"

\footnotetext{
${ }^{7}$ Las copias y ediciones posteriores añadieron los dibujos y grabados (como la de Florencia de 1513, de la que se han reproducido la fig. 7. Ergata o Cabrestante y 2. Cabria)

${ }^{8}$ Descrito por M. VITRUVIO ("De Architectura” $10,1,5$ y 10, 2,2) y por M. PORCIUS CATO (“De agricultura" 19, 12)
} 
El cabrestante (o "ergata-ae" ${ }^{9}$, Fig. 1.10): es una especie de torno, pero con eje vertical y por ello más fácil de operar al accionar los brazos de palanca. Descrito también por Vitruvio ${ }^{10}$, como resultado de esta disposición, se pueden mover pesos mayores y emplear como fuerza motriz animales. Un relieve romano con una representación de este tipo de máquina se puede ver en el Museo de la Civiltà Romana que representa las obras de desagüe del lago Fucino, en el que se empleó para extraer los materiales en las zonas excavadas. Parece que también se empleó una máquina similar para la colocación de los obeliscos egipcios que se llevaron a Roma en el 30 a.C.

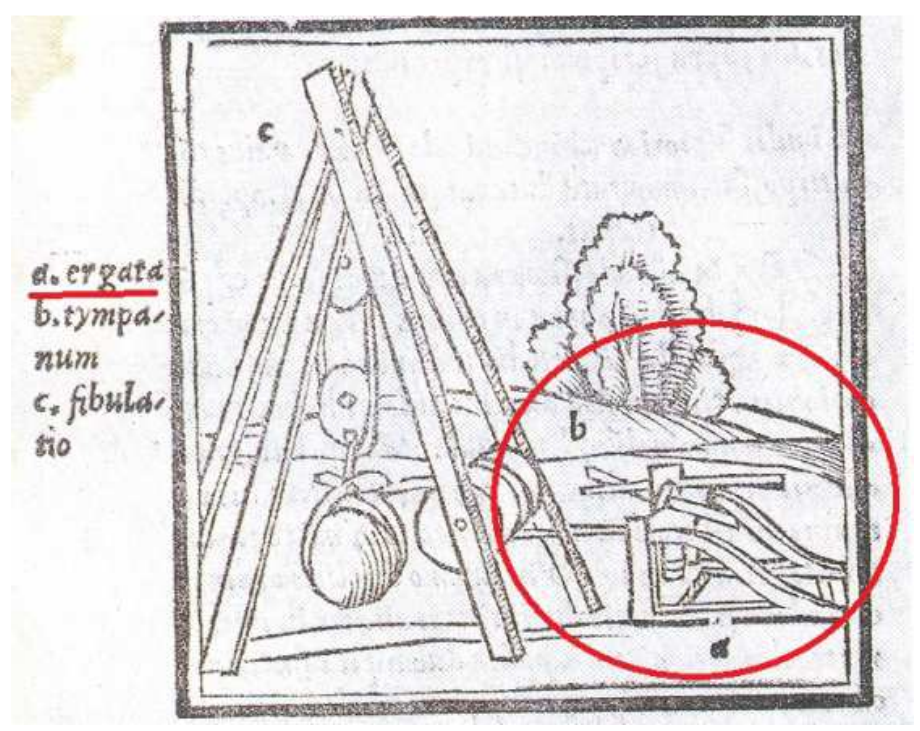

Figura 1.10: "Ergata-ae", o cabrestante

Cuando se precisa elevar mayores pesos, se emplea la cabria [Fig.1.11 y 1.12], formada por un armazón de madera formada por varias piezas inclinadas, unidas por la parte superior. Un torno horizontal (o sucula), colocado entre dos de estos soportes inclinados y movido a mano permite multiplicar la fuerza ejercida por dos hombres que alternativamente lo mueven [Fig.6 y 8], o bien puede conectarse con un ergate o cabrestante [Fig.1.10]. La cuerda que se enrolla en el tambor del torno, pasa por un aparejo formado por una o varias poleas (o "troclea", que algunos Ilaman "rechamus" según explica Vitruvio al describir la cabria ${ }^{11}$ ) suspendido del vértice superior de la estructura de madera y que está formado por poleas con rodelas o ruedas ("orbiculus") que permiten el giro de la cuerda o maroma. La que aparece en la imagen corresponde a la edición de 1513 hecha en Florencia del texto de Vitruvio, a la que se añadieron figuras para sustituir a las perdidas del texto original. Este tipo de aparejos con

\footnotetext{
${ }^{9}$ El cabrestante, en latín "ergata-ae", aparece también como orgate o hergate en "Los veintiún libros de los ingenios y las máquinas"

${ }^{10}$ M. VITRUVIO ("De Architectura” 10, 2,7)

${ }^{11}$ M. Vitruvius Pollio ("De Architectura” 10, 2,2)
} 
poleas aparecen también en un relieve de terracota de época romana encontrado en la vía Cassia [Fig.10], citado por Jean Pierre Adam (1984) que explica que muestra una máquina para elevar grandes bloques de piedra.

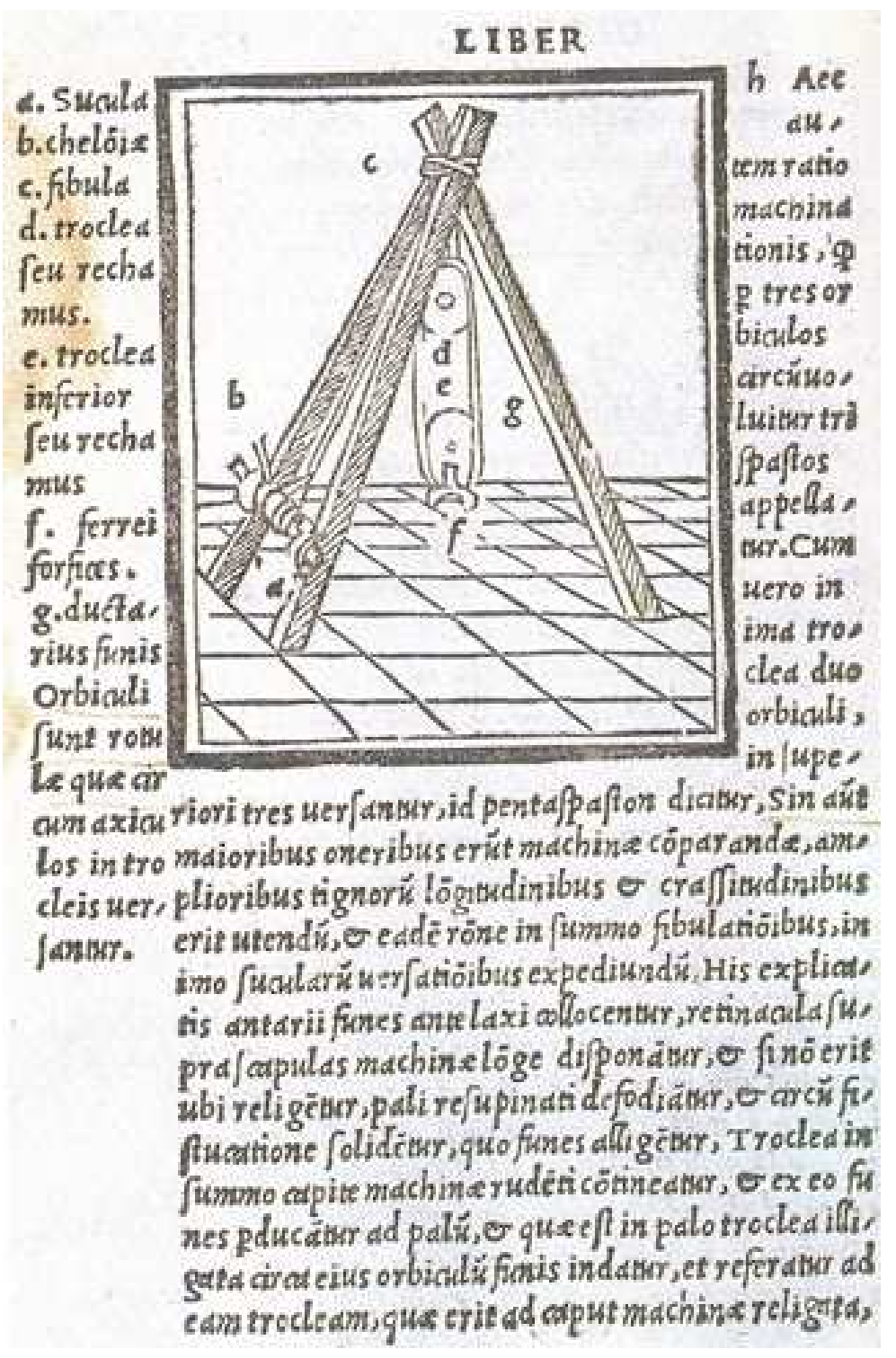

Figura 1.11: Cabria

Se puede sustituir una polea sencilla ("orbiculus") por varias ("orbiculi"), constituyendo el aparejo múltiple ( "troclea" o "trochlea") que permite aumentarla carga que se quiere elevar. Vitruvio describe un tipo de cabria empleada por los griegos denominada "tripaston" ${ }^{12}$, según el número de poleas que tiene, donde indica que la "trochlea" superior tiene dos ruedas ("orbiculi"), que giran sobre sus ejes y por las que pasan dos maromas o cables ("finis ductaria") que llegan a la "trochlea" inferior que tiene una sola rueda y a cuyo extremo se fijan unas tenazas de hierro ("ferreus forfex") cuyas puntas entran en unas perforaciones previstas

\footnotetext{
${ }^{12}$ M. Vitruvius Pollio ("De Architectura” 10, 2,3)
} 
en las caras opuestas del sillar que se quiere elevar. Si la máquina tiene una "trochlea" superior con tres ruedas y una "trochlea" inferior con dos ruedas, se denomina "pentapaston" y "polypaston" si tiene tres.

Para la sujeción o enganche de los sillares, además de los "canes" o la "holivela" empleados por los griegos, que requerían mucha mano de obra, los romanos añadieron el sistema de las tenazas de hierro ("ferreus forfex" o "ferrei forfices"), "genuinamente romano por su sencillez y economía" ${ }^{13}$, que también se empleó mucho en la construcción medieval. Descritas por Vitruvio como "tenazas de hierro cuyos dientes se ajustan a los agujeros que previamente se han horadado en los bloques de piedra" ${ }^{14}$.

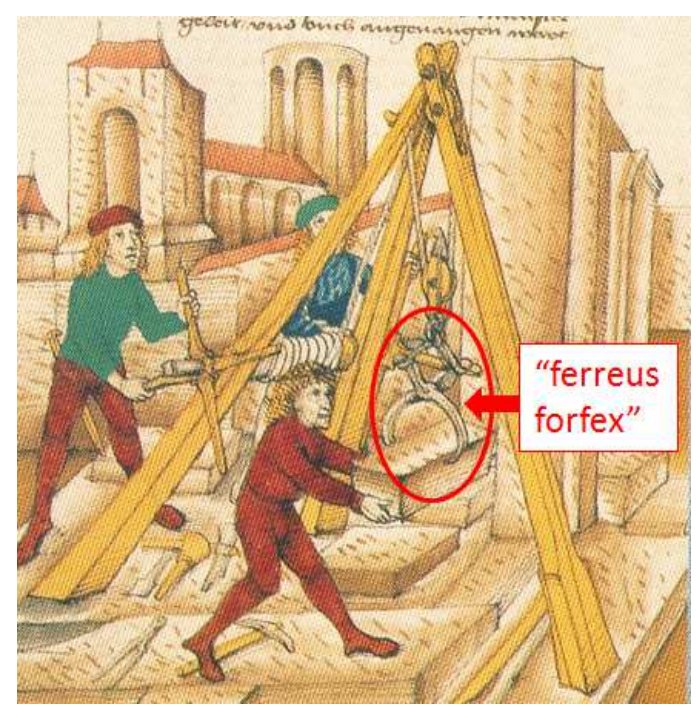

Figura 1.12: Cabria con tenazas de hierro ("ferreus forfex")

Si era necesario elevar cargas mayores, se construía una máquina de mayores dimensiones, que era necesario levantar con otras poleas y maromas ("funes antariae") y sujetarlas con otras cuerdas ("retinaculum") enganchadas a estacas ("palus") clavadas en el suelo y con las propias palancas ("vecte") sujetas al torno o cabestrante ("sucula") elevar la máquina. A este tercer aparejo de poleas ("epagon" para los griegos, "artemon" para los romanos) que se añadía al "polypaston", se ataban unos cables o maromas ("funes antariae"), de los que podían tirar hasta tres filas de hombres para levantar pesos importantes. Según describe Vitruvio ${ }^{15}$ : "Al pie de la máquina se acopla una tercera polea, que los griegos llaman epagon y nosotros artemon. Esta polea se amarra a su base y consta de tres rodelas por las que pasan

\footnotetext{
${ }^{13}$ Ignacio González Tascón (2002; p.142)

${ }_{14}$ M. Vitruvius Pollio ("De Architectura” 10, 2)

${ }^{15}$ M. Vitruvius Pollio ("De Architectura" 10, 2,9)
} 
los cables para ser tirados por hombres. Así, tirando tres filas de hombres, sin necesidad de cabestrante, suben rápidamente la carga hacia arriba".

Se puede además sustituir el torno horizontal ("súcula") por una rueda de gran diámetro ("maius tympanum"), con travesaños en el interior para que puedan accionarla varios hombres, andando en su interior. Como explica Ignacio González Tascón (2002): “Con este dispositivo se consigue además una mayor seguridad, pues no hay que olvidar que los tornos de mano carecían de trinquete de seguridad, que es un invento medieval tardío, mientras que el funcionamiento del "maius tympanum" no depende de un solo hombre sino de varios y, sobre todo, tiene un brazo de multiplicación mucho mayor". El mejor ejemplo de este tipo ingenio con "polypaston" y con rueda ("maius tympanum") está representado en un relieve procedente de la tumba de $\mathrm{Q}$. Haterius Tychicus, empresario de obras públicas, que se $\begin{array}{lllll}\text { conserva actualmente en los Museos Vaticanos16 [Fig.1.13] } & \end{array}$

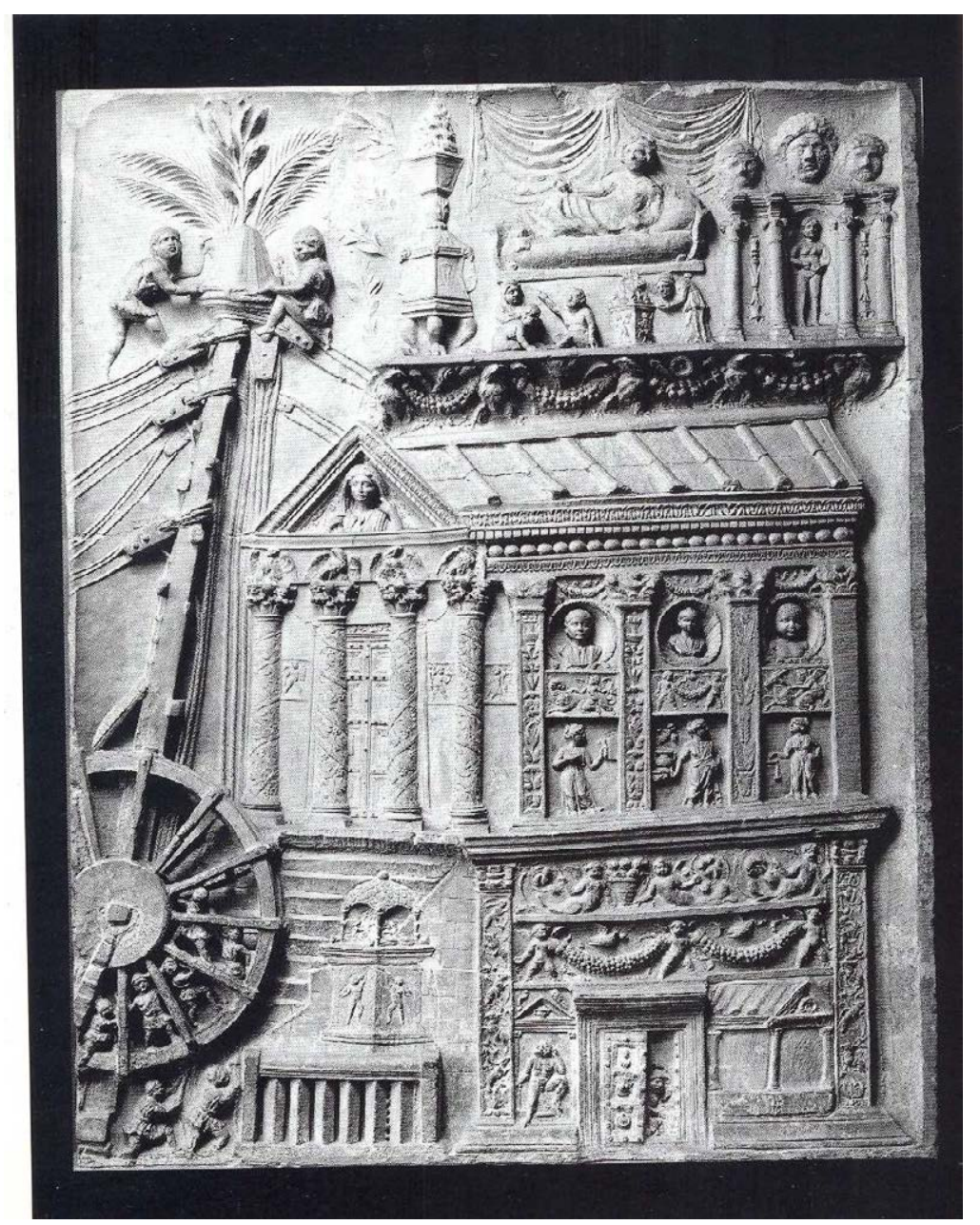

Figura 1.13: Grúa con "polypaston" y con rueda ("maius tympanum")

\footnotetext{
${ }^{16}$ La fecha según los distintos especialistas varía entre c. 100-110 dC ó 81-96 dC. en la época de Domiciano
} 
Cuando aparece una máquina similar a lo que hoy denominamos grúa es difícil de determinar, aunque algunas imágenes como estas [Fig.1.14 y 1.15], de manuscritos medievales ${ }^{17}$, empiezan a aproximarse mucho más que lo que se ha denominado "çigueña". Se aprecian algunas de las mejoras que, según Alain Erlande-Brandenburg (1994), aparecen en las grúas medievales y suponen un cambio respecto a las romanas: el contrapeso y la doble polea. También indica que algunas de ellas son pivotantes y que el pescante puede llegar a 3 metros, lo que con las poleas, agrupadas como ya habían hecho los romanos, aumenta su eficacia ${ }^{18}$. Su accionamiento era en general mediante un torno (la "Sucula" romana) o, como en el ejemplo de la grúa romana del relieve funerario ya comentada, por una rueda de gran diámetro lo que permite descargar las pesadas piedras de una barcaza para la construcción de un puente o elevar cargas importantes o materiales a cierta altura en la de un edificio. Otra característica importante según este especialista medieval es que estos sistemas de elevación que aparecen con el estilo gótico, empiezan a montarse directamente sobre la parte ya realizada de las cubiertas de los edificios [Fig. 1.15] o sobre una plataforma apoyada en ellos, lo que facilita su montaje y desmontaje según avanza la obra, hasta la parte más alta de las bóvedas. Este hecho ha permitido que se conserven algunos de ellos como el de la catedral de Salisbury del siglo XIV o los de las francesas Beauvais, Chalons-sur-Marne. Pero también cambia el sistema de andamios, que pasan a apoyarse en el muro en vez de en el suelo y cuya función pasa a ser sólo una plataforma de trabajo por lo que son mucho más ligeros y económicos. La circulación vertical de personas para acceder a este nivel, se realiza mediante escaleras helicoidales, que eran las que se construían primero.

\footnotetext{
17 "Construcción de un puente" en la "Crónica privada de Berna" denominada "de Spiez" (Diebold Schilling, 1484-1485). Manuscrito Ms Hist. Helv. I-16, de la sección de Historia suiza de la Burgerbibliothek de Berna, Suiza. . Y "Construcción de la torre de Babel" miniatura del Códice Cod. Bibl. $2^{\circ} 5$, de la Württembergische Landesbibliothek de Stuttgart.

${ }^{18}$ Alain Erlande-Brandenburg (1994), "Quand les cathédrales étaient peintes “. Ed. Gallimard. Se podria poner en duda esta afirmación si no tuvieramos en cuenta que este tipo de " mecanismos básicos" se añade y combina con las grandes ruedas de accionamiento; considero que esta afirmación no implica que se desconocieran tipologías anteriores como la "çigueña”.
} 


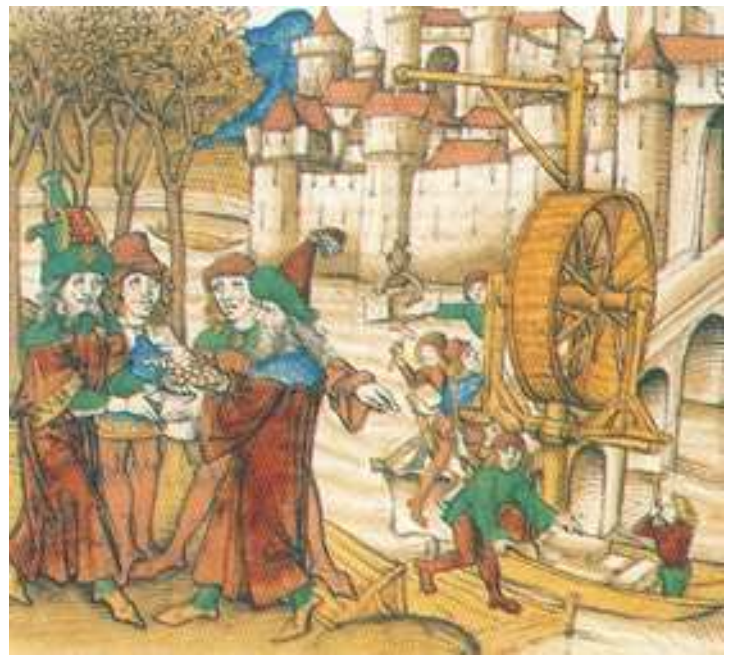

Figura 1.14:"Construcción de un puente"

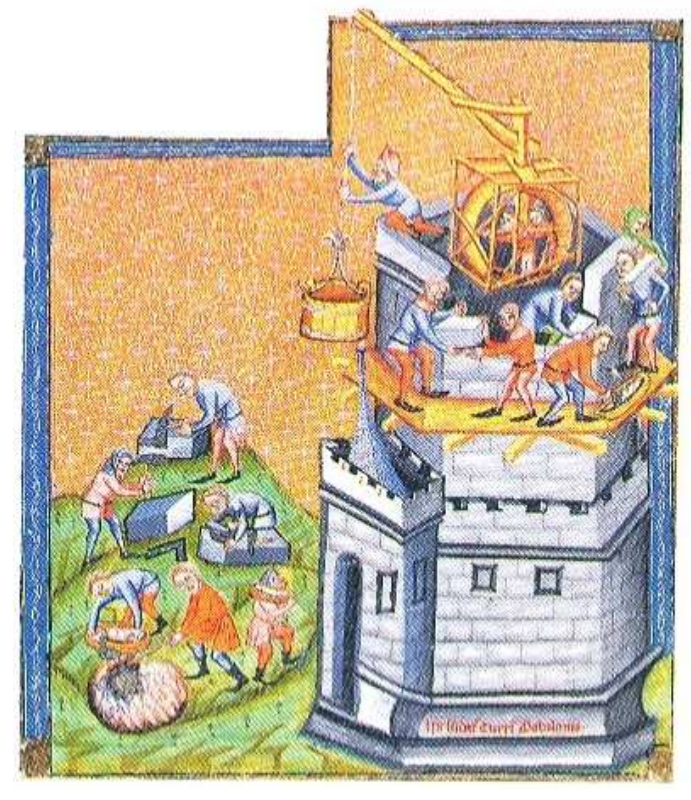

Figura 1.15: "Construcción de la torre de Babel"

En "Los veintiún libros de los ingenios y las máquinas", ${ }^{19}$ aparece una imagen de lo que ya se llama "grua" [Fig.1.16] acompañada de una detallada descripción de su funcionamiento, que además explica porque se llama así.

\footnotetext{
19 "Los veintiún libros de los ingenios y las máquinas" (Pseudo Juanelo Turriano, 1564- 1579). Manuscritos sig. 3372 a 3376de la Biblioteca Nacional de Madrid. Ed. Colegio Oficial de Ingenieros de Caminos, Canales y Puertos de Madrid. Prólogo de Juan Antonio García-Diego (1983). Vol. II, p. 516.
} 


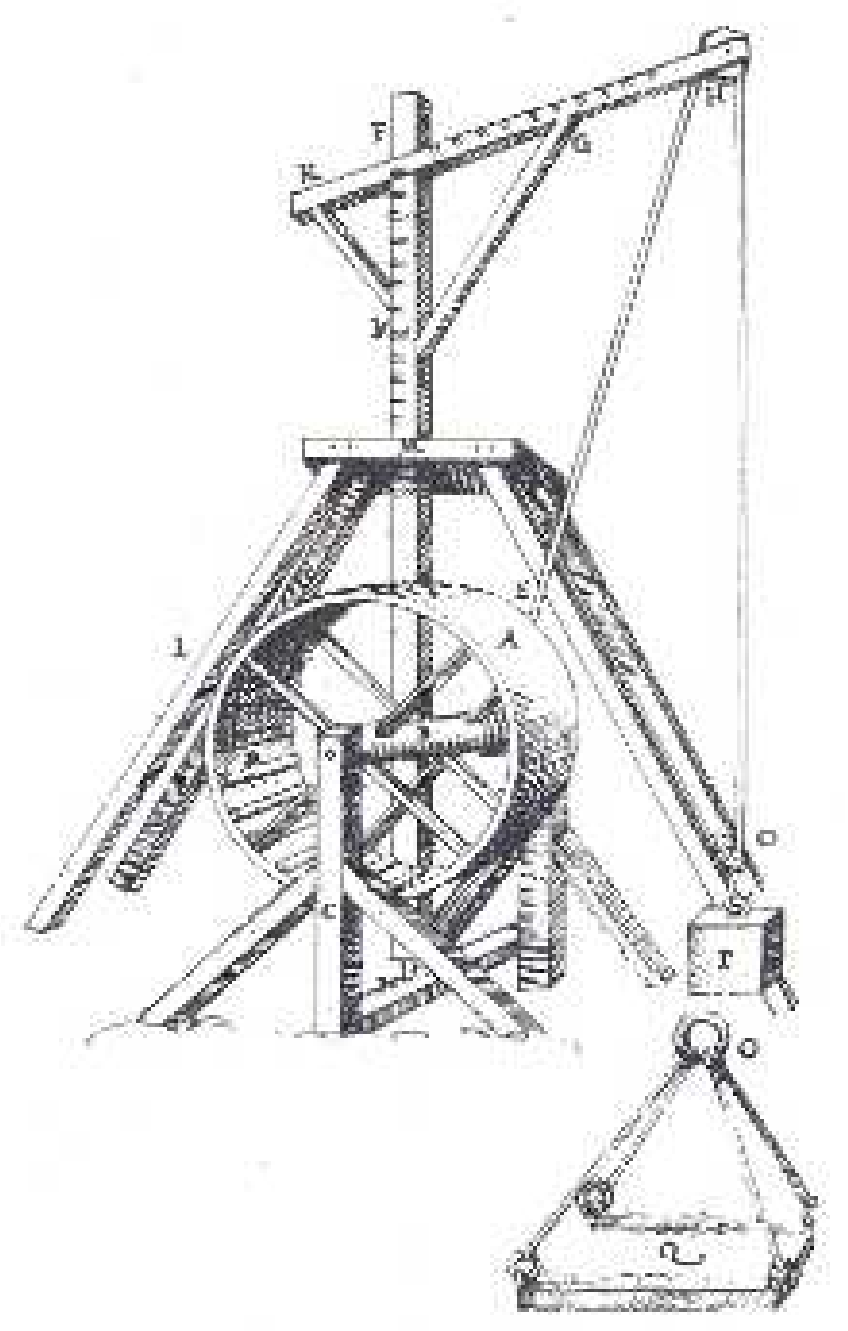

Figura 1.16: Grúa en "Los veintiún libros de los ingenios y las máquinas"

La descripción es la siguiente:

"La grua es un instrumento de madera, el qual sube en alto las piedras de las obras. Es de si muy alto, esta assentado baxo en el suelo del edifiçio y otras vezes se acomoda en alto según la necesidad del lugar. Subense muy grandes pesos con la grua y llevase con ella qualquier parte de la obra, sin ninguna trabaxo, por causa q' el árbol o mastil juego sobre un perne de hierro en al N. La rueda A que su exe es B el qual juega ha los dos cabos sobre los pies es C y este exe recoge la cuerda de la grua que es $E$ la qual pasa por la carrucha H. La grua assi se llama por causa de su largo cuello que saca el madero $\mathrm{K}$ que tiene la carrucha $\mathrm{H}$ y tiene aq'llos dos rebotantes $\mathrm{G}$ que la sustenta y hay puestas unas clavijas de madera algo largas que sirven de escalones, y la armadura $M$ tiene derecho el pie del árbol $\mathrm{F}$ la qual armadura tiene quatro rebotantes que la 
sustenta la cuerda tiene al cabo una anilla con un gancho que es $O$ y el peso es $P$. Hay otros que le ponen unas tablas de madera gruessa, que tiene a los quatro angulos quatro sortijas de hierro con quatro pedaços de cuerda que se viene a asis con la cuerda $E$ este pedaço $Q$ tiene diversos nombres entre offiçiales; llamale cada qual como quisiere; porque unos le llaman el cavallo, otros asno, otros albardón, otros la zivilla de la grua, otros coraçon como aquel de las balanças de pesar las cosas"

En el periodo histórico que denominamos Renacimiento, empiezan a difundirse con más detalle, mediante los "Tratados", conocimientos que en la etapa Medieval habían sido exclusivamente difundidos entre los miembros de los gremios, asociaciones profesionales especializadas. Sigue manteniéndose un cierto hermetismo, pero arquitectos e ingenieros compiten por conseguir no sólo ser los mejores y más hábiles, sino que también se les conozca por ello y así poder dirigir las obras más emblemáticas. Los procedimientos empleados para la construcción de algunos edificios están gracias a esto mejor documentados y se han hecho estudios históricos sobre los dos ejemplos que pasamos analizar: la cúpula de la iglesia de Santa María de las Flores, en Florencia, Italia y el monasterio de El Escorial en España.

Puede dar una idea de la importancia de esta labor de difusión de su trabajo, la conversación entre dos personajes del libro "Della Tranquillità dell’animo" de Leon Battista Alberti, un arquitecto esencial del Renacimiento italiano, y tiene lugar debajo de la cúpula recién construida por Filippo Brunelleschi para Santa María de las Flores, en Florencia. El político Agnolo Pandolfini, desilusionado y retirado de la vida pública, habla con Nicola de Medici, un hombre más joven cuyo banco ha quebrado dejándole arruinado. Después de comentar distintos métodos para mejorar el ánimo como el vino, la música, las mujeres, y el deporte, le explica de esta manera cual es el que considera más efectivo.

"Estoy acostumbrado a pasarme la mayor parte de la noche, cuando la agitación de mi espiritu me llena de preocupaciones, buscando alivio de estos amargos problemas y tristes pensamientos, a través de imaginar y construir en mi mente una máquina de la que nadie haya oído hablar, para mover y desplazar cargas, haciendo posible crear cosas grandes y maravillosas" 20 .

Esto explica la admiración y envidia que despertaron las máquinas que Filippo Brunelleschi diseñó para construir la cúpula de Santa María de las Flores, descritas y copiadas por sus contemporáneos como Leonardo Da Vinci o Taccola, en algunos casos cambiando pequeños

\footnotetext{
20 "Della Tranquillità dell’animo" ( Leon Battista Alberti, 1441), citado en "Brunelleschi's dome" (Ross King, 2000). Traducción del inglés: M. Flórez de la Colina
} 
detalles para hacerlas pasar por propias en sus tratados, como aparece descrito en la publicación de Ross King (2000).

Brunelleschi diseñó una máquina para izar materiales a la cúpula entre 1420 y 1421 , cuya fuerza estaba accionada por bueyes, posiblemente parecida a la que aparece en el dibujo de Taccola [Fig. 1.17] accionada por un caballo. En el dibujo vemos un accionamiento a través de una fuerza motriz animal, sustituyendo a la humana que aparecía en las figuras anteriores, y un sistema que ya está formado por varias ruedas dentadas combinadas y con ejes perpendiculares, además del ingenioso sistema que aparece en la parte inferior.

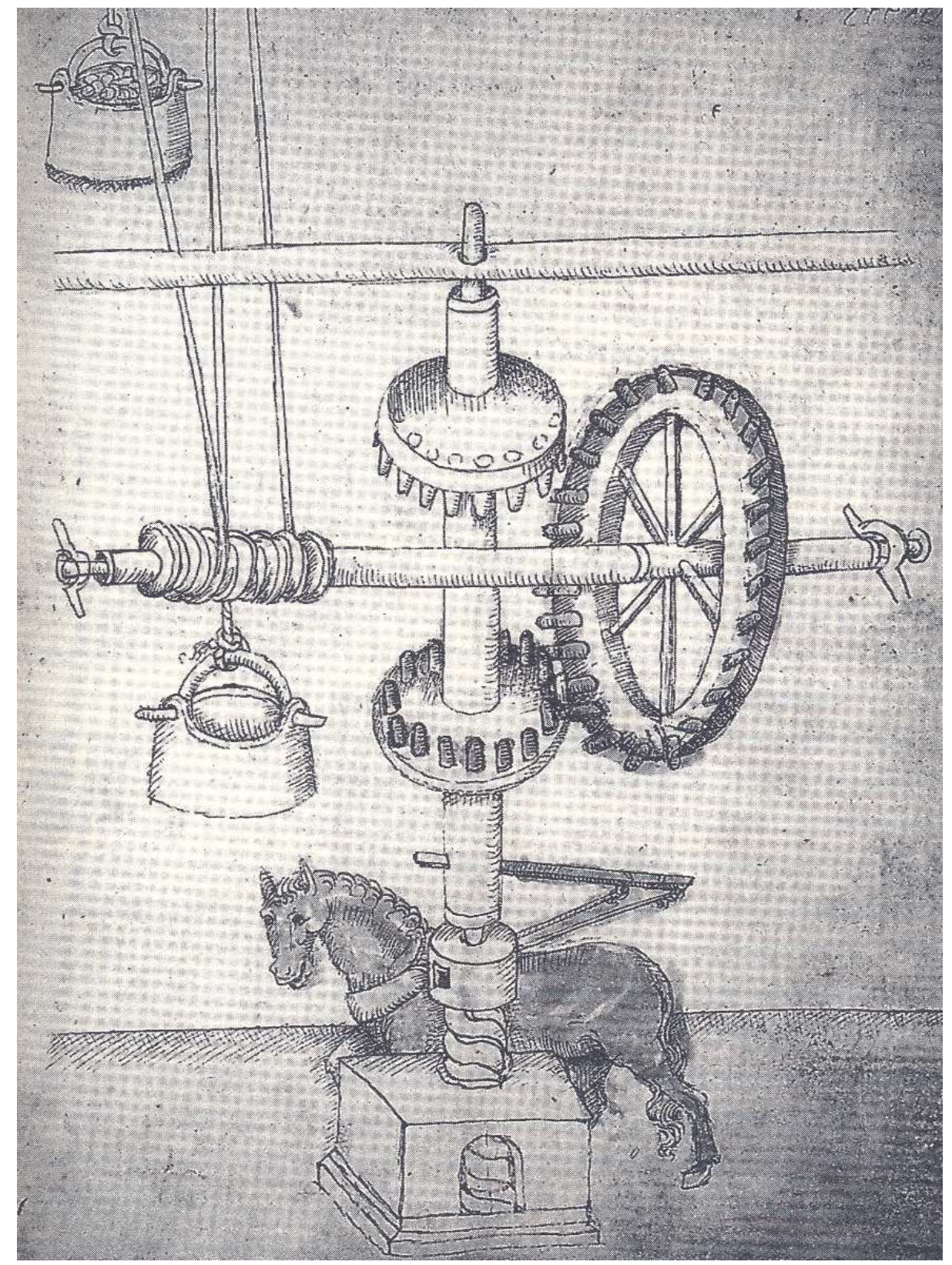

Figura 1.17: Máquina para elevar materiales, basada en la que Filippo Brunelleschi empleó en Santa María de las Flores en Florencia (1420 - 1421). Tratado Taccola 
Pero para finalizar la cúpula era necesaria otra máquina que no sólo elevara los materiales a gran altura, sino también desplazar lateralmente dichas cargas y situarlas con precisión en el punto adecuado. También Leonardo Da Vinci quedó impresionado y copió el "Castello" [Fig. 1.18], una nueva grúa que combinaba un mástil de madera con una viga horizontal que podía pivotar. Ross King (2000) describe así esta grúa:

“Conocida como el castello, esta nueva grúa consistía en un mástil de madera en cuya parte superior se había colocado una viga que podía pivotar horizontalmente. Estaba apoyada a gran altura sobre la cúpula. La viga horizontal tenía tornillos, carriles deslizantes y un contrapeso. Uno de los tornillos horizontales movía el contrapeso por el carril deslizante, mientras que el otro manipulaba la carga que podía también subirse o bajarse por medio de un elemento giratorio."

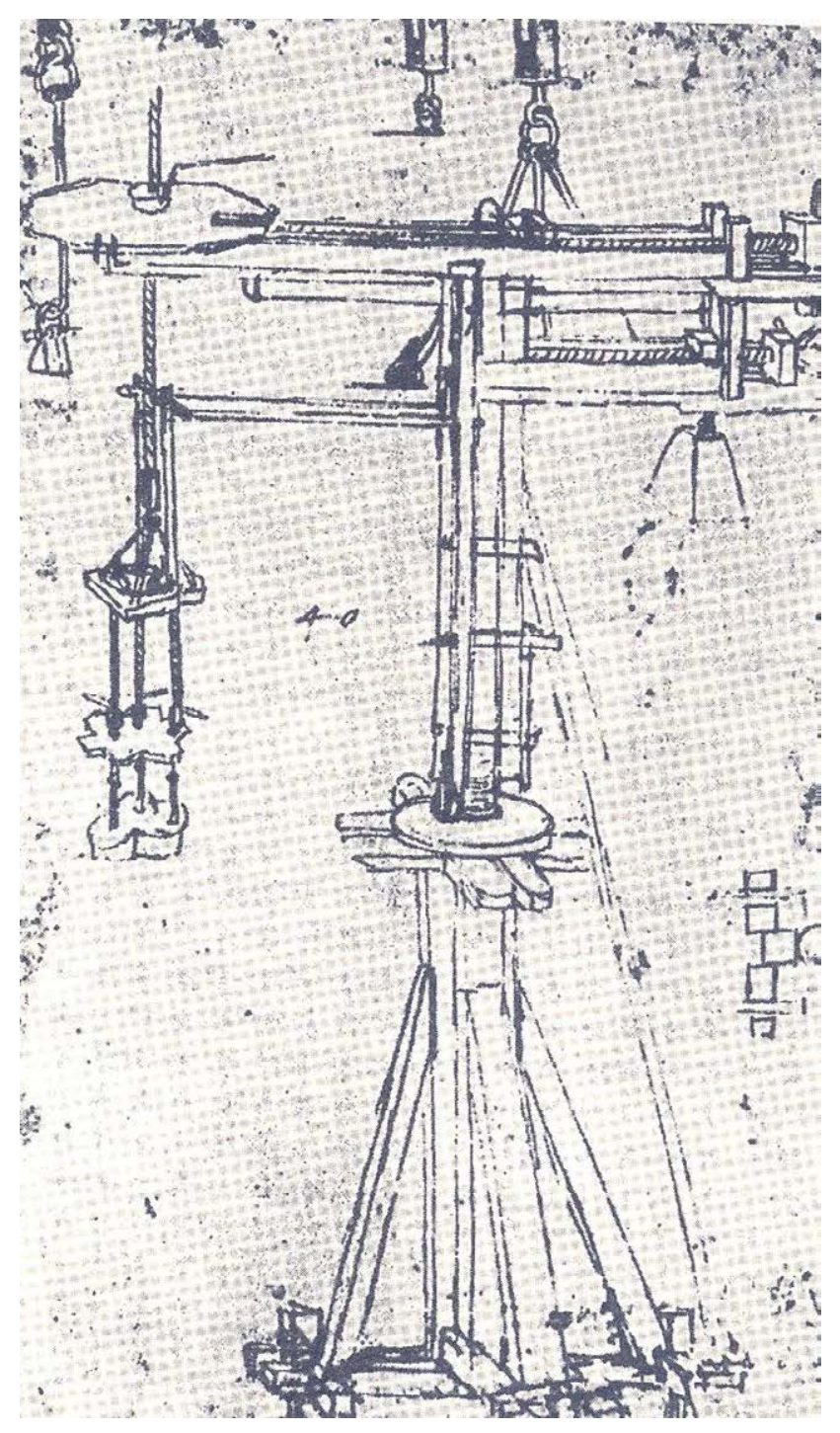

Figura 1.18: "Castello" de Filippo Brunelleschi empleado en Santa María de las Flores en Florencia. Dibujo de Leonardo Da Vinci 


\subsubsection{El Monasterio de El Escorial}

La vista del monasterio del Escorial atribuida a Juan de Herrera (1576) ${ }^{21}$ y conservada en la colección del Marqués de Salisbury en el Reino Unido [Fig.1.19], nos relata un proceso constructivo que resultó sorprendente por su rapidez, pese a ser un novedoso diseño arquitectónico. El rey Felipe II buscó hacer de este edificio un símbolo de su reinado y de la monarquía española, que en ese momento abarcaba amplios territorios en varios continentes, y lo logró.

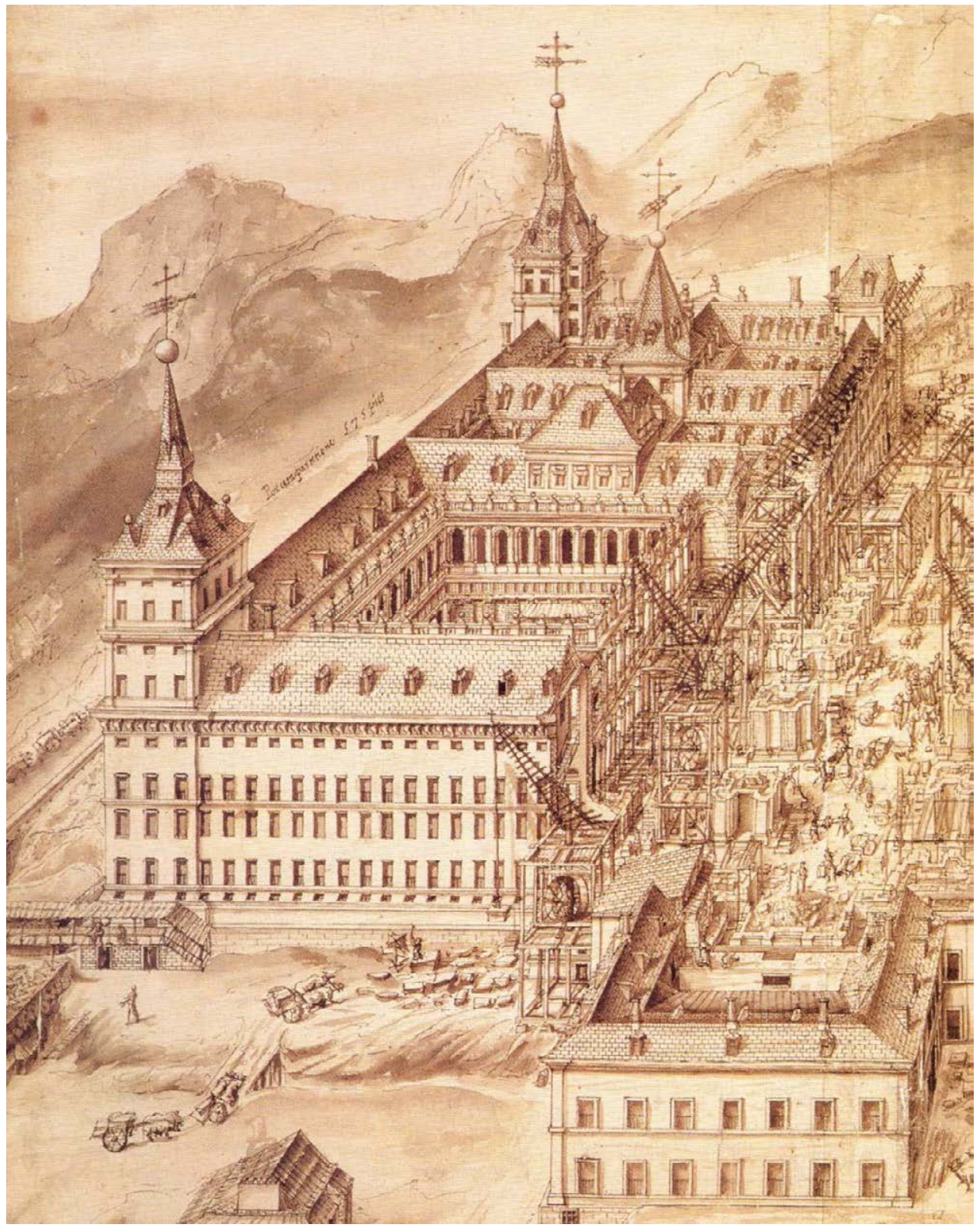

Figura 1.19: Detalle de la vista del monasterio del Escorial durante su construcción

\footnotetext{
${ }^{21}$ En El manuscrito de Juan de Herrera indebidamente titulado "Architectura e Machinas" (Luis Cervera Vera, 1996). Valencia. Ed. Patrimonio Ediciones S.L.
} 
Para realizar esta obra se emplearon unos procedimientos constructivos muy avanzados para su época, intentando conseguir la máxima eficacia con los medios disponibles. Destaca el papel del arquitecto Juan de Herrera, que se hizo cargo de las obras al fallecer en 1567 el arquitecto Juan Bautista de Toledo. Luis Cervera Vera (1996) da datos muy interesantes sobre las grúas que aparecen en la vista citada conservada en la colección del Marqués de Salisbury: atribuye su diseño a Juan de Herrera que escribió hacia 1575 un manuscrito sobre los principios para diseñar y construir grúas y otras máquinas, y su construcción al aparejador Juan Mijares ayudado por Juan Betesolo ${ }^{22}$.

Estas grúas son muy parecidas a las descritas en "Los veintiún libros de los ingenios y las máquinas", pero según indica Ignacio González Tascón ${ }^{23}$ : "Tienen dos ruedas, lo que posibilitaba aumentar la seguridad, al permitir la sustitución de uno de los gruistas sin perder el control de la máquina, cosa que sí ocurriría si había tan sólo una rueda y un único operario" [Fig.1.20].

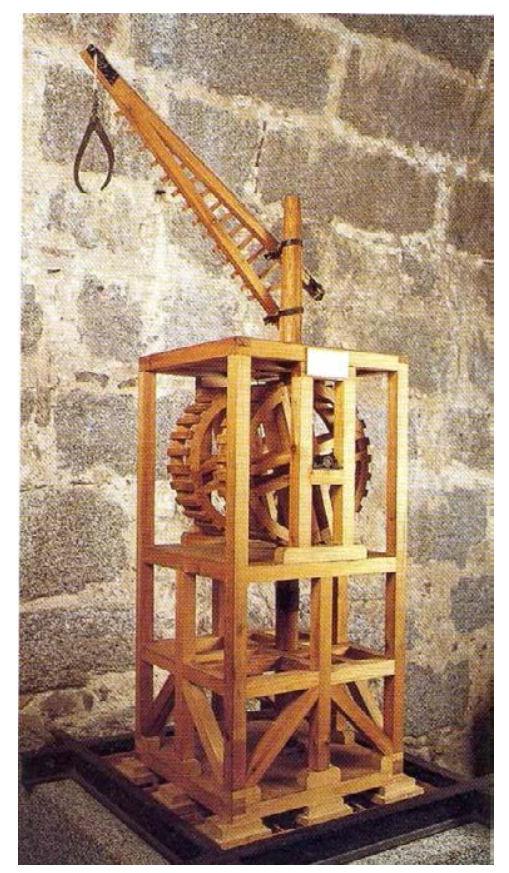

Figura 1.20: Maqueta de las grúas de Juan de Herrera del Museo de Construcción del Monasterio de El Escorial.

\footnotetext{
${ }^{22}$ CERVERA VERA, Luis (1996). El manuscrito de Juan de Herrera indebidamente titulado "Architectura e Machinas". Valencia. Ed. Patrimonio Ediciones S.L. pp.34-46

${ }^{23}$ GONZÁLEZ TASCÓN, Ignacio. (1998). "Los caminos y los puentes" en Felipe II. Los ingenios y las máquinas. Ed. Sociedad Estatal para la conmemoración de los centenarios de Felipe II y Carlos V y Ministerio de Fomento. Catálogo de la exposición, Real jardín Botánico, CSIC, Pabellón de Villanueva. pp.123-124
} 
Empleaban para fijar las piedras que se elevaban el sistema ya descrito de las tenazas de hierro ("ferreus forfex" o "ferrei forfices") y poleas. Se conserva una de ellas en el Museo de Construcción del Monasterio de El Escorial [Fig.1.21 y 1.22].

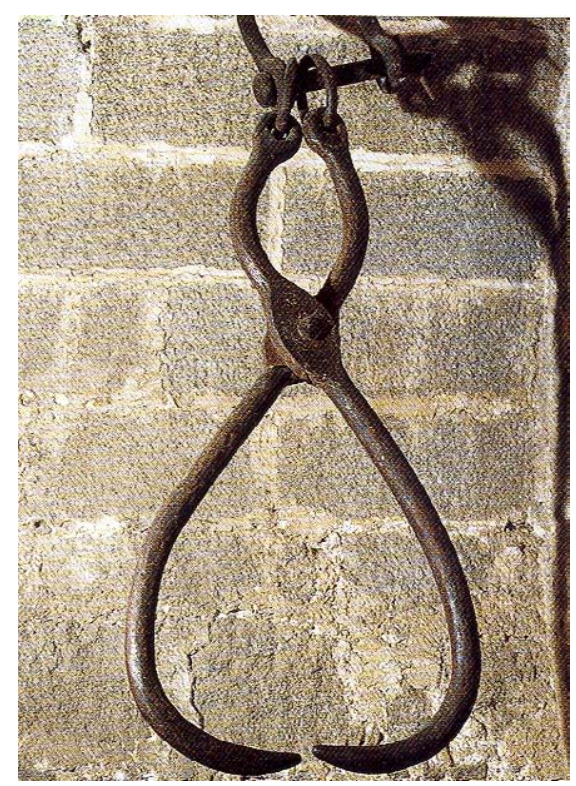

Figura 1.21: Tenazas de hierro ("ferreus forfex") para elevar piedras, Monasterio de El Escorial.

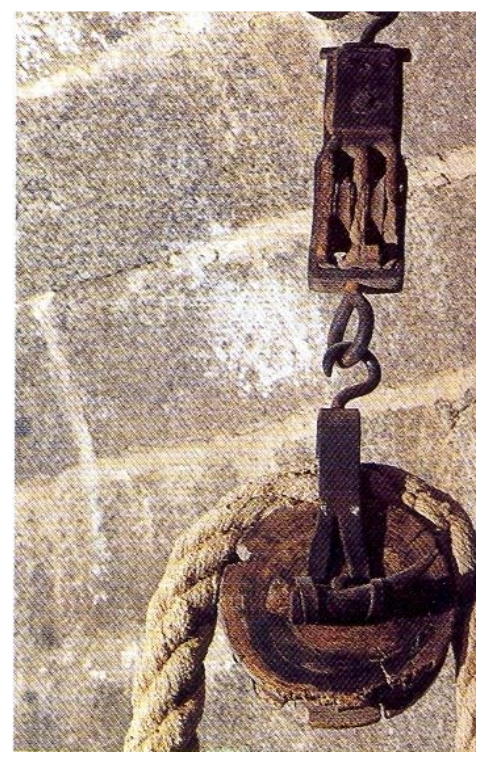

Figura 1.22: Polea para elevar piedras, Museo de Construcción del Monasterio de El Escorial. 


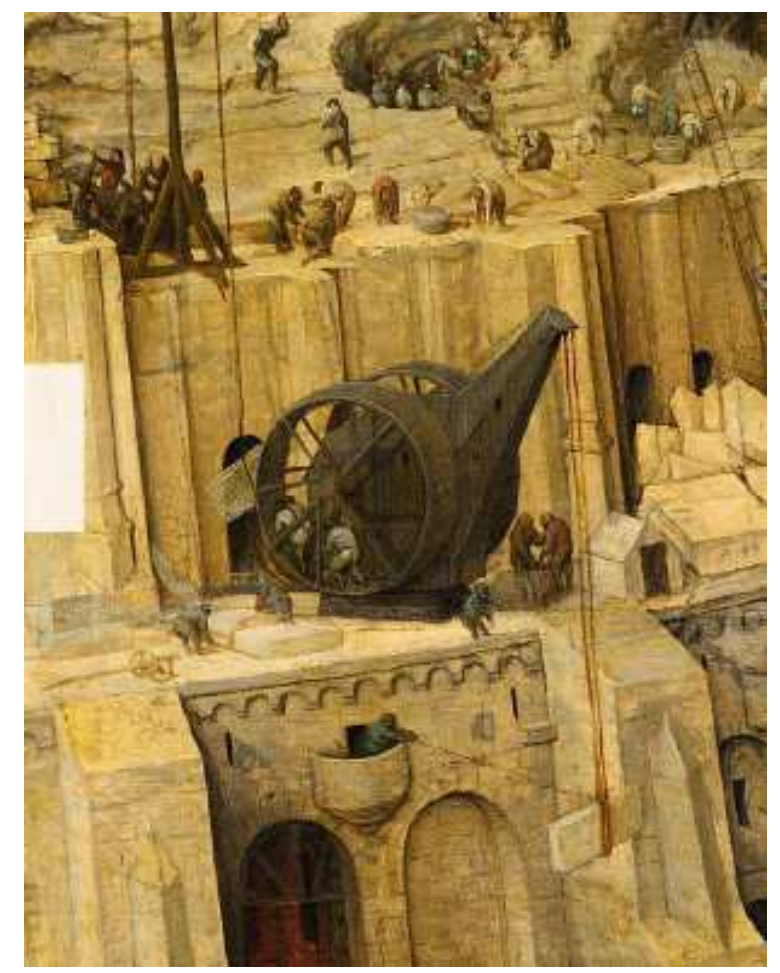

Figura 1.23: Detalle del cuadro "la torre de Babel" de Peter Bruegel', con una grúa de doble rueda

\subsubsection{Historia reciente: siglos XIX, XX y XXI}

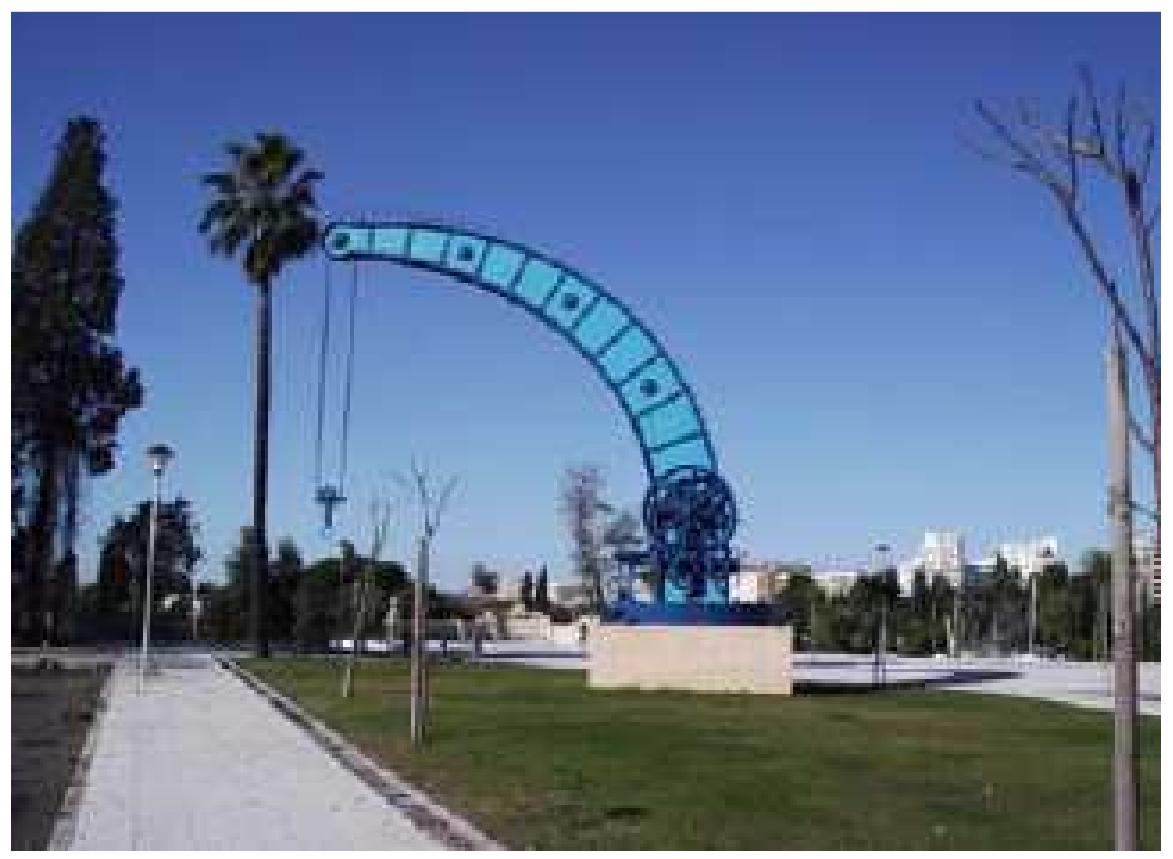

Figura 1.24: Grúa Fairbairn. (1875) Mánchester, del puerto de Sevilla, potencia 90 tn. 


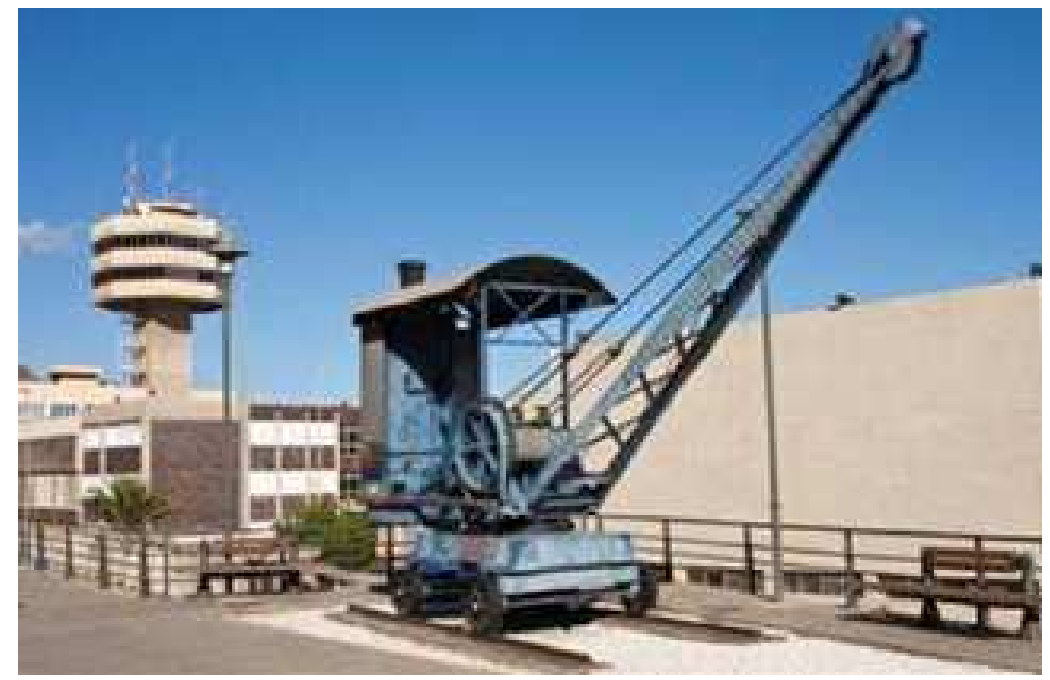

Figura 1.25: Grúa de vapor del puerto de Tenerife (1920)

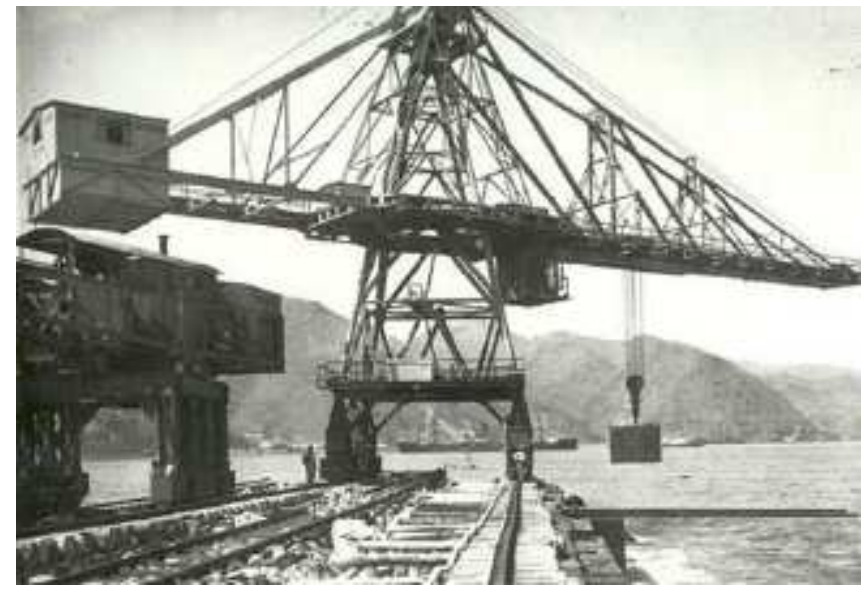

Figura 1.26: Primera grúa Titán del puerto de Tenerife (1887)

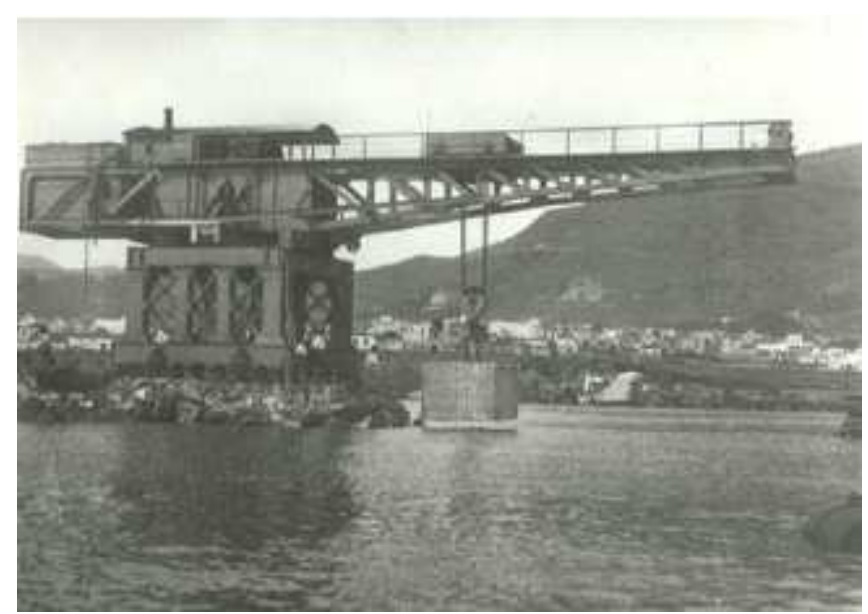

Figura 1.27: Segunda grúa Titán del puerto de Tenerife (1893) 


\section{3.- RELACIÓN INDISOCIABLE CON EL SECTOR DE TRANSPORTES ESPECIALES}

Es muy importante entender la indisociable relación de los sistemas de elevación y los de transporte especialmente cuando se trata de cargas de magnitud importante. Es muy corriente en el sector de grandes cargas ver medios de transporte realizando elevaciones:

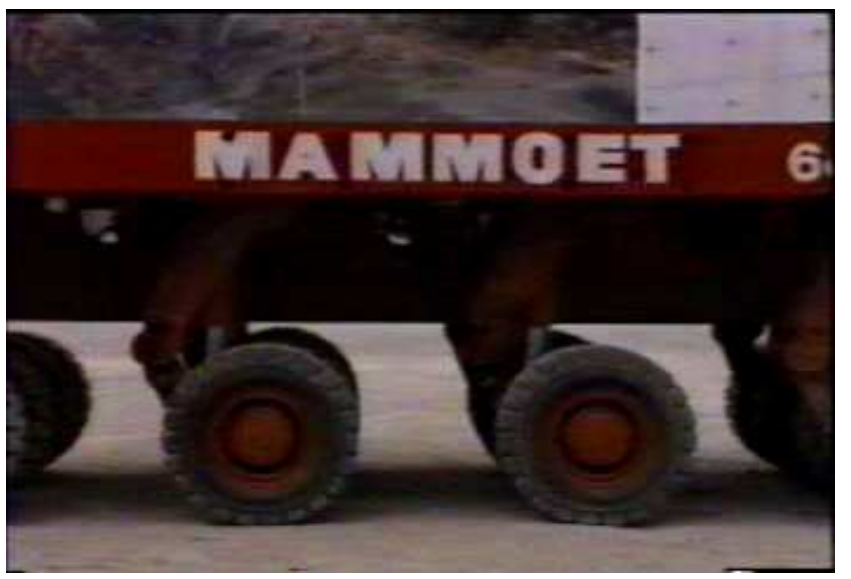

Figura 1.28: Carretones autopropulsados SPMT sin carga con los cilindros extendidos elevando su plataforma (max. 600 milímetros en cada carrera vertical)

Esta carrera vertical que tienen muchos medios de transporte horizontal como los carretones autopropulsados SPMT, los carretones convencionales de transporte especial, muchos patines de deslizamiento horizontal sobre raíles de teflón, tienen en principio la misión fundamental de poder auto cargar y auto descargar las piezas que van a transportar. En efecto, cuando se trata de transportar una pieza de varios cientos o miles de toneladas, sería muy caro, o incluso en algún caso inviable o imposible, utilizar grúas u otros sistemas de elevación para cargar la pieza sobre el equipo de transporte y luego descargarla una vez realizado el transporte. Es por ello que los equipos de transporte especial suelen disponer de esa carrera vertical que les permite introducirse por debajo de las piezas a transportar, levantar su plataforma entrando en carga al contacto con la pieza y elevarla para su transporte. La auto descarga se realiza de la misma forma pero a la inversa.

Sin embargo, esta posibilidad les convierte en potenciales sistemas de izado ya que pueden elevar una pieza o bajarla mediante maniobras sucesivas. El proceso es laborioso ya que la carrera es bastante pequeña y a cada paso hay que apoyar la pieza, calzar o descalzar el equipo de transporte para poder realizar la carrera siguiente. 
Se utilizan estos sistemas sobre todo cuando la altura a elevar no es excesiva y sobre todo cuando el equipo de transporte ha sido necesario, está presente en obra y ahorra movilizar una grúa u otro sistema de izado. Un ejemplo significativo serían ciertas estructuras de hormigón como puentes, etc.

Como veremos más adelante, incluso se ha realizado investigación y desarrollo en este sentido que ha dado lugar a sistemas muy novedosos para los que se han convertido los tradicionales patines de deslizamiento horizontal en un sistema de izado vertical con el que se han batido records del mundo en el sector Offshore llegando a elevar más de 20.000 toneladas a más de 20 metros de altura.

También ocurre el fenómeno inverso a lo anterior que es la utilización de grúas o sistemas de elevación para realizar o colaborar en transportes. Esto es especialmente frecuente cuando en una ruta de transporte existe algún obstáculo difícil de salvar con equipos de transporte especial como por ejemplo el paso debajo de un viaducto de carretera que deja un gálibo insuficiente o el paso por encima de un pequeño puente que no resistiría el paso de un trasporte especial.

En el caso de la siguiente fotografía se trata de 2 grúas de celosía sobre cadenas que elevaron unas cámaras de coque por encima de un rack de tubería cuyo gálibo no permitía que pasaran como los demás transportes por debajo de él:

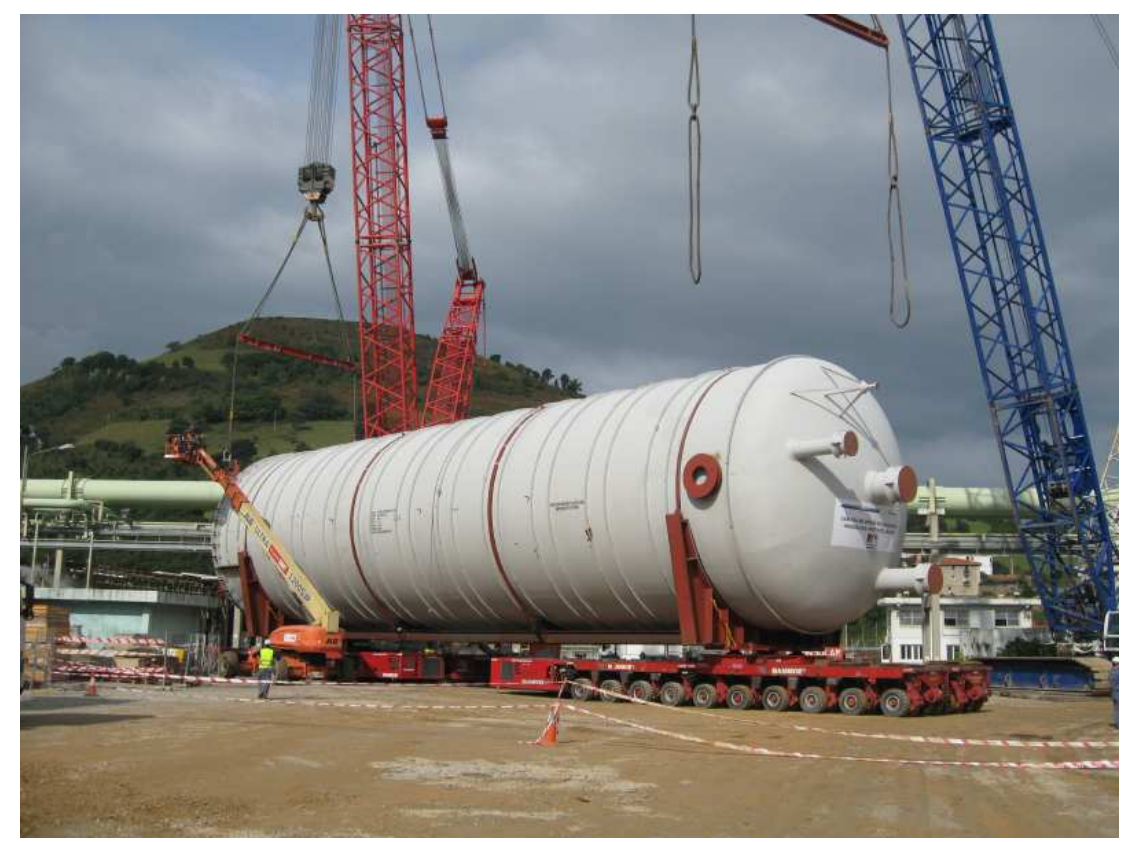

Figura 1.29: Maniobra con dos grúas durante el transporte de las cámaras de coque de Petronor para pasar por encima de los racks de tuberías debido al gálibo insuficiente de los mismos (2009) 
Desde luego esta relación entre transportes e izados no es nueva ya que en la antigüedad ya se elevaban bloques mediante el uso de rampas transportándolos hacia arriba intentado que la fricción fuese lo menor posible.

La utilización de medios de transporte e izados no está siempre claramente diferenciada en el mundo de la construcción y de hecho es fundamental "mezclar" ambos tipos de recursos (transporte y elevación) cuando se quiere dar una solución innovadora para problemas de maniobras de grandes cargas y sería un grave error independizar ambas disciplinas. Un gran número de empresas, tanto grandes como pequeñas, trabajan en ambas disciplinas: elevación y transporte. Es difícil encontrar por lo tanto una empresa de grúas que no tenga en mayor o menor medida equipos de transporte.

De hecho en ingles se habla de transporte horizontal ("horizontal transport") o transporte vertical ("vertical transport") para referirse a lo que en español denominaríamos habitualmente transporte e izados respectivamente.

Es por lo tanto muy importante tener en cuenta que los medios que se tradicionalmente se clasificarían como medios de transporte horizontal son también equipos y maquinaria a tener en cuenta en el mundo de la elevación y actúan frecuentemente como autenticas máquinas de elevación. 


\section{4.-TIPOLOGÍA DE GRÚAS}

Se pueden establecer multitud de clasificaciones de grúas en función del parámetro que elijamos para diferenciarlas: tipo de pluma, función o tipo de trabajo, tipo de apoyo, etc.

No hay un parámetro específico y se suelen denominar en el mercado muchas veces por su característica más significativa. Por ejemplo las grúas muy específicas como las que se usan para un tipo de actividad muy concreto: Grúas portuarias, grúas de cimentaciones, puentes grúas (para naves industriales), blondines para presas, etc. Dentro de las grúas portuarias se clasifican a su vez: de pico pato, Portainers (para contenerdores), etc.

En el caso de las grúas móviles más generalistas o versátiles, las clasificaciones más habituales son por el tipo de pluma: Celosía o telescópica o por el tipo de apoyo: sobre camión, sobre cadenas u orugas, sobre pedestal, sobre anillo o ringer, sobre raíles, sobre barcaza (o cabría) etc.

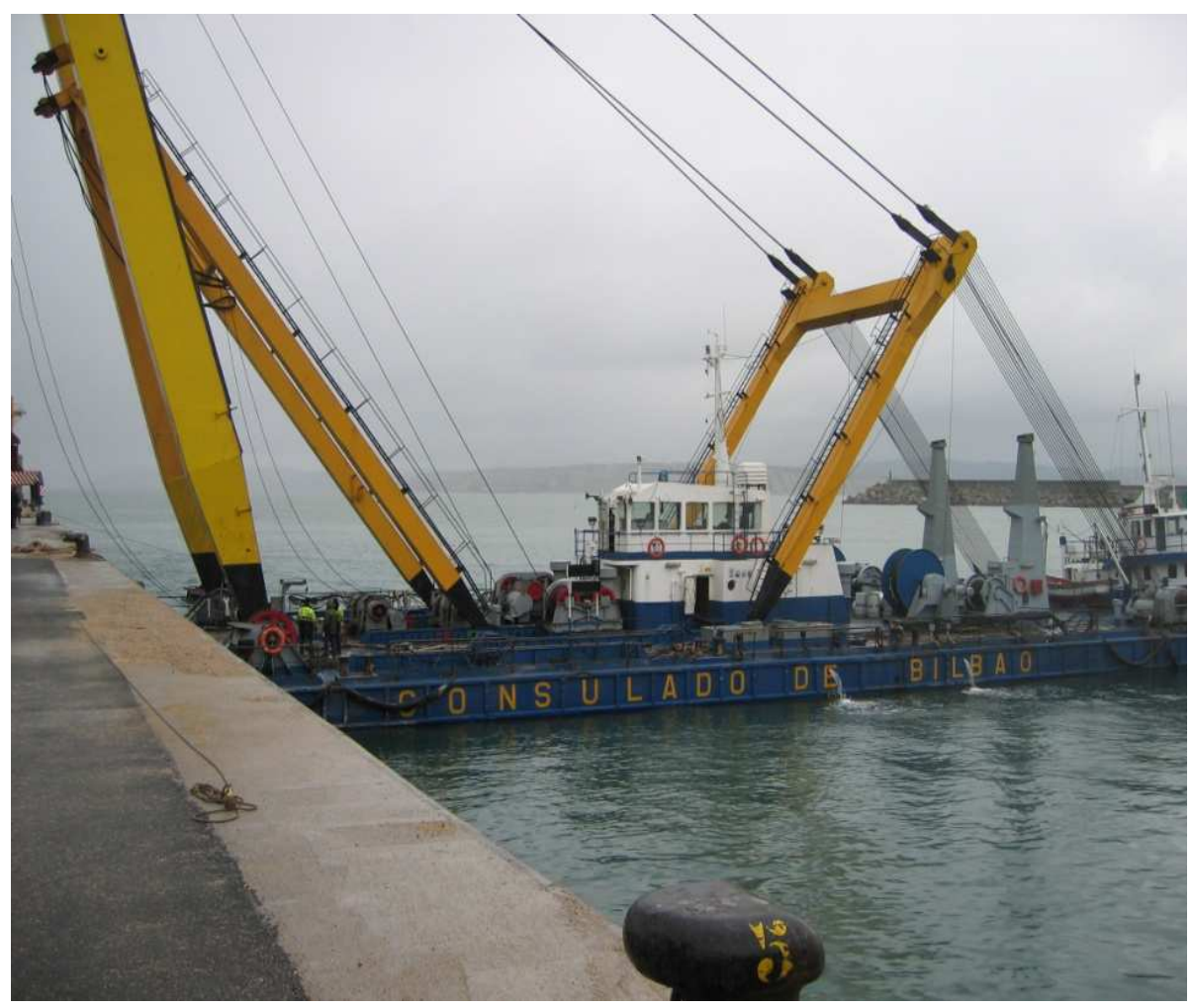

Figura 1.30: Cabria del Puerto de Bilbao (2005) 
Dentro de las posibles combinaciones, lo más habitual que encontramos son grúas de celosía sobre cadenas y grúas telescópicas sobre camión pero también existen grúas de celosía sobre camión que se han hecho algo más frecuentes gracias al sector eólico ya que presentan ventajas para cambiar la grúa de emplazamiento entre las diferentes torres que hay que montar dentro de un parque eólico. También, aunque más raras todavía, son las telescópicas sobre cadenas que pueden ser eficaces en obras en las que la grúa se tenga que estar desplazando frecuentemente por la obra pero la pluma de celosía tenga problemas en dicho desplazamiento por haber gálibos limitados (cables eléctricos, grúas torre trabajando, etc.)

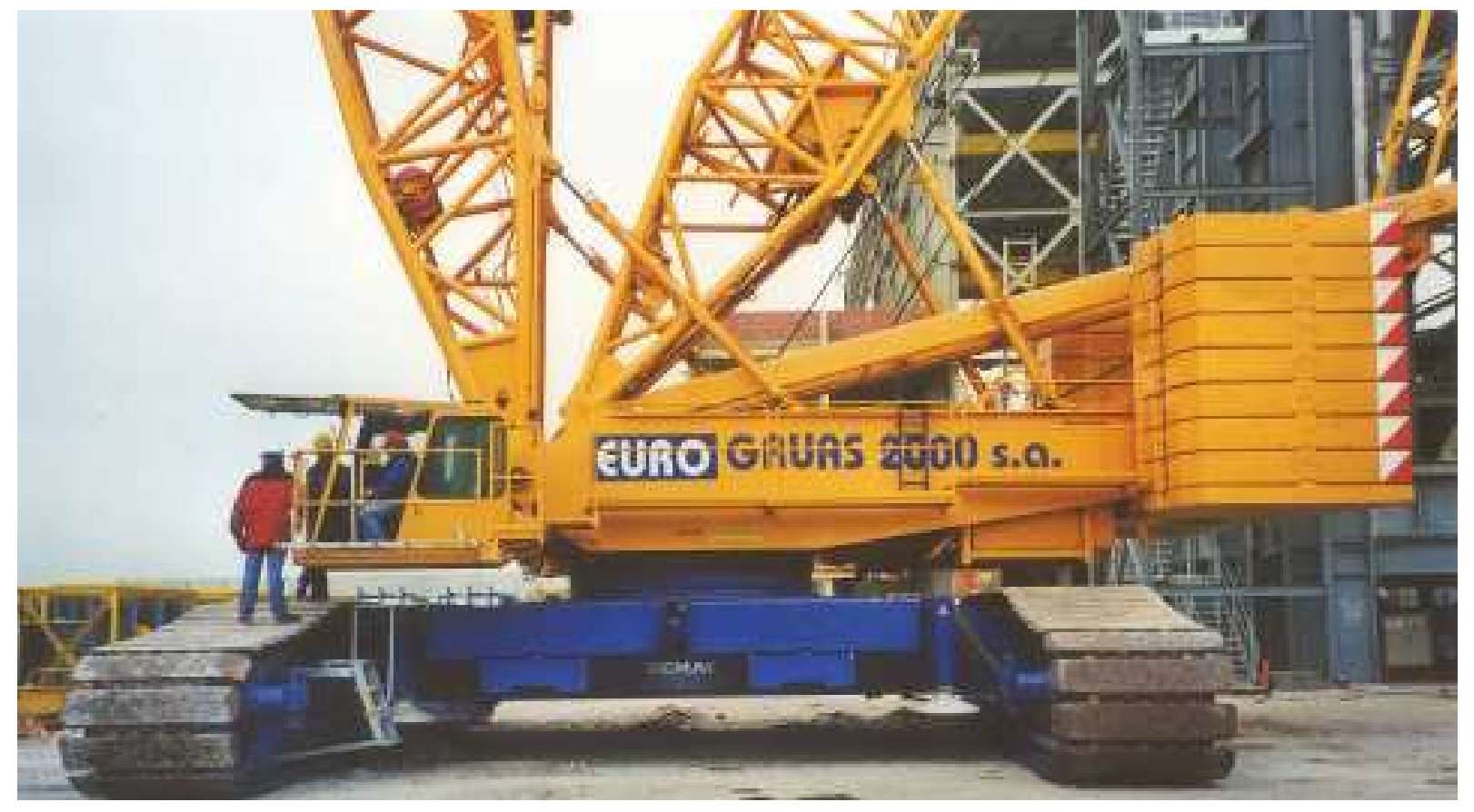

Figura 1.31: Grúa Celosía sobre cadenas (Central de ciclo Combinado de Castejón, Navarra, 2002) 


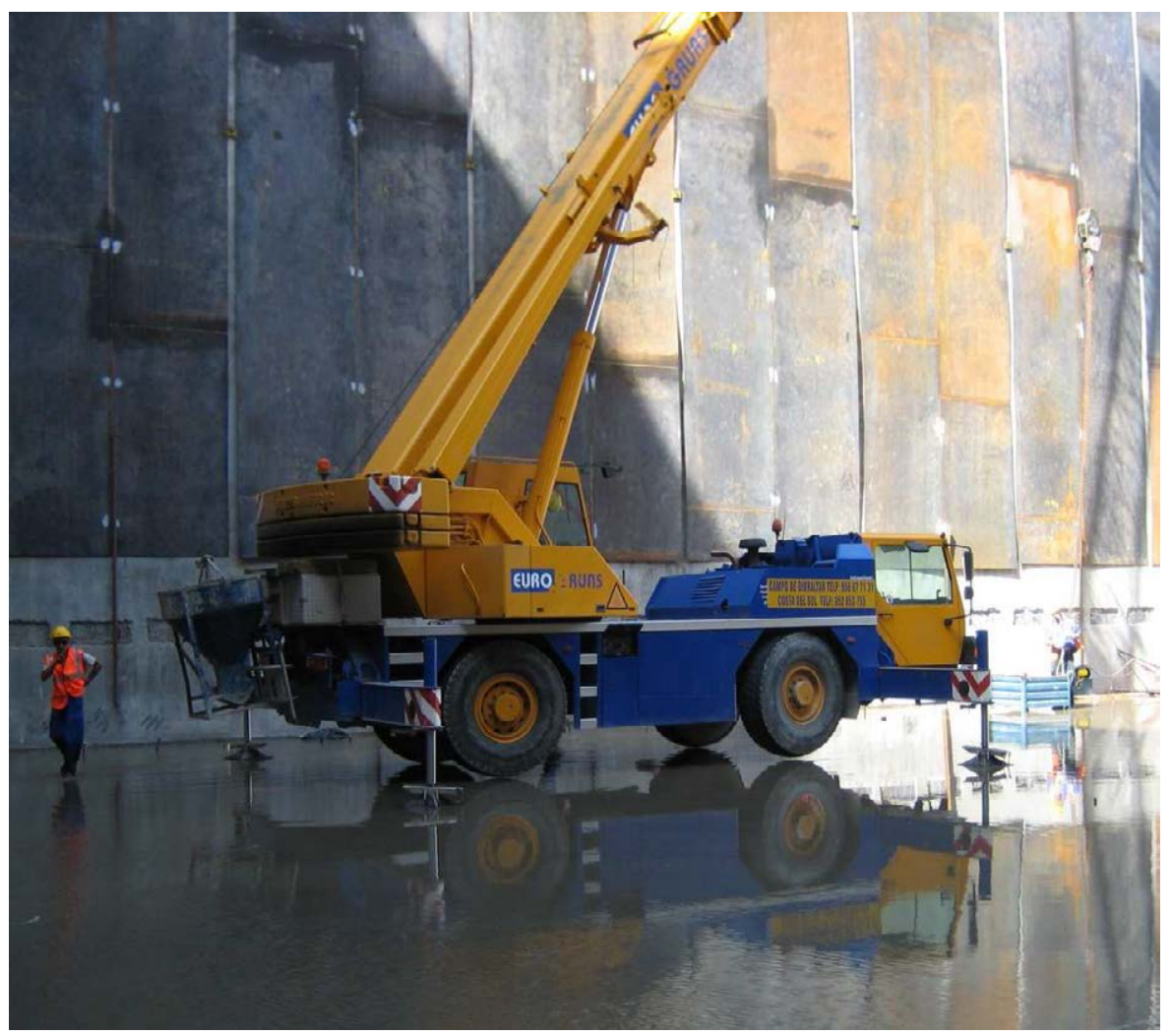

Figura 1.32: Grúa telescópica sobre camión (Cajón del Adriatic LNG terminal, Algeciras 2006)

Una tipología de grúa que no se puede olvidar por su especificidad pero también por tratarse de un símbolo en el mundo de las grúas es la grúa torre que como se ha comentado anteriormente es sin duda la "reina" en el mundo de la edificación aunque es tan versátil que se usa en un enorme tipo de trabajos totalmente diferentes como la construcción de puentes, presas, obras industriales, etc.

Las ventajas que ofrece cada tipología de grúas son muy variadas y pueden venir de la adaptación al trabajo concreto a realizar por dicha máquina o a otros factores como precio de alquiler o compra, facilidad de movilizarla y desmovilizarla a los lugares de trabajo, capacidades de carga, o simplemente su disponibilidad.

Se citan a continuación algunas posibles ventajas en función de las tipologías que resultan interesantes a la hora del desarrollo del sector y por lo tanto de la investigación y desarrollo de nuevos diseños: 
- Las grúas de celosías sobre cadenas suelen ser más baratas en alquiler a largo plazo que una celosía sobre camión para maniobra similar sobre todo si es a radio importante. Además permite moverse sobre sus cadenas por la obra y moverse con carga suspendida si el terreno es plano. Los modelos de mayor capacidad de esta tipología son grúas de las más potentes a nivel mundial (terrestres), sólo superadas por las grandes grúas de celosía sobre anillo y sólo desde la aparición de estas últimas a finales de los noventa.

- Las grúas telescópicas sobre camión, son baratas y rápidas de movilizar a obra ya que llegan circulando sobre su propio camión y se estacionan en cuestión de horas sobre sus estabilizadores dependiendo lógicamente de su tamaño. Las celosías sobre cadenas sin embargo requieren un número importante de camiones para su movilización a obra y su montaje dura varios días requiriendo además medios auxiliares como grúas telescópicas, etc. durante dichos periodos de montajes, desmontajes, cargas de sus piezas y descargas.

- Las grúas torre son como ya hemos señalado las grúas ideales para la edificación por sus características combinadas de alcance, distribución, brazo horizontal, precio a largo plazo, etc.

- Las grúas sobre anillo o ringer presentan una distribución de cargas sobre el terreno buena y como se ha comentado, los modelos mayores son hoy en día las grúas terrestres mayores del mundo.

- Las celosías sobre camión son menos frecuentes pero permiten trasladar el cuerpo principal de la grúa sobre el camión lo cual les da una ventaja importante para muchos parques eólicos.

- Etc.

Existe también una clasificación de grúas en la legislación española que muestra incluso sus croquis dibujados y que por su interés para esta investigación se incluye como anexo ya que al fin y al cabo es la clasificación legal por tipologías. 


\section{5.- GRAFICO Y TABLAS DE CARGAS}

El gráfico y las tablas de capacidad de una grúa es lo que cualquier usuario, ya sea proyectista o responsable de obra, necesita para planificar una maniobra, dimensionar una grúa, comprobar su validez, etc.

En lo que se refiere a este estudio, no se va a entrar en detalles ni explicaciones de estos elementos que por otra parte son bien conocidos en el sector (ver: "Apuntes de Sistemas de Elevación, Grúas" de Miguel Flórez de la Colina y José Flórez Alía).

Sin embargo es necesario resaltar que dentro de las tablas de capacidad de las grúas, los valores que limitan la capacidad de la máquina a radio corto vienen dados por la rotura de algún elemento como el cable mientras que los valores a radios más importantes, son limitaciones de carga debidas al momento de vuelco de la grúa. En cada caso se toman por supuesto los valores más restrictivos a la hora de hacer la tabla. Los valores de vuelco que se incluyen en las tablas hoy en día, son valores del 75\% (normalmente indicado en la propia tabla) por lo que llevan ya incluido su coeficiente de seguridad.

Antiguamente era más fácil encontrar tablas en las que se mostraba esa frontera de los valores debidos a rotura o a vuelco con lo que sólo con ver la tabla se sabía cuál era la limitación de la máquina para un trabajo de izado. Esto ya no se suele ver en absoluto.

La capacidad nominal de la grúa viene dada por la capacidad a radio mínimo aproximadamente y por lo tanto indica la resistencia de la máquina a rotura pero no al vuelco y sin embargo, es en esa zona de la tabla de los valores de vuelco donde normalmente se realizan las maniobras de grúas. Se observa una cierta incongruencia por lo tanto que da lugar frecuentemente a que la capacidad esperada de una grúa no sea la real.

Por este motivo parecería más lógico usar un valor del momento de vuelco admitido para definir la capacidad de una grúa. De los valores de la tabla, se puede obtener el valor máximo del momento de vuelco llamado MLM por sus siglas en inglés (Maximum Load Moment). 


\section{6.- NOMENCLATURA DE GRÚAS}

La forma de designar una grúa que se usa hoy en día de forma muy extendida a nivel mundial es la propia capacidad de carga máxima de la grúa.

Usar dicho parámetro para la nomenclatura de las grúas es muy engañoso ya que no define bien el tipo de máquina, ni siquiera sus capacidades reales y da lugar a errores tanto a las personas muy especializadas en el mundo de las grúas como a las que son usuarios ocasionales de estas máquinas.

Es casi corriente en una obra que se solicite por ejemplo una grúa de 100 toneladas para levantar una carga de 80 o 90 toneladas (y ese margen de diferencia se deja como coeficiente de seguridad). Causa entonces sorpresa cuando se descubre que la grúa que hay que alquilar es quizás de 300 o 500 toneladas en función del radio de trabajo y otros factores (alturas, obstáculos, etc.) que tengan en su caso.

Pero más allá de ese ejemplo quizás algo extremo, la capacidad máxima de la mayoría de las grúas es a radio muy corto y como hemos visto anteriormente en el apartado de las tablas de carga, los valores que limitan la capacidad de carga a radios cortos son por rotura de elementos como los cables, la pluma etc.

En cuanto el radio es un poco más importante, los valores de las tablas de capacidades vienen limitados por el momento máximo que puede admitir la máquina pudiendo producirse el vuelco de la misma. Estos valores de vuelco no corresponden sistemática ni proporcionalmente a la carga máxima de la grúa pudiendo llegar en algunos casos a ser antagónicos ya que una pluma muy reforzada a compresión y por lo tanto muy pesada puede mejorar los valores a radio corto pero empeora los valores a radios importantes ya que su peso propio mete un momento de vuelco que se combina con el de la carga izada.

Se crea también de esta manera una tentación comercial de los fabricantes de intentar obtener una alta capacidad nominal (que "vende" mejor la grúa) aunque esta no se corresponda con las capacidades de la grúa a radios un poco mayores (limitados por el vuelco) que son los radios de trabajo que con mayor probabilidad se vayan a utilizar más frecuentemente a lo largo de la vida de la máquina.

Cuando comparamos las capacidades de grúas de similar tonelaje nominal observamos diferencias enormes de capacidades a radios importantes. 
Esto puede ser debido a la tipología de las grúas por ejemplo: las telescópicas ven reducida su capacidad en función del radio de forma mucho más drástica que las celosías.

Pero también se observa que modelos de grúas casi análogos (e incluso a veces del mismo fabricante) dan capacidades de carga a radios importantes completamente diferentes.

La nomenclatura oficial de las grúas, el nombre que le pone el fabricante a cada modelo de grúa, es totalmente heterogénea y desorganizada ya que cada fabricante utiliza sistemas propios.

Alguno de estos sistemas de nomenclatura tiene alguna relación con el tipo de grúa e incluso con su capacidad como es el caso de Liebherr en la que las cifras posteriores al 1 son la capacidad nominal de carga (carga máxima a radio mínimo aprox.), las letras se refieren a la tipología de la grúa. Sin embargo en el caso de otros como Terex Demag, el número no tiene aparentemente ningún significado e incluso tiende a crear aun más confusión que el usar la máxima capacidad nominal (como veremos a continuación). Así por ejemplo, entre las grúas de Demag CC2800 y CC4200 hay un porcentaje de diferencia de capacidad bastante inferior que el que sería de esperar en función de los números indicados en sus nombres. Sus capacidades nominales son de 600 toneladas y 800 toneladas respectivamente (que como vemos, poco tienen que ver con los nombres elegidos por Terex Demag).

La grúa parecida y competidora a la CC2800 de Terex pero de marca Liebherr, sería la LR1600 que al menos si indica que es una grúa de 600 toneladas. Sin embargo, a simple vista y para las personas no conocedoras de estos temas, esta grúa última parecería una máquina muy inferior en capacidad a la CC2800.

Por todo lo anterior, sería deseable aunque casi imposible tal y como están las cosas, que la nomenclatura de las grúas se cambiara y se usara por ejemplo el máximo momento (MLM: Maximum Load Moment) como vienen haciendo últimamente algunos fabricantes, especialmente los de muy grandes grúas:

MSG50: 50.000 toneladas metro.

PTC200: 200.000 toneladas metro.

Como vemos el nombre describe la tipología (Platform Twinring Containerized) y luego indica el máximo momento de la máquina. 


\section{7.- LEGISLACIÓN Y NORMATIVA}

Este apartado no pretende analizar ni enumerar exhaustivamente la legislación aplicable en el mundo de las grúas sino dar una idea de la situación actual, ver brevemente el marco legislativo existente en el sector de las grúas y ver de qué forma puede afectar al estudio Técnico Económico objeto de esta investigación.

La legislación en el sector de las grúas es muy compleja y va desde legislación específica de grúas a legislación de temas que afectan a las grúas pero no es central del sector como por ejemplo legislación de maquinaria en general, legislación de seguridad en obras, etc. Es importante distinguir también la legislación dirigida a los usuarios de grúas en maniobras como es el caso de la Española que se verá a continuación de la legislación dirigida al diseño y construcción de nuevas grúas como es el caso de la legislación Norteamericana por ejemplo.

Legislar sobre ambos temas es muy importante para garantizar el buen uso de esta maquinaria y el trabajo en obra con seguridad dado que las maniobras de izado son un punto muy sensible dentro de la seguridad en la construcción.

La legislación más aplicable directamente a las grúas en España está en: RD 837/ 2003 y el RD 836/ 2003 de 27 de junio. Estos aprueban respectivamente los nuevos textos de las ITC AEM 2 sobre Grúas torre e ITC AEM 4 sobre Grúas móviles autopropulsadas, en sustitución de la misma ITC aprobada por el Real Decreto RD 2370/ 1996 de 18 de noviembre.

La nueva normativa amparada por el R.D. tiene como propósito ampliar los criterios de seguridad, las condiciones de utilización, mantenimiento, revisión e inspección oficial de todas las grúas móviles del parque nacional existente. Además, permite el seguimiento de las condiciones de seguridad más allá del mantenimiento preventivo y la inspección fijada por el propio fabricante de la máquina.

La legislación sobre grúas móviles autopropulsadas incluye las normas NTP, en concreto la NTP 208. Aunque no sean de obligado cumplimiento, vienen recogidas en una disposición normativa vigente. La norma NTP 208 expone una visión general de los riesgos específicos y de las normas de prevención de riesgos y medidas de inspección recomendadas a la hora de trabajar con grúas móviles. 
La legislación sobre el diseño y construcción de grúas no existe prácticamente en España pero realmente hay muy poca construcción de grúas excepto en el campo de las grúas torre ya que hay marcas españolas que están vendiendo este tipo de grúas a nivel mundial. Pero en cualquier caso, el mundo de la venta de grúas está hoy en día completamente globalizado y de hecho la mayor parte de grúas son fabricadas por grandes multinacionales que venden a nivel mundial. Al querer vender el mismo modelo de grúa en todo el mundo, ya se sea una gran multinacional o una fábrica mediana de grúas torre, es imprescindible cumplir con las legislaciones de todos o de la mayor parte de los países, especialmente con la Norteamericana, Australiana, Europea, etc. y además con lo más restrictivo de cada una de ellas para que la grúa pueda ser vendida a cualquier país sin problemas. Aunque se quisiera vender a una sola de estas grandes zonas comerciales para así cumplir sólo con la legislación aplicable a esa zona y así no necesitar cumplir el resto, esto restaría aun así posibilidades a esa posible venta ya que la maquina tendría limitada su movilidad y su venta de segunda mano a otros mercados.

Con las situaciones de crisis que se están atravesando estos últimos años se ve que esta venta de segunda mano es fundamental para poder tener la flexibilidad necesaria de los parques de maquinaria a las contracciones y expansiones económicas y por ello cumplir la legislación globalmente a nivel mundial es crucial.

\subsection{1.- Legislación de Seguridad}

Los textos vigentes en materia de seguridad que se tomarán en cuenta para este análisis son:

\section{Reales Decretos:}

Aplicables al uso de máquinas en general

RD. 1435/1992 por el que se dictan las disposiciones de aplicación de la Directiva del Consejo 89/392/CEE, relativa a la aproximación de las legislaciones de los Estados miembros sobre máquinas.

RD. 1215/97 por el que se establecen las disposiciones mínimas de seguridad y salud para la utilización por los trabajadores de los equipos de trabajo.

Mantenimiento de equipos (Manual de uso y mantenimiento/ Mantenimiento por personal competente/ Registro de revisiones) 
Mantenimiento de equipos Si disponen de marcado CE ( Manual de uso y mantenimiento/ Mantenimiento por personal indicado por el fabricante /Revisiones según indicación del fabricante)

\section{Aplicables al uso de grúas:}

RD 836/ 2003 por el que se aprueba una nueva Instrucción técnica complementaria «MIE-AEM2» del Reglamento de aparatos de elevación y manutención, referente a grúas torre para obras u otras aplicaciones.

RD 837/ 2003 por el que se aprueba el nuevo texto modificado y refundido de la Instrucción técnica complementaria «MIE-AEM-4» del Reglamento de aparatos de elevación y manutención, referente a grúas móviles autopropulsadas.

Dada la importancia de esta normativa en España, se adjuntan en los Anexos nํ1 y nำ2.

\section{Normas UNE:}

Se han tomado en consideración estas normas porque inciden sobre aspectos de la seguridad en la utilización de los distintos componentes y modalidades de trabajo con grúas móviles. Atañen en particular las características de los equipos eléctricos; equipos neumáticos, hidráulicos, etc. También regulan la estabilidad, el accionamiento, las instrucciones de servicio y de mantenimiento entre otros.

- UNE-58-110-1990. Aparatos de elevación. Grúa-Torre. Vocabulario.

- UNE-58-104-1987 Aparatos de elevación. Vocabulario. Parte 1. Tipos de aparatos de elevación Parte 3. Conceptos generales Parte 4. Componentes Parte 5. Limitadores e indicadores

- UNE-58-101-1992. Aparatos pesados de elevación. Condiciones de resistencia y seguridad en las grúas torre desmontables para obra. Parte 1. Condiciones de diseño y fabricación

- UNE-58-101-1992. Aparatos pesados de elevación. Condiciones de resistencia y seguridad en las grúas torre desmontables para obra. Parte 2. Condiciones de instalación y utilización 
- UNE-58-101-1992. Aparatos pesados de elevación. Condiciones de resistencia y seguridad en las grúas torre desmontables para obra. Parte 3. Documentación

- UNE-58-101-1992. Aparatos pesados de elevación. Condiciones de resistencia y seguridad en las grúas torre desmontables para obra. Parte 4. Vida de la grúa

- UNE-58-132-1991. Aparatos de elevación. Reglas de cálculo. Parte 6: Reglas de seguridad UNE-58-143-1995. Aparatos de elevación. Cabinas. Parte 3: Grúas-Torre

- UNE-58000-2003. Manejo de grúas y artefactos para elevación y transporte de pesos. Ademanes de mando normalizados

- UNE-EN-1492-4:2005. Eslingas textiles. Seguridad. Parte 4: Eslingas de elevación fabricadas con cuerdas de fibras naturales y químicas para uso general

\subsection{2.- Legislación sobre el carnet de Gruista}

Hasta esta legislación, cualquier persona podía teóricamente sin carnet subirse a operar por ejemplo una grúa de 600 toneladas en España pero no podía sin carnet conducir un ciclomotor. En otros países de Europa ya existía este tipo de carnet de gruista que consigue profesionalizar el sector y es muy beneficioso para la seguridad aunque probablemente incrementa los costes salariales de los gruistas que ya necesitan disponer de un carnet según su categoría.

La asociación de empresas de grúa y transportes especiales europea (ESTA: European Association of abnormal road transport and mobile cranes) lleva a cabo un proyecto para intentar uniformizar la formación de los gruistas a nivel europeo.

El ANEXO VI al Real Decreto 836/2003 y Real Decreto 837/2003 que disponen las modalidades de obtención y para impartir el Carné de gruista u operador de grúa torre detallando los siguientes puntos de ley:

1. Objeto y ámbito de aplicación.

2. Carné de gruista u operador de grúa torre.

3. Requisitos para la obtención del carné. 


\section{Curso teórico-práctico.}

5. Entidades reconocidas para impartir cursos.

6. Expedición y validez del carné.

\subsection{3.- Legislación Administrativa}

La normativa de seguridad de máquinas RD 1435/92 y su modificación por el RD $56 / 95$, permiten definir las normas aplicables en cuanto a circulación, procedimientos de certificación y marcado CE.

Legislación específica aplicable a grúas torres desmontables de obra:

El mismo RD 1215/1997 ya citado anteriormente

RD 836/ 2003 ITC MIE-AEM2

RD 56/1995 por el que se modifica el Real Decreto 1435/1992 de 27 de noviembre relativo a las disposiciones de aplicación de la Directiva del Consejo 89/392/CEE sobre máquinas.

Éste adapta los textos a la evolución inducida por la integración de España a la UE.

En el Real Decreto 1435/1992 ya se especificaban las normas de puesta en servicio e inspecciones por organismos de control de la administración como sigue:

- Mantenimiento específico; Cada 6 meses

- Autorización de puesta en servicio por Administración. Inspecciones por un Organismo de Control de la Administración a los 4 años, luego cada 3 años, y después cada año a partir de los 9 años para grúas grupo I, de los 10 años grupo II, 14 años para grupo III

Legislación específica aplicable a grúas móviles autopropulsadas usadas

El mismo RD 1215/1997 ya citado anteriormente

RD 837/ 2003 ITC MIE-AEM4

RD. 56/1995 por el que se modifica el Real Decreto 1435/1992. de 27 de noviembre relativo a las disposiciones de aplicación de la Directiva del Consejo 89/392/CEE sobre máquinas. 
Éste adapta los textos a la evolución inducida por la integración de España a la UE.

En el Real Decreto 1435/1992 ya se especificaban las normas de puesta en servicio e inspecciones por organismos de control de la administración como sigue:

- Mantenimiento específico; por Empresa conservadora, periodicidad según manual.

- Inspecciones por un organismo de control de la administración A los 3, 6, 8, 10 años y luego cada año.

Permisos de circulación:

El interlocutor es la Dirección General de Tráfico quien consulta con los titulares de las vías transitadas por la grúa.

Registro de grúas:

Para utilizar una grúa en el marco de una obra hay que registrarla previamente acerca de la Comunidad Autónoma en la que está domiciliada la empresa que emplea dicha grúa. 


\section{OBJETIVOS}

\section{1.- OBJETIVOS RELACIONADOS CON LOS PARÁMETROS DE CAPACIDAD DE LAS GRÚAS}

Las grúas tienen unos nombres comerciales elegidos por los fabricantes que muy a menudo no tienen ningún significado real con respecto a las características de la máquina, tanto de su tipología como de su capacidad.

Es de uso común para definir la capacidad de una grúa así como para nombrarla en una obra el valor de su tonelaje nominal que es aproximadamente igual a su capacidad de carga a radio mínimo. Este punto crea una controversia importante ya que este valor de tonelaje a radio mínimo resulta a menudo engañoso a la hora de definir la capacidad real de una grúa y no permite comparar correctamente una grúa con otra. Algunos fabricantes han intentado introducir nomenclaturas que relacionen la grúa con su tipología como es el caso de Liebherr cuyas letras indican la tipología de la grúa pero sin embargo los números (después del primer uno), indican la capacidad nominal de la grúa.

A la hora de pensar en otros valores que pudieran servir mejor para definir la capacidad de una grúa, el máximo momento de vuelco MLM por sus siglas en inglés (Maximum Load Moment) es probablemente la mejor posible alternativa ya que como se ha indicado anteriormente en el estado del arte, en la tabla de capacidad de una grúa los valores a radio corto suelen significar una limitación de capacidad por rotura pero en cuanto el radio es un poco significativo, los valores suelen significar una limitación por el momento de vuelco de la máquina. La mayoría de maniobras con grúa se suelen hacer por lo tanto usando valores de la tabla de capacidad de la zona limitada por vuelco y por lo tanto es lógico analizar este parámetro como alternativa al tonelaje nominal. En raras ocasiones se ha mencionado el valor del máximo momento de vuelco MLM en el propio nombre de la grúa para intentar dar una idea de la capacidad de la grúa más ajustada a la realidad y precisamente ha sido recientemente, en las nuevas grúas record del mundo de tipología ringer (montadas sobre anillo) donde se puede encontrar esta denominación. Las últimas grúas gigantes en salir al mercado en el año 2011 fueron las PTC140 y PTC200 cuyos números indican 140.000 t.m de MLM y 200.000 t.m de MLM respectivamente. 
En la presente investigación se va a realizar un análisis técnico financiero de unas grúas seleccionadas según sus tipologías y tamaños con el objetivo de comparar ambos parámetros en cuanto a su fiabilidad técnica y sus posibles repercusiones económicas a la hora definir las capacidades de las grúas. Se espera poder obtener las oportunas conclusiones que permitan determinar si el valor del MLM es realmente la magnitud a utilizar para definir las capacidades de las grúas mejor que el valor al uso del tonelaje nominal.

Sería bueno observar también si estos diferentes parámetros se comportan correcta y homogéneamente según las distintas tipologías de grúas ya que como se ha mencionado anteriormente, aunque todas son máquinas de elevación, las variedad de este tipo de maquinaria es muy significativa. Podría darse el caso de que uno de los dos parámetros sea más eficaz para una determinada tipología y el otro sea mejor para otra.

En cualquiera de los casos, el resultado que se obtenga podría afectar al sector grúas en su conjunto ya que se podría confirmar por ejemplo el uso que se hace actualmente del tonelaje nominal obteniendo o no posibles limitaciones de eficacia a este parámetro. También sería posible que se pueda llegar a la conclusión que el MLM sea un parámetro mejor para la definición de la capacidad de una grúa en cuyo caso significaría un impacto muy importante a los usos establecidos de la denominación de este tipo de maquinaria a nivel mundial e implicaría indicar o realizar recomendaciones de posibles acciones para la mejora de este sector de las máquinas de elevación mediante cambios sustanciales en la nomenclatura de las máquinas.

Estas posibles conclusiones podrían contribuir por tanto a una mejor definición y nomenclatura de las grúas con el consiguiente impacto a la hora de elegir una determinada maquinaria para la realización de un proyecto o la ejecución de una obra. Puede, de esta manera, arrojar luz y claridad al usuario final de la maquina (que no siempre es un especialista en este tipo concreto de maquinaria).

Además, puede afectar al diseño y construcción de grúas ya que el uso de uno u otro parámetro puede cambiar el foco a donde se dirige la máxima atención del fabricante. Al fin y al cabo el precio de una grúa depende de su capacidad y si la percepción del cliente de la capacidad real de la máquina cambia, también puede cambiar el precio de la misma.

Como se ha visto en el estado del arte un parámetro implica mayor resistencia a radio corto y el otro mayor momento de vuelco admisible. El fabricante puede intentar mejorar la capacidad 
de la grúa hacia una u otra dirección que no siempre coinciden como se ha explicado en el estado del arte.

Paralelamente a la comparativa del momento máximo (MLM) y el tonelaje nominal se quieren calcular diversos momentos de vuelco a distintos radios de distintas máquinas ya que esto serviría entre otras cosas para analizar precisamente el comportamiento de los momentos de vuelco en función del radio de trabajo y también en función de su valor máximo el MLM. Es distinto si la variación del momento es pequeña y no difiere mucho del MLM que si esta variación resulta ser importante al variar el radio de trabajo. Cuanto menos varíe, más fiable será el uso del MLM como parámetro. Tanto si las variaciones del momento de vuelco son pequeñas como si son importantes (especialmente en este último caso), es interesante estudiar si el máximo momento que puede dar una grúa frente al vuelco se produce a radios mínimos, medios o máximos. Este factor podría ser también una diferencia importante entre ambos parámetros ya que como es sabido, la capacidad de carga en tonelaje es máxima a radio mínimo en prácticamente todas las grúas y va decreciendo al aumentar el radio.

\section{2.- OBJETIVOS RELACIONADOS CON LA COMPARATIVA DE LAS GRÚAS ESTUDIADAS}

En función de estos parámetros que definen la capacidad de las grúas, se quiere utilizar el análisis técnico financiero de las distintas grúas seleccionadas para comparar la eficiencia técnica y económica de las máquinas analizadas en función de sus tamaños y también según sus tipologías.

Las grúas van perdiendo capacidad según aumenta el radio de trabajo debido al momento de vuelco pero se quiere analizar si esa variación es análoga en las distintas máquinas o estas se comportan de forma diferente ante esa variación, es decir si ese decremento es más o menos fuerte en función de la tipología o tamaño.

Las distintas tipologías de grúas operan en rangos de tonelaje diferentes aunque coinciden en grandes franjas de capacidades, las grúas de celosía tienen un rango de capacidades más amplio que las telescópicas y estas que las torres, se observa que la mayor de las celosías es mucho mayor que la más grande de las telescópicas y esta que la mayor de las grúas torre. 
Recientemente (en los últimos 10015 años) han hecho su aparición en el mercado los mayores modelos de grúas terrestres del mundo que coinciden en elegir la tipología de grúas ringer (sobre anillo) fundamentalmente por el mejor reparto de cargas sobre el terreno que con esas capacidades se convierte en un factor determinante. Con el análisis de las grúas de distintas tipologías, se puede intentar constatar si la tipología de una grúa es un factor meramente funcional de la máquina o si tiene también relación con las capacidades de las grúas como puede parecer a priori de esta mera observación. Dicho de otra manera, se podría estudiar si la elección de una determinada tipología de grúa para un izado concreto está solamente motivada por las características de la grúa según el tipo de trabajo a realizar o si depende también de la capacidad que se necesita de la grúa para ese determinado trabajo.

Se pretende con este análisis responder a preguntas como:

- ¿Son más eficientes las grúas cuanto mayor es su capacidad o se dispara el coste al intentar hacer grúas demasiado grandes?

- ¿Los tamaños pequeños de cada tipología son también competitivos o disminuye la eficiencia cuando la grúa es demasiado pequeña?

- ¿ ¿Hay diferencias sustanciales de eficiencia en función de las distintas tipologías de las grúas?

Las posibles respuestas a estas preguntas pueden dar una orientación con respecto al potencial de investigación en este tipo de maquinaria y donde se pueden destinar mejor los recursos para la innovación y desarrollo de nuevas máquinas. También puede permitir entender con datos concretos la futura evolución de esta maquinaria en el sector de la construcción civil e industrial. 


\section{3.- OBJETIVOS RELACIONADOS CON EL ANÁLISIS DEL SECTOR DE LA ELEVACIÓN.}

Se quiere realizar un análisis del sector de las grúas y sistemas de elevación con el objetivo de entender cómo se estructura, cual es su funcionamiento y que motivaciones o frenos intervienen en la innovación de estas máquinas.

Es un hecho claro que este sector se ha desarrollado enormemente en los últimos años y es capaz de generar investigación y desarrollo internamente con unas enormes capacidades de ingeniería que requieren importantes inversiones tanto en la propia ingeniería como en la construcción de nuevos prototipos. Las nuevas grúas cada vez mayores requieren un gran "know how" tanto del diseño de la propia estructura y accesorios como del sector en el que tienen que trabajar posteriormente las máquinas con el fin de encajar en el tipo de obras en las que tienen que funcionar de la mejor manera posible.

Con este análisis junto con el análisis económico financiero de grúas y de sus parámetros de capacidad se pretende poder llegar a conclusiones acerca de:

- Cómo es el proceso innovador de las grúas, quienes lo realizan y recomendaciones de cómo se puede impulsar así como evitar las circunstancias que puedan frenarlo.

- El futuro del sector de la elevación en el mundo de la construcción, su importancia, su impacto a nivel de riesgos tanto de seguridad como económicos, su impacto en la planificación y la estrategia de organización de una obra, etc.

- Si la innovación surge para responder a necesidades del mercado o surge por el propio dinamismo del sector creando así su propio mercado e influyendo sobre las posibilidades y capacidades del sector de la construcción. 


\section{METODOLOGÍA.}

Se va a realizar un análisis del sector de la elevación, de los "actores" que intervienen, de los factores que le afectan, de su evolución y de sus capacidades de ingeniería, diseño e innovación, pero centrado en analizar las influencias, las evoluciones y los equilibrios del propio sector interna y externamente para dirigirlo hacia la obtención de resultados acerca de los factores que impulsan el desarrollo y la innovación y aquellos que los frenan.

Se va a realizar también un análisis técnico financiero de grúas. Se seleccionan para ello grúas de distintos tamaños y tipologías con objeto de obtener una serie de parámetros cuyo análisis permita responder a los objetivos que se han planteado para esta investigación.

\section{1.- ANÁLISIS DEL SECTOR DE GRÚAS Y SISTEMAS DE ELEVACIÓN}

Se va a analizar el sector de las grúas y sistemas de elevación estudiando en primer lugar la maquinaria, los distintos actores que intervienen en el sector (usuarios finales, empresas de grúas, fabricantes, etc.), el marco actual de desarrollo y las propias capacidades de ingeniería.

El siguiente paso será estudiar los factores que impulsan o frenan la innovación y a través de casos concretos de lo ocurrido en los últimos años estudiar el origen de la innovación como respuesta a necesidades existentes o como impulso interno propio del sector.

\section{2.- SELECCIÓN DE GRÚAS A ANALIZAR}

En lo referente a tipologías de grúas, se eligen las tres más importantes en cuanto a número de grúas y presencia de las máquinas en la construcción actual tanto civil como industrial: 
- Grúas de celosía sobre cadenas.

- Grúas telescópicas sobre camión.

- Grúas Torre.

No se incluyen en el análisis otros tipos de grúas como las grúas sobre ringer que estaban desapareciendo cada vez más hasta experimentar un nuevo auge con los nuevos desarrollos de grúas gigantes de la última década, ni las grúas tipo cabria sobre barcaza que no son nada comparables con las terrestres, ni las grúas de sectores muy específicos como las portuarias generales o las de contenedores, etc. Tampoco se han considerado modelos "mezclados" como las celosías sobre camión o las telescópicas sobre cadenas que además abundan mucho menos.

Para poder realizar un estudio comparativo no sólo de las diferentes tipologías sino también por tamaños dentro de cada una de ellas, se han seleccionado 3 grúas de distintos tamaños dentro de cada tipología. Al no coincidir los rangos de capacidades entre las tres tipologías de grúas, no podemos elegirlas de las mismas capacidades como sería deseable por homogeneidad. (Por ejemplo, las 3 grandes de 1.000 toneladas, etc.). Dentro de cada tipología hay que buscar qué grúa se considera grande, qué grúa mediana y qué grúa pequeña.

\section{Tamaño grande:}

El criterio para elegir la grúa de tamaño grande dentro de cada una de las tres tipologías de grúas no ha sido elegir la más grande del mundo que en el caso de las celosías sería la LR13000 de 3.000 toneladas de capacidad nominal y de marca Liebherr ya que estas grúas que baten records son hoy por hoy prototipos y sólo se ha construido una máquina de ese modelo, igual que ocurre con la Demag CC12600 que es la grúa sobre cadenas de Terex Demag más grande del mundo única y que fue superada por el modelo de Liebherr desde el año 2010 aproximadamente. La grúa telescópica más grande en estos momentos es la LTM11250 de Liebherr de 1.250 toneladas de capacidad nominal que no es única y se han construido bastantes unidades pero tampoco resulta muy representativa al ser de poca producción pero además estar fuera del rango de las telescópicas. La siguiente en capacidad sería una grúa de 700 toneladas de capacidad nominal (como se puede observar casi la mitad de capacidad en toneladas nominales aunque posiblemente la diferencia de capacidad real sea aún mayor). En el caso de las grúas torre también está una grúa única: la Kroll K 10000 cuyo modelo es único y 
sale frecuentemente en documentales de televisión como la grúa más grande del mundo (aunque sin precisar que eso es sólo cierto dentro de las grúas torre).

Se ha elegido para esta clasificación de tamaños grandes: la grúa de celosía sobre cadenas LR11350 de la marca Liebherr y de 1.350 toneladas de capacidad nominal por ser una grúa de celosía de muy gran tamaño pero ya con una serie de producción de máquinas de bastantes unidades. De esta forma es una grúa que no se hallará disponible en muchos países para su alquiler pero si en los distintos continentes con más de una unidad por continente en general y según la actividad económica.

En telescópicas una grúa AC700 de 700 toneladas de capacidad nominal y marca Terex Demag que como se ha señalado es una de las más grandes pero relativamente habituales en los países. Y en grúas torre se ha elegido la grúa Potain MD3200 que es su modelo comercial de mayor capacidad sin ser un prototipo.

\section{Tamaño mediano:}

Para la selección de la grúa de tamaño mediano se no se ha seguido el criterio de la media matemática entre la grande y la pequeña sino que se han elegido dentro de cada tipología grúas de tamaño medio (o medio grande) pero que sean representativas por su presencia, características o tamaño especial.

Como celosía se ha elegido la CC2800 de la marca Terex Demag de 600 toneladas de capacidad por su representatividad y gran éxito y además ser una grúa que está disponible (probablemente con varias unidades) en cualquier país que tenga cierta actividad de construcción.

Como telescópica se ha elegido la LTM1200 de 200 toneladas de capacidad y marca Liebherr por ser también una grúa muy representativa y además puede que sea la frontera entre las telescópicas disponibles en casi cualquier ciudad mediana.

Como grúa torre mediana la MD610 40 de 40 toneladas de capacidad nominal y marca Potain (Manitowoc) por motivos análogos a los anteriores. 


\section{Tamaño pequeño:}

Para la categoría de grúas pequeñas, no se han elegido tampoco las más pequeñas de cada tipología porque se perdería representatividad de la máquina ya que los tamaños pequeños suelen ir perdiéndose y siendo no competitivos con respecto a otros medios de izados y soluciones como pueden ser los camiones pluma que llevan su propio brazo articulado y que han ido aumentando sus capacidades de izado hasta el punto de canibalizar el mercado de las pequeñas grúas telescópicas o torres. De la misma manera, las pequeñas celosías van siendo cada vez menos competitivas comparadas con las telescópicas.

Se han elegido: la 2200E de celosía sobre cadenas de 80 toneladas de capacidad y marca Sennebogen. La grúa GMK4080 de marca Grove (Manitowoc) telescópica y de capacidad nominal 80 toneladas y la grúa J52NS de marca Jaso y capacidad nominal 5 toneladas. Ninguna de las 3 es la más pequeña de su tipología pero siendo de baja capacidad cada una dentro de su tipología tienen ya un tamaño razonable que las haga representativas.

Para cada una de estas nueve grúas se van a analizar sus características y tablas de capacidades para obtener los parámetros y valores que se necesitan para este estudio.

\section{3.- PARÁMETROS CONSIDERADOS A CALCULAR Y ANALIZAR}

Los parámetros que se van a utilizar son los siguientes:

Con respecto a los valores de la tabla de la grúa a considerar:

- Radio mínimo (Rmin): Radio mínimo de la grúa.

- Toneladas de capacidad a radio mínimo (Tmin)

- Radio máximo (Rmax): Radio máximo al que puede trabajar la grúa.

- Toneladas de capacidad a radio máximo (Tmax)

- Radio 30 metros (R30): Radio 30 metros de la grúa.

- Toneladas de capacidad a radio $30 \mathrm{~m}$ (T30)

- Momento máximo de la grúa (MLM: "Maximum Load Moment") 
Con ellos obtendremos:

- El momento a radio mínimo (Mrmin)

- El momento a radio máximo (Mrmax)

- El momento a radio 30m (Mr30)

Justificación del uso de dichos parámetros:

Es totalmente lógico utilizar los radios de trabajo mínimos y máximos de las grúas ya que definen en gran medida las posibilidades de la grúa y en especial el radio mínimo ya que la capacidad máxima a ese radio es la capacidad nominal de la grúa y hasta el nombre de la máquina.

Se ha decidido en este estudio, contemplar también el radio de trabajo de las grúas de 30 metros que es hasta cierto punto una medida más arbitraria que las anteriores pero el motivo de la misma es tener un valor intermedio a efectos de la posterior comparativa y por lo tanto no es de fundamental importancia para las conclusiones si este radio se toma de $25 \mathrm{~m}$, de $30 \mathrm{~m}$ o de $35 \mathrm{~m}$ sino el hecho de disponer de un valor en ese rango intermedio.

El considerar el momento máximo de la grúa (MLM) se ha justificado ya antes como alternativa a usar como parámetro la capacidad nominal de la grúa únicamente.

\section{4.- METOdOLOGía PARA EL CÁlCULO DE COSTE POR HORA DE LAS GRÚAS}

Se va a realizar un estudio económico financiero básico para obtener el coste hora de las distintas máquinas que no tiene porque corresponderse con los precios de alquiler comerciales que puedan existir en el mercado ya que estos últimos se ven afectados por oferta y demanda con todo lo que ello significa y que distorsionaría nuestro estudio y con ello la posibilidad de alcanzar los objetivos buscados. 
El coste por hora de máquina se va a componer de los siguientes costes:

- Amortización.

- Costes financieros / Intereses.

- Consumos.

- Mantenimiento.

- Coste del operador.

Nota: No se va a realizar actualización de los precios a una fecha concreta ya que se estima que no es relevante entrar en ese nivel de detalle a efectos de la comparativa que se está realizando y más aún tratándose de unos periodos de tiempo considerados (para amortizaciones, etc.) de medio plazo y no de largo

El valor de la amortización va a ser sin duda el fundamental en los costes horarios ya que el resto de costes son lógicamente pequeños comparado con este. La amortización depende del valor de compra de la máquina y por lo tanto también de la oferta, la demanda y condiciones del mercado. Sin embargo, este precio no distorsiona este estudio de la misma manera que el anteriormente mencionado precio de alquiler horario de una grúa por los siguientes motivos:

- El mercado al que se refiere es otro completamente diferente ya que los actores son otros. Tal y como hemos visto anteriormente el alquiler se realiza entre una empresa de grúas y su cliente.

Esta relación se ve afectada enormemente por situaciones muy variables localmente: disponibilidad en el país, forma de trabajo, normas de seguridad, etc.

- La venta de la grúa la realizan los fabricantes que suelen ser grandes multinacionales a las empresas de grúas. Este precio no depende prácticamente de circunstancias locales sino de las características de la máquina y de sus costes de fabricación.

Estos precios de venta presentan sin embargo un inconveniente importante de cara a su estudio y utilización y es que son complejos de obtener con cierta fiabilidad ya que se trata de cantidades importantes que ofertan un número muy limitado de grandes empresas. Una cantidad ofertada sólo será fiable cuando esté ofertada para una venta en firme a una 
empresa concreta. Ha sido necesario basarse por lo tanto en este caso y para estos datos en la experiencia profesional de los especialistas consultados en el mundo de las grúas.

Los costes financieros de la inversión realizarán mediante cuadros simples de cálculo de intereses del capital invertido a lo largo del periodo de amortización de cada grúa.

Los otros tres costes: consumos, mantenimiento y coste horario del operador se obtendrán mediante resultados empíricos consultados directamente a empresas de grúas tanto españolas como extranjeras. Son datos también complicados de obtener ya que las empresas son muy reacias a proporcionarlos ya que los consideran en muchas ocasiones información confidencial. Tiene su lógica ya que al ser muy variables, afectan a su capacidad competitiva en el mercado. En el caso del mantenimiento, muestra a menudo si la empresa es seria a la hora de realizar un buen mantenimiento de sus máquinas o no. Dependiendo de esta reputación, los clientes tendrán más o menos seguridad a la hora de usar esas grúas e incluso el valor de segunda mano de cada máquina se verá afectado si se sabe que una empresa realiza un mantenimiento deficiente de su maquinaria. En algunos casos, estos valores son también difíciles de obtener porque muchas empresas usuarias de grúas sencillamente son pimes (no como los fabricantes) y no llevan el registro de estos costes por cada una de sus máquinas de forma controlada y ordenada. 


\section{ANÁLISIS DEL SECTOR DE GRÚAS Y SISTEMAS DE ELEVACIÓN.}

\section{1.- MAQUINARIA Y ACTORES QUE INTERVIENEN.}

\subsection{1.- Maquinaria existente en distintos sectores:}

\subsubsection{1.- Por tipología (Torre, telescópica, celosía, etc.)}

Como se ha explicado en el Estado del Arte (ver apartado no 1.4), hay muchas posibilidades para la clasificación de las grúas por tipologías y no se va a entrar aquí de nuevo en estas posibilidades de clasificación.

También en la legislación hay una preocupación por la clasificación y definición de las grúas móviles que queda patente cuando se observa que se llega a incluir cuatro páginas de croquis de tipos y ejemplos de grúas móviles en la Instrucción Técnica complementaria (ITC) MIE-AEM4 (ver BOE incluido en el anexo nํ2).

En este punto se quiere resaltar que la tipología de las grúas afecta de forma considerable a la organización del sector en cuanto a su influencia en la organización de las empresas.

Es difícil encontrar empresas de grúas que comercialicen a la vez grúas móviles y grúas torre y cuando una empresa trabaja con ambas tipologías, lo organiza con departamentos completamente independientes.

Ocurre también que cuando una empresa de alquiler de grúas telescópicas empieza a comprar grúas de celosía (normalmente para poder optar a trabajar en maniobras de mayores cargar y capacidades) se encuentra frecuentemente con grandes dificultades de gestión de ambas tipologías. Este caso se ha podido observar recientemente en el mercado Español en el que en los últimos 15 años, muchas empresas de grúas telescópicas de ámbito Autonómico o Nacional 
habían empezado a comprar grúas de celosía y luego han ido vendiéndose todas esas grúas de celosía para volver a trabajar sólo con grúas telescópicas.

Podría atribuirse esta venta a la llegada de la crisis que ha provocado que las empresas tengan que reducir drásticamente su estructura y deshacerse de mucha maquinaria y personal y por ello han tenido que vender su máquinas de celosía. Efectivamente la crisis es el factor determinante para esta situación pero no el único. Si fuese el único, sería difícil de explicar el motivo de porque vender casi la totalidad del parque de grúas de celosía y conservar un parque de telescópicas solamente. Especialmente cuando la crisis ha reducido más los márgenes de las telescópicas que el de las de celosía precisamente por la oferta y la demanda, ya que tras la crisis, en el mercado Español, es mucho más difícil encontrar una grúa de celosía que una telescópica.

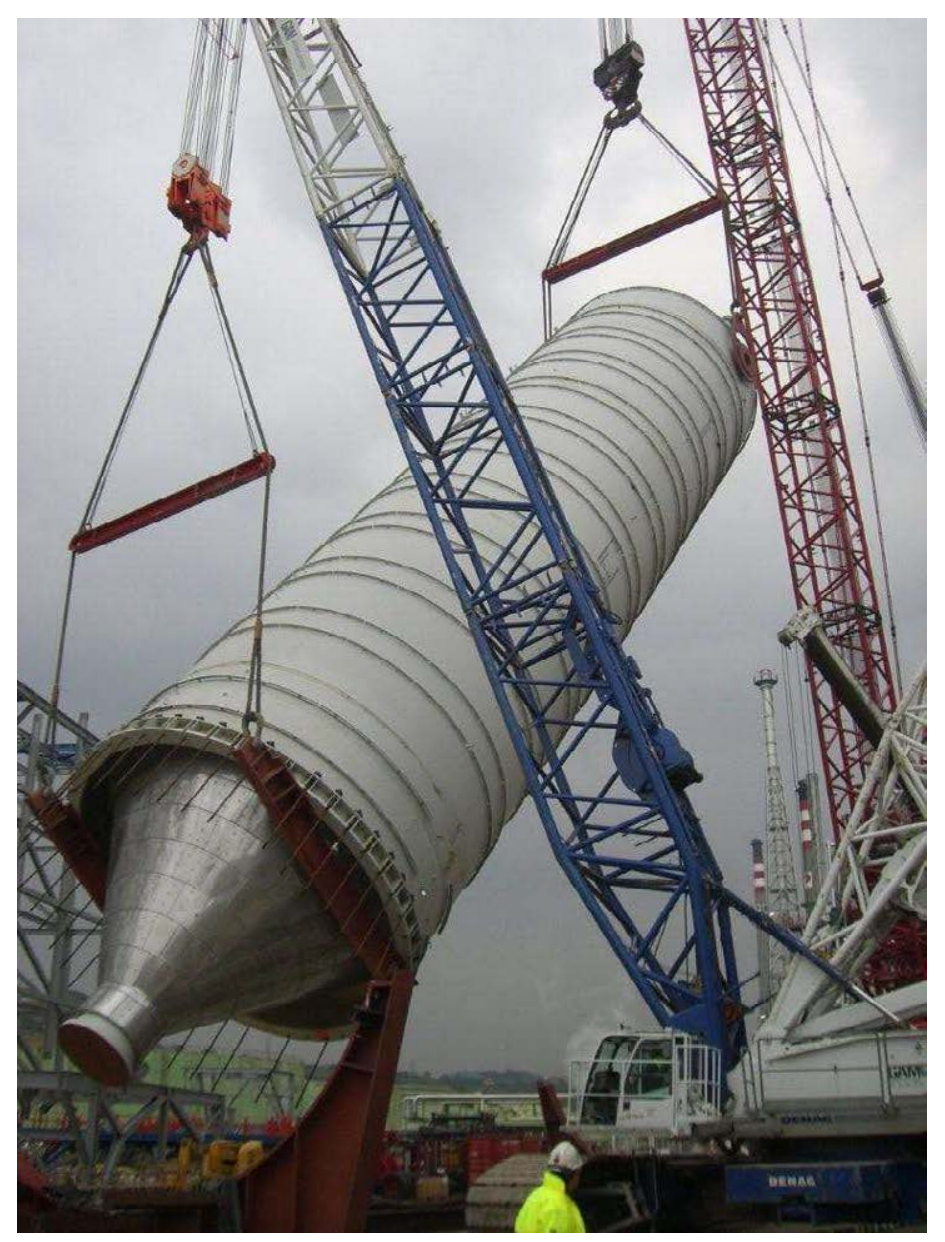

Figura 4.1: Izado de Cámara de Coque en la Refinería de Petronor en 2010 con dos grúas de celosía para verticalizarla: LR11350 y CC2500 de 1.350t y 500t respectivamente. 
La respuesta a estas cuestiones está en la organización comercial y de producción de las empresas en función de la tipología de las grúas.

Nivel comercial, la tipología de las grúas afecta claramente a la empresa propietaria de las máquinas. Si bien un determinado cliente como por ejemplo una de las grandes constructoras civiles españolas pueda subcontratar o alquilar en el mercado cualquier tipología de grúa, será muy diferente el departamento que la solicite, el tipo de obra en la que haga falta, forma de contrato que se realice y el plazo de aviso previo con el que se contrate.

Un ejemplo de lo anterior, es que una grúa torre o telescópica pequeña la necesitará cualquier tipo de obra, se contratará probablemente en alquiler, se solicitará quizás con unos pocos días de antelación (a veces la tarde anterior), habrá posiblemente un contrato marco de alquiler de maquinaria, etc.

Una gran grúa de celosía, la necesitará por lo general una obra bastante singular, se realizará un contrato específico para ese trabajo y es mucho más probable que se haga un subcontrato para la ejecución de unas determinadas maniobras que la solicitud de un simple alquiler de la máquina sin más. El plazo de aviso previo puede ser de varios meses y en ocasiones de uno o dos años.

Los motivos de esta diferencia son: la ingeniería de elevación necesaria para los trabajos en cuestión, la disponibilidad de los equipos, el precio de la máquina, el riego de las maniobras, etc.

Uno de los factores que marcan una gran diferencia es que las grandes grúas, requieren de una zona comercial mucho mayor que las pequeñas pero cuando además se trata de grúas de celosía, el área de trabajo tiene forzosamente que ser mayor ya que la movilización de la máquina de obra a obra es completamente distinta que la de las telescópicas (ya que estas tienen su margen de acción en un radio bastante reducido). Dicho de otra forma, para ser competitivo en el alquiler de grúas telescópicas hay que ser una empresa con implantación local y ámbito regional, para ser competitivo en el alquiler de grúas de celosía, hay que ser una empresa de ámbito mucho más grande: nacional para celosías pequeñas y medianas, Europeo para celosías medianas y grandes y mundial para las muy grandes maquinas de nueva construcción.

La organización comercial de la empresa de grúas es por lo tanto completamente diferente para el alquiler de grúas telescópicas que para grúas de celosía: ámbito geográfico de 
actividad, necesidad o no de departamento técnico, conocimientos legales distintos, nivel de ingeniería a realizar, etc.

Y lógicamente, el funcionamiento operativo de las empresas de grúas también se ve afectado enormemente por la tipología de grúas que tenga la empresa. Una empresa con celosías tiene que tener personal con disponibilidad para viajar y residir en otras zonas, capacidad de trabajo en diversos países, capacidades financieras diferentes, jefes de proyecto para ejecución ya que no se suele limitar al alquiler de maquinaria, etc.

\subsubsection{2.- Por sectores de actividad (Puertos, eólicos, cimentaciones, etc.)}

En el apartado anterior se han analizado especialmente las grúas de distintas tipologías pero que son versátiles para poder trabajar en diferentes sectores de construcción civil e industrial.

Sin embargo hay muchos otros tipos de grúas que son específicos para un determinado tipo de trabajo: las grúas portacontenedores que sirven en los puertos para cargar y descargar los contenedores a buques, las grúas portuarias y de astilleros, las grúas generales pero que han sido modificadas y adaptadas para trabajar específicamente en el sector eólico o en el de cimentaciones de obra civil, etc.

Estas grúas se diseñan para que cumplan específicamente con su función y por lo tanto no disponen de movimientos o capacidades innecesarios para su trabajo. Por ejemplo una grúa Portainer, no tiene capacidad de giro, sus movimientos se limitan a su desplazamiento sobre raíles a lo largo del muelle para poder recorrer el buque de proa a popa y llegar hasta donde está atracado el buque. También se desplaza el carretón de carga a lo largo de la pluma entre el muelle y el buque y sube y baja para cargar y descargar los contenedores. De esta forma, se ahorra una gran cantidad de costes y además la grúa tiene gran velocidad en los movimientos que realiza de forma que su rendimiento para la carga y descarga de contenedores es muy superior a cualquier otra grúa que realice esos trabajos. En los puertos pequeños con poco tráfico, no se puede realizar la inversión para tener una grúa Portainer y estas maniobras se realizan con otra grúa mucho menos rentable para estos trabajos pero que sirve para otras funciones. 


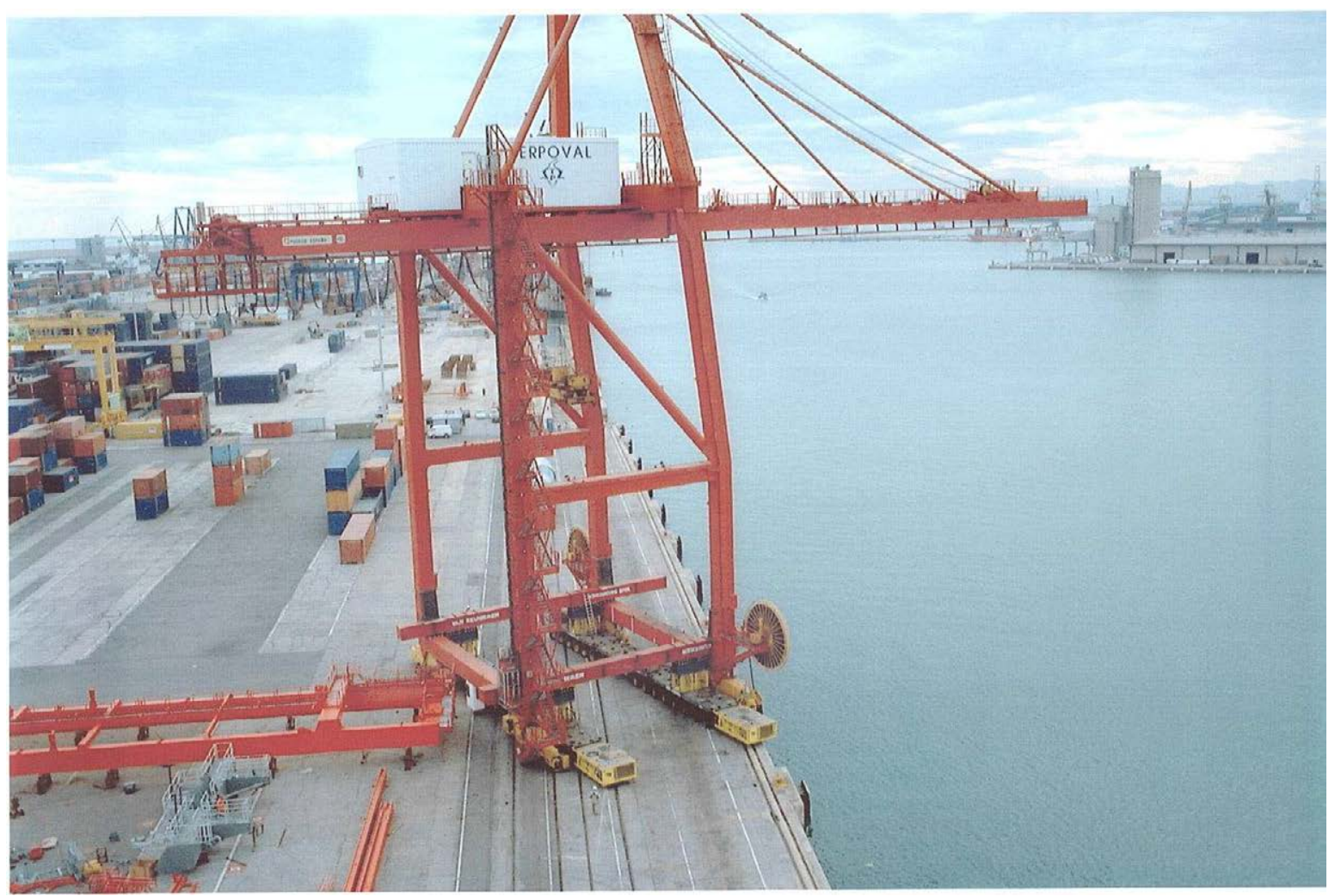

Figura 4.2: Grúa Portainer en el Puerto de Valencia mientras es transportada con carretones SPMT

\subsubsection{3.- ¿Versatilidad o especialización?}

Esta idea de máquinas "especializadas" del apartado anterior es otra opción de construir y diseñar grúas en función del trabajo que tienen que realizar con el fin de optimizarlas para su función en lugar de diseñarlas con la mayor versatilidad posible para que se puedan realizar precisamente los trabajos más variados con la misma máquina.

Se puede decir que son caminos diferentes y quizás opuestos a la hora de realizar investigación y desarrollo de nuevos diseños. Ambas perspectivas abren campos de actuación muy interesantes para la innovación.

Si se utiliza una máquina versátil, se puede usar en multitud de obras y la ocupación de la máquina suele ser alta. Cuando la ocupación (porcentaje de tiempo de utilización de la grúa) aumenta, el coste por hora disminuye y la grúa puede ser más rentable. Además, si un sector entra en crisis, es fácil utilizar la grúa para trabajos en otro sector. Este tipo de grúas versátiles suele ser el habitual en las empresas dedicadas al alquiler de grúas. 
Si se utiliza una máquina especializada, para un tipo de trabajo concreto, se puede optimizar el coste y la forma de trabajar la grúa exactamente para las maniobras a realizar.

El sector eólico es un buen ejemplo de esta situación ya que ha estado muchos años utilizando grúas móviles de celosía para el izado de los generadores en los parques. En realidad, este tipo de grúas no parece idóneo para el izado de generadores eólicos ya que son caras para esa función, el ancho de las cadenas dificulta el desplazamiento de la grúa entre el emplazamiento de un generador y el siguiente (requiere un camino de rodadura de 10 o 14 metros de ancho) lo cual en montaña es muy difícil o imposible a parte del impacto ambiental que crea. Desmontar y remontar la grúa en cada emplazamiento sale también carísimo y sin embargo en cuanto las alturas de las torres y el peso de las nacelles sobrepasaron unos determinados valores, las grúas telescópicas ya no tenían capacidad y sólo había en el mercado las grúas de celosía para poder realizar las maniobras.

Una solución era utilizar las celosías sobre camión, menos corrientes en el mercado que sobre cadenas pero facilitaban el transporte del cuerpo de máquina entre torres eólicas. Luego empezaron a salir las grúas de celosía existentes pero en versión NT "Narrow track" (con ancho de cadenas reducido) para que el ancho de los caminos de rodadura entre torres eólicas fuese la mitad o menos.

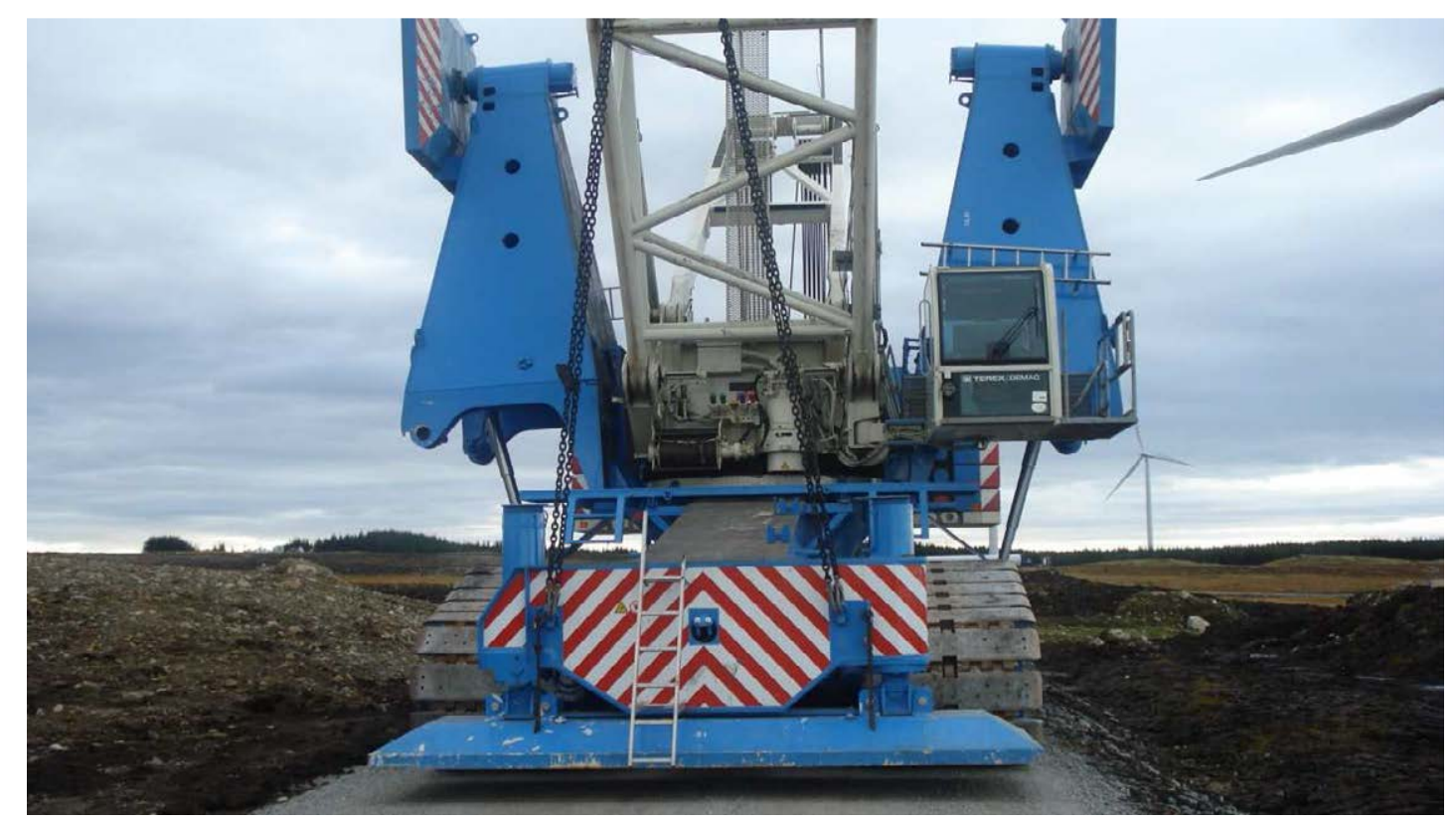

Figura 4.3: Terex Demag CC2800 NT de ancho reducido de cadenas para desplazarse por parque eólico. 
Este desarrollo de grúas era más una adaptación de la maquinaria existente más que una innovación total para el trabajo tan especifico a realizar. Es importante resaltar que el desarrollo lo realizaron los grandes fabricantes de grúas y no las empresas alquiladoras de grúas (que si compraron en ocasiones estas máquinas) ni tampoco los usuarios finales que son los constructores de parque eólicos o los tecnólogos de turbinas eólicas.

Es curioso que los tecnólogos de generadores eólicos no realizasen en este campo I+D+| para mejorar el procedimiento de izado y montaje de las torres ya que los costes de podían probablemente mejorar sensiblemente.

Este es un ejemplo de cómo una necesidad del mercado clara de diseñar una grúa o sistema de izado especializado y adaptado a un tipo de trabajo concreto y que hubiera significado importantes ahorros en costes, no se ha cubierto adecuadamente a lo largo de muchos años por que los distintos actores que intervenían no han estado interesados. Los tecnólogos de generadores eólicos que hubieran ahorrado costes y problemas de montaje posiblemente no lo han estudiado dado que están en otro sector y dedican sus esfuerzos a su propia tecnología de generación eléctrica. Las empresas alquiladoras y fabricantes no están excesivamente interesados porque hubiese significado tener que invertir recursos en una maquinaria especifica que podría canibalizar los productos que ya estaban comercializando. Además de haber desarrollado un sistema realmente barato y eficaz, esto podía facilitar la entrada a este mercado de izados a otras empresas que no tuviesen preliminarmente grúas a amortizar reduciéndoles las barreras de entrada.

\subsection{2.- Actores que intervienen en el sector de grúas.}

Como se ha visto en el apartado anterior es muy importante en el sector conocer y estudiar a los actores que intervienen en el proceso de ejecución de los proyectos de construcción así como sus características, intereses, capacidad de inversión, tamaño, capacidad de innovación, etc.

En efecto, dichas características, capacidades y formas de funcionar van a condicionar las posibilidades de desarrollo e innovación de las grúas y resto de sistemas de elevación. 
Se realiza la siguiente clasificación sabiendo que es bastante general pero que permite en este estudio aproximarse a la realidad del sector y comprender las capacidades y circunstancias de las distintas partes.

\subsubsection{1.- Usuarios finales.}

Se incluyen en esta categoría las empresas constructoras que realizan los proyectos. También se incluyen las empresas promotoras de proyectos o propietarias de plantas fábricas o instalaciones en cuanto tengan acceso directo al sector de las grúas bien porque compren o alquilen este tipo de maquinaria directamente o porque se involucren de alguna manera en el proceso constructivo, etc.

Esto agrupa lógicamente a una gran cantidad de tipos de empresas. En la construcción, se incluyen constructoras civiles, ingenierías, especialmente las contratistas EPC muy corrientes en la construcción industrial, astilleros, plantas de offshore, talleres metálicos, caldererías, montadores mecánicos, prefabricadores, etc. En el campo de los propietarios de instalaciones entran refinerías, plantas químicas, centrales eléctricas, terminales portuarias, etc.

En el pasado en España y hoy en día en algún país, era corriente que los propietarios de instalaciones o fábricas tuviesen las grúas en propiedad y gestionasen directamente sus parques de maquinaria. Sin embargo, hoy en día, en general a nivel mundial, es muy poco corriente dicha situación y aunque estas empresas que se han llamado aquí usuarios finales, suelen ser grandes y con importantes capacidades financieras y de inversión, no suelen ser propietarios de este tipo de maquinaria y recurren al alquiler de las grúas o incluso a la subcontratación del las maniobras a realizar.

La mayoría de las excepciones a lo anterior son precisamente las grúas específicamente diseñadas para una función tal y como se ha detallado en los apartados 4.1.1.2 y 4.1.1.3. el ejemplo mencionado de las grúas portacontenedores es también muy válido en este caso ya que suelen ser propiedad de la terminal portuaria de contenedores dada su especificidad para este trabajo. 


\subsubsection{2.- Propietarios: empresas de grúas}

Se definen aquí a los "propietarios de grúas" a los que se conoce en el mercado "empresas de grúas y maniobras". En realidad, muy a menudo no son tampoco propietarios de las máquinas ya que puede que estén en renting, etc. Sin embargo son las empresas que realmente usan y mantienen las máquinas. Se engloba también en este grupo a multitud de empresas de muy diversos tipos ya que hay desde empresas muy locales que operan muy pocas grúas telescópicas o torre hasta otras empresas que trabajan a nivel mundial y operan grúas de enorme capacidad que pueden ser prototipos record en el mundo.

A pesar de ello, la práctica totalidad de estas empresas son PYMES y las más grandes que son multinacionales son en realidad pequeñas multinacionales (hasta máximo unos 4.000 empleados a nivel mundial contando con los operadores) sobre todo si las comparamos con el tamaño de las empresas que son sus clientes (grandes constructoras o petroleras) e incluso si las comparamos a sus proveedores principales (Terex Demag, Liebherr, Manitowoc) que son grandes multinacionales con gran capacidad. Frecuentemente son empresas familiares, incluso las mayores del sector.

Es importante esta característica que las empresas de grúas sean más pequeñas que sus clientes o proveedores ya que influye de forma importante en el sector dado que tienen menores capacidades de inversión (además requieren mucha para su funcionamiento habitual) y menores capacidades de investigación y desarrollo y sin embargo tienen el conocimiento de las grúas, las mejoras que se les puede realizar, las necesidades que ven que pueden surgir en el mercado, etc.

Sin entrar en mucho detalle, se van a clasificar a continuación en dos grandes grupos y de nuevo es una clasificación muy genérica que no responde a la totalidad de los casos pero ayuda a analizar el sector:

\section{Empresas locales de alquiler:}

Suelen ser empresas de una persona o familiares que se dedican al alquiler de una flota mayor o menor de grúas telescópicas y alguna otra tipología o máquina en función de su área de actividad, competencia en dicha área, antigüedad de funcionamiento, capacidad de inversión, etc. Este tipo de alquiler de grúas telescópicas se llama a veces "grúa taxi" por la poca 
necesidad de ingeniería y el poco plazo de aviso que suele haber. En España estas empresas suelen trabajar en el ámbito de una autonomía o incluso provincia y hay pocos casos que operen a nivel nacional.

Estas empresas suelen enfrentarse a un gran salto cualitativo cuando entran en el campo de las grúas de celosía ya que cuando compran este otro tipo de máquinas saltan paralelamente a trabajar a nivel nacional o de varias autonomías, a necesitar ingeniería, jefes de proyecto, etc. Es difícil determinar si este ámbito nacional da estabilidad a estas empresas o bien si sería necesario que el salto geográfico fuese más bien a nivel de continente en lugar de limitarse a un país como España ya que un solo país no da estabilidad en caso de crisis ni permite operar con una flota importante de maquinaria en situación económica normal lo cual no da una situación de sostenibilidad a la empresa.

\section{Grandes empresas de alquiler y proyectos:}

Suelen ser antiguas empresas locales que han conseguido crecer en pocas décadas desde el estado visto en el apartado anterior a trabajar en varios países o incluso a nivel mundial a pesar de no ser grandes multinacionales. Suelen operar unas flotas relativamente importante de grúas de celosía y telescópicas aunque a menudo de forma independiente para cada tipología.

En las últimas dos décadas, este tipo de empresas ha jugado un papel crucial en la innovación, desarrollo y comercialización de nuevas grúas diseñando nuevas máquinas y sistemas de elevación llegando incluso a prototipos record del mundo de capacidad. Han entrado así en el campo de sus proveedores fabricantes de grúas que han sacado también nuevas máquinas pero a remolque de los desarrollos realizados por sus propios clientes. A continuación se analizarán algunos de estos nuevos desarrollos.

\subsubsection{3.- Fabricantes}

Se agrupan aquí varios tipos de empresas aunque, como se ha mencionado, predominan entre los fabricantes las grandes multinacionales de origen Alemán o Americano. Realizan el diseño y construcción de las grúas y las venden en el mercado a las empresas de grúas y a los usuarios finales mencionados en los apartados anteriores. Suelen realizar la investigación y desarrollo 
en el sector de grúas con la excepción de los desarrollos comentados en el apartado anterior que han hecho recientemente sus clientes.

Sin embargo no son usuarios de las grúas con lo cual no se enfrentan en el día a día a sus transportes, sus montajes, sus maniobras en proyectos reales, etc.

En el caso de grúas torre, existen fabricantes más pequeños que consiguen competir contra los grandes grupos (incluyendo a empresa españolas fabricantes). Sin embargo en el caso de grúas telescópicas y de celosía, la única competencia que ha surgido en los últimos años a los grandes fabricantes tradicionales son fabricantes de origen Chino que son también muy grandes empresas.

\subsection{3.- Mundialización.}

Como se ha comentado en los apartados anteriores (ver especialmente punto 4.1.3.), las empresas de grúas se encuentran en una situación en la que pueden trabajar en un ámbito local y si quieren crecer, tienen prácticamente que pasar a un ámbito mundial o al menos una zona de trabajo internacional ya que se encuentran pocas empresas de tamaño medio que sean sostenibles a largo plazo trabajando en ámbito nacional con flotas importantes.

Esta mundialización tiene muchas implicaciones importantes para el sector. Desde la capacidad técnica y logística, a la preparación y flexibilidad del personal. En lo referente a las máquinas, se convierte en una necesidad absoluta el que tengan la versatilidad de trabajar en todos los países y por lo tanto su adaptación a todas las normativas así como la versatilidad de poder trabajar en distintos sectores dentro de la construcción: civil, petroquímico, offshore, eléctrico, etc.

Estás necesidades son un requisito del servicio a distintos países y sectores pero también un factor a tener en cuenta en la estrategia de las empresas de grúas ya que suponen una ventaja considerable a la hora de afrontar crisis de países o de sectores concretos y permiten a una empresa con una flota importante de maquinaria sobrevivir cambiándose de país o de sector en lugar de tener que reducir y vender su parque de maquinaria consiguiendo así una estabilidad que no tienen las empresas que trabajan en unos ámbitos geográficos o de actividad más reducidos. 
Según los distintos países y continentes, existen unas diferencias muy importantes en el sector de las grúas, transportes especiales y sistemas de elevación. Existen normativas diferentes, existen costumbres distintas ya que en algunos sitios es más corriente el uso por ejemplo de grúas de celosía (como en E.E.U.U.) para obras en las que en otros lugares se usarían más frecuentemente telescópicas (Europa), etc. Existen también diferencias enormes en el precio de la maquinaria y se puede llegar a pagar por el alquiler de una determinada máquina de dos a tres veces más según el país en el que se alquile y esto resulta sorprendente ya que los costes no difieren en esos porcentajes; en el fondo la grúa la construye una multinacional en su fábrica igual para un continente que para otro y es la mayor parte del coste hora de la máquina generalmente. Además, la diferencia de sueldos de gruistas y demás costes no son tampoco de tanta magnitud.

\subsection{4.- Otros sistemas de elevación: de personas, pequeña maquinaria, etc.}

Hay una gran cantidad de sistemas de elevación y pequeña maquinaria que tiene mucha importancia en el mundo de la construcción y que también afecta enormemente a su funcionamiento. Hacer una lista de la misma sería extenso y probablemente incompleto, hay sistemas poco conocidos y otros enormemente utilizados. A efectos de este estudio, lo que se quiere considerar es su influencia (o potencial) en el sector.

Cabe distinguir en este campo la elevación de personas y la de materiales. En el mundo de los materiales la cantidad de máquinas y equipos es enorme. La máquina quizás más habitual en obra es la carretilla elevadora (forklift en inglés y a veces usado también en Español) o manipuladora cuando su brazo es telescópico.

Es menos corriente ver grandes cambios e innovaciones en este tipo de maquinaria de elevación pero un ejemplo claro de lo contrario es el desarrollo y enorme impacto de la maquinaria de elevación de personas, las plataformas aéreas, tijeras, articuladas, cestas, etc.

Su desarrollo ha sido espectacular en las últimas dos décadas y el parque de esta maquinaria en el país ha superado las 20.000 unidades antes del comienzo de la crisis en España.

El motivo ha sido sin duda la seguridad en el trabajo de personas frente a colgar una jaula del gancho de una grúa (frecuentemente prohibido hoy en día por muchas legislaciones) u otros métodos de elevar personas. También ha supuesto un ahorro considerable al reducir el 
volumen de andamios para el acceso de personas y la posibilidad de acceso rápido a muchos puntos de la obra con una ganancia enorme de tiempo al no tener que esperar el montaje de un andamio.

Estas innovaciones en pequeñas máquinas tienen implicaciones importantes en el desarrollo, organización y costes de una obra. Las carretillas y manipuladoras, ahorran muchas maniobras de pequeñas grúas y de hecho, junto con los camiones pluma son probablemente las causantes de la progresiva desaparición de pequeñas grúas telescópicas con el consiguiente ahorro. En el caso de la plataformas de elevación de personas el impacto ha sido aún mayor tal y como se ha explicado.

4.1.5.- Otros sistemas de elevación especiales: Pórticos, gatos de cable, gatos trepantes, spmt, etc.

Además de las grandes grúas, existen para maniobras especiales otros sistemas de elevación que pueden ser a menudo alternativas interesantes. En muchas ocasiones son "competencia" directa de las grúas para muchos izados pero en realidad, dadas sus diferentes características técnicas, precios, formas de montaje, etc. suelen ser alternativas eficaces para ciertas maniobras en las que las grúas tienen menos eficacia por el motivo que sea: espacio disponible, costes, etc.

\subsubsection{1.- Pórticos y gatos de cable}

Hoy en día es frecuente utilizar para izados especiales pórticos equipados con gatos de cable "strandjacks" que pueden elevar o bajar una carga de forma análoga a cómo trabajan los gatos de pretensar hormigón. Este equipo, hace precisamente que empresas que se dedican a pretensado y postesado de hormigón, tengan a menudo un departamento de izados especiales que ejecutan con este tipo de gatos (sin usar normalmente grúas ya que no suelen disponer de ellas). Los gatos de cable se usan tanto para maniobras en vertical como en horizontal ya que como se ha explicado en el punto 1 de estado del arte, los movimientos horizontal y vertical están muy ligados siendo ambos maniobras especiales ejecutadas con equipos similares. 
Con respecto al sector, los gatos de cable introducen por lo tanto otras empresas en el mundo de maniobras que no disponen de grúas pero pueden competir contra las empresas de grúas propiamente dichas. Hay lógicamente empresas que combinan ambos sistemas de elevación aunque no es excesivamente frecuente y suelen ser las grandes empresas que operan internacionalmente las que ofrecen ambos sistemas dado que, de nuevo, la gestión de ambos equipos es tan diferente a nivel comercial y operativo que supone un salto muy importante para una empresa entrar en el otro campo de actividad.

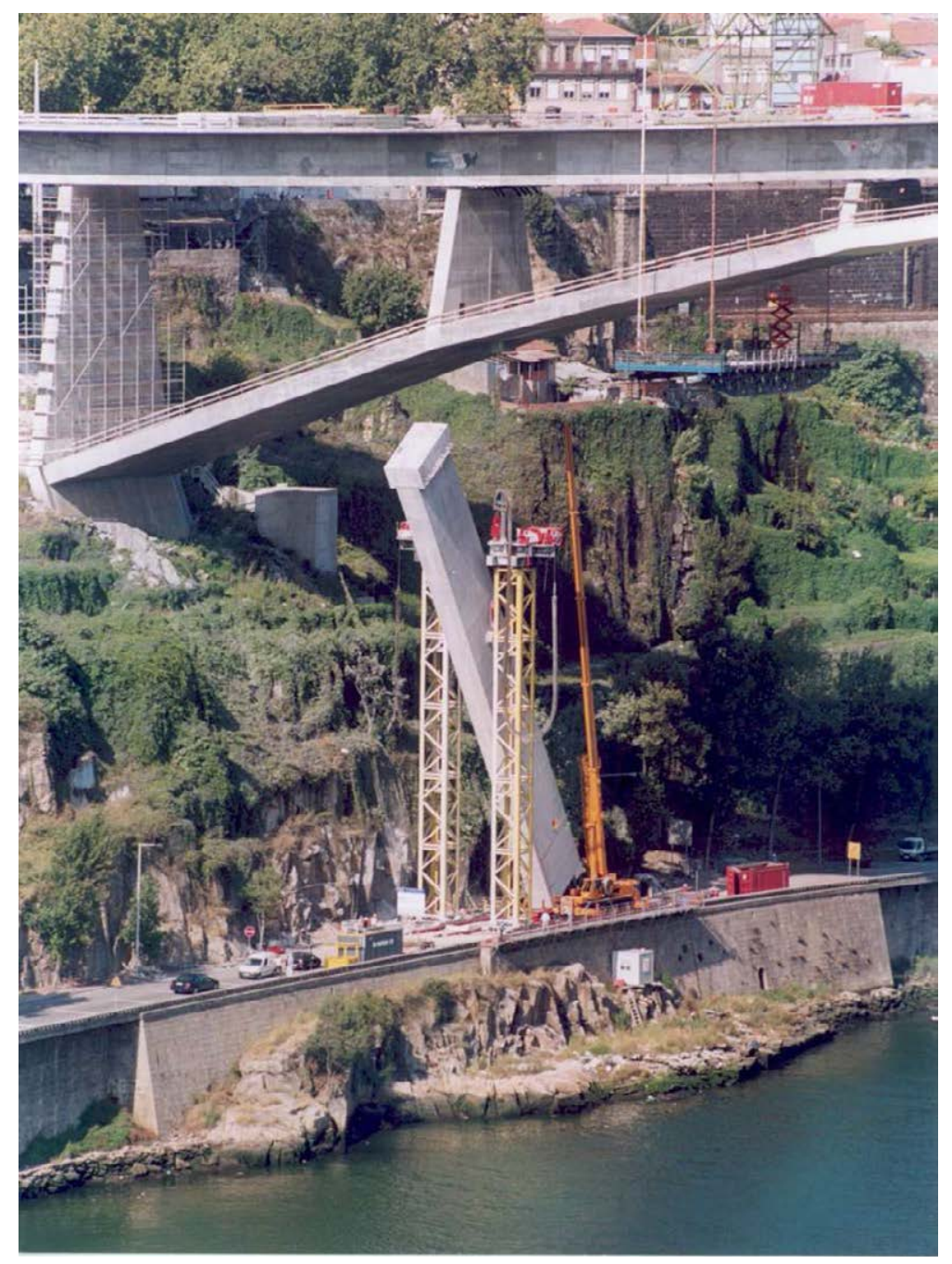

Figura 4.4: Maniobra con torres, gatos de cable (dos de 900 toneladas) y patines de deslizamiento para el volteo de las columnas temporales de Puente Infante Dom Henrique (Oporto, año 2002)

\subsubsection{2.- Gatos trepantes}


Otro sistema de izado para pequeños empujes verticales (pequeños en cuanto a alturas porque pueden izar grandes cargas) son los gatos trepantes. Estos gatos van empujando una carga usando su corto recorrido vertical y se tienen que ir calzando o descalzando según se eleve o se descienda la carga. De esta forma, se recoge el cilindro del gato y se empieza con la siguiente carrera. Este sistema rara vez compite con una maniobra de grúa y sin embargo es un sistema de elevación frecuentemente asociado a los transportes especiales ya que puede ayudar a cargar y descargar los equipos de transporte ganando un poco de altura la pieza a transportar. Requiere mucha mano de obra en la maniobra por la colocación de los calzos que suele ser madera de lata resistencia.

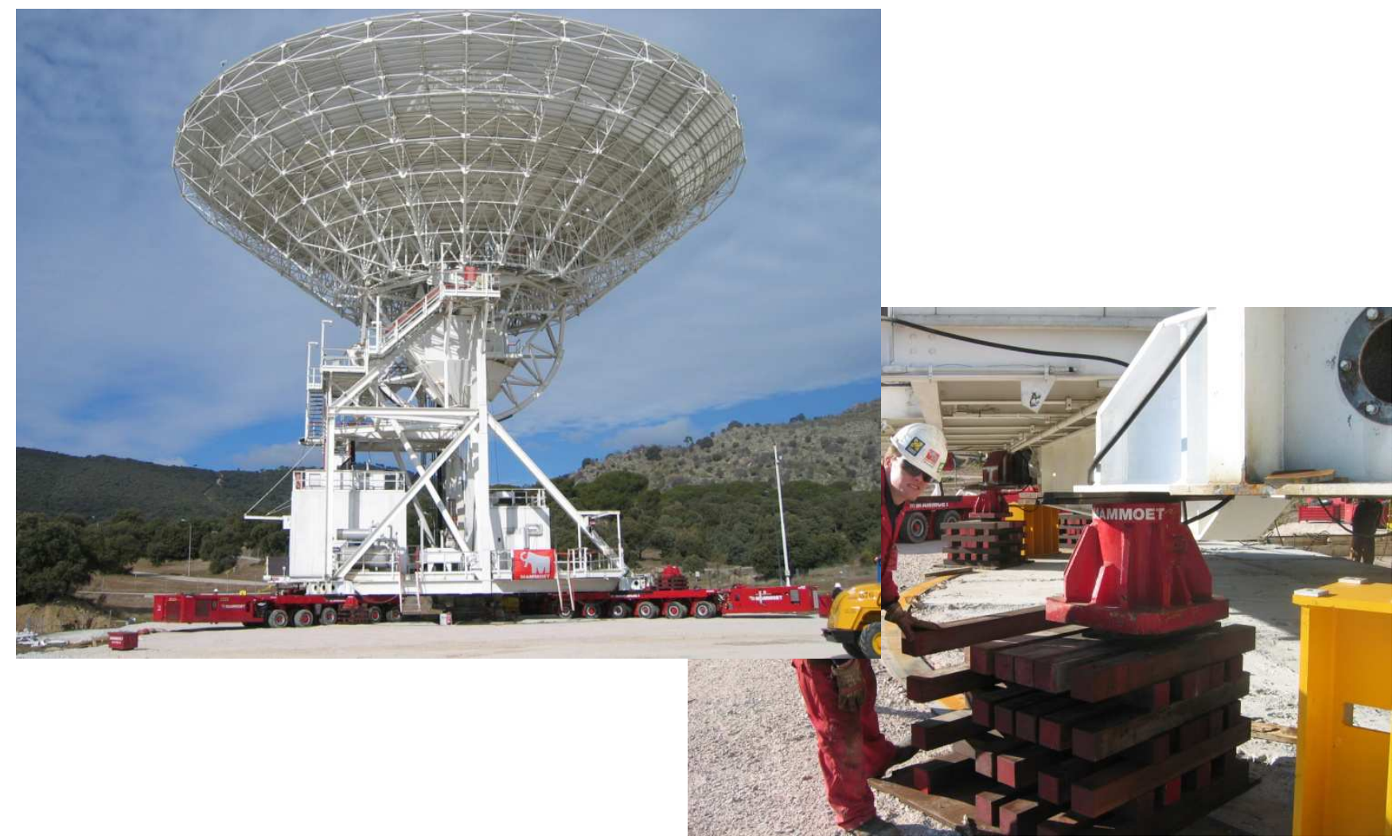

Figura 4.5: Gateo de una Antena(INTA- NASA) en Robledo de Chavela para elevarla y poder introducir los SPMT debajo para su transporte

Hoy en día se ha perfeccionado este sistema de empuje con el desarrollo reciente de diversos equipos de izado que son también de empuje con principios similares a los gatos trepantes tradicionales pero que ofrecen posibilidades y capacidades impensables hace unos años. Se usan aquí los patines de deslizamiento para grandes transportes horizontales pero como 
sistemas de izado aprovechando el recorrido vertical de su cilindro para auto carga. Se estudiará su influencia en el punto 4.5 posteriormente.

\subsubsection{3.- Carretones SPMT (Self Propelled Modular Trailers)}

Aunque en principio sean equipos de transporte especial, tal y como hemos visto en el estado del arte, la capacidad que tienen de recorrido vertical de 600 milímetros, normalmente usada para auto cargar y auto descargar, se puede aprovechar para empujar o bajar una gran carga por recorridos y calzando o descalzando de forma análoga a como se hace con los gatos trepantes.

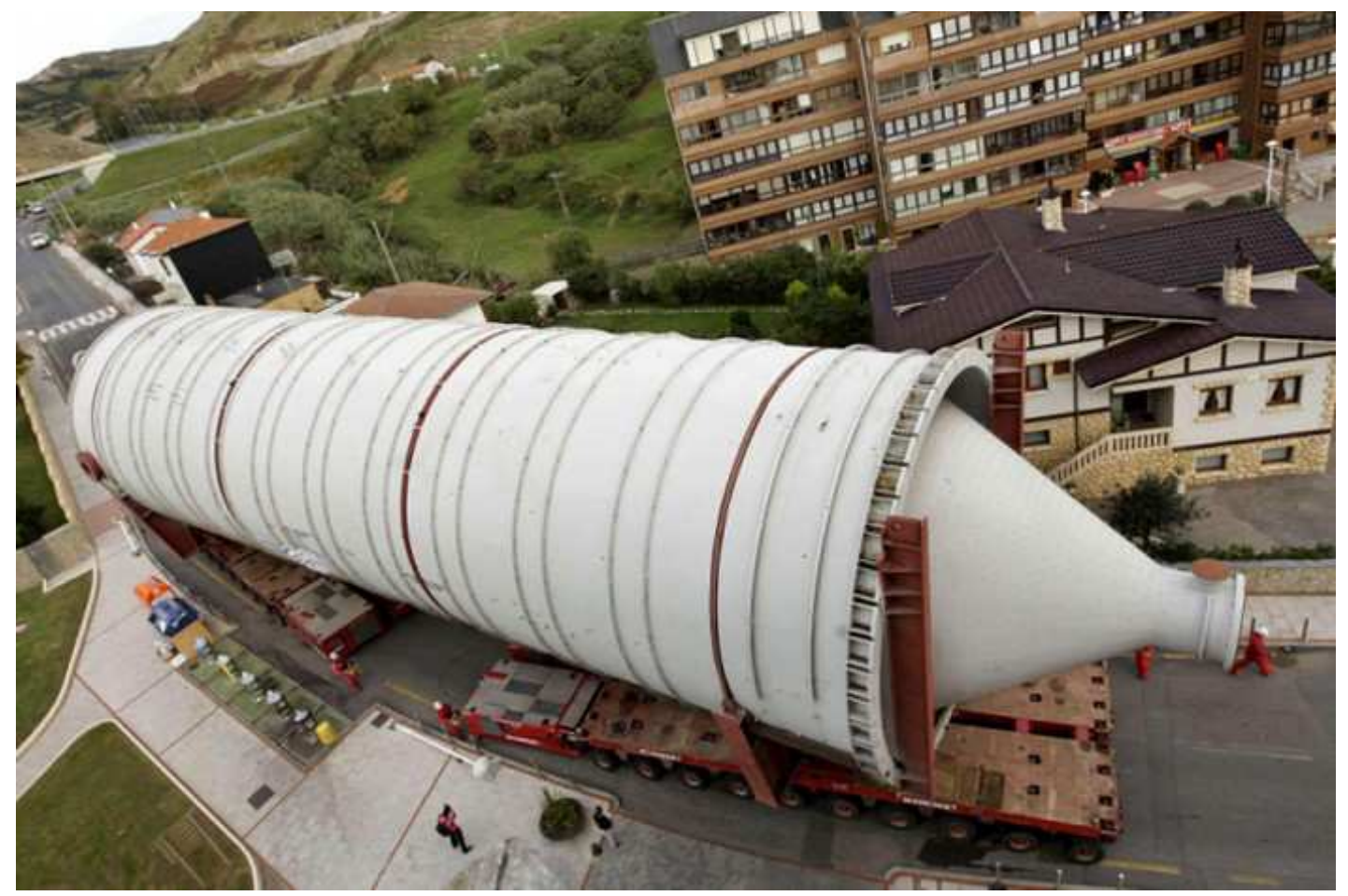

Figura 4.6: Transporte de Cámaras de Coque de 480 toneladas a Petronor sobre SPMT

Los últimos sistemas de izado trepantes se han combinado a veces con los carretones SPMT permitiendo realizar maniobras con movimientos horizontales y verticales con esta combinación de equipos que aumenta su eficacia y ofrece una alternativa a una maniobra tradicional de grúa permitiendo mover muy grandes cargas con costes menores. Estos 
desarrollos junto con la complementariedad que ofrecen en general los SPMT usados con grúas los convierten en un equipo casi imprescindible para las grandes empresas de grúas que quieran trabajar sobre todo con grandes grúas de celosía y poder ofrecer múltiples soluciones técnicas para grandes izados.

En los nuevos proyectos modulares, los SPMT están cada vez más sustituyendo a los grandes medios de izado: grandes grúas y pórticos a la hora de colocar en obra las piezas modulares prefabricadas habitualmente en otro país. El ahorro no sólo consiste en evitar esos medios de izado sino que los SPMT además se usan ya para el transporte de los módulos a obra y por lo tanto el uso de su recorrido vertical para la colocación, no suele incrementar a penas el coste del propio transporte.

\subsection{6.- Desarrollo en materiales auxiliares: material de izado, etc.}

Para la realización de maniobras es necesario lógicamente mucho material auxiliar como eslingas, grilletes, balancines, marcos, etc.

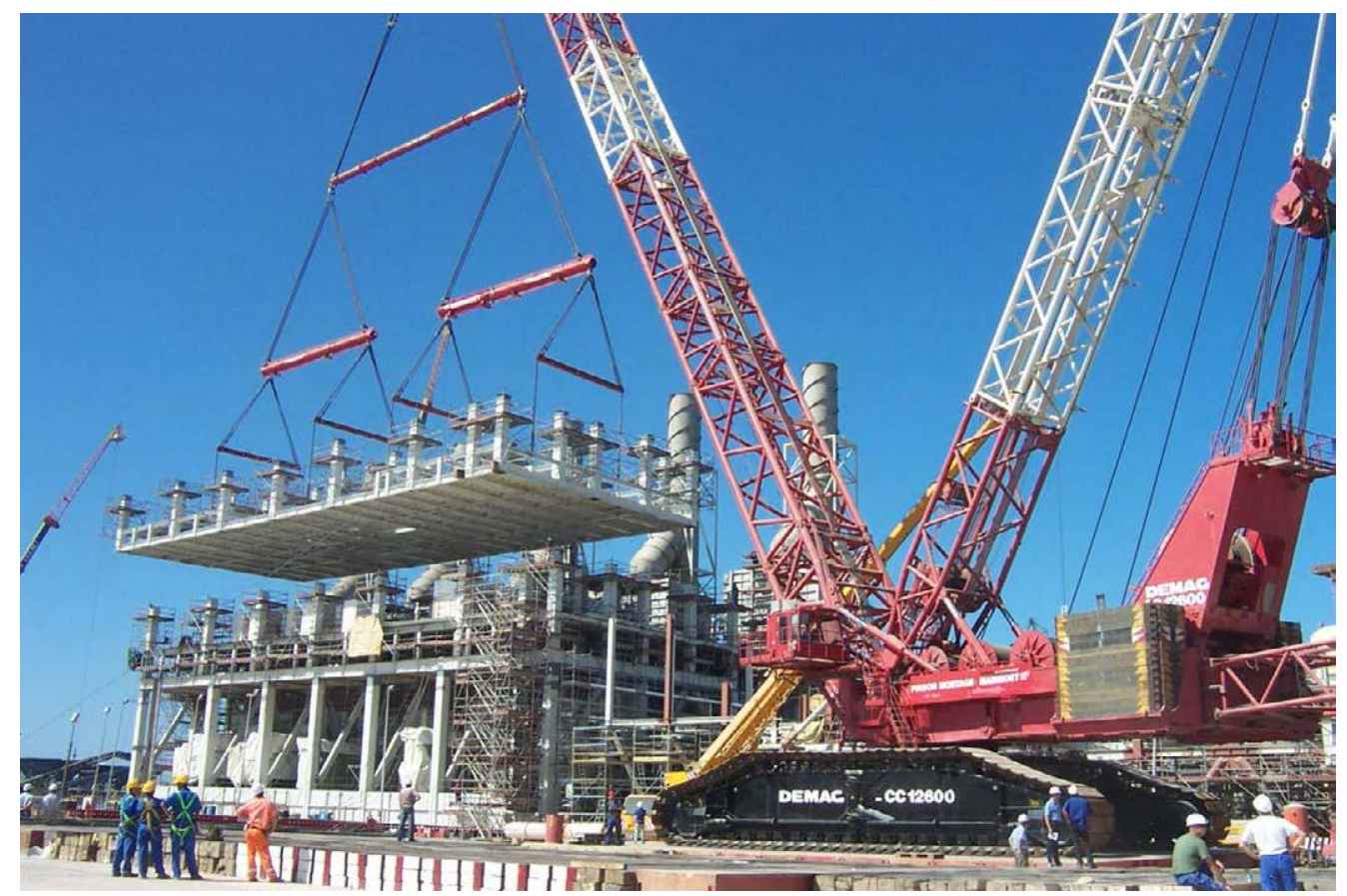

Figura 4.7: Izado en Dragados Offshore Cádiz con la Demag CC12600 de 1.600 toneladas usando tres niveles de balancines y multitud de eslingas y griletes de alta capacidad. El total del material de izado utilizado superaba las 100 toneladas de peso. 
Este material también se está desarrollando constantemente en los últimos tiempos lo cual es lógico ya que al aumentar los medios de izado, aumentan la tipología de las piezas a izar, sus cargas y los requisitos de agarre de las mismas. Ello crea unas nuevas necesidades de material de izado no sólo cuantitativas o de capacidad sino también cualitativas y hay que desarrollar nuevos equipos como por ejemplo eslingas que puedan modificar ligeramente su longitud para facilitar el posicionamiento del centro de gravedad bajo el gancho sin inclinar las piezas lo cual es muy importante en los nuevos proyectos modulares en los que no se puede o no se debería estar en medio de la maniobra añadiendo y quitando grilletes por el antiguo procedimiento para conseguir estas variaciones de longitud.

También se necesita cada vez más el poder medir la carga en cada eslinga ya que al tener un sistema de material de izado más complejo con muchas eslingas, balancines en varios niveles, etc. No siempre se puede controlar la carga de cada elemento y tener la posibilidad de medir la carga de las eslingas garantiza la seguridad de la maniobra.

Al alcanzar grandes alturas de maniobras también se ha necesitado desarrollar sistemas para poder realizar la apertura a distancia de un grillete a control remoto desde abajo con el fin de evitar el uso de una plataforma aérea muy cara o sencillamente que no exista ninguna con dicha altura. Es importante en este caso que el sistema ofrezca mucha seguridad que evite una apertura indeseada durante la maniobra provocando la caída de la carga.

Se pueden encontrar y enumerar más sistemas de reciente desarrollo pero en lo que afecta a nuestro estudio de mercado, se ve claramente que las empresas de grúas necesitan no sólo una mayor inversión en este tipo de equipos sino también una capacidad de inventarlos y desarrollarlos internamente que puede darles grandes posibilidades competitivas y un valor añadido muy importante frente al simple alquiler de maquinaria que desarrollaban antiguamente.

\subsection{7.- Modularización y prefabricación.}

El mercado mundial de la construcción tiende cada vez más a la prefabricación de elementos para abaratar costes, mejorar plazos y mejorar la seguridad de las obras. En obra civil los prefabricados han ganado terreno sin duda en las últimas décadas y también en industrial. Sin embargo en obras industriales, se está asistiendo cada vez con más frecuencia a la Modularización de las plantas construidas. Esta construcción de módulos en un origen 
diferente a la obra y frecuentemente en otro país implica la necesidad de transportar e izar piezas mucho más grandes y pesadas y por lo tanto exige un desarrollo de los equipos de transportes e izados especiales así como una complejidad mayor a la hora de programar y preparar las maniobras.

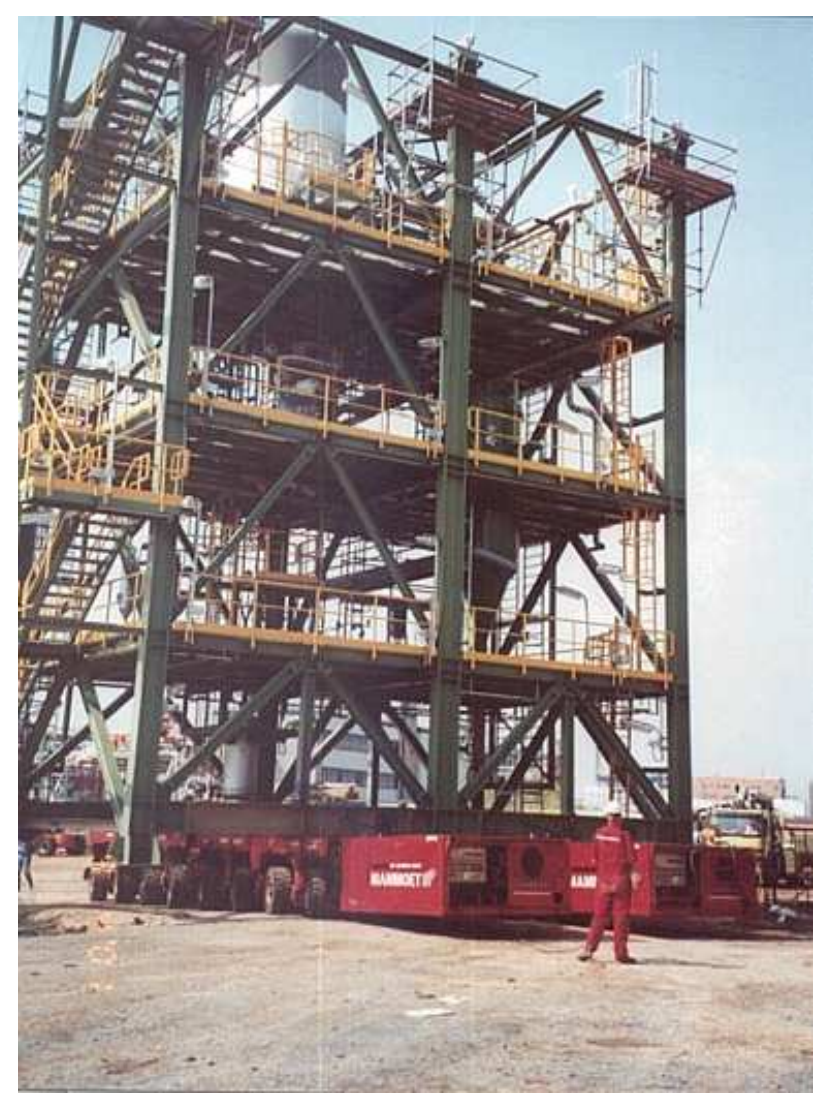

Figura 4.8: Construcción y transporte de módulos en Tarragona para planta química

Los motivos de la modularización pueden ser variados: mal clima en el lugar de construcción de las plantas industriales (Canadá, Noruega, Siberia) que permite trabajar muy poco tiempo al año, abaratar costes cuando se construyen plantas en países de alto coste de mano de obra (Australia, Canadá, Noruega, etc.), escasez de mano de obra cualificada cuando se construyen plantas en países en vías de desarrollo, etc.). En cualquier caso, la tendencia de sector de la construcción industrial es claramente hacia la modularización y con los motivos expuestos no parece que vaya a cambiar sino a aumentar cada día más lo cual presiona al sector de las grúas hacia la innovación.

4.1.8.- Relación de las grúas con diversas variables de la construcción y la economía: 


\subsubsection{1.- Tamaño de obra o tipo de proyecto:}

Se observa que se evoluciona desde una necesidad de grúas como sencilla maquinaria de alquiler cuya necesidad se resuelve en el día a día de una obra a que la Estrategia de Elevación y Grúas sea algo a tener muy en cuenta desde los inicios de un proyecto si se quiere construir con bajos costes, mejoras de plazos y de seguridad. Esto que es cada día más necesario, se convierte en imprescindible en grandes proyectos de grandes cargas y modulares ya que se podría llegar a la ridícula situación de no disponer del medio de izado (escaso a nivel mundial) o de llegar a situaciones de empeorar la situación de espacio o de plazos de una obra que la paralice o dispare los costes por mala planificación.

Muy a menudo se elige por ejemplo una gran grúa que permita no solo realizar las maniobras de grandes cargas de la obra sino que gracias a su gran capacidad, alcance a toda la obra o una gran zona de forma que pueda también realizar las pequeñas maniobras ahorrando así en pequeñas grúas, en espacio y en complejidad de múltiples pequeñas maniobras.

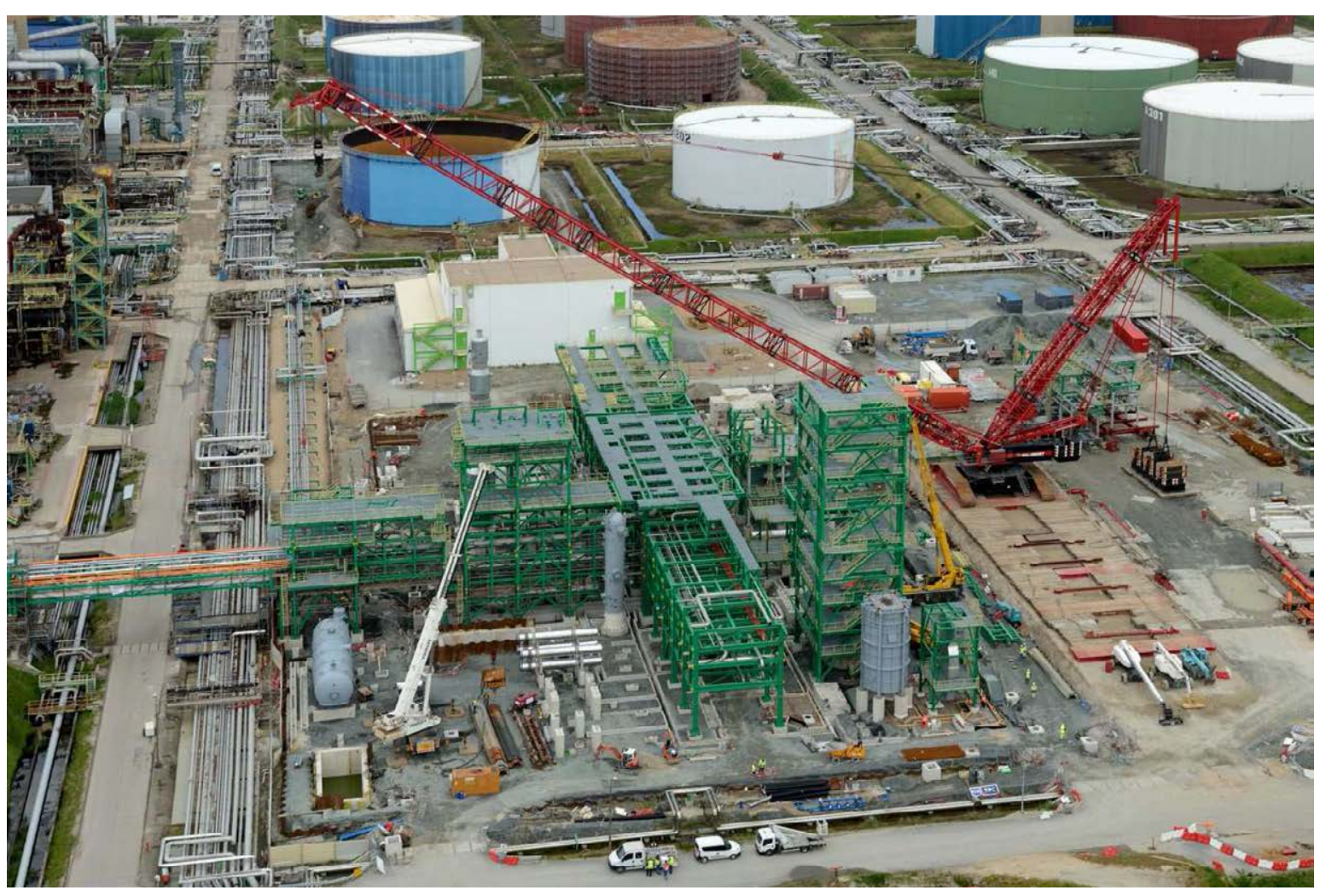

Figura 4.9: Grúa LR11350 (1.350 toneladas de capacidad nominal) con capacidad de "barrer" toda una planta para poder realizar con ella la práctica totalidad de las maniboras. Francia, 2013. 
El tipo de obra industrial o civil cambia también esa cultura de maniobras ya que incluso en los países desarrollados el mundo civil prioriza mucho más los bajos costes de la maquinaria mientras que el mundo de la construcción industrial es muy exigente con la calidad y la seguridad de las maniobra aunque eso signifique un aumento de coste (lo cual frecuentemente significa a largo plazo ahorros en muchos otros temas: avería, seguridad, eficiencia, planificación, etc.)

\subsubsection{2.- El lugar de la obra.}

El lugar de la obra es de fundamental importancia ya que puede haber mayor o menor disponibilidad de maquinaria de elevación variando también los costes en cantidades de 2 y 3 veces para la misma grúa en alquiler y en mucha mayor medida si se tienen que movilizar las grúas desde otro país.

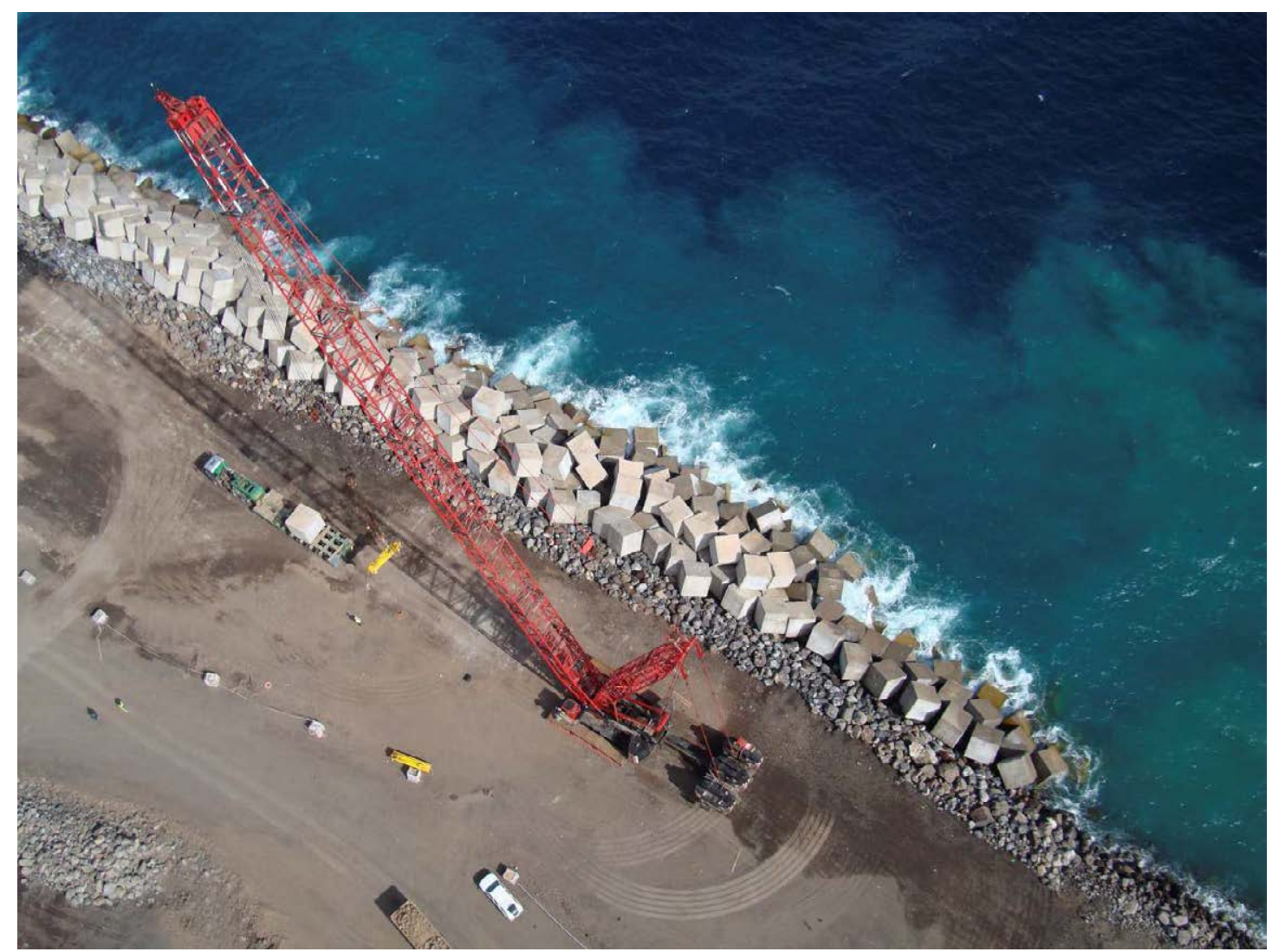

Figura 4.10: Grúa LR1350 colocando bloques de hormigón en la escollera del dique de la Esfinge, Gran Canaria 2008. 
La normativa de grúas puede ser muy diferente y especialmente la relativa a la seguridad de las maniobras y la cultura de ejecución que priorizará el buen uso de maquinaria moderna en buen estado o el de maquinaria vieja en malas condiciones a bajo coste.

El clima es también un factor determinante a la hora de elegir la estrategia de medios de elevación para una obra.

\subsubsection{3.- Variable macroeconómicas: Incremento del PIB de un país / Inversión en construcción.}

Sería muy interesante, aunque no es el objeto de este estudio ya que constituiría un complejo estudio en sí mismo, poder encontrar relaciones entre variables macroeconómicas de un país o una zona económica (UE, EEUU, etc.) y el sector de las grúas: parque de grúas de un país, tipología de las grúas disponibles, antigüedad, inversión en innovación, etc.

Se pretende aquí dar unas pocas ideas al respecto que puedan contribuir al análisis que se realiza del mercado. La actividad de las grúas está relacionada con el mantenimiento de las infraestructuras pero sobre todo con la construcción de nuevas. El tamaño del parque de esta maquinaria estará más relacionado con variables de crecimiento o de actividad del sector de la construcción que con el tamaño total de la economía de un país. Si tomamos el ejemplo de estos últimos años antes de la crisis europea, el parque de grúas de celosía en España era enorme y casi comparable al existente en Alemania. Sin embargo los parques de grúas de celosía de países como Francia y Reino Unido que no tenían tanta actividad de construcción en esos mismos años, a pesar de tener un PIB superior al Español y sectores industriales muy superiores a España, tenían parques de grúas de celosía muy reducidos comparables al de España en la época de la crisis en el que el número de grúas de celosía trabajando en el país se ha reducido en un $90 \%$ aproximadamente.

No sólo la actividad de la construcción afecta, la cultura de construcción, la de seguridad, el peso de la industria frente a la obra civil, etc. afectan también al parque de maquinaria de elevación quizás no tanto en su volumen como en su composición, calidad y antigüedad. Y por lo tanto también a la voluntad e interés de las empresas en innovar y desarrollar nuevas máquinas mejores y más seguras. 


\section{2.- INGENIERÍA DE GRÚAS Y ELEVACIÓN.}

El mundo de las grúas y de los sistemas de elevación requiere de ingeniería especializada y como hemos visto cada día es más necesaria la capacidad de este tipo de ingeniería para las empresas del sector. Se puede dividir el tipo de ingeniería que se realiza en el mundo de las grúas en tres tipos diferentes. La ingeniería de fabricación necesaria para la construcción de una máquina, la ingeniería de grúas a nivel de usuario que es la que define una maniobra de trabajo de las grúas y por último la ingeniería de innovación que desarrolla nuevas máquinas o sistemas de elevación.

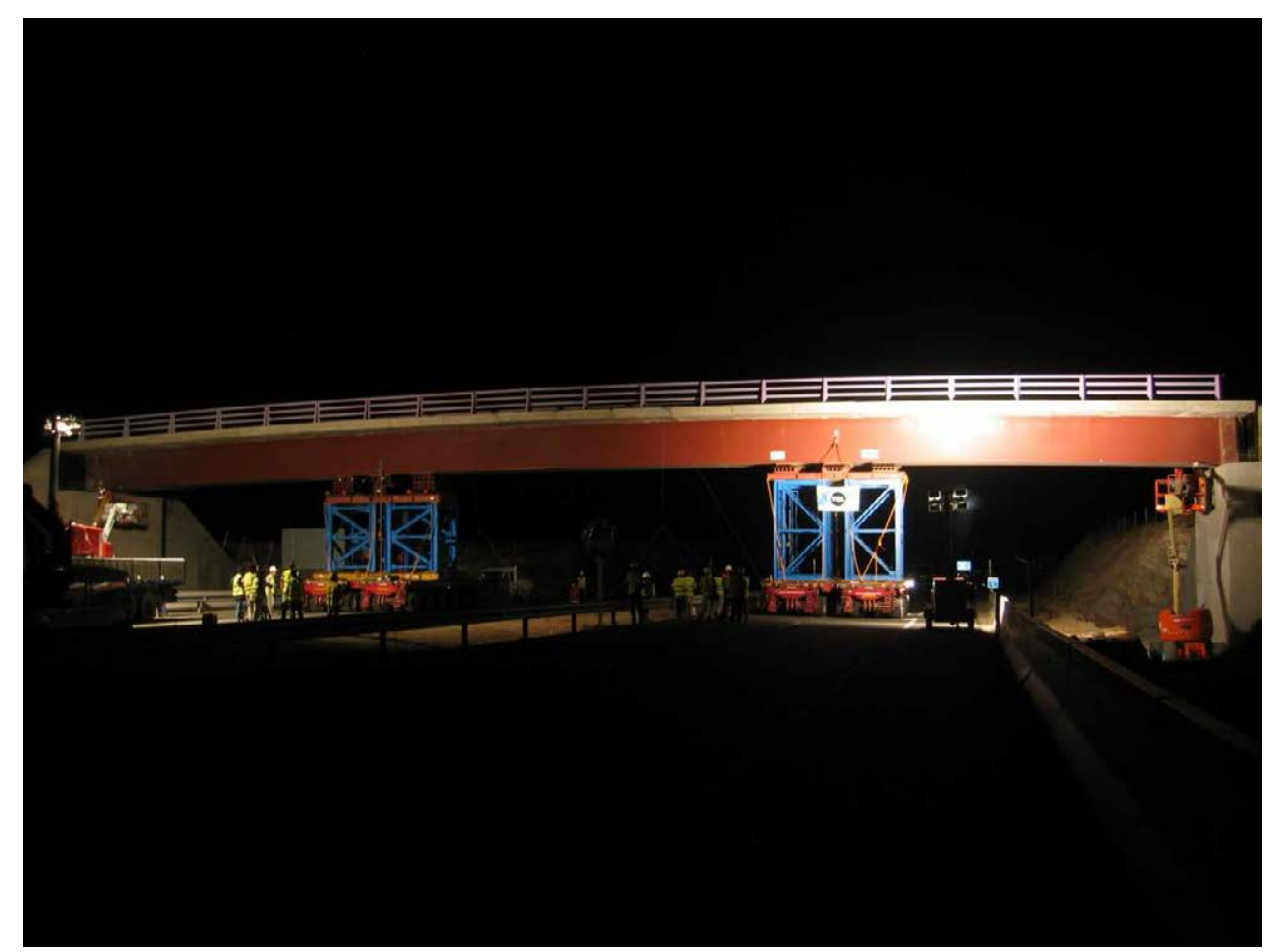

Figura 4.11: Transporte de puente mixto para su recolocación en la A42 a la altura de Toledo izándolo con SPMT y torres de celosía. Agosto de 2009.

\subsection{1.- Ingeniería de fabricación.}

Es la ingeniería para la construcción de grúas que calcula estructuralmente una grúa, sus tablas de carga, define la construcción de la máquina, etc.

Esta ingeniería es la que realizan los fabricantes de grúas para construir las máquinas que luego venden al mercado. Es lógico pensar que una empresa que dispone de este tipo de 
ingeniería está bien preparada para poder realizar nuevos diseños de grúas y desde luego para mejorar y optimizar los modelos existentes.

\subsection{2.- Ingeniería de proyecto.}

Es la ingeniería que permite diseñar proyectos o maniobras de elevación utilizando las grúas existentes y basada por supuesto en las tablas de carga que proporciona el fabricante. Esta ingeniería es la que usan las empresas de grúas que ofrecen dicho servicio además del puro alquiler de la maquinaria lo cual es cada vez más solicitado sobre todo para maniobras de envergadura. Los usuarios finales cada vez necesitan más este tipo de ingeniería que realizaban muchos años atrás cuando disponían de sus propios parques de maquinaria y que habían poco a poco abandonado y subcontratado frecuentemente a las empresas de grúas.

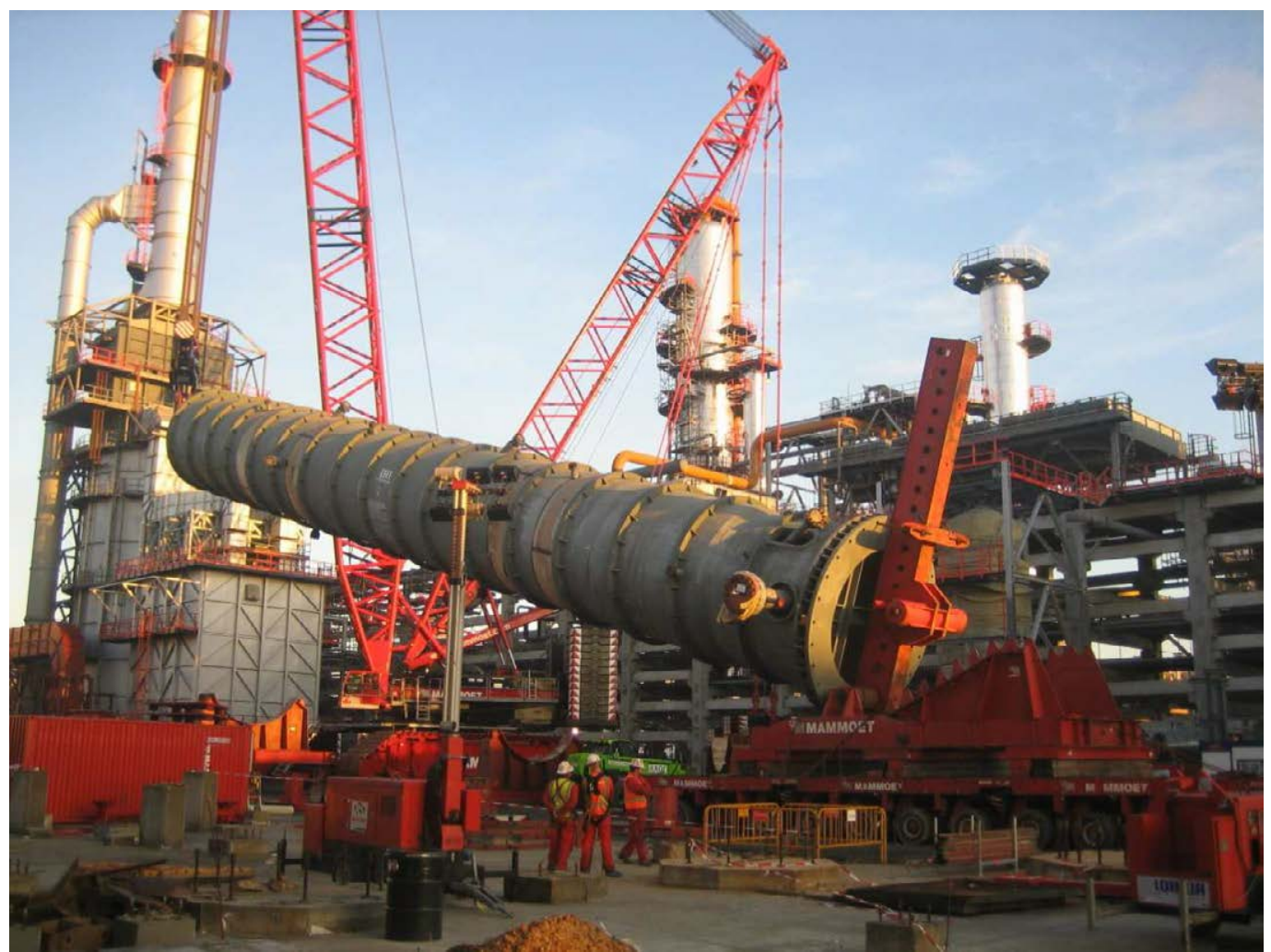

Figura 4.12: Maniobra de verticalización combinando grúa CC6800 de 1.250t de capacidad con carretones SPMT que realizan la retenida de la maniobra usando una mesa de volteo. Refinería de Huelva, año 2008.

Recientemente se observa que muchos usuarios finales vuelven a tener sus propios departamentos internos de ingeniería de elevación ya que aunque las empresas de grúas se la 
pueden proporcionar, se ven en esta necesidad cuando tienen que preparar la estrategia de construcción de una obra compleja y especialmente las modulares. De hecho, esta ingeniería de elevación se incluye frecuentemente junto con otras disciplinas de construcción en departamentos llamados de "constructabilidad" (del inglés "constructability") o similar.

\subsection{3.- Investigación, desarrollo innovación.}

A primera vista se ve que la ingeniería para diseñar nuevos modelos de grúas es una continuación de la ingeniería de fabricación de una máquina ya que hay que calcular y diseñar las partes de una nueva máquina y la base de ese conocimiento estará en las empresas que disponen de una buena ingeniería de construcción de grúas.

Sin embargo, para tener ideas innovadoras tanto de mejoras en grúas existentes como de nuevas máquinas que cubran necesidades del mercado o que puedan resolver problemáticas existentes es fundamental trabajar en la ingeniería de maniobras o proyectos que dan dicho conocimiento al enfrentarse constantemente a las problemáticas existentes en la realidad.

Para tener una buena ingeniería para poder innovar en el sector de las grúas, es muy necesario tener importantes conocimientos en las ingenierías de diseño y en la de maniobras sin embargo, estos conocimientos suelen estar separados entre las empresas fabricantes y las usuarias lo cual dificulta sin duda la innovación en el sector.

Un ejemplo muy ilustrativo de lo anterior es el diseño de algunos nuevos desarrollos como los SPMT que se realizaron en los años 80 en colaboración entre una empresa de grúas y transportes especiales y un fabricante. De esta colaboración surgieron los SPMT que han tenido mucho éxito en el mercado mundial y para combinar los intereses de ambas empresas, el fabricante no podía vender este equipo durante los primeros cinco años nada más que a la empresa con la que colaboraba siendo libre posteriormente de venderlos a cualquier otra empresa en el mercado. 


\section{3.- SEGURIDAD.}

No se va a entrar en un gran detalle en el mundo de la seguridad de maniobras ya que este tema se trata de forma general en muchos trabajos y concretamente existen incluso estudios de accidentes de grúas además de bastante información disponible al respecto, al contrario de lo que ocurre en muchos otros campos del mundo de las grúas.

Los factores causantes de un accidente en el mundo de las grúas pueden ser múltiples aunque cabe mencionar como factor fundamental el fallo del apoyo de las grúas: terreno, cimentaciones, etc. También es importante la realización de un buen proyecto de una maniobra que además respete las tablas de cargas y limitaciones de las máquinas (viento, inclinación, etc.). Por supuesto los sistemas de seguridad de la propia máquina como limitadores de carga que no deben nunca puentearse.

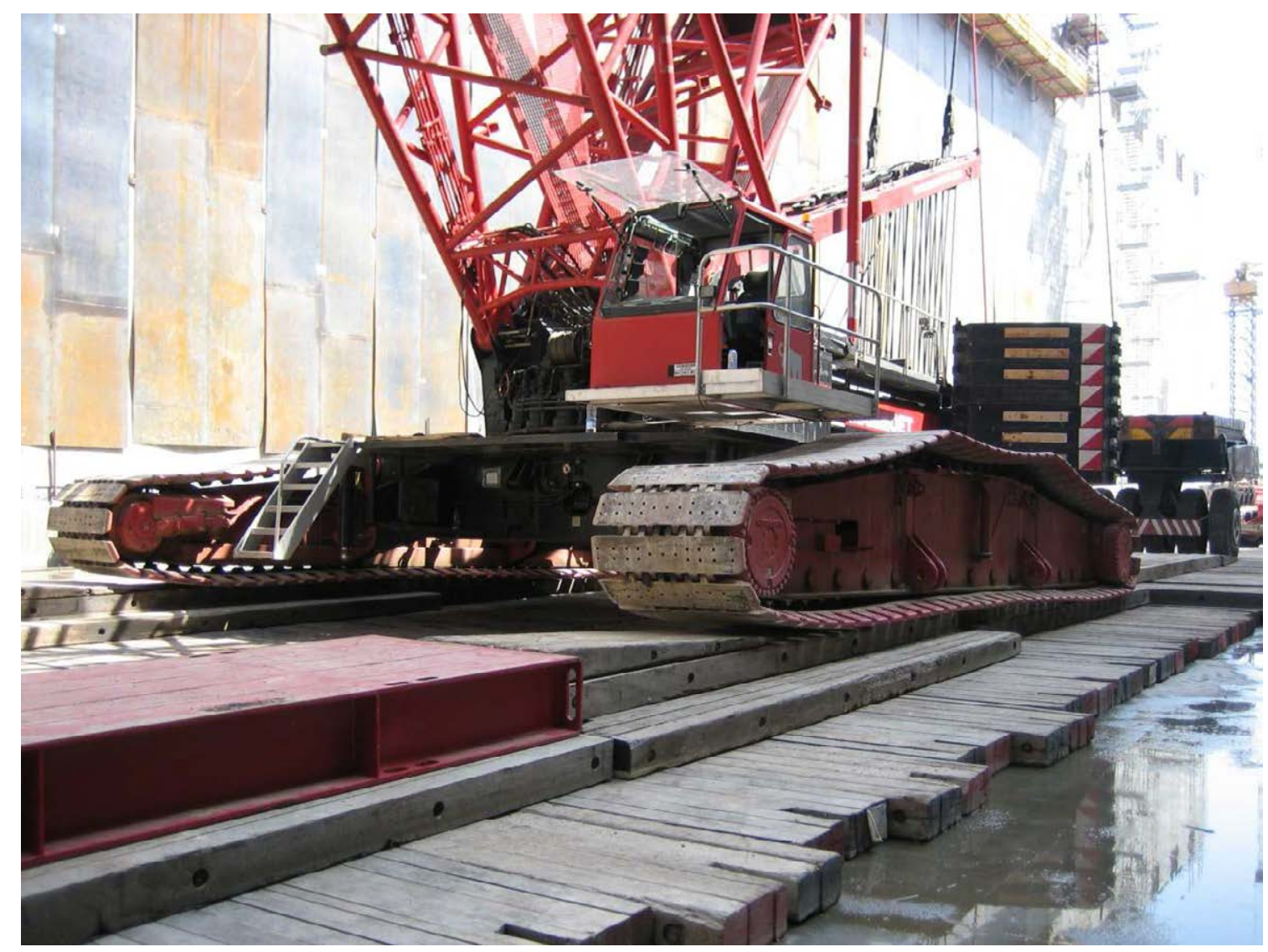

Figura 4.13: Grúa LR1350 de 350t de capacidad nominal colocándose sobre 3 capas de reparto de cargas (dos de madera y una de vigas cajón metálizas) para poder trabajar sobre forjado de hormigón postesado. Proyecto Adriatic Terminal LNG, Algeciras 2006. 
La legislación en materia de seguridad así como la propia cultura de seguridad que exista en las empresas participantes determina el buen hacer en los trabajos. Esta cultura y legislación se obtiene con un trabajo constante y una concienciación de las empresas y sus trabajadores. Es fundamental en este sector ya que se realizan actividades con alto riesgo y por supuesto los avances técnicos de maquinaria, los sistemas de seguridad y una buena ingeniería de maniobras son cruciales.

El mal uso de una máquina, sobrepasando sus tablas de capacidad, a veces incluso puenteando sus limitadores así como la mala selección de una grúa para una determinada maniobra tanto si se hace por desconocimiento como si se hace por ahorro de costes pueden por el contrario acabar en accidentes muy graves.

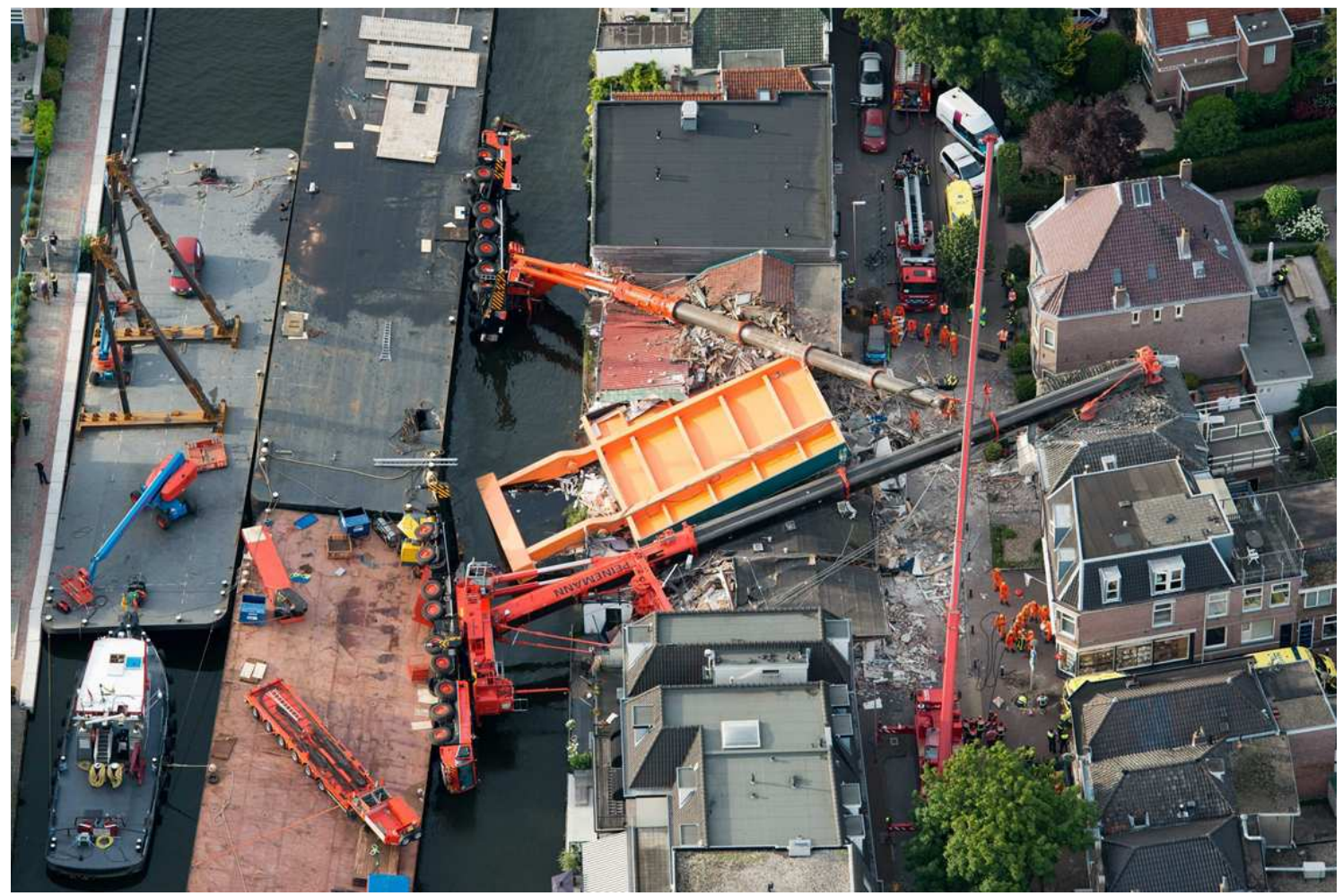

Figura 4.14: Accidente de dos grandes telescópicas en Holanda en el verano de 2015 trabajando sobre barcazas. 


\section{4.- NECESIDADES DE INNOVACIÓN.}

Se quiere analizar en este punto cuales pueden ser las necesidades del mercado que impulsan la innovación en el sector de las grúas para entender mejor el origen de las motivaciones a la hora de realizar nuevos diseños.

\subsection{1.- Por capacidad y tamaño.}

Uno de los motivos que han impulsado el diseño y la construcción de nuevas grúas ha sido sin duda el lograr aumentar la capacidad de izado y construir cada vez grúas más grandes. En unas décadas en España se ha pasado de considerar una grúa de 100 toneladas grande a considerarla prácticamente pequeña y alquilarla de forma rutinaria.

El aumento de la capacidad de esta maquinaria en las últimas décadas ha sido espectacular. Y concretamente en los últimos 20 años. Los fabricantes importantes de grúas tenían modelos de alta capacidad de celosía sobre cadenas y la mayor en el mundo era hace un par de décadas la Demag CC12600 de unas 1.600 toneladas de capacidad. Uno de los problemas de esta gran máquina es su movilización y desmovilización a obra ya que hay que transportarla en más de 100 camiones de los cuales muchos son transportes especiales. Sus mismas cadenas se tienen que desmontar en cuatro trozos y aun así también son transportes especiales. Sólo existe una máquina de este modelo de grúa en el mundo y en aquella época el gran competidor Liebherr no tenía ningún modelo de ese tamaño. Las grandes empresas de grúas a nivel mundial (dos grupos Holandeses se lanzaron cada uno a construir la grúa más grande del mundo y cada uno lo realizo de formas muy distintas aunque si se ve el resultado de ambos diseños en fotos parezcan muy parecidas:

Ambas son de celosía sobre anillo (para el mayor posible reparto de cargas) y tienen pluma en forma de A.

Sin embargo son máquinas enormemente diferentes en su concepción. La PTC es más parecida a una grúa tradicional en cuanto a su sistema de elevación, giro, etc.

La MSG es en realidad un mecano que usa los sistemas de elevación precisamente alternativos a las grúas. El tiro se realiza mediante cuatro gatos de cable de 900 toneladas (pudiendo 
realizar un tiro máximo de 3.600 toneladas), el giro se hace mediante patines de deslizamiento usados en las maniobras de transporte horizontal de grandes cargas.

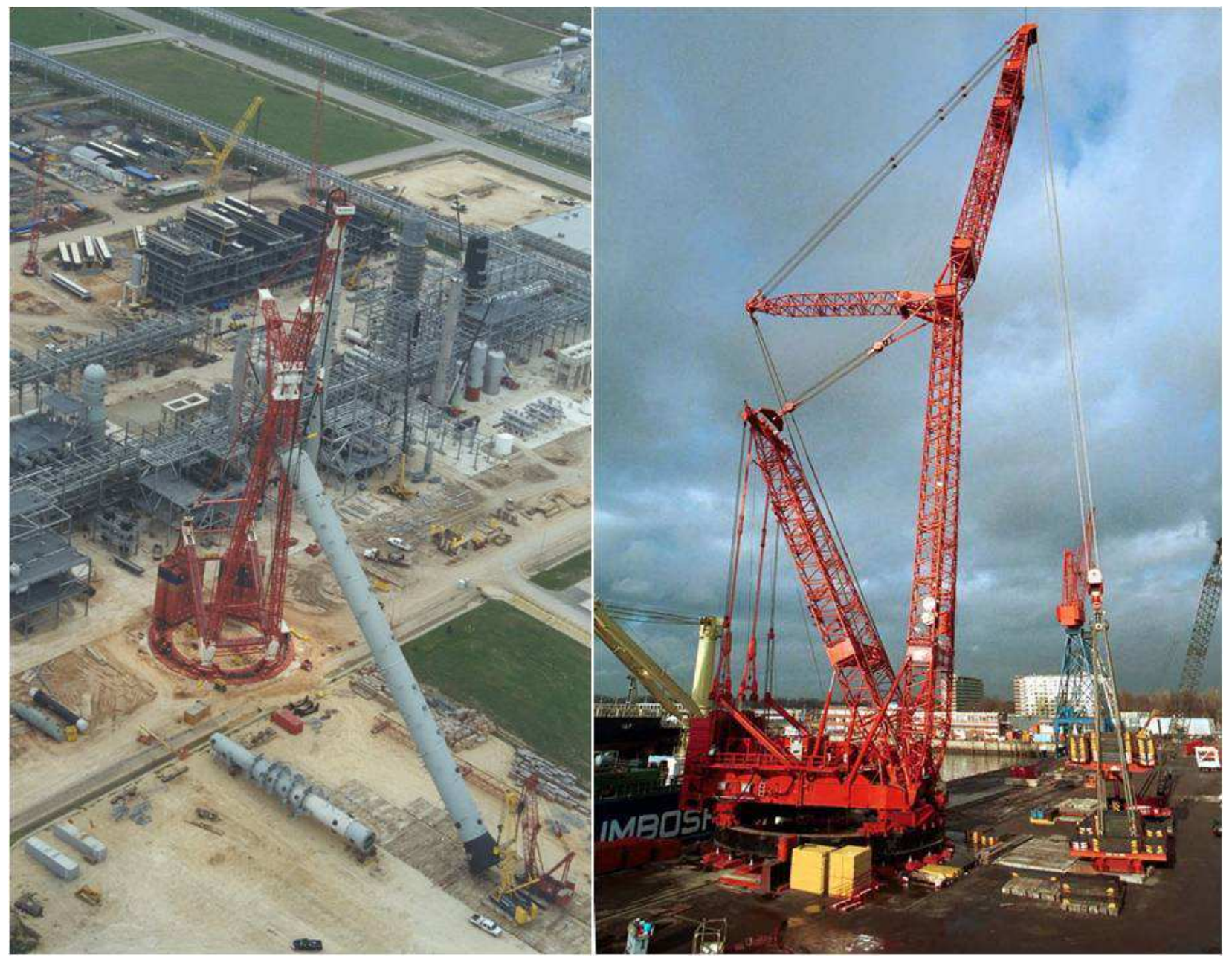

Figura 4.15: Grúas MSG y PTC de 3600 y hasta unas 5.000 toneladas de capacidad aprox.

Ambas empresas querían mejorar el problema de las movilizaciones de estas grandes máquinas a las obras y ambas coincidieron que todas las piezas de las grúas tenían que ser de tamaño contenedor y había que resolver el problema de transportar más de 2.000 toneladas de contrapeso (no olvidemos que un camión convencional en Europa no puede cargar más de 24 toneladas). Con una simple división se observa el número de camiones sólo para el contrapeso y su coste cada vez que se desplazan las máquinas. La solución a este problema del contrapeso fue resuelta de forma muy distinta por ambas empresas.

La MSG utiliza contrapesos que son contenedores rellenos de arena de forma que no hay que estar transportando acero muerto de obra a obra sino usar arena localmente para rellenar y 
vaciar los contenedores. También se pensó en la posibilidad de llenar los contenedores de agua pero esa opción no se ha usado por la inercia que puede tener el agua al girar la grúa.

En el caso de la PTC, se solucionó el problema del transporte de los contrapesos con una combinación ingeniosa. Hay que transportar obligatoriamente los tramos de pluma de celosía que suponen mucho volumen y poco peso. Sin embargo los contrapesos son mucho peso y muy poco volumen ya que son piezas de acero, cuando un camión normal transporta 20 toneladas de contrapeso nos parece a simple vista que la plataforma va prácticamente vacía y sin embargo el camión va cargado cerca de su capacidad máxima. La idea fue construir los tramos de pluma y los contrapesos de forma que se puedan transportar unido en un mismo camión y con tamaño contenedor, una pieza da el peso y la otra el volumen y no se desperdicia la capacidad de los camiones que iban a transportar la pluma de todas formas.

Esta contenerización de las grandes grúas es un paso fundamental ya que permite transportarlas a cualquier lugar de forma relativamente sencilla (los contenedores llegan a cualquier sitio del mundo) y además se evitan los transportes especiales y lo que es más importante, los permisos para transportes especiales que según cuál sea el país pueden tardar días o meses en obtenerse con el consiguiente perjuicio para poder transportar la grúa con cierta agilidad en breve plazo.

\subsection{2.- Por especialización para el tipo de trabajo.}

Otro motivo de nuevos desarrollos de grúas es el comentado anteriormente de la especialización de las grúas. Puede ser muy interesante para según qué tipos de trabajos a realizar con grúas el diseñar y construir una grúa específicamente pensada para esos trabajos que consiga mejorar los costes ya que evitamos dotarla de capacidades innecesarias.

El caso de las grúas portacontenedores es un buen ejemplo de este tipo de grúas que responde a la necesidad de descargar los buques portacontenedores con un máximo de eficiencia ya que los tiempos de uso de los muelles y los de parada de los barcos representan unos costes enormes.

El sector eólico es otro trabajo que presentaba una gran necesidad de un diseño de algún sistema de izado específico que ahorrara los costes del uso de grúas de celosía convencionales 
o parcialmente adaptadas como lo son las de vía estrecha. Sin embargo esta necesidad no se ha concretado en ningún diseño innovador que resolviera el problema (al menos hasta ahora).

\subsection{3.- Por evolución en la forma de ejecución de proyectos: Modularización.}

Los cambios en la forma de trabajar en la construcción y de concebir y realizar los proyectos suponen nuevas necesidades de grúas y sistemas de elevación.

La cultura de seguridad que impulsa la mejora de los sistemas de seguridad propios de las máquinas (limitadores, etc.), impulsa la mejora del mantenimiento de las grúas así como el uso de grúas en buen estado y más modernas.

Las piezas han ido creciendo progresivamente requiriendo también grúas cada vez más grandes y potentes pero sin duda uno de los cambios que más ha afectado al mundo de las grúas y maniobras especiales y más va a afectar todavía en los próximos años es la modularización de los proyectos. Construir pequeños o grandes módulos es muy interesante para este tipo de proyectos por muchos motivos de costes, plazos, seguridad, etc. pero estos módulos pequeños, grandes o enormes (a veces varios miles de toneladas) tienen que ser transportados y colocados en su emplazamiento final. Las grúas necesarias para esas maniobras pueden ser escasas y frecuentemente hay que contratarlas con mucho tiempo de antelación para asegurarse su disponibilidad.

\subsection{4.- Por "vacios" en lo existente.}

En ocasiones el sector de las grúas deja vacíos de capacidad en la gama de las grúas y esos vacíos crean una necesidad. Una explicación es, a veces, que por sacar una grúa de muy superior capacidad, el salto que se da es muy grande y se crea un hueco en la gama de capacidades. Analizando por ejemplo las grúas de celosía hace unos pocos años se podía observar que había mucho modelos entre las 250 y las 750 toneladas y sin embargo de ahí se saltaba a las $1.250 t$. Entre 1.250 y 1600 , hay de nuevo varios modelos. El hueco entre 750 y 1.250 toneladas creaba una clara necesidad en el mercado de grúa de una capacidad intermedia. El fabricante Liebherr vio clara esa necesidad y presentó en la feria de Bauma 
(Munich) de 2013 la nueva LR11000 de 1.000 toneladas de capacidad dando respuesta a esta necesidad del mercado.

\subsection{5.- Por competencia.}

La competencia es otro de los factores que crea una necesidad en el mercado para el desarrollo de grúas. Para estudiar este factor en el sector de grúas se pueden analizar varios ejemplos pero es muy interesante estudiar lo ocurrido en los últimos años en el campo de las grandes grúas a nivel mundial. Liebherr que se había quedado atrás en el campo de las grandes grúas de celosía mientras que su competidor Demag tenía la CC12600 de 1.600 toneladas. Además de lo anterior las empresas de grúas Mammoet y Van Seumeren habían desarrollado las grandes grúas Ringer MSG y PTC. Liebherr desarrolló la nueva LR13000 de 3.000 toneladas de capacidad para poder competir contra las anteriores y la presentó en Munich en 2.010-11.

En paralelo las empresas de izados especiales competencia de Mammoet y Van Seumeren (que se habían fusionado) también desarrollaron nuevos modelos más parecidos a la MSG y a la PTC para poder competir en el mercado contra Mammoet ya que en un cierto momento tenía las únicas máquinas de gran capacidad que había en el mundo. Los márgenes en esa gama son lógicamente más importantes que en las pequeñas grúas de alquiles. 


\section{5.- ANÁLISIS DE CASOS CONCRETO DE NUEVOS DESARROLLOS.}

Es interesante intentar comprender si en el sector de las grúas, las innovaciones se realizan para dar respuesta a una necesidad del mercado como podría parecer evidente o bien ocurre la situación inversa: se realiza una innovación que introduce en el sector una nueva máquina y la simple existencia de este equipo crea la necesidad en el mercado.

Esta situación inversa se puede observar en otros sectores de la economía como puede ser el lanzamiento de los smartphones que ha creado una necesidad en el mercado mundial cuando hace unos años la necesidad de los clientes era un teléfono móvil sencillo para llamar.

Se realiza a continuación un estudio de varios casos en el sector de la elevación y maniobras especiales intentado clasificar cada caso en una de las dos casuísticas aunque en ocasiones no está claro al $100 \%$ la pertenencia a una u otra.

\subsection{1.- Casos en los que una necesidad provoca una innovación.}

Se han comentado anteriormente en el punto 4.4. grupos de motivos que crean necesidades de mercado. Son ejemplos claros de esta situación:

- El desarrollo de grúas de celosía sobre cadenas de vía estrecha para responder a la necesidad del sector eólico para el mejor desplazamiento de la grúa entre la construcción de una torre y la siguiente.

- El desarrollo de grúas portuarias y en especial de las grúas portacontenedores para conseguir la máxima eficiencia en la carga y descarga de los buques.

- Nueva grúa LR11000 de 1.000 toneladas de capacidad para "rellenar" un hueco en la gama de grúas de celosía.

- Grúas SGC120 (3.200 toneladas de capacidad) de Sarens y SK350 (5.000 Toneladas de capacidad) para competir contra las series MSG y PTC.

- Grúa LR13000 para competir con la Demag CC12600 y resto de grandes grúas ringer. 
Hay más ejemplos muy interesantes de analizar de respuestas del sector con innovaciones a necesidades del mercado:

\subsubsection{1.- Grúas portuarias o de buques de alta capacidad:}

Cuando se realizan transportes especiales de cargas importantes como pueden turbinas de centrales eléctricas, transformadores, generadores, columnas de refinerías, etc. hay que cargar y descargar a buque y desde buque estas piezas pesadas que pueden pesar en general entre las 100 y 2.000 toneladas (en casos excepcionales se sobrepasan incluso las $2.000 \mathrm{t}$ ). El problema es que en la gran mayoría de los puertos del mundo no hay grúas portuarias con más de 60 o 100 toneladas de capacidad. Para solucionar este problema se recurre en ocasiones a grúas terrestres, para cargas no muy altas (hasta 200 o 300t) se puede hacer la maniobra con grandes grúas telescópicas si se dispone localmente).

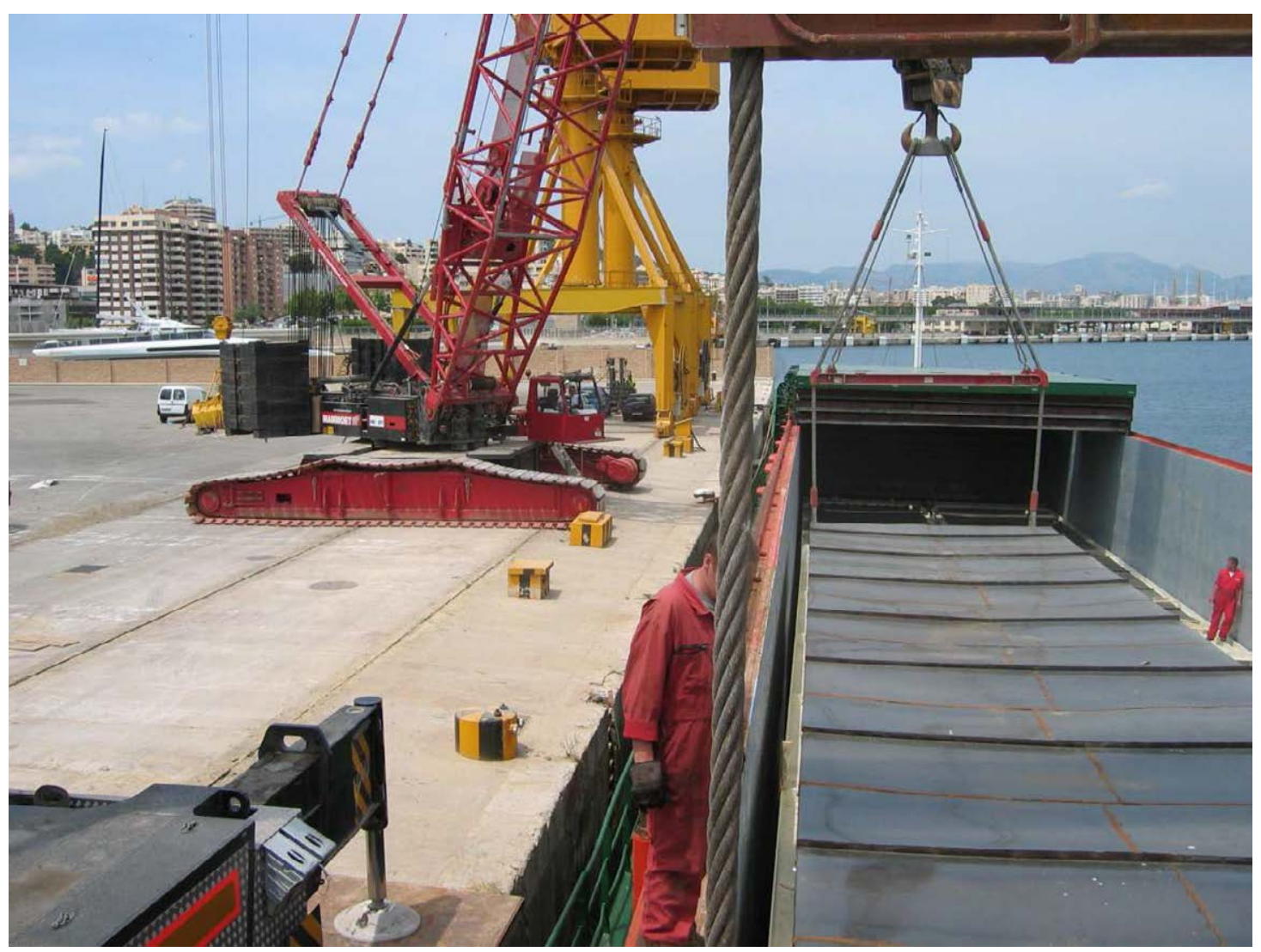

Figura 4.16: Grúa de celosía descargando en tándem con una telescópica en el Puerto de Palma de Mallorca los módulos de la central de ciclo combinado de Son Reus. 
Cuando ya se pasa a grúas de celosía la maniobra se encarece notablemente y ello provoca que se recurra a realizar el transporte marítimo con un buque "Heavy Lift" o con grúas propias. Estos buques están equipados en sus costados con grúas que puedan cargar y descargar las piezas pesadas. Hasta hace unos años, el buque de mayor capacidad (único en el mundo) combinaba 2 grúas de 550 toneladas cada una pudiendo cargar y descargar piezas de hasta 1.100 t. En los últimos años se han construido y están navegando buques con dos grúas de 900 toneladas cada una combinables para izar piezas de hasta 1.800 toneladas.

El problema es que el número de este tipo de barcos es reducido y además su coste es muy alto por lo que era muy importante poder realizar el diseño de una grúa portuaria de alta capacidad que se pueda transportar fácilmente de uno a otro puerto (no se puede dejar permanente ya que este tipo de maniobras surge en un puerto en muy contadas ocasiones) y que sea mucho más barata que una gran grúa móvil ya que se pueden reducir movimientos innecesarios para esta actividad de carga y descarga de barcos tales como el giro, el desplazamiento sobre cadenas, etc.

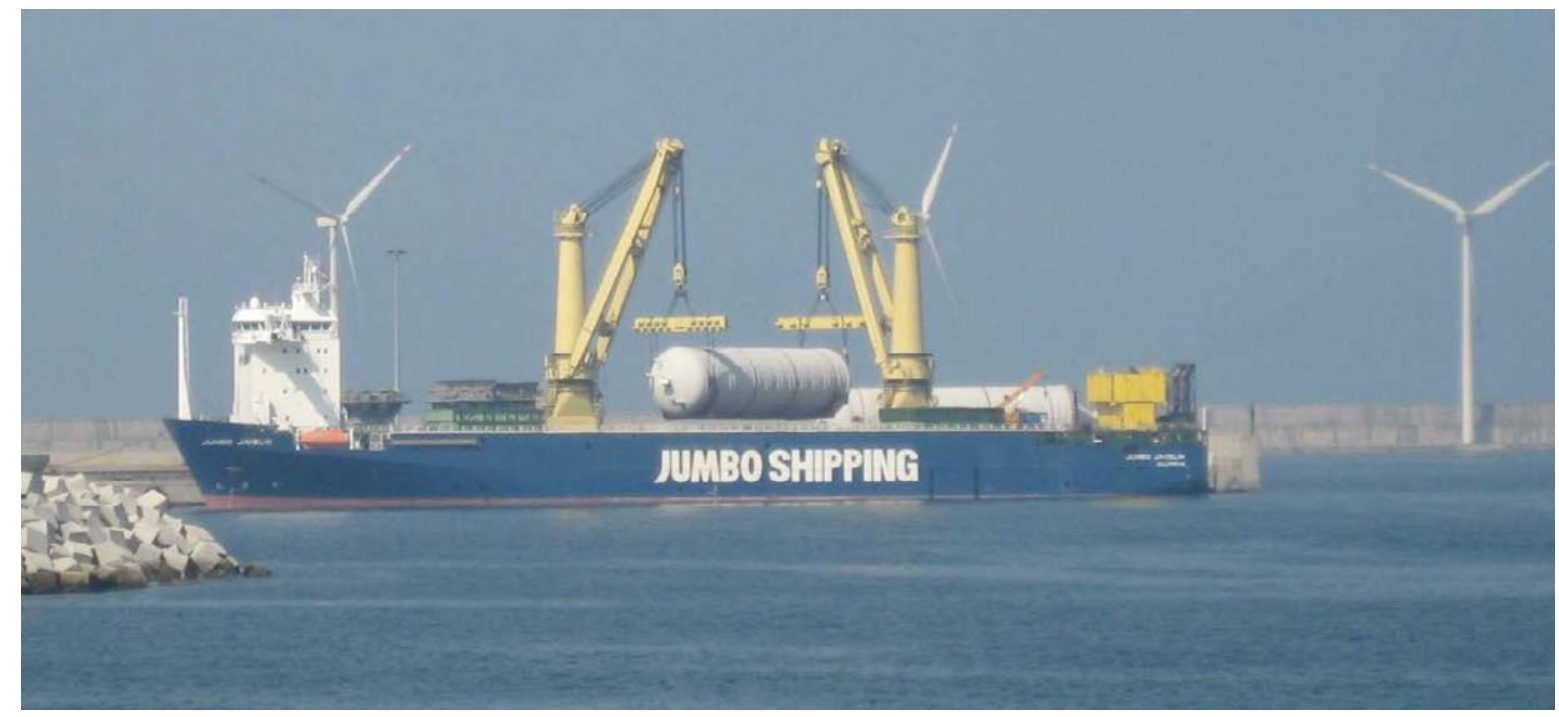

Figura 4.17: Descarga de cámaras de coque de 480 toneladas en el Puerto de Bilbao desde buque con 2 grúas de 900 toneladas de capacidad cada una.

Dos grandes empresas de grúas han construido en estos últimos años este tipo de grúa portuaria de alta capacidad para este tipo de maniobra específica. Están también contenerizadas para poder transportarlas entre puertos con bajos costes. 


\subsubsection{2.- Izado en el año 2001 del Submarino Kursk:}

En agosto del año 2.000 se hunde en el mar de Barents el submarino ruso Kursk. En los meses siguientes, el gobierno Ruso saca una licitación para izarlo y se pide que se realice la maniobra en el 2001. Dadas las malas condiciones meteorológicas en la zona, es necesario realizar la maniobra antes de la llegada del mal tiempo a principios de Octubre. No existe en el mundo un sistema de elevación para poder izar un submarino de 18.000 toneladas.

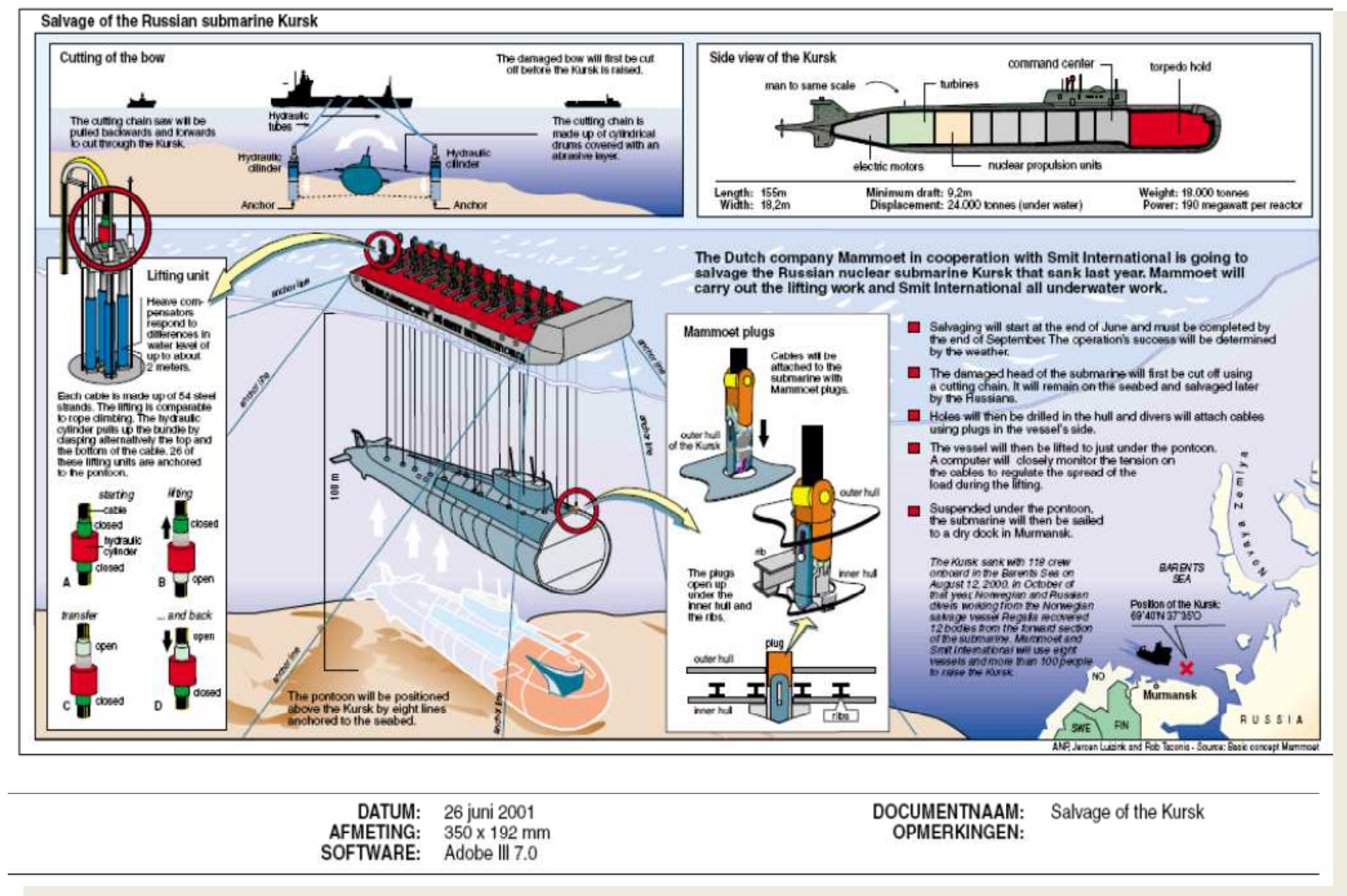

Figura 4.18: Presentación de la propuesta de la maniobra para el izado del Submarino Ruso Kursk

Como se puede observar en la figura de la presentación de la maniobra de izado, el procedimiento requería de equipos no existentes en aquel momento y que se tuvieron que diseñar, calcular, probar y construir en un tiempo muy reducido (la adjudicación se hizo en primavera del año 2001 y la maniobra de izado en la madrugada del 8 de Octubre de 2001).

Hubo que diseñar este sistema de izado nunca visto hasta el momento que consiste en colocar los gatos de cable habituales en maniobras de izado terrestres sobre el casco de una barcaza para tirar desde ella y que los cables atravesando la propia barcaza se anclasen al casco del 
submarino. De esta forma al tirar con los gatos (de 900 toneladas cada uno) el submarino se izaría hasta colocarse bajo el casco de la barcaza y poder llevarlo de esta forma hasta el puerto Ruso de Múrmansk. Además era necesario el diseño nuevo de varios equipos auxiliares para el izado: "arpones " para el agarre de los cables de izado al casco del submarino, enrolladores de cables de izado para evitar el desorden de los cables sobre la barcaza que se iba a utilizar para la maniobra (hasta entonces sólo existían los "paraguas" que se muestran en la figura para que el cable cayera muerto por el otro lado), taladro de la barcaza para pasar los cables de izado ya que los gatos estaban colocados sobre la barcaza, sistema de corte de la proa del submarino para evitar un desprendimiento de muchas toneladas durante la maniobra dado que la proa estaba muy dañada por la explosión.

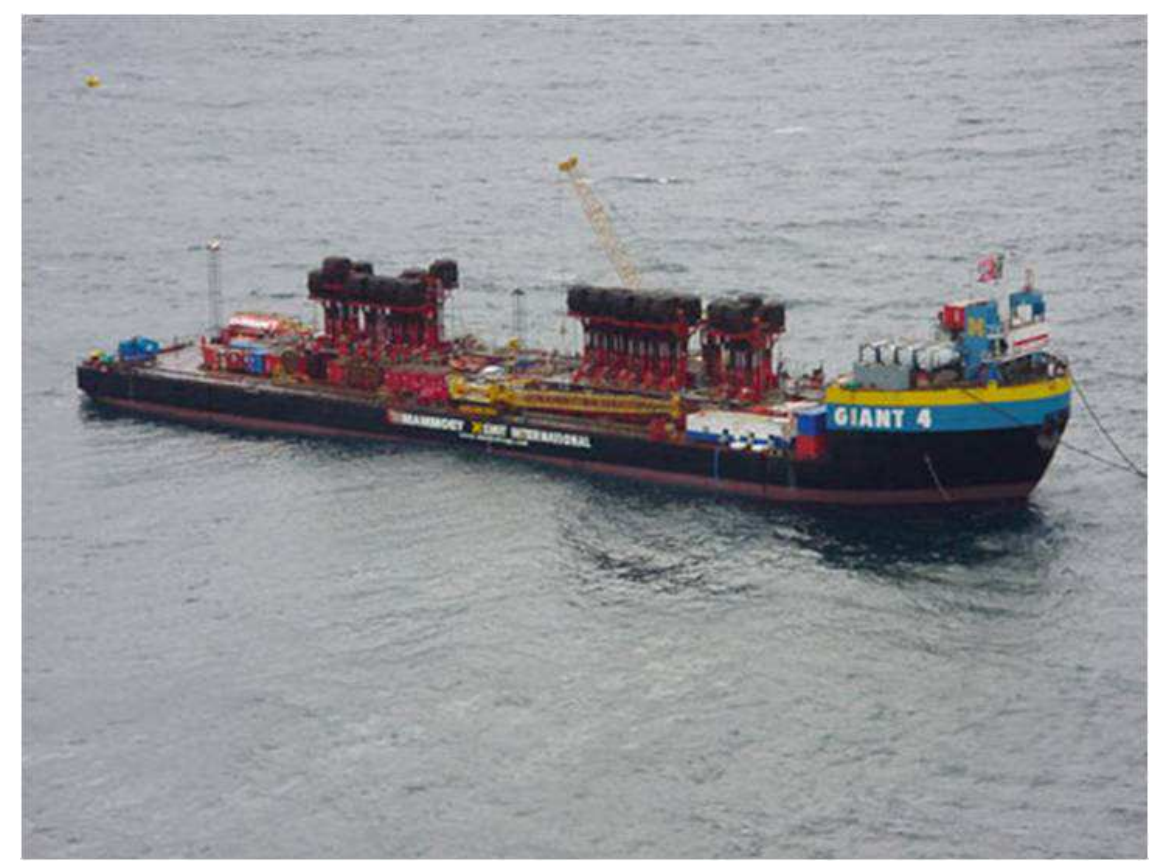

Figura 4.19: Barcaza Giant 4 con los gatos de cable para el izado del Kursk.

Pero el desarrollo más considerable de cara a los izados especiales fue probablemente el sistema de empuje para mantener la tensión de los cables de izado. Al estar los gatos sobre una barcaza flotando y el submarino fijo en el fondo al principio de la maniobra, se planteaba el problema de la tensión variable en los cables de izado según la barcaza subía y bajaba por el efecto del oleaje. Para mantener la tensión de los cables de izado se desarrollo un sistema con cilindros que empujaba a los gatos hacia arriba cuando la barcaza bajaba y hacia abajo cuando la barcaza subía. De esta forma, los gatos de cable tenían una posición casi estática a pesar de estar colocados sobre una barcaza que se movía. 
Estas innovaciones se realizaron en tiempo record para poder realizar técnicamente una maniobra tan compleja y arriesgada como fue esta. El resultado es que en los años posteriores estas innovaciones han permitido avances en el sector y actualmente se instalan sistemas de equilibrado similares en buques con grúas y plataformas elevadoras de personas sobre barco para el acceso a plataformas offshore.

\subsection{2.- Casos en los que una innovación provoca una necesidad.}

\subsubsection{1.- Grandes Grúas Ringer.}

En ocasiones, puede ocurrir que se haga una innovación de una nueva grúa o sistema de elevación y no se haga por la existencia de una necesidad concreta del mercado. Es difícil identificar estas situaciones porque si el sistema o la máquina tienen éxito, es porque el mercado los usa y se adapta a ellos creándose de esta manera la necesidad de dichas máquinas y puede parecer que respondían a esas necesidades. Pero si se analiza en detalle, la necesidad real no existía anteriormente.
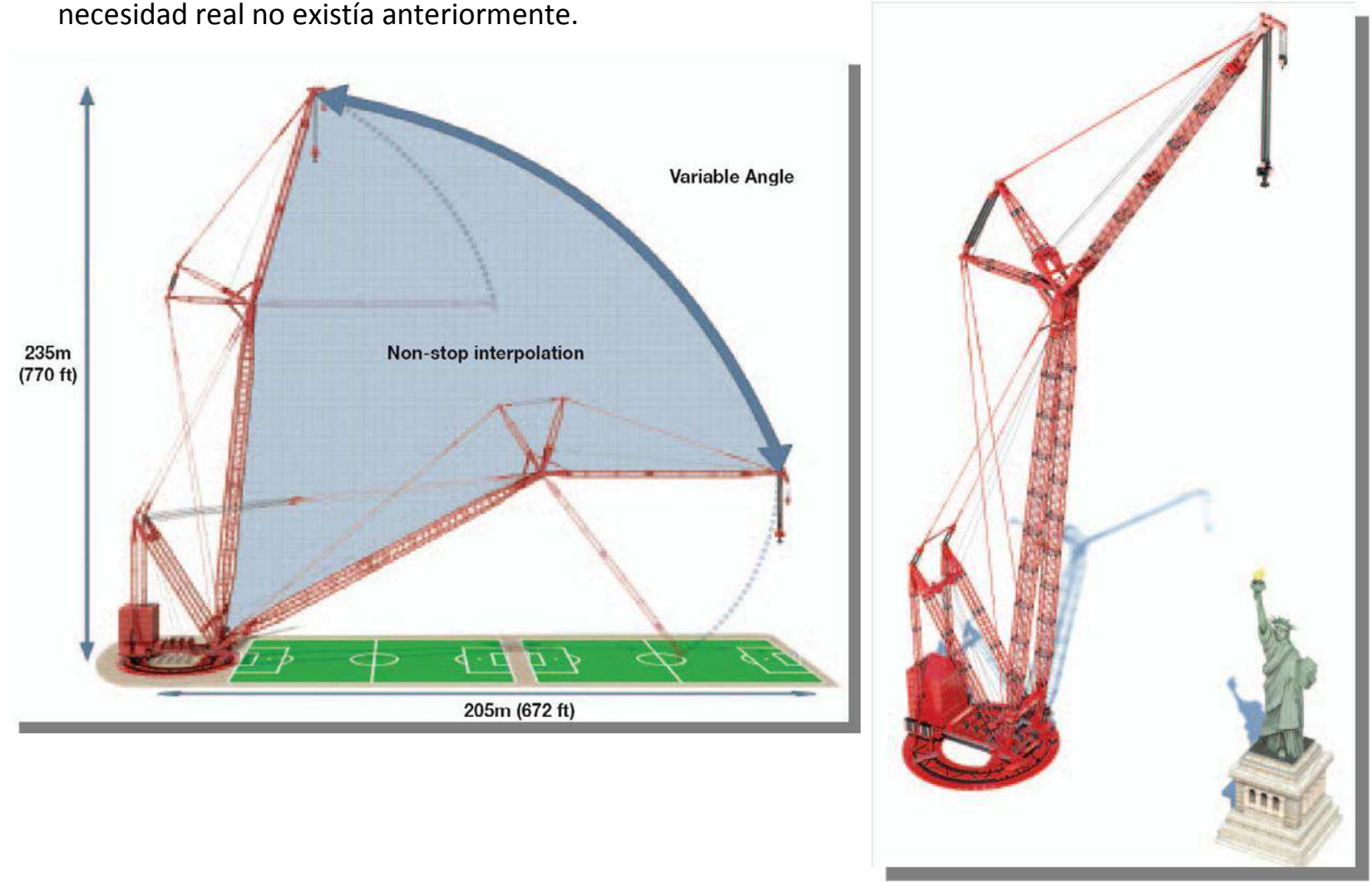

Figura 4.20: Segunda generación de PTC presentadas en Julio de 2011: PTC140 y PTC200 
Un ejemplo de lo anterior es el diseño de las grandes grúas MSG y PTC de 3.600 y hasta 5.000 toneladas de capacidad. Antes de su diseño y construcción, la grúa más grande que existía en el mercado de grúas terrestres era la Demag CC12600 de celosía sobre cadenas (de cuyo modelo sólo se construyo una grúa en el mundo). Ningún usuario diseñaba ni construía lógicamente ninguna pieza a izar que no pudiera ser izada con la mayor grúa existente en el mundo ya que haría inviable su construcción y por lo tanto la necesidad no existía en el mercado. Además ninguna constructora ni ingeniería había solicitado nunca una oferta a ninguna empresa de grúas de una grúa de 3.000 toneladas ya que no existía. Sin embargo al conocer el mercado mundial la existencia de esas nuevas máquinas, se empezó a construir contando con utilizarlas para las maniobras a realizar en las obras creándose una demanda difícil de atender con las pocas unidades que se iban construyendo.

\subsubsection{2.- SPMT}

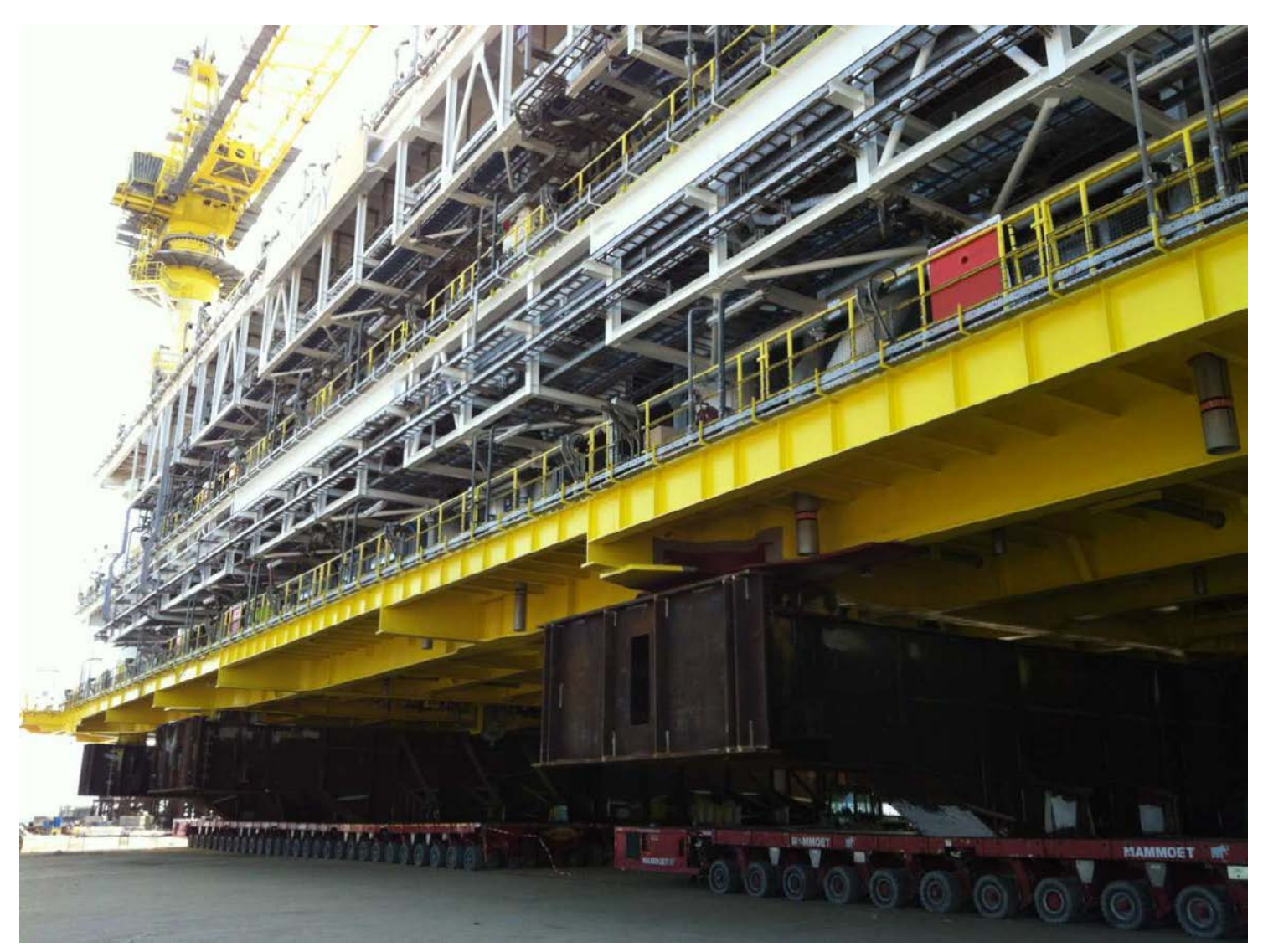

Figura 4.21: Transporte sobre SPMT una plataforma Offshore de más de 9.000 ton y loadout sobre barcaza, Cádiz, marzo de 2013. 
El caso de los carretones autopropulsados SPMT es similar al anterior ya que existían en el mercado los carretones convencionales con cabeza tractora que realizaban los movimientos de grandes cargas y sin embargo una empresa de grúas y transportes especiales trabajando conjuntamente con otra empresa fabricante diseñan y construyen este tipo de máquina y tiene tal éxito, especialmente para el movimiento y embarque de plataformas offshore que pronto se crea una necesidad y un mercado importante para este novedoso tipo de plataforma.

\subsubsection{3.- Sistema de empuje vertical de grandes cargas.}

Para izar grandes plataformas de Offshore se realizaban habitualmente maniobras con gatos de cable colocados sobre torres de izado y se tiraba de ellas hacia arriba. Este sistema funcionaba a pesar de ser caro, complejo de instalar, y requería muchas veces dejar huecos en las plataformas offshore para pasar las torres de izado.

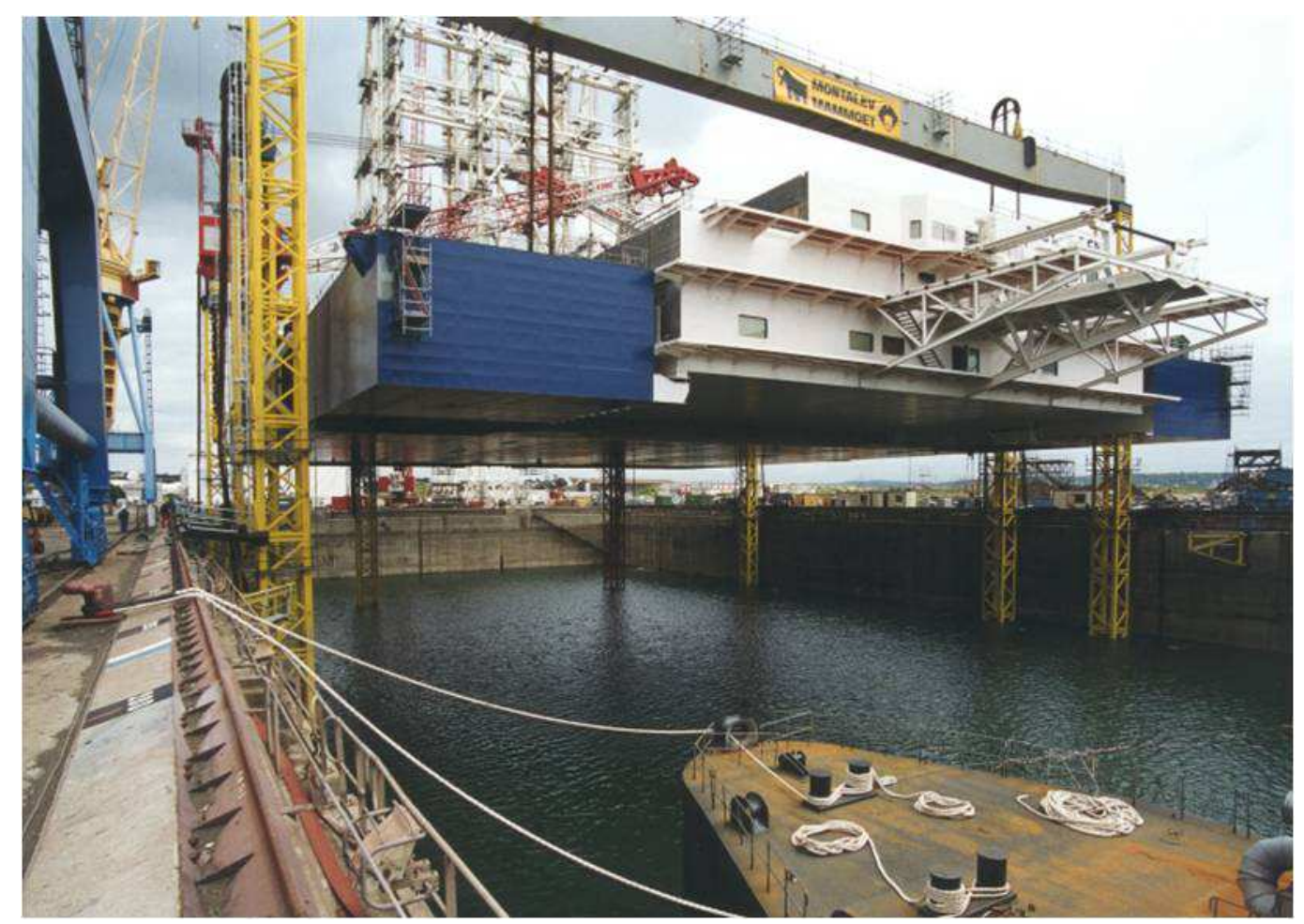

Figura 4.22: Sistema de torres con gatos de cable para izar el módulo de 7.000 toneladas en Brest en el año 2000. Fue record de este tipo de izado en su momento. 
Se desarrolló hace pocos años un nuevo sistema para este tipo de maniobras que consiste en realizar un empuje desde debajo utilizando patines de deslizamiento (sin moverlos) y sus cilindros de empuje vertical con carrera de 600 milímetros. A cada vez que se empuja la carrera de un gato, se va calzando con cilindros verticales para ir ganando altura. En las primeras maniobras se empujaron unas 14.000 toneladas a 12 metros de altura y posteriormente para poder empujar más altura se empezó a arriostrar para evitar el pandeo de los apoyos.

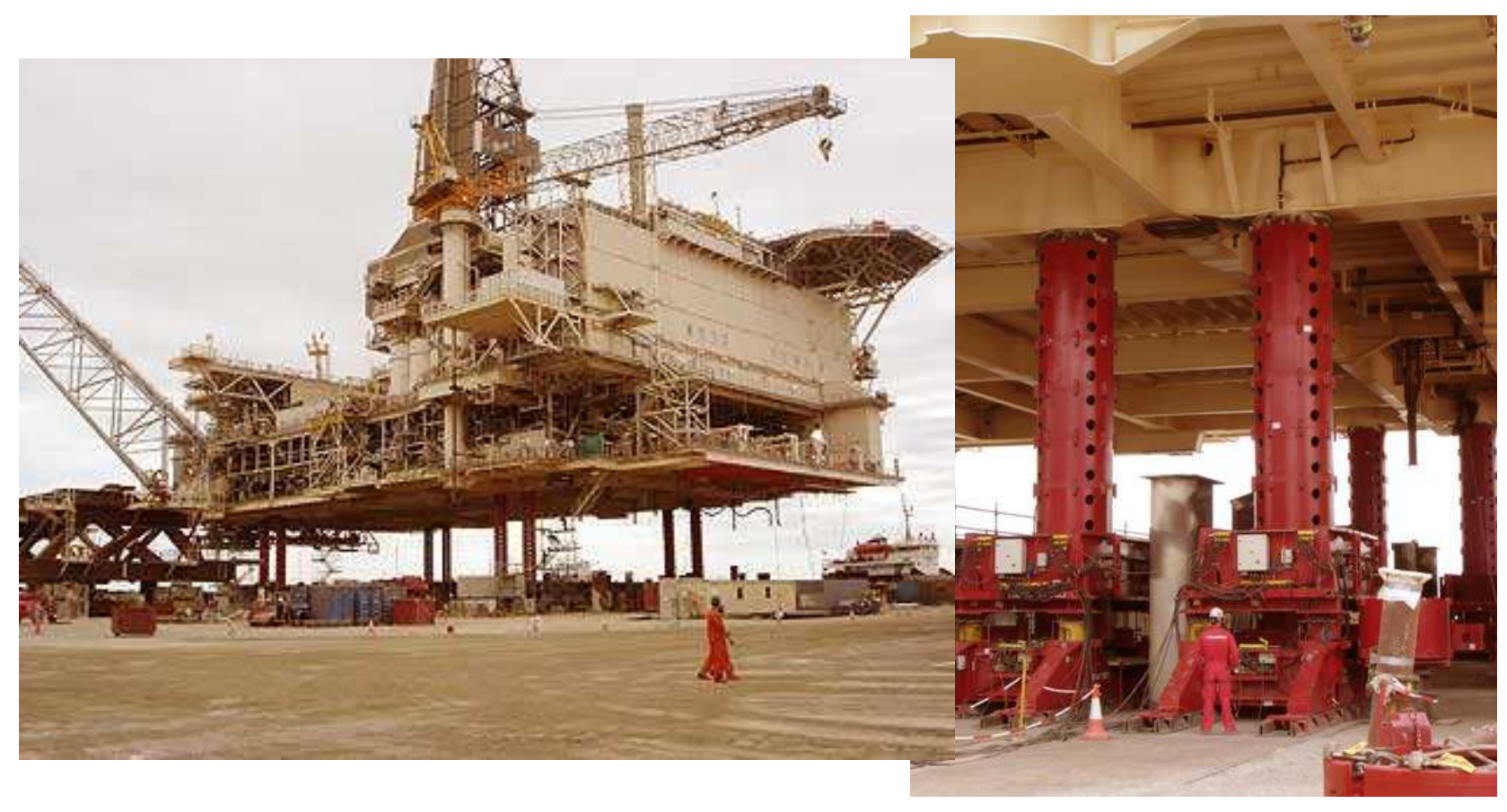

Figura 4.23: Sistema de empuje para izar una plataforma Offhore de 14.000 toneladas (aprox.) unos 12 metros de altura usando patines de deslizamiento. 


\section{6.- MOTIVACIONES Y DESMOTIVACIONES ECONÓMICAS DE LAS INNOVACIONES.}

\subsection{1.- Márgenes y riesgos comerciales de las innovaciones.}

La motivación para una empresa para realizar las numerosas innovaciones que se han estudiado suelen ser los importantes márgenes que se pueden obtener al desarrollar nuevas máquinas y sistemas de elevación. Lógicamente, la competencia acaba sacando una máquina similar al mercado al cabo de un tiempo y los márgenes se van reduciendo con el tiempo pero además de dichos márgenes, queda la reputación ganada con los clientes por las posibilidades de soluciones técnicas desarrolladas.

Sin embargo, cuando una empresa innova suele necesitar realizar importantes inversiones con sus propios recursos financieros y no siempre el resultado tiene éxito en el mercado. En el caso en las que las innovaciones respondan a una necesidad ya existente y concreta del mercado, el porcentaje de posibilidades de fracaso se reduce pero sin embargo es bastante alto cuando se innova sin que exista ya la demanda ya que si la empresa no es capaz de crear dicha demanda del producto (independientemente que este sea muy bueno) se puede producir un fracaso comercial que significa la pérdida de lo invertido.

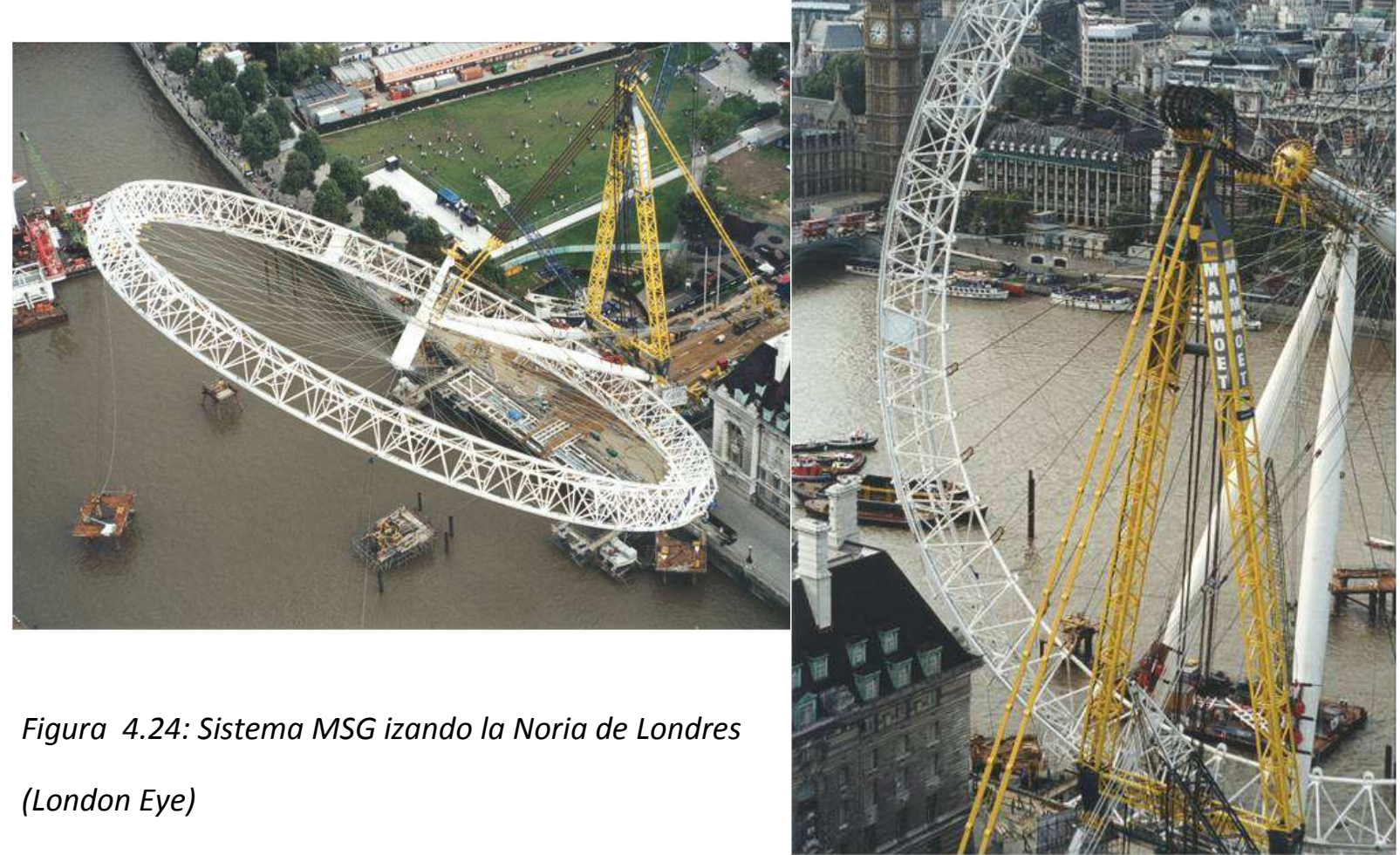




\subsection{2.- "Canibalizaciones" de productos existentes. Barreras de entrada.}

Hay también frenos importantes para las empresas a la hora de desarrollar nuevas máquinas o sistemas de elevación como pueden ser:

- Las "canibalizaciones" de productos existentes: Si la empresa está amortizando grúas ya compradas hace no mucho tiempo y sale al mercado un modelo mejor y más eficiente, se puede encontrar en la situación en la que los clientes prefieren usar los nuevos modelos en lugar de las máquinas que todavía no están amortizadas y $\sin$ embargo se han quedado obsoletas. Los fabricantes pueden de esta forma causar un gran perjuicio a sus clientes que principalmente son empresas de grúas.

- Reducción o destrucción de barreras de entrada: Otro freno a la innovación puede ser cuando el nuevo producto es tan bueno que resulta enormemente más barato que el existente y no difícil de copiar o de construir similar. Empezar una empresa de grúas tiene unas importantes barreras de entrada y una de las más importantes es el capital necesario para poder tener una flota relevante de máquinas ya que estas son muy caras. Si se consigue mejorar un determinado tipo de maniobra consiguiendo hacerla con un nuevo sistema mucho más barato, se facilita la entrada de nuevos posibles competidores a un sector en el que no hay muchas empresas precisamente por las importantes barreras de entrada existentes.

\subsection{3.- Cambio del "producto" ofrecido: del "alquiler" de una grúa a la "solución" de} un proyecto.

La gran cantidad de innovaciones que se han producido en los últimos años significan un esfuerzo enorme de ingeniería dedicada a dicho fin pero también un aumento en la ingeniería de proyectos para utilizar adecuadamente todos estos equipos. La complejidad de las máquinas aumenta, y el personal tanto de ingeniería como de ejecución tiene que estar más preparado. Las empresas del sector van transformándose de ser meros alquiladores de maquinaria sin prácticamente "Know how" interno en la empresa a ser empresas con potentes ingeniería y jefes de proyecto preparados no sólo capaces de ejecutar proyectos complejos sino también de diseñarse incluso sus propias máquinas que antes compraban siempre a los fabricantes. 


\section{ANÁLISIS COMPARATIVO TÉCNICO FINANCIERO.}

Es necesario realizar un análisis económico financiero comparativo de distintas grúas de diferentes tipologías para establecer la relación que existe entre la capacidad de las grúas, la tipología y los costes de dichas máquinas. Para empezar este análisis es importante elegir los parámetros a utilizar para lograr que los resultados nos den la información realmente buscada.

\section{1.- INTRODUCCIÓN}

Como se ha explicado anteriormente, el tonelaje de una grúa que frecuentemente se utiliza como nombre de la misma o como definición de su capacidad es una medida un tanto engañosa de la capacidad real de uso de la máquina en circunstancias reales. Además, es usado inadecuadamente como herramienta de marketing lo cual exagera aún más su inadecuación para ser la medida real óptima para definir la capacidad de una grúa.

Efectivamente, la capacidad nominal suele ser la máxima que tiene la grúa en sus tablas a radio mínimo y con una configuración de pluma muy limitada. Esta no es la forma de trabajo habitual de la máquina pero podría ser una buena referencia si estuviese relacionada de alguna manera "razonable" (o proporcional) con el resto de valores de la tabla de capacidades. Si bien es cierto que el tonelaje máximo a radio corto nos da una cierta idea de la capacidad de la grúa, nos encontramos frecuentemente con grúas en las que el tonelaje a un radio medio o alto no tiene relación "lógica" con el tonelaje a radio corto si comparamos las tablas de distintas máquinas como vamos a hacer en este capítulo (aunque tampoco sea este nuestro objetivo principal aquí).

Este problema viene como hemos dicho del hecho que a radios medios o altos, la capacidad de la grúa viene limitada por el vuelco de la máquina mientras que a radio corto la limitación es por rotura (ver punto apartado 1.5)

No sólo no hay una relación de proporcionalidad entre estos dos tipos de limitaciones de las grúas sino que resultan incluso contradictorios. Por ejemplo: si queremos incrementar la 
capacidad de una grúa de celosía a radio corto, puede ser necesario reforzar la capacidad a compresión de la pluma. Esto significa probablemente más acero y por lo tanto más peso propio de la pluma. Al abatir la pluma para trabajar a radios largo nos encontramos lógicamente con que el peso propio de la pluma se suma al momento de vuelco de la carga reduciendo así la capacidad de la grúa a partir de radios medios.

De esta forma, dos grúas de la misma tipología y muy parecida capacidad nominal, pueden dar capacidades a radios importantes que no guardan proporción ni lógica con su capacidad nominal.

Para ilustrar lo anterior con un ejemplo de los muchos que podemos encontrar con incongruencias al comparar tablas de grúas, vamos a ver el caso de la LR1750 y LR1600 que son dos grúas de la misma tipología (celosía sobre cadenas) e incluso de la misma marca (Liebherr):

LR1600/2 con 90m de pluma principal y contrapeso superlift a 80 metros de radio: 77,1 toneladas de capacidad según las tablas oficiales.

LR1750/2 Con 91m de pluma principal y contrapeso superlift a 80 metros de radio: 63,4 toneladas de capacidad según las tablas oficiales.

Al ser ambas grúas de Liebherr, sus capacidades nominales son $600 t$ y $750 t$ respectivamente con lo cual sería de esperar que la de mayor capacidad nominal diera más capacidad de carga en cualquier zona de la tabla sobre todo existiendo una diferencia de $150 t$ de capacidad nominal entre ambas que es notable.

Este ejemplo anterior compara grúas de la misma tipología (celosía sobre cadenas), pero si extendemos esta comparación a grúas de distinta tipología como pueden ser una celosía y una telescópica, la diferencia resulta aun más chocante.

LR1200: capacidad máxima a 30 metros de radio: 25,2t

Capacidad máxima a 80 metros de radio: $4,5 \mathrm{t}$

LTM1200: capacidad máxima a 30 metros de radio: $16,6 \mathrm{t}$

Capacidad máxima a 80 metros de radio: $1,3 \mathrm{t}$ 
Comparando esta vez una grúa celosía sobre cadenas con una telescópica sobre camión ambas de 200t nominales y de la misma marca vemos que como era de esperar debido a las tipologías, según aumenta el radio, la grúa celosía da capacidades de carga muy superiores a la telescópica. Para valores de radio medios como $30 \mathrm{~m}$ la celosía ya da $50 \%$ más de capacidad y para radio muy alto de 80 metros la capacidad es más del triple.

A esto hay que añadir que esta comparación se ha hecho sin contrapesos superlift que son más frecuentes en las celosías por lo que en podría haber sido aun mucho mayor la diferencia en caso de comparar grúas mayores con dichos contrapesos disponibles.

Esto es lógico desde un punto de vista técnico ya que la tipología de las grúas de este último ejemplo es diferente y en las grúas telescópicas la capacidad a radio se pierde mucho más rápidamente que en la grúas de celosía (peso propio de la pluma diferente, geometría distinta, etc.)

Por último, otro factor que puede distorsionar también la relación entre la capacidad a radio corto (capacidad "oficial" de la grúa) y a radio alto de las grúas y que no depende ni de la tipología ni de consideraciones puramente técnicas es la tentación de cara al marketing de la máquina de tener una capacidad "oficial" alta ya que a fin de cuentas es la característica con la que se comercializa una grúa. Se pueden diseñar configuraciones con mucha capacidad a radio corto que luego ni siquiera se vendan en la realidad ya que no tienen una utilidad práctica en las obras pero al existir le dan una capacidad nominal a la grúa más elevada de la que se podría esperar del resto de los valores de sus tablas.

Por los motivos anteriormente expuestos, no vamos a limitarnos en el siguiente análisis a la capacidad nominal de la grúa que es el valor habitual considerado en todo el mundo sino que usaremos también el momento de vuelco en tonelada.metro lo cual nos servirá también para comprobar con resultados lo expuesto anteriormente tal y como se ha explicado anteriormente en la metodología. 
Los parámetros que vamos a utilizar según la metodología son los siguientes:

Con respecto a los valores de la tabla de la grúa a considerar:

- Radio mínimo (Rmin): Radio mínimo de la grúa.

- Toneladas de capacidad a radio mínimo (Tmin)

- Radio máximo (Rmax): Radio máximo al que puede trabajar la grúa.

- Toneladas de capacidad a radio máximo (Tmax)

- Radio 30 metros (R30): Radio 30 metros de la grúa.

- Toneladas de capacidad a radio 30m (T30)

- Momento máximo de la grúa (MLM: "Maximum Load Moment”)

Para la obtención de estos valores se consultarán las tablas oficiales de cada una de las grúas seleccionadas. En varios casos hay que buscar y comparar configuraciones ya que según los distintos montajes de la grúa, se pueden obtener mejores o peores capacidades a radio 30 metros o radios máximos de trabajo.

En el caso del MLM hay pocas grúas que proporcionen directamente este valor a los usuarios y será necesario analizar la tabla de capacidades de la grúa para obtener la configuración y radio al que la grúa trabaja con un momento de vuelco máximo y por supuesto obtener este valor de momento.

Con los datos anteriores obtendremos:

- El momento a radio mínimo (Mrmin)

- El momento a radio máximo (Mrmax)

- El momento a radio 30m (Mr30) 


\section{2.- ANALISIS TÉCNICO DE DIVERSAS GRÚAS}

Para este análisis económico financiero, se han seleccionado grúas de distintos tamaños y tipologías tal y como se ha descrito y justificado en la metodología.

Para cada una de estas nueve grúas se van a analizar a continuación sus características y tablas de capacidades para obtener los parámetros y valores que se necesitan para este estudio.

Se empezará por las grúas de celosía, luego las telescópicas y por último las grúas torre. Dentro de cada tipología se analizarán de mayor a menor. 


\subsection{1.- Grúa LR11350:}

Grúa de celosía sobre cadenas de la marca Liebherr de 1.350 toneladas de capacidad nominal. Se adjunta el diagrama con pluma principal y superlift de la página 33 de las tablas de la grúa:

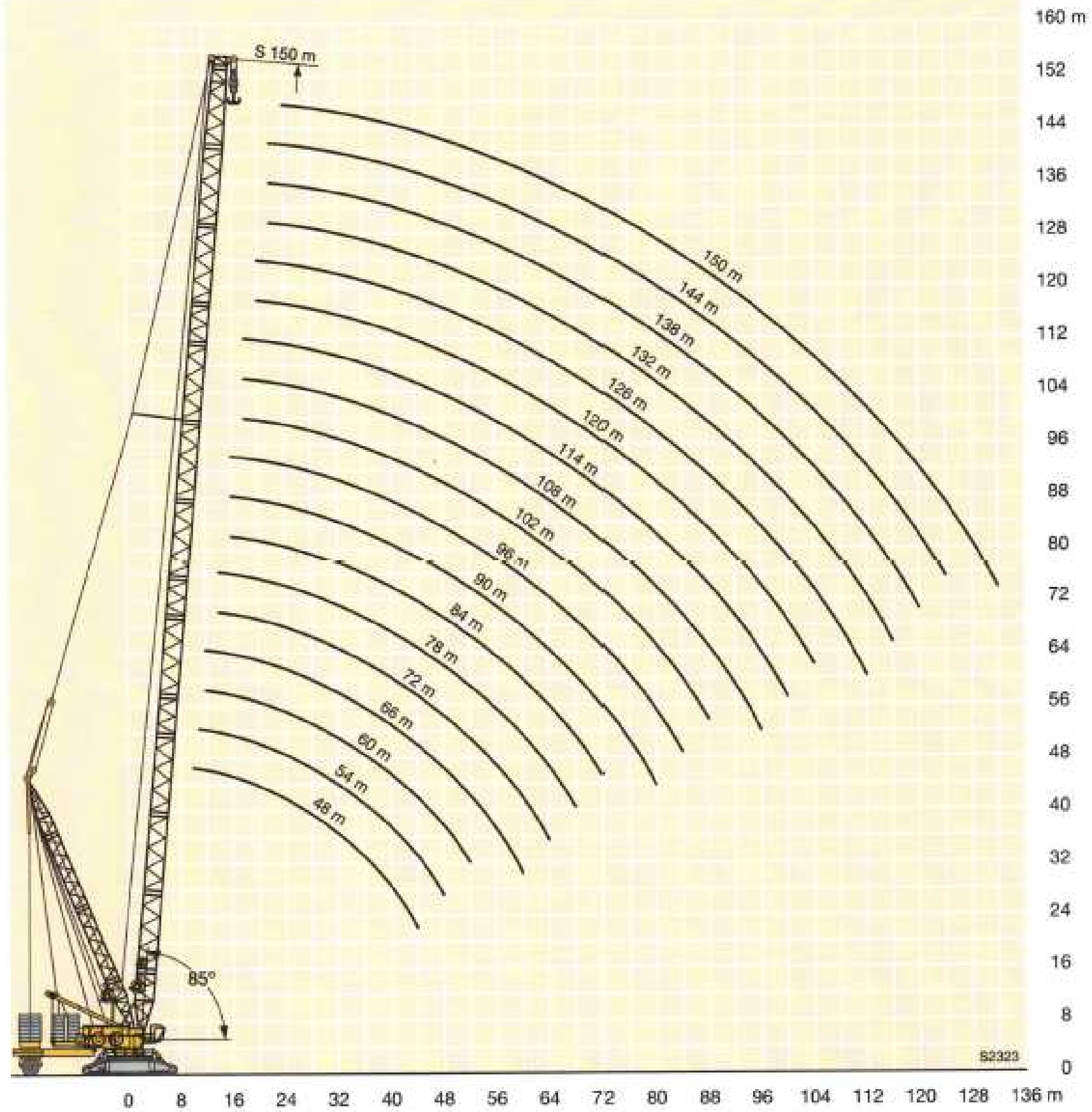

Figura 5.1: Extracto de la parte superior de la página no 33 de las tablas oficiales de la grúa LR11350 mostrando el gráfico de la misma 
Según obtenemos en el siguiente extracto de la tabla de la grúa LR11350 (página 34 de las tablas oficiales de Liebherr), el radio de trabajo de dicha máquina para su capacidad nominal es de 12 metros y con una pluma principal de 60 metros de longitud, la capacidad de la grúa es de 1.350 toneladas en configuración SDBW2 (con pluma principal y superlift ver página no 21 para las configuraciones de la grúa). En esta grúa se da el caso no habitual de no coincidir la máxima capacidad de la grúa con el radio mínimo de posible trabajo de la máquina. Efectivamente, el radio de trabajo más corto que se puede encontrar en las tablas es de 8 metros pero en esos radios cortos no alcanza la capacidad máxima.

A efectos de este estudio y por homogeneidad con las otras máquinas tomaremos como valores de radios y capacidades mínimos los correspondientes a la capacidad nominal aunque la grúa sea capaz de izar a radios algo inferiores.

El momento que obtenemos por tanto a radio mínimo es de:

MomRmin $=1.350 \times 12=16.200 \mathrm{~m} . \mathrm{t}$

SDBW2

$548-78$

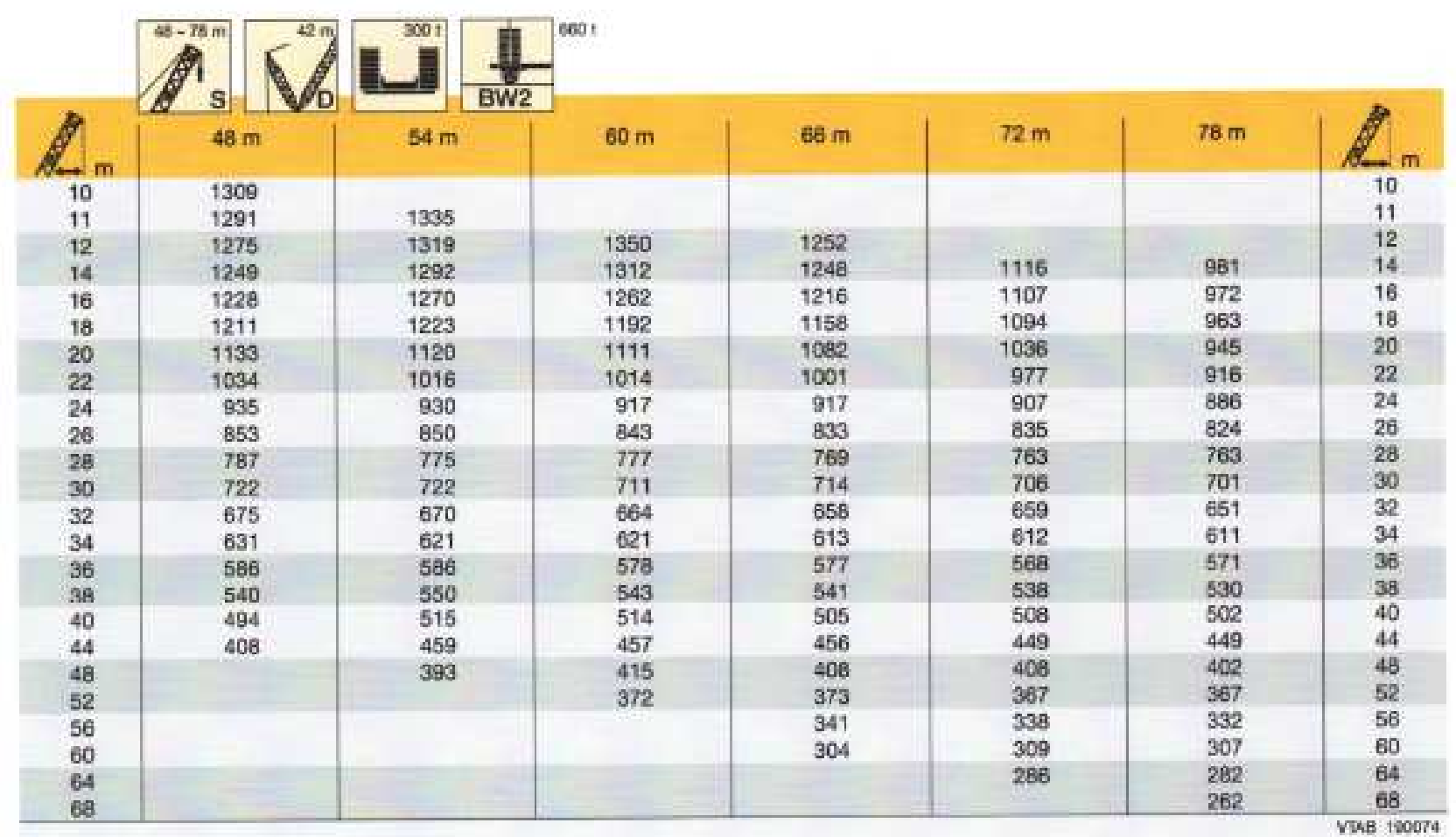

Figura 5.2: Extracto de la página no 34 de las tablas oficiales de la grúa LR11350 
Procedemos de la misma manera para el radio máximo:

En la página no 32 hayamos la configuración que nos permite trabajar a 132 metros de radio con una capacidad de 70 toneladas como se puede observar en el siguiente extracto de la tabla:

\section{SD/SDB/B2/BW}

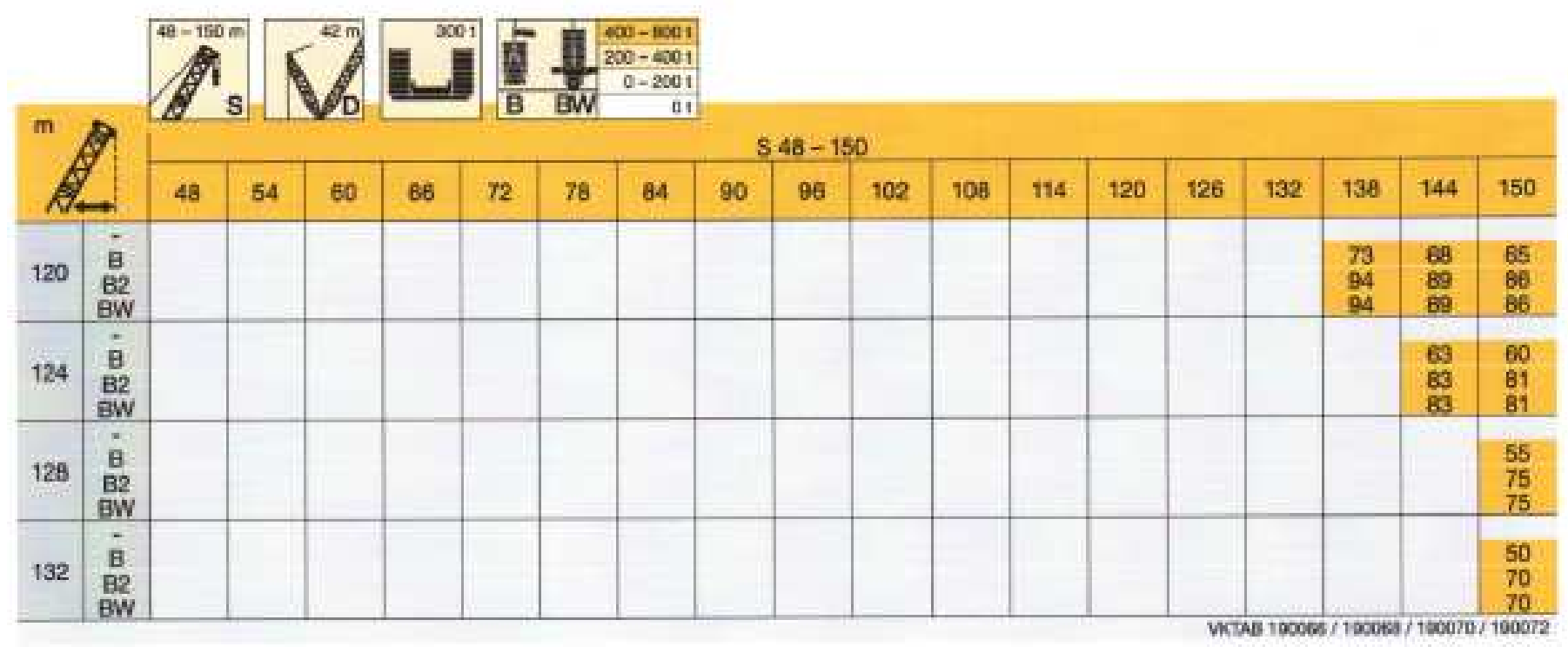

Figura 5.3: Extracto de la página no 32 de las tablas oficiales de la grúa LR11350

En este caso en momento será:

MomRmax $=70 \times 132=9.240$ m.t

Para un radio de 30 metros, se tiene la máxima capacidad con pluma de 48 metros de longitud y configuración SDBW (pluma principal con superlift). Como se puede ver en la siguiente tabla de la página 25, dicha capacidad es de 728 toneladas: 


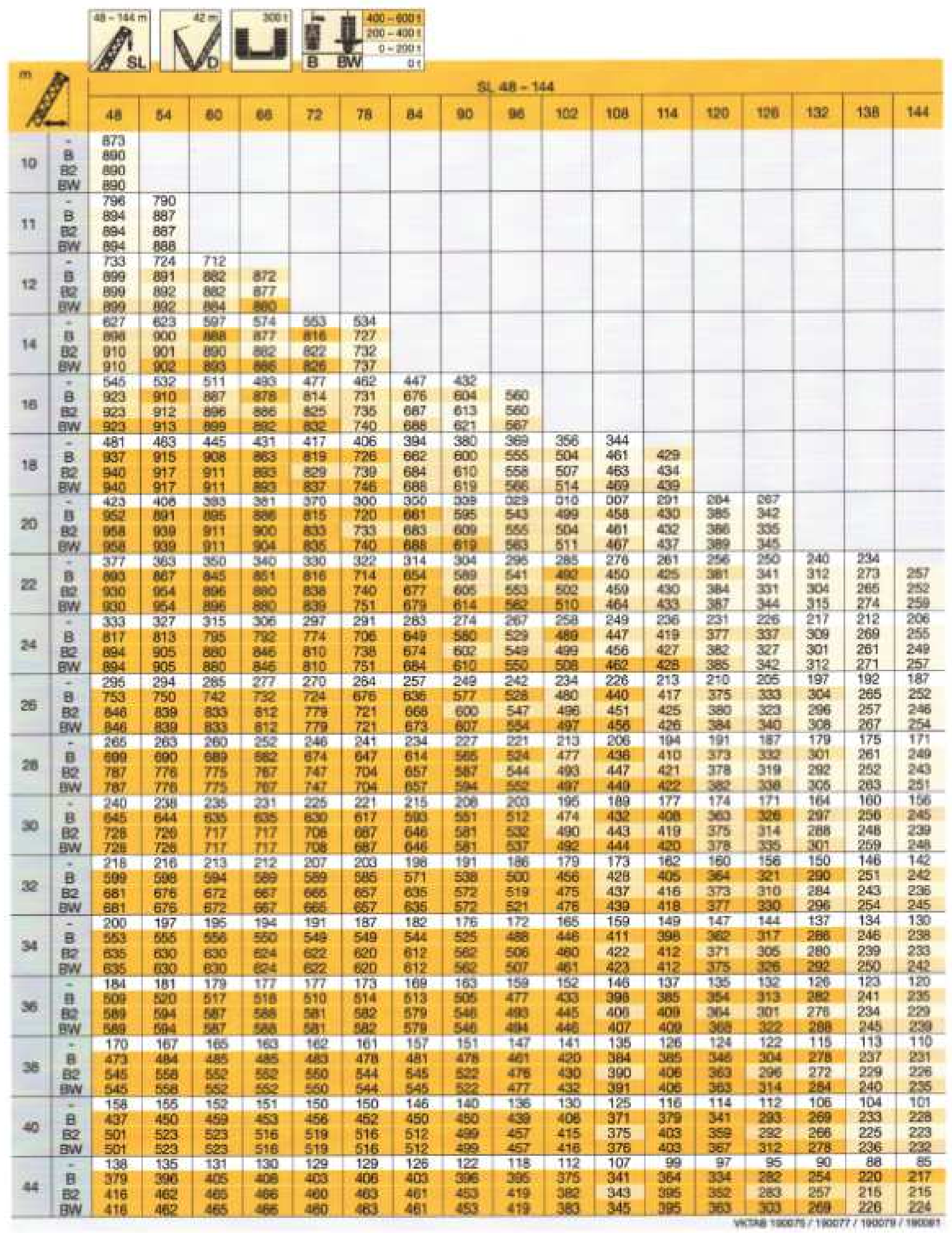

Figura 5.4: Extracto de la página no 25 de las tablas oficiales de la grúa LR11350 
En este caso en momento será:

MomR30 $=30 \times 728=21.840 \mathrm{~m} . \mathrm{t}$

El momento Máximo de la grúa LR11350 que nos da el fabricante es de 22.748 m.t (1034 t a $22 \mathrm{~m}$ ) que como vemos es algo superior aunque bastante similar al obtenido para radio $=30$ metros.

Vemos por lo tanto que esta grúa celosía sobre cadenas no tiene su máximo momento (MLM) a radio mínimo ni máximo sino a radios medios pero de cierta magnitud. 
Los resultados de capacidades obtenidos para la grúa LR11350 se resumen en la siguiente tabla:

\begin{tabular}{|c|c|}
\hline & $\begin{array}{l}\text { Grúa Celosía } \\
\text { LR11350 }\end{array}$ \\
\hline Radio minimo & 12,00 \\
\hline ton a Rmin & $1.350,00$ \\
\hline Radio máximo & 132,00 \\
\hline ton a Rmax & 70,00 \\
\hline Radio 30 & 30,00 \\
\hline ton a R30 & 728,00 \\
\hline Mom Rmin & $16.200,00$ \\
\hline Mom R30 & $21.840,00$ \\
\hline Mom Rmax & $9.240,00$ \\
\hline Max load moment & $22.748,00$ \\
\hline
\end{tabular}

Figura 5.5: Tabla resumen de resultados técnicos obtenidos para la grúa LR11350 


\subsection{2.- Grúa CC2800-1}

Grúa de celosía sobre cadenas de la marca Terex (antigua Demag) de 600 toneladas de capacidad nominal tal y como indica el fabricante en la página 1 de las tablas de la grúa:

\section{⿴囗十 TEREX}

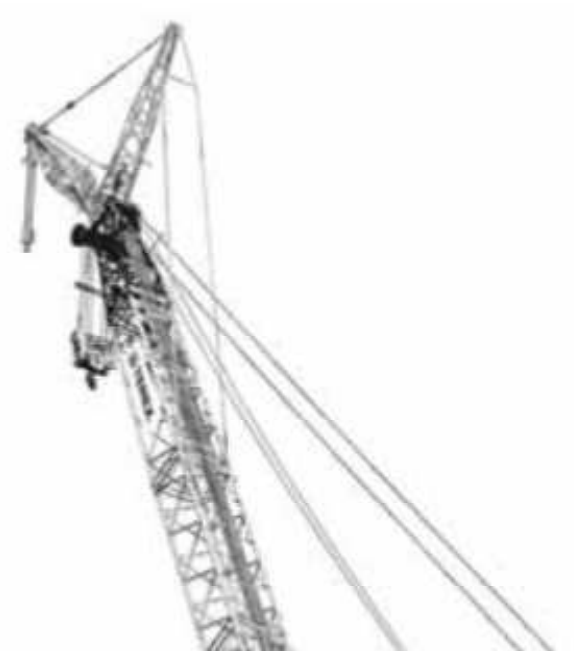

CC 2800-1

Crawler Crane

$600 t$ capacity

Datasheet metric

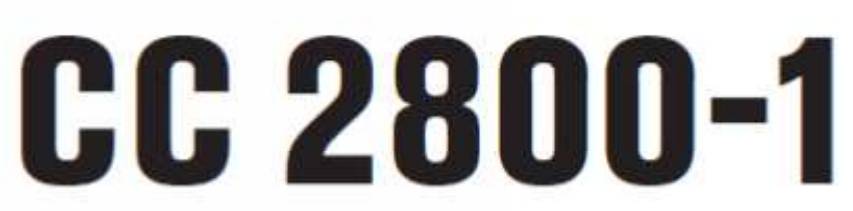

Figura 5.6: Extracto de la parte superior de la página no1 de las tablas oficiales de la grúa CC2800-1

Según obtenemos en el siguiente extracto de la tabla de la grúa CC2800-1 (página 14 de las tablas oficiales de Terex), el radio mínimo de trabajo de dicha máquina es de 6 metros y con una pluma principal de 24 metros de longitud, la capacidad de la grúa es de 600 toneladas en configuración SH (con pluma principal ver página no 10 para las configuraciones de la grúa).

Corresponde lógicamente la capacidad a radio mínimo de la máquina (600t.) con la capacidad nominal oficial con la que el fabricante define la grúa en el inicio del catálogo de características y tablas de la máquina. 
El momento que obtenemos por tanto a radio mínimo es de:

MomRmin $=600 \times 6=3.600 \mathrm{~m} . \mathrm{t}$

SH

CC 2800-1

\begin{tabular}{|c|c|c|c|c|c|c|c|c|c|c|c|c|}
\hline E & $180 t+60 t 2 B$ & & En & $8,40 \mathrm{r}$ & & 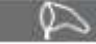 & $9.8 \mathrm{~m} / \mathrm{s}$ & & $360^{\circ}$ & & EN130 & ISO \\
\hline (ણ) & $24,0 \mathrm{~m}$ & $30,0 \mathrm{~m}$ & $36,0 \mathrm{~m}$ & $42,0 \mathrm{~m}$ & $48,0 \mathrm{~m}$ & $54,0 \mathrm{~m}$ & $60,0 \mathrm{~m}$ & $66,0 \mathrm{~m}$ & $72,0 \mathrm{~m}$ & $78,0 \mathrm{~m}$ & $84,0 \mathrm{~m}$ & to \\
\hline $\mathrm{m}$ & $t$ & $t$ & $t$ & $t$ & $t$ & $t$ & $t$ & $t$ & $t$ & $t$ & $t$ & $\mathrm{~m}$ \\
\hline 6 & 600,0 & - & - & - & - & - & - & - & - & - & - & 6 \\
\hline 7 & 561,0 & 554,0 & 567,0 & - & - & - & $\cdot$ & - & - & - & $\cdot$ & 7 \\
\hline 8 & 506,0 & 502,0 & 499,0 & 496,0 & 494,0 & . & . & - & . & - & - & 8 \\
\hline 9 & 410,0 & 408,0 & 407,0 & 406.0 & 405,0 & 404,0 & 404,0 & - & - & - & $\cdot$ & 9 \\
\hline 10 & 337,0 & 335,0 & 334,0 & 332,0 & 331.0 & 330,0 & 330,0 & 329.0 & 301,0 & - & - & 10 \\
\hline 12 & 247,0 & 245,0 & 243,0 & 241,0 & 240,0 & 239,0 & 239,0 & 238,0 & 237,0 & 236,0 & 212,0 & 12 \\
\hline 14 & 193,0 & 191,0 & 190,0 & 188.0 & 186,0 & 185,0 & 185,0 & 184,0 & 183,0 & 182,0 & 181,0 & 14 \\
\hline 16 & 158,0 & 156,0 & 154,0 & 152,0 & 151,0 & 150,0 & 149,0 & 148,0 & 147,0 & 147,0 & 145,0 & 16 \\
\hline 18 & 133,0 & 131,0 & 129,0 & 127,0 & 126,0 & 125,0 & 124,0 & 123,0 & 122,0 & 121,0 & 120,0 & 18 \\
\hline 20 & 115,0 & 113,0 & 111,0 & 109,0 & 107,0 & 106,0 & 105,0 & 104,0 & 103,0 & 102,0 & 101,0 & 20 \\
\hline 22 & 101,0 & 98,5 & 96,5 & 94,5 & 93,0 & 91,5 & 90,5 & 89,5 & 88,5 & 88,0 & 86,0 & 22 \\
\hline 24 & - & 87,5 & 85,0 & 83,0 & 81,5 & 80,0 & 79,0 & 78,0 & 77.0 & 76,0 & 74,5 & 24 \\
\hline 26 & - & 78,0 & 76,0 & 73,5 & 72,0 & 70,5 & 69,5 & 68,5 & 67,5 & 66,5 & 65,0 & 26 \\
\hline 28 & - & 70,5 & 68,0 & 66,0 & 64,0 & 63,0 & 61,5 & 60,5 & 59,5 & 58,5 & 57,0 & 28 \\
\hline ח & & & & & & & & & & & & \\
\hline
\end{tabular}

Figura 5.7: Extracto de la página no 14 de las tablas oficiales de la grúa CC2800-1

Procedemos de la misma manera para el radio máximo:

En la página no 53 hayamos la configuración que nos permite trabajar a 142 metros de radio con una capacidad de 4 toneladas como se puede observar en el siguiente extracto de la tabla:

\begin{tabular}{|lccccccc|}
110 & - & - & - & 29,5 & 24,2 & 23,0 & - \\
\hline 114 & - & - & - & 27,9 & 22,7 & 21,0 & - \\
118 & - & - & - & - & 21,3 & 19,0 & - \\
\hline 122 & - & - & - & - & 20,1 & 16,0 & - \\
124 & - & - & - & - & 19,5 & 15,0 & - \\
\hline 126 & - & - & - & - & - & 14,0 & - \\
130 & - & - & - & - & - & 11,0 & - \\
134 & - & - & - & - & - & 8,0 & - \\
138 & - & - & - & - & - & 6,0 & - \\
142 & - & - & - & - & - & 4,0 & - \\
\hline
\end{tabular}

Figura 5.8: Extracto de la página no 53 de las tablas oficiales de la grúa CC2800-1 
En este caso en momento será:

MomRmax $=4 \times 142=568 \mathrm{~m} \cdot \mathrm{t}$

Para un radio de 30 metros, se tiene la máxima capacidad con pluma de 54 metros de longitud y configuración SSL (pluma principal con superlift colocado a $17 \mathrm{~m}$ de distancia). Como se puede ver en la siguiente tabla, dicha capacidad es de 239 toneladas:

\begin{tabular}{|c|c|c|c|c|c|c|c|c|c|c|c|c|c|c|c|c|}
\hline & $180 t+6$ & t $2 B$ & & 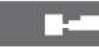 & & $40 \mathrm{~m}$ & & & 9.8 & $1 / s$ & & $360^{\circ}$ & & EN1 & 13000 & / ISO \\
\hline & & SSL & & HSSLS7] & 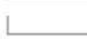 & SSL & 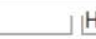 & HSSLS7] & & SSL & & HSSL_S7 & & SSL & & HSSL_S7 \\
\hline () & $11-15$ & $5 \mathrm{~m}$ & $17 \mathrm{~m}\lrcorner \mathrm{L}^{1}$ & $11-15 \mathrm{~m}$ & $11-1$ & $5 \mathrm{~m}$ & $17 \mathrm{~m}$ & $11-15 \mathrm{~m}$ & $11-1$ & $5 \mathrm{~m}$ & $17 \mathrm{~m} \sqcup \mathrm{L}^{1}$ & $11-15 \mathrm{~m}$ & & $15 \mathrm{~m}$ & $17 \mathrm{~m}$ & $11-15 m$ \\
\hline $\mathrm{m}$ & $t$ & $t$ & $t$ & $t$ & $\mathrm{t}$ & $t$ & $t$ & $\mathrm{t}$ & $t$ & $t$ & $t$ & $t$ & $t$ & $t$ & $t$ & $t$ \\
\hline 10 & 358,0 & 599,0 & 599,0 & - & 356,0 & 593,0 & 593,0 & - & 355,0 & 580,0 & 580,0 & - & 354,0 & 525,0 & 525,0 & 525,0 \\
\hline 12 & 261,0 & 583,0 & 583,0 & - & 259,0 & 574,0 & 574,0 & - & 258,0 & 580,0 & 580,0 & - & 257,0 & 525,0 & 525,0 & 525,0 \\
\hline 14 & 204,0 & 519,0 & 549,0 & $\cdot$ & 202,0 & 516,0 & 534,0 & $\cdot$ & 201,0 & 514,0 & 532,0 & $\cdot$ & 200,0 & 512,0 & 525,0 & 511,0 \\
\hline 16 & 166,0 & 454,0 & 482,0 & - & 165,0 & 451,0 & 479,0 & - & 163,0 & 449,0 & 477,0 & - & 162,0 & 448,0 & 475,0 & 446,0 \\
\hline 18 & 140,0 & 403,0 & 428,0 & - & 138,0 & 401,0 & 426,0 & - & 136,0 & 399,0 & 423,0 & - & 135,0 & 397,0 & 422,0 & 396,0 \\
\hline 20 & 120,0 & 363,0 & 371,0 & - & 118,0 & 360,0 & 382,0 & - & 116,0 & 358,0 & 380,0 & - & 115,0 & 356,0 & 378,0 & 355,0 \\
\hline 30 & 67,5 & 203,0 & 196,0 & - & 65,5 & 220,0 & 220,0 & - & 63,5 & 226,0 & 234,0 & - & 62,5 & 224,0 & 239,0 & 224,0 \\
\hline 34 & - & $\cdot$ & $\cdot$ & - & 54,5 & 180,0 & 178,0 & - & 52,5 & 193,0 & 194,0 & - & 51,0 & 192,0 & 202,0 & 193,3 \\
\hline 38 & - & - & - & - & 46,8 & 149,0 & 143,0 & - & 44,6 & 161,0 & 161,0 & - & 43,0 & 167,0 & 171,0 & 166,3 \\
\hline 42 & - & - & - & - & - & - & - & - & 38,4 & 137,0 & 133,0 & - & 36,5 & 146,0 & 146,0 & 143,0 \\
\hline 46 & - & - & - & - & - & - & - & - & - & - & - & - & 31,3 & 123,0 & 123,0 & 121,6 \\
\hline 49 & - & - & - & - & - & - & - & - & - & - & - & - & - & - & $\cdot$ & 110,0 \\
\hline
\end{tabular}

Figura 5.9: Extracto de la página no 17 de las tablas oficiales de la grúa CC2800-1

En este caso en momento será:

MomR30 $=30 \times 239=7.170 \mathrm{~m} . \mathrm{t}$

El momento Máximo de la grúa CC2800 que nos da el fabricante es de 7.710 m.t que como vemos es algo superior aunque bastante similar al obtenido para radio $=30$ metros

Vemos por lo tanto que esta grúa celosía sobre cadenas no tiene su máximo momento (MLM) a radio mínimo ni máximo sino a radios medios pero de cierta magnitud. 
Los resultados de capacidades obtenidos para la grúa CC2800 se resumen en la siguiente tabla:

\begin{tabular}{|c|c|}
\hline & $\begin{array}{l}\text { Grúa Celosía } \\
\text { CC2800 }\end{array}$ \\
\hline Radio minimo & 6,00 \\
\hline ton a Rmin & 600,00 \\
\hline Radio máximo & 142,00 \\
\hline ton a Rmax & 4,00 \\
\hline Radio 30 & 30,00 \\
\hline ton a R30 & 239,00 \\
\hline Mom Rmin & $3.600,00$ \\
\hline Mom R30 & $7.170,00$ \\
\hline Mom Rmax & 568,00 \\
\hline Max load moment & $7.710,00$ \\
\hline
\end{tabular}

Figura 5.10: Tabla resumen de resultados técnicos obtenidos para la grúa CC2800 


\subsection{3.- Grúa Sennebogen 2200E:}

Grúa de celosía sobre cadenas de la marca Sennebogen de 80 toneladas de capacidad nominal tal y como se observa en el diagrama de la grúa de la página $\mathrm{n}$-4 de sus tablas oficiales:

\section{크므 Kranausrüstung Crane Equipment}

\section{Hauptausleger}

Main boom

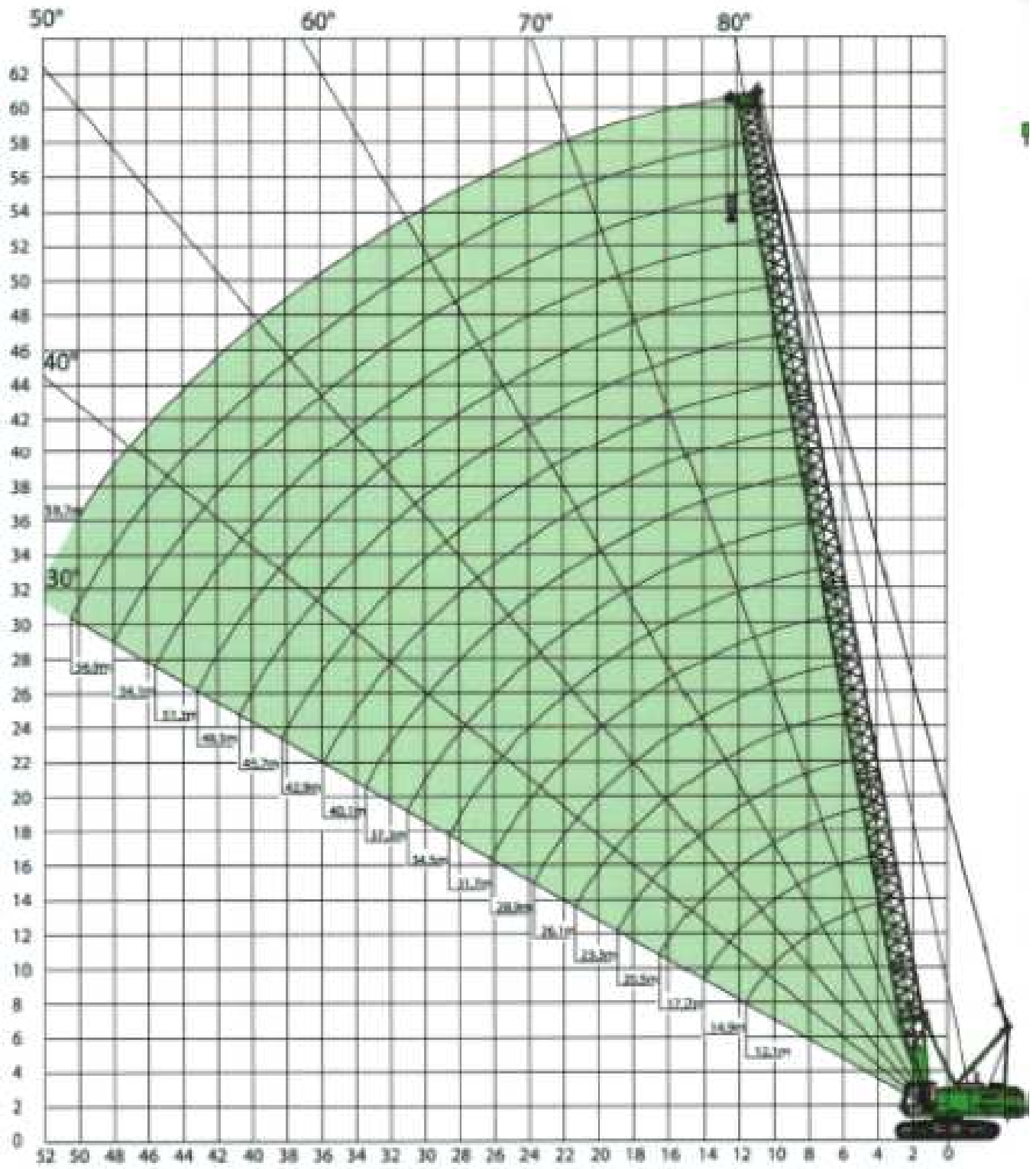

Figura 5.11: Diagrama de la grúa Sennebogen 2200E de la página no4 de las tablas oficiales de la grúa. 
Según obtenemos en el siguiente extracto de la tabla de la grúa 2200E (página 5 de las tablas oficiales de Sennebogen), el radio mínimo de trabajo de dicha máquina es de 4 metros y con una pluma principal de 12,1 metros de longitud, la capacidad de la grúa es de 80 toneladas en configuración de pluma principal.

Corresponde lógicamente la capacidad a radio mínimo de la máquina (80t.) con la capacidad nominal oficial con la que el fabricante define la grúa en el inicio del catálogo de características y tablas de la máquina.

El momento que obtenemos por tanto a radio mínimo es de:

MomRmin $=80 \times 4=320 \mathrm{~m} \cdot \mathrm{t}$

\begin{tabular}{|c|c|c|c|c|c|c|c|c|c|c|c|c|c|c|c|c|c|c|}
\hline 25: & \multicolumn{18}{|c|}{ Auslegertange $/$ boom length $[\mathrm{m}]$} \\
\hline $\begin{array}{l}\text { Ausladung } \\
\text { radivas imi }\end{array}$ & 12,1 & 14,9 & 11,1 & 20,5 & 24.1 & 26,1 & 289 & 31, & 34.5 & 37,3 & 40,1 & 42,9 & [45:7] & 40,5 & 51,1 & 54,1 & 559 & 59,7 \\
\hline 4,0 & 00.0 & $\mathrm{w}^{\prime}$ & & & & & & & & & & & & & & & & \\
\hline 5.0 & 640 & 60.0 & 582 & \%श & & & & & & & & & & & & & & \\
\hline 6.0 & 49.5 & 47,6 & 46,7 & 44,8 & 43.0 & गृ? & & & & & & & & & & & & \\
\hline 20 & 388 & 38.8 & 387 & 32 & 361 & 35,0 & 339 & $x+1$ & & & & & & & & & & \\
\hline 8.0 & 318 & 3,8 & 31.7 & 3.6 & 3.1. & 30.0 & 283 & 28.4 & 263 & $4{ }^{2}$ & & & & & & & & \\
\hline 2.0 & 269 & 25,8 & 26.8 & 26,7 & 26.5 & 26.5 & 25.8 & 25.0 & 242 & 23.6 & 222 & 78 & $7 W$ & & & & & \\
\hline 10.0 & 23.3 & 23.2 & 23,1 & 23,0 & 229 & 22.8 & 22.8 & 22,3 & 21,7 & 21,1 & 20.8 & 20.0 & 190 & 92 & $\mathrm{~g}$ & & & \\
\hline 110 & 20.4 & 20.3 & 203 & 20.2 & 200 & 19.9 & 200 & 198 & 195 & 190 & 10.6 & 181 & 126 & 121 & 167 & 12 & $4 h$ & \\
\hline 120 & te.2 & 10.1 & 10.0 & 12.9 & 170 & 127 & 12 & 17,6 & 124 & 113 & 16.9 & 16,5 & 16.0 & 15.6 & 15.2 & 14.0 & 14.5 & 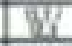 \\
\hline 13.0 & 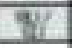 & 16,2 & 16.2 & 16,0 & 159 & 15,8 & 15.8 & 15,7 & 15.6 & 15,4 & 15.4 & 15.1 & 147 & 14,3 & 140 & 13.5 & 13.2 & 129 \\
\hline 14.0 & & 14.7 & 14.5 & 14.5 & 144 & 14,3 & 14.3 & 14,2 & 14.0 & 13,9 & 13.9 & 13,8 & 13.5 & 13,3 & 12.8 & 12.5 & 12.2 & 11.9 \\
\hline 150 & & 81 & 133 & 13.2 & 131 & 13.0 & 13.0 & 129 & 127 & 12.6 & 12.6 & 12.5 & 123 & 121 & 118 & 11.5 & $\pi 12$ & 10 \\
\hline 50 & & & 122 & 12.1 & 120 & 11.9 & 11.9 & $\pi, 7$ & $\pi 5$ & $\pi .5$ & 11.5 & $\pi 3$ & 112 & 111 & 110 & 10,7 & 10.4 & 101 \\
\hline$n, 0$ & & & $W$ & 11.2 & 1100 & 10.9 & 109 & 109 & 107 & 10.5 & 10.5 & 10.4 & 103 & 10.1 & 10.0 & 29 & 9.5 & 24 \\
\hline 13,0 & & & & 10,3 & 10.2 & 1001 & 10.1 & 9.9 & 9.8 & 9.7 & 9.7 & 9.5 & 9,4 & 9.3 & 9.2 & 9.2 & 9,0 & 8,7 \\
\hline 120 & & & & 86 & 9.5 & 9.3 & 9.3 & 9.2 & 21 & 8.9 & 8.9 & 8.8 & 8.1 & 85 & 8.4 & 8.4 & 8.3 & 81 \\
\hline 20.0 & & & & 13 & 8.8 & 8.7 & 8.7 & 8.5 & 8.4 & 8.3 & 8.3 & 8.1 & 8.0 & 29 & 78 & $n$ & 26 & 2.5 \\
\hline $\boldsymbol{n} 0$ & & & & & $\overline{l i k}$ & 26 & 76 & 74 & 73 & $\pi$ & $\pi$ & 10 & 6.9 & 6.7 & 63 & 6,6 & 6.5 & 6.4 \\
\hline 24,0 & & & & & & b. & हI & $b, 3$ & 6.4 & 6,2 & 62 & 5,1 & D.U. & 9.8 & 5.1 & 11 & 5,0 & 3,4 \\
\hline 25.0 & & & & & & 86 & 5.9 & 5,8 & 5.5 & 5.5 & 5.5 & 5.3 & 5.2 & 5.1 & 5,0 & 49 & 4.8 & 47 \\
\hline 22.0 & & & & & & & $\mathrm{X}$ & 5.2 & 5.0 & 49 & 4.8 & 4.7 & 4.6 & 44 & 4.3 & 4.3 & 42 & 40 \\
\hline 30.0 & & & & & & & & $\sqrt{6 h}$ & 45 & 4,3 & 43 & 4,2 & 4.0 & 2.9 & 38 & 17 & 16 & 1.5 \\
\hline 12,0 & & & & & & & & & 畋 & 3,9 & 3.8 & 3.7 & 3.5 & 3.4 & 3.3 & 2.3 & 3.1 & 10 \\
\hline 40 & & & & & & & & & & 146 & 34 & 3,3 & 13 & 3.0 & 29 & 2.8 & 27 & 2.5 \\
\hline 26.0 & & & & & & & & & & & 11 & 2.9 & 23 & 2.6 & 25 & 25 & 23 & 2,2 \\
\hline 280 & & & & & & & & & & & 84 & 26 & 25 & 23 & 22 & 22 & 20 & 19 \\
\hline 40,0 & & & & & & & & & & & & 35 & 22 & 2.0 & 19 & 19 & 1,7 & 1.6 \\
\hline 42.0 & & & & & & & & & & & & & 39 & 1.8 & 1.7 & 1.5 & 1.5 & 13 \\
\hline 44.0 & & & & & & & & & & & & & & If & 15 & 14 & 12 & u \\
\hline 46,0 & & & & & & & & & & & & & & & 13 & 12 & 1.0 & 0.9 \\
\hline 48,0 & & & & & & & & & & & & & & & & 10 & 0,8 & 0,7 \\
\hline 80,0 & & & & & & & & & & & & & & & & 9 & 0.7 & 0.5 \\
\hline 52.0 & & $T A B=1$ & No. 220 & $02-60$ & $217 / 2$ & $50 \%$ & $125 \mathrm{SH}$ & & & & & & & & & & $\overline{M 6}$ & \\
\hline $\mathbf{4 . 0}$ & & & & & & & & & & & & & & & & & & \\
\hline 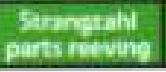 & 20 & 8 & 7 & 6 & 6 & 5 & 4 & 4 & 4 & 4 & -3 & $\mathbf{3}$ & $3:$ & 3 & 3 & 2 & 2 & 2 \\
\hline
\end{tabular}

Figura 5.12: Extracto de la página no 5 de las tablas oficiales de la grúa $2200 E$ 
Procedemos de la misma manera para el radio máximo:

En la página no 7 hayamos la configuración que nos permite trabajar a 58 metros de radio con una capacidad de 0,6 toneladas que es con 40,1 metros de pluma principal, 24,3 metros de plumín colocado con un ángulo de 25 o como se puede observar en el siguiente extracto de la tabla:

\begin{tabular}{|c|c|c|c|c|c|c|c|c|c|c|c|c|c|c|c|c|c|c|c|c|}
\hline \multirow{5}{*}{ 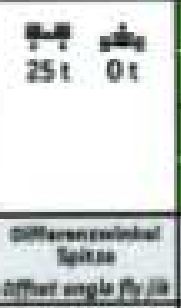 } & \multicolumn{20}{|c|}{ Hauptauslegeriange/ main boom length [m] } \\
\hline & \multicolumn{6}{|c|}{28.9} & \multicolumn{6}{|c|}{34,5} & \multicolumn{6}{|c|}{40,1} & \multicolumn{2}{|c|}{45,7} \\
\hline & \multicolumn{20}{|c|}{ Spitzenauslegerlange / fixed jib iength [m] } \\
\hline & \multicolumn{2}{|c|}{13,1} & \multicolumn{2}{|c|}{18,7} & \multicolumn{2}{|c|}{24,3} & \multicolumn{2}{|c|}{13,1} & \multicolumn{2}{|c|}{187} & \multicolumn{2}{|c|}{24,3} & \multicolumn{2}{|c|}{13,1} & \multicolumn{2}{|c|}{18,7} & \multicolumn{2}{|c|}{24,3} & \multicolumn{2}{|c|}{13,1} \\
\hline & 5 & $\frac{2}{25^{*}}$ & 5 & $\frac{6}{25}$ & 5" & $\frac{\alpha}{2 s^{\circ}}$ & $5^{*}$ & $\frac{d}{2 s^{*}}$ & 5 & $2 \frac{1}{2 s^{*}}$ & s & is: & 5 & $\frac{4}{25}$ & 5 & $\frac{a f}{25}$ & 5 & $\frac{1}{25}$ & 5 & $\frac{d}{25}$ \\
\hline $\begin{array}{l}\text { Ausiadung } \\
\text { radius Imi }\end{array}$ & & & & & & & & & & & & & & & & & & & & \\
\hline 10,0 & $\mathrm{De}$ & & & & & & & & & & & & & & & & & & & \\
\hline$\pi, 0$ & tuo & & ans & & & & 15.5 & & & & & & & & & & & & & \\
\hline 12,0 & 150 & & 125 & & mest & & 151 & & $r x=x$ & & & & 123 & & & & & & exes & \\
\hline 13.0 & 141 & & 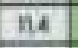 & & 10 & & $11 \mathrm{~s}$ & & 112 & & $\operatorname{sins}$ & & 28 & & cores & & & & ni & \\
\hline 14,0 & 12.5 & avint & $\pi 3$ & & 6.9 & & E.? & & $\pi i$ & & 4 & & 02.2 & & 82 & & wast & & 00 & \\
\hline 15,0 & 124 & a3 & $\pi 2$ & & 51 & & III) & 125 & 100 & & E.? & & 32 & & $M$ & & 84 & & 18 & \\
\hline 16.0 & $\pi .5$ & 03 & 101 & & 6.1 & & 80.1 & $\pi 1$ & 10 & & 6 & & Ea & 151 & 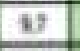 & & 5 & & 35 & \\
\hline 120 & 103 & net. & 103 & ind & 4 & & 180 & vis & 100 & & $\mathrm{M}$ & & 4 & ini & 3 & & 61 & & ain & $M$ \\
\hline 18,0 & M.T & 100 & 9.8 & $\mathrm{ez}$ & f... & & 01 & $\mathrm{nex}$ & 2 & new & 25 & & 93 & Xs: & 4 & & a & & 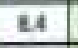 & $\mathrm{ks}$ \\
\hline 180 & 2.0 & vi & 20 & 11 & 6. & & 21 & 4.4 & E) & 2 & B & & 4 & 20 & 4 & avel & 6 & & 13 & $\underline{4}$ \\
\hline 20,0 & 19 & 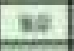 & en & 3 & B. & $\cos 1$ & $E 0$ & $u$ & in & 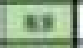 & 4 & $\sin$ & $2 s$ & est & 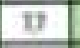 & s) & 6 & & $\mathrm{~B}$ & ey \\
\hline 22,0 & $n$ & in & $n$ & 1 & 61 & $u$ & 69 & 14 & 10 & 19 & 63 & \begin{tabular}{|l|}
00 \\
\end{tabular} & 6 & 24 & E) & 25 & 4 & ist & 4 & $E$ \\
\hline $54 ; 0$ & $6 a$ & $u$ & 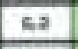 & $\pi$ & 50 & 5 & 50 & $*$ & 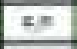 & $\mathrm{cu}$ & 21 & $\mathrm{su}$ & 53 & ne & $\mathrm{sa}$ & 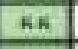 & $a$ & $\therefore$ & 55 & 5 \\
\hline 28,0 & 35 & 13 & 10 & 3 & 11 & 13 & 12 & 5 & 5 & 0 & $u$ & 1.1 & 12 & 85 & 10 & 60 & 31 & 4 & 6 & 13 \\
\hline 28,0 & 43 & 12 & 4 & 31 & 50 & U. & 48 & 24 & 46 & $3 x$ & 4 & 10 & 0 & 41 & 4 & 13 & 4 & 3 & 21 & 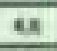 \\
\hline 30.0 & 4,1 & 9 & 44 & 4 & 4.5 & \pm 2 & 40 & 4 & 0 & 4 & 4 & 5,0 & 11 & 42. & III & CI & 49 & 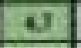 & 15 & 40 \\
\hline 12.0 & 13 & es & 19 & $u$ & 40 & $u$ & 13 & $x y$ & 13 & 4 & 17 & 4 & 33 & 17 & 13 & 4 & 25 & $u$ & 20 & 1.3 \\
\hline 34.0 & 14 & 1) & 15 & II & 13 & $a$ & 13 & 4 & 11 & 3 & 13 & 4 & 23 & 11 & 3 & 14 & II & 13 & 38 & 210 \\
\hline 36.0 & 31 & 23 & i1 & 13 & 3.2 & $y$ & 28 & 30 & $2 s$ & 31 & 3 & In & 213 & 21 & 26 & 32 & $2 y$ & 13 & 2.2 & 2.5 \\
\hline 38.0 & 23 & 23 & 28 & II & 2.8 & 24 & 24 & 23 & 21 & 23 & 28 & III & 21 & 21 & $u$ & 28 & 21 & II & 15 & 27 \\
\hline 40,0 & tinsi & 2aves & 2.5 & 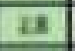 & 2 & 11 & 2.2 & 24 & $2 u$ & 28 & 23 & 20 & 6 & $n$ & 8 & 2.5 & 20 & 8,1 & 4 & $u$ \\
\hline 42.0 & & & 2.2 & 28 & 21 & 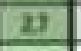 & 10 & 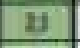 & $\mathrm{u}$ & 23 & 20 & 24 & 11 & 18 & 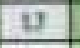 & 2.2 & 4 & 24 & 4 & 18 \\
\hline 44,0 & & & 2045 & 22 & 21 & 24 & thes: & tili & $u$ & 20 & 16 & 23 & $u$ & 16 & $u$ & iv & 13 & 21 & $\mathrm{t}$ & $u$ \\
\hline 46,0 & & & & $n=1$ & 18 & 23 & & ine: & $u$ & 4 & 18 & 29 & $u$ & 14 & 13 & 16 & 11 & 12 & 89 & 13 \\
\hline 48,0 & & & & & 4 & 13 & & & $u$ & u & 16 & 4 & $\Leftrightarrow$ & u & 10 & 14 & $u$ & $u$ & a) & $a x$ \\
\hline 50,0 & & & & & wes & $\mathrm{u}$ & & & & cant & u & 15 & & ines & $a$ & 12 & 29 & 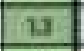 & 0.5 & a! \\
\hline 12.0 & & & & & & 1awis & & & & & 10 & 13 & & & at & 10 & 0.8 & $\mathrm{u}$ & & us \\
\hline 84.0 & \multirow{2}{*}{\multicolumn{6}{|c|}{ 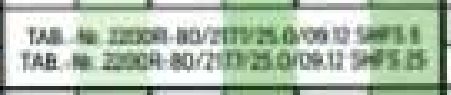 }} & & & & & conter & 11 & & & coses & as & es & At & & \\
\hline 56,0 & & & & & & & & & & & & anse & & & & cons & & E..) & & \\
\hline 100 & & & & & & & & & & & & & & & & & & nat & & \\
\hline 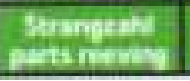 & z. & 2 & 2 & $y$ & 1 & 1 & $z$ & ? & $\boldsymbol{I}$ & $\boldsymbol{z}$ & 1. & 1 & 2 & 2 & $z$ & 1. & 1. & 1 & 2 & 2 \\
\hline
\end{tabular}

Figura 5.13: Extracto de la página no 7 de las tablas oficiales de la grúa $2200 E$ 
En este caso en momento será:

MomRmax $=0,6 \times 58=34,8$ m.t

Para un radio de 30 metros, se tiene la máxima capacidad con pluma de 28,9 metros, plumín de 24,3 metros colocado con un ángulo de 25 ․ Como se puede ver en la misma tabla de pluma con plumín de la página nำ, dicha capacidad es de 5,2 toneladas:

En este caso en momento será:

MomR30 $=30 \times 5,2=156$ m.t

El momento Máximo de la grúa 2200E es de 320 m.t que como vemos es idéntico al momento a radio mínimo aunque también en algún otro radio también. Vemos por lo tanto que esta grúa celosía sobre cadenas tiene su máximo momento (MLM) a radio mínimo lo cual no es muy habitual que se produzca como se puede observar en el resto de casos estudiados. 
Los resultados de capacidades obtenidos para la grúa 2200E se resumen en la siguiente tabla:

\begin{tabular}{|c|c|}
\hline & $\begin{array}{l}\text { Grúa Celosía } \\
2200 \mathrm{E}\end{array}$ \\
\hline Radio minimo & 4,00 \\
\hline ton a Rmin & 80,00 \\
\hline Radio máximo & 58,00 \\
\hline ton a Rmax & 0,60 \\
\hline Radio 30 & 30,00 \\
\hline ton a R30 & 5,20 \\
\hline Mom Rmin & 320,00 \\
\hline Mom R30 & 156,00 \\
\hline Mom Rmax & 34,80 \\
\hline Max load moment & 320,00 \\
\hline
\end{tabular}

Figura 5.14: Tabla resumen de resultados técnicos obtenidos para la grúa $2200 E$ 


\subsection{4.- Grúa AC700}

Grúa Telescópica sobre camión de la marca Terex Demag de 700 toneladas de capacidad nominal tal y como indica su propio nombre (cosa que no ocurre en esta marca Terex Demag con su gama de grúas de celosía sobre cadenas en las que el nombre no tiene nada que ver con su capacidad y no siempre en su gama de telescópicas).
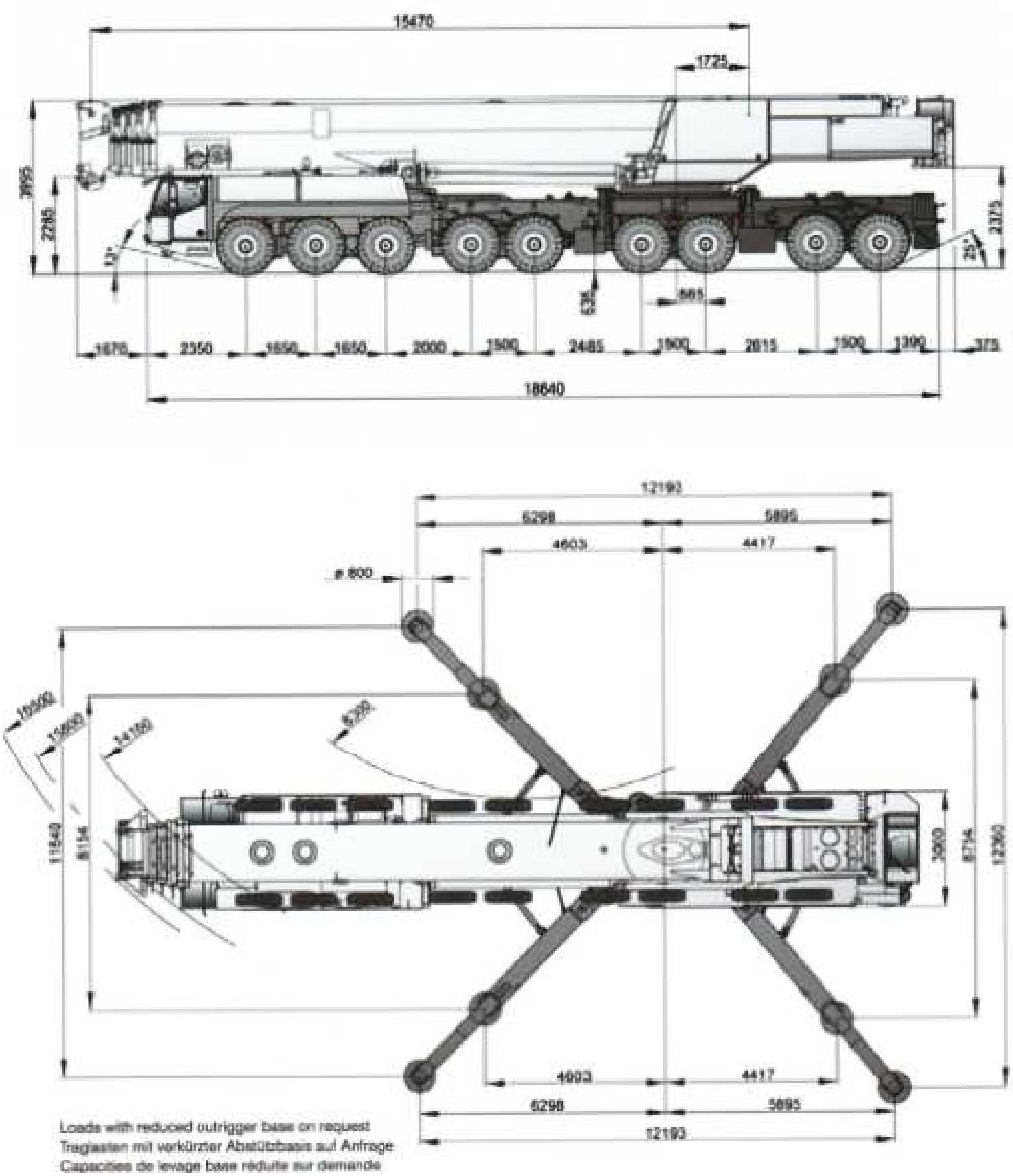

Figura 5.15: Extracto de la página no5 de las tablas oficiales de la AC700 con sus dimensiones 


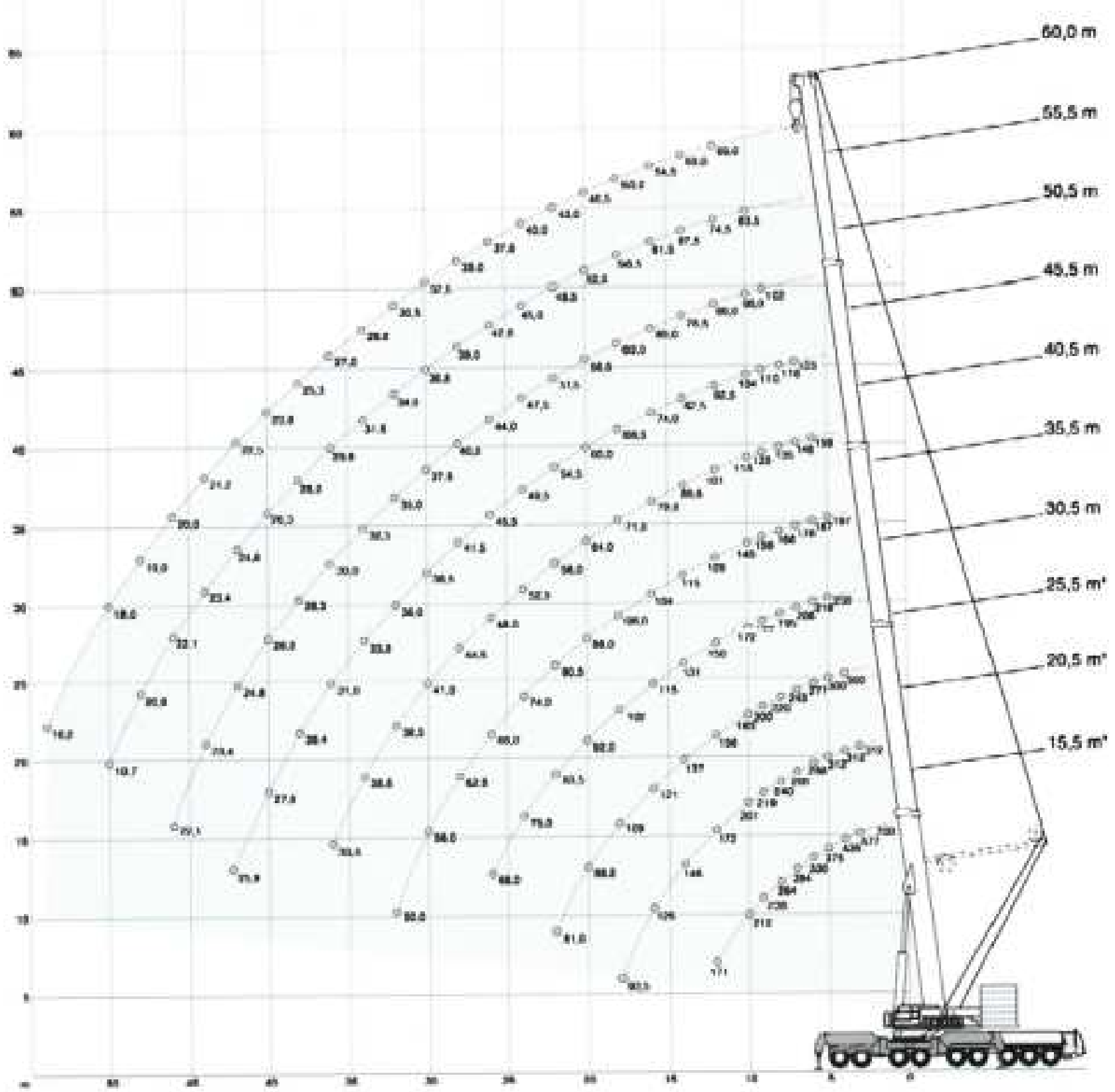

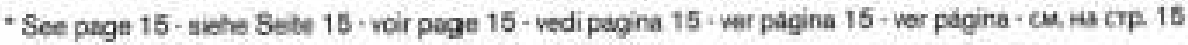

Figura 5.16: Extracto de la página no 14 de las tablas oficiales de la AC700 con su diagrama con pluma principal 
Según obtenemos en el siguiente extracto de la tabla de la grúa AC700 (página no 15 de las tablas oficiales de Terex), el radio mínimo de trabajo de dicha máquina es en principio de 2 metros y con una pluma principal de 15,5 metros de longitud, la capacidad de la grúa es de 700 toneladas. Corresponde lógicamente la capacidad a radio mínimo de la máquina (700t.) con la capacidad nominal oficial con la que el fabricante define la grúa en el inicio del catálogo de características y tablas de la máquina.

Sin embargo es importante comentar que esta capacidad a radio mínimo es más teórica que real ya que observando el gráfico y las dimensiones de la máquina, se hace difícil imaginar que carga real con dimensiones reales pueda tener la geometría adecuada para realizar este izado y sobre todo sabiendo que hay que dejar un metro de resguardo entre pluma y carga para evitar colisiones. Es significativo, observar en este caso como la tabla oficial de cargas no indica la cifra del radio para la capacidad de 700 toneladas se entiende que es menor de 3 .

A efectos reales esta grúa da la capacidad de 577 toneladas a radio 3 metros y esta debería ser probablemente su capacidad nominal a efectos prácticos per evidentemente no es lo mismo comercialmente hablar de una grúa de 700 toneladas que de una de 577 toneladas...

A efectos de este estudio se tomarán los datos oficiales del fabricante como se hace para todas las grúas consideradas aunque en este caso el uso como capacidad nominal de la grúa de este tonelaje a radio mínimo sea especialmente irreal.

El momento que obtenemos por tanto a radio mínimo es de:

MomRmin $=700 \times 2=1.400 \mathrm{~m} \cdot \mathrm{t}$ 


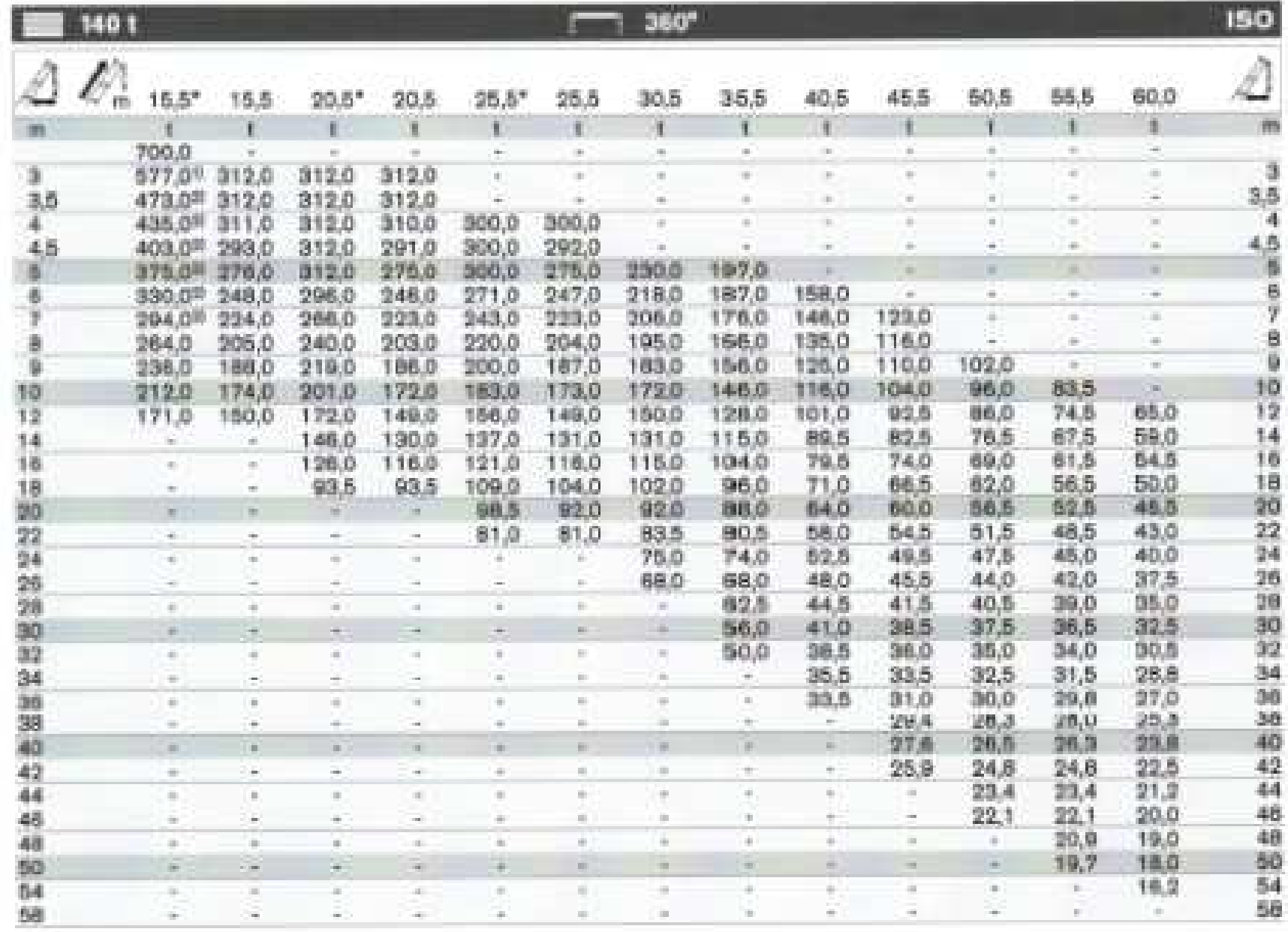

Figura 5.17: Extracto de la página no 15 de las tablas oficiales de la AC700

Procedemos de la misma manera para el radio máximo:

En la página no 41 hayamos la configuración que nos permite trabajar a 110 metros de radio con una capacidad de 3,8 toneladas como se puede observar en el siguiente extracto de la tabla: 


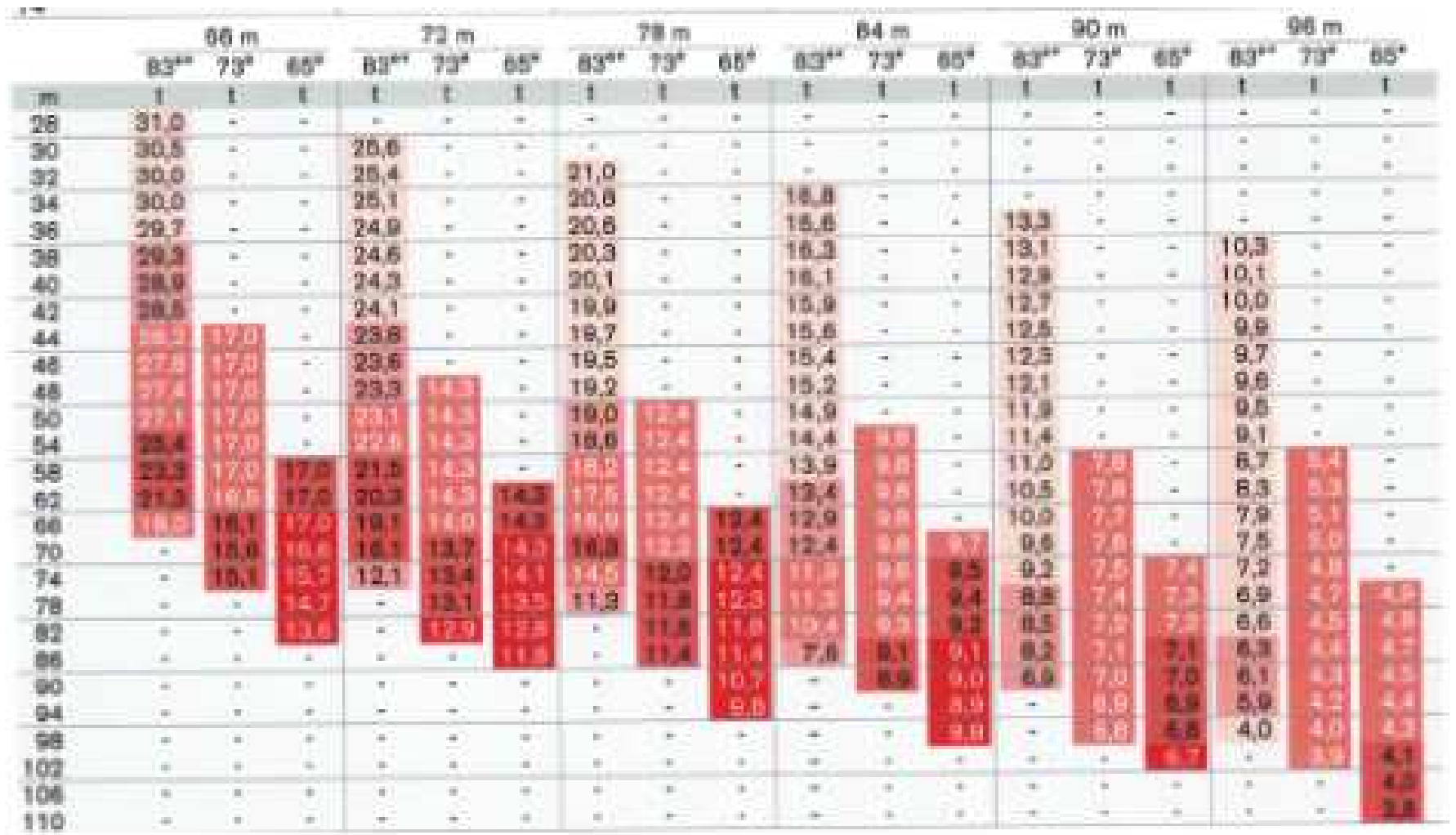

Figura 5.18: Extracto de la página no 41 de las tablas oficiales de la grúa AC700

En este caso en momento será:

MomRmax $=3,8 \times 110=418$ m.t

Para un radio de 30 metros, se tiene la máxima capacidad en la tabla de la página no 30 con pluma principal de 19,5 metros de longitud $(15,5+4)$, plumín de 42 metros, con un ángulo de 83 - de la pluma. Como se puede ver en la tabla ya mencionada, dicha capacidad es de 69,5 toneladas:

En este caso en momento será:

MomR30 $=30 \times 69,5=2.085$ m.t

El momento Máximo de la grúa AC700 es de 2.124 m.t (236t x 9m) que como vemos es algo superior aunque bastante similar al obtenido para radio mínimo $=30$ metros. 
Vemos por lo tanto que esta grúa telescópica sobre camión tiene su máximo momento (MLM) en radios intermedios.

Los resultados de capacidades obtenidos para la grúa AC700 se resumen en la siguiente tabla:

\begin{tabular}{|c|c|}
\hline & $\begin{array}{l}\text { Grúa Telescópica } \\
\text { AC700 }\end{array}$ \\
\hline Radio minimo & 2,00 \\
\hline ton a Rmin & 700,00 \\
\hline Radio máximo & 110,00 \\
\hline ton a Rmax & 3,8 \\
\hline Radio 30 & 30,00 \\
\hline ton a R30 & 69,50 \\
\hline Mom Rmin & $1.400,00$ \\
\hline Mom R30 & $2.085,00$ \\
\hline Mom Rmax & 418,00 \\
\hline Max load moment & $2.124,00$ \\
\hline
\end{tabular}

Figura 5.19: Tabla resumen de resultados técnicos obtenidos para la grúa AC700 
Grúa Telescópica sobre camión de la marca Liebherr de 200 toneladas de capacidad nominal tal y como indica su propio nombre ya que Liebherr indica en los nombres de sus grúas su capacidad nominal (sin contar la primera cifra detrás de las letras).

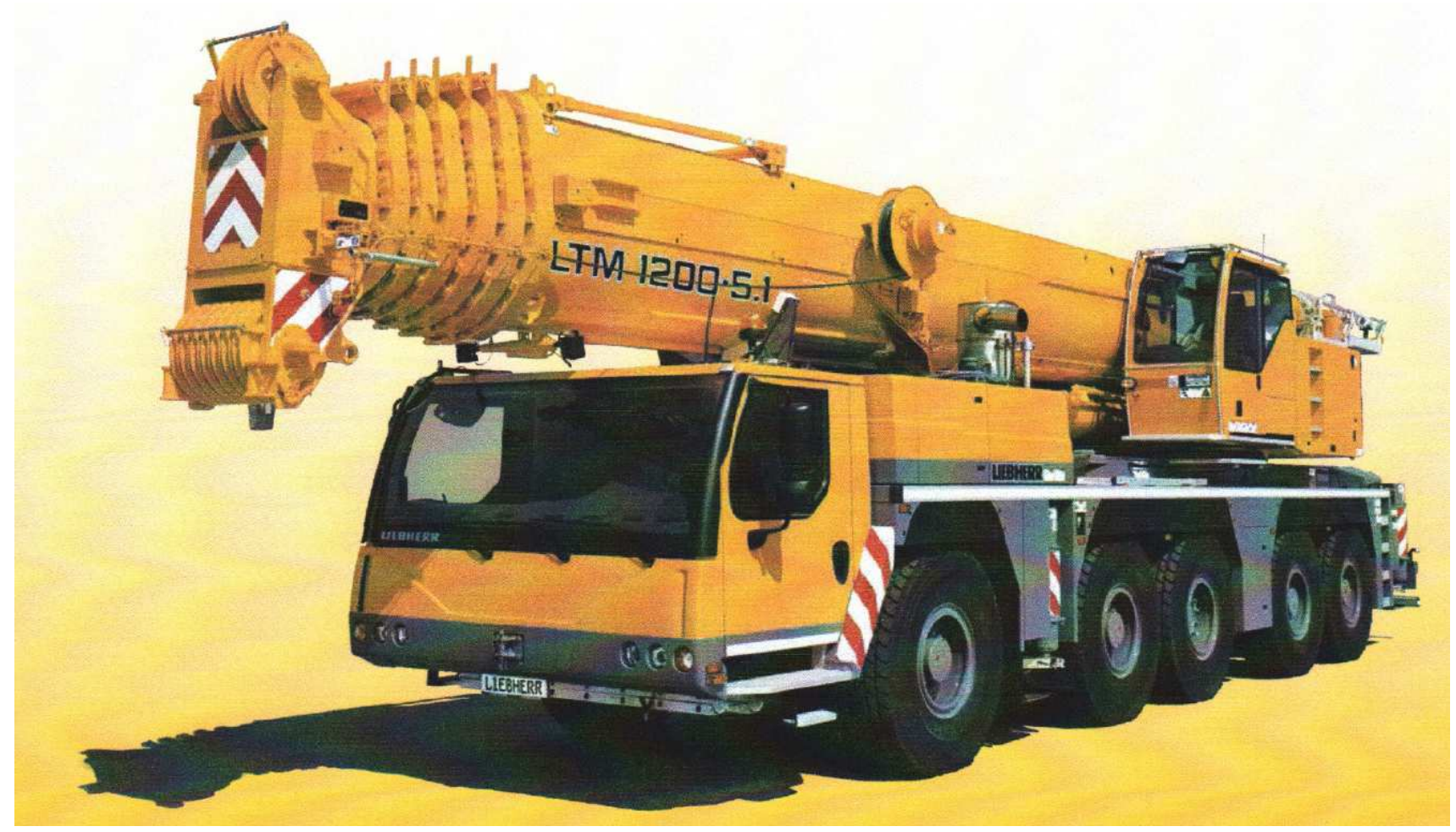

Figura 5.20: Extracto de la página no1 de las tablas oficiales de la LTM1200

Según obtenemos en el siguiente extracto de la tabla de la grúa LTM1200 (página 4 de las tablas oficiales de Liebherr), el radio mínimo de trabajo de dicha máquina es de 3 metros y con una pluma principal de 13,2 metros de longitud, la capacidad de la grúa es de 200 toneladas. Corresponde lógicamente la capacidad a radio mínimo de la máquina (200t.) con la capacidad nominal oficial con la que el fabricante define la grúa en el inicio del catálogo de características y tablas de la máquina. 
El momento que obtenemos por tanto a radio mínimo es de:

MomRmin $=200 \times 3=600 \mathrm{~m} . \mathrm{t}$

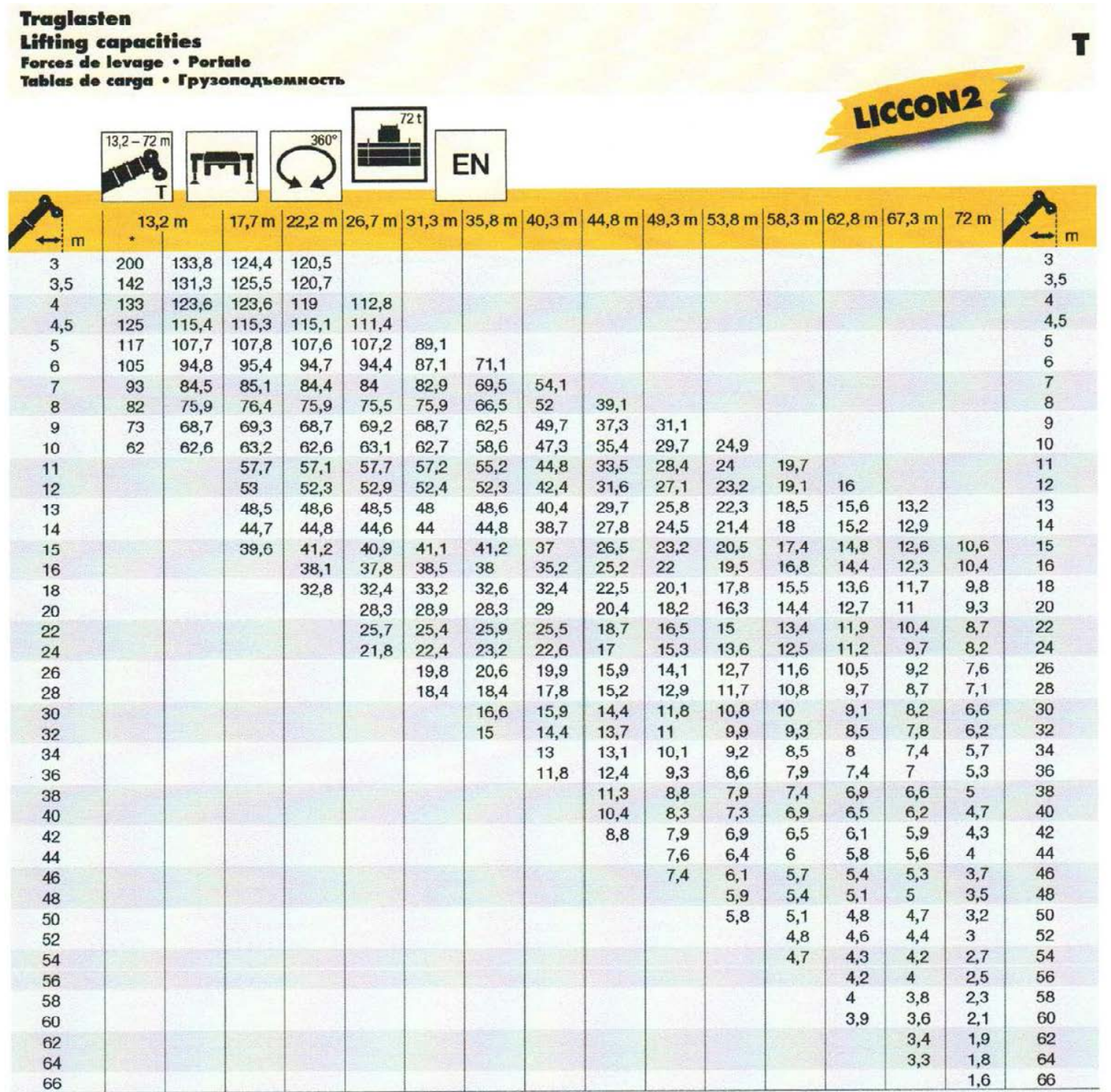

Figura 5.21: Extracto de la página no4 de las tablas oficiales de la LTM1200

Procedemos de la misma manera para el radio máximo:

En la página no 25 hayamos la configuración que nos permite trabajar a 80 metros de radio con una capacidad de 1,3 toneladas como se puede observar en el siguiente extracto de la tabla: 


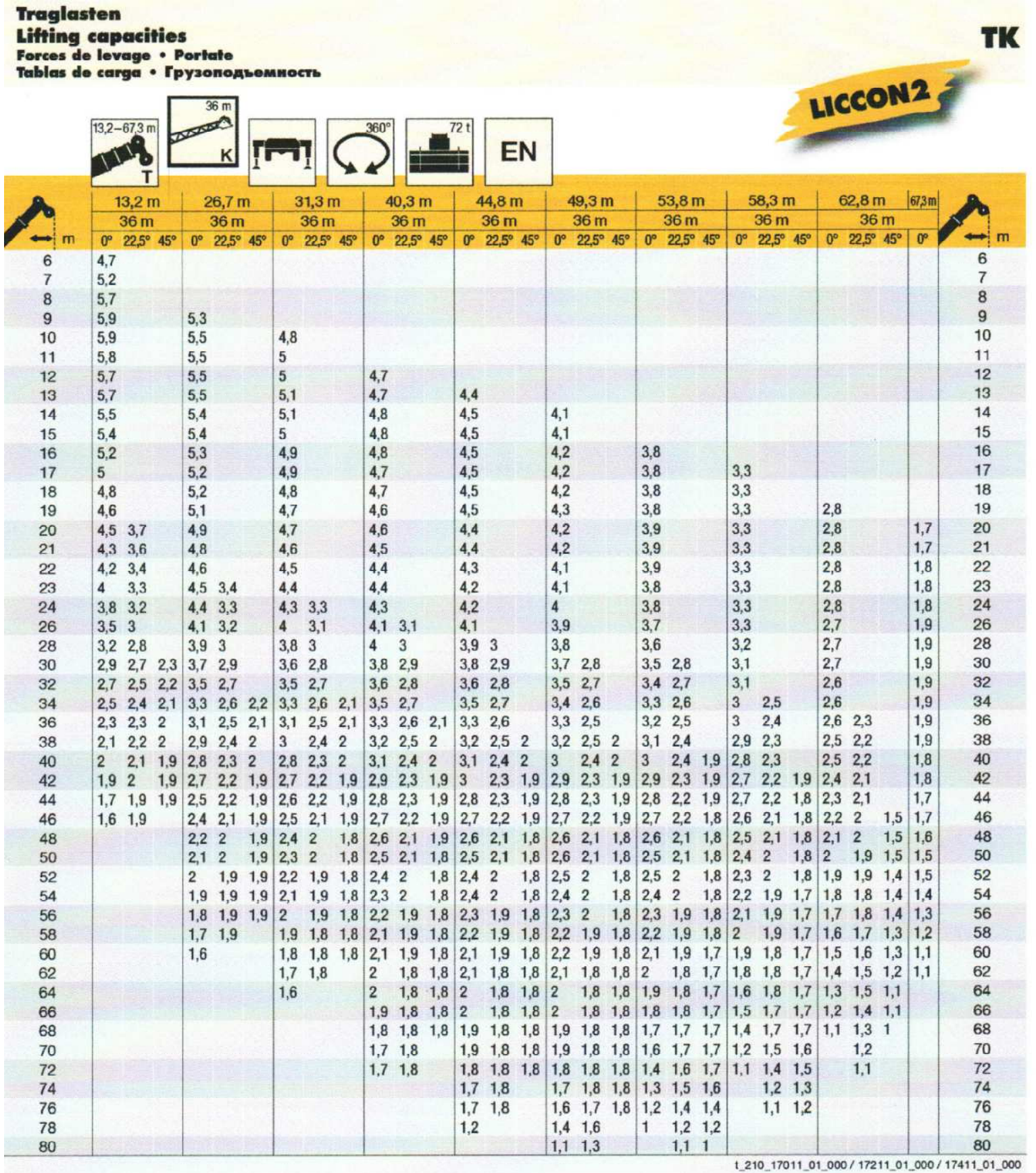

Figura 5.22: Extracto de la página no 25 de las tablas oficiales de la grúa LTM1200

En este caso en momento será:

$\operatorname{MomRmax}=1,3 \times 80=104$ m.t 
Para un radio de 30 metros, se tiene la máxima capacidad en la misma tabla de la página no4 con pluma principal de 35,8 metros de longitud. Como se puede ver en la tabla ya mencionada, dicha capacidad es de 16,6 toneladas:

En este caso en momento será:

MomR30 $=30 \times 16,6=498 \mathrm{~m} \cdot \mathrm{t}$

El momento Máximo de la grúa LTM1200 de 657 m.t que como vemos es algo superior aunque bastante similar al obtenido para radio mínimo $=3$ metros.

Vemos por lo tanto que esta grúa telescópica sobre camión tiene su máximo momento (MLM) cerca de su radio mínimo. 
Los resultados de capacidades obtenidos para la grúa LTM1200 se resumen en la siguiente tabla:

\begin{tabular}{|c|c|}
\hline & $\begin{array}{l}\text { Grúa Telescópica } \\
\text { LTM1200 }\end{array}$ \\
\hline Radio minimo & 3,00 \\
\hline ton a Rmin & 200,00 \\
\hline Radio máximo & 80,00 \\
\hline ton a Rmax & 1,30 \\
\hline Radio 30 & 30,00 \\
\hline ton a $\mathrm{R} 30$ & 16,60 \\
\hline Mom Rmin & 600,00 \\
\hline Mom R30 & 498,00 \\
\hline Mom Rmax & 104,00 \\
\hline Max load moment & 657,00 \\
\hline
\end{tabular}

Figura 5.23: Tabla resumen de resultados técnicos obtenidos para la grúa LTM1200 


\subsection{6.- Grúa GMK4080}

Grúa Telescópica sobre camión de la marca Grove (del grupo Manitowoc) de 80 toneladas de capacidad nominal tal y como indica su propio nombre ya que Grove indica en las últimas 3 cifras, del nombre de su serie GMK, su capacidad nominal.

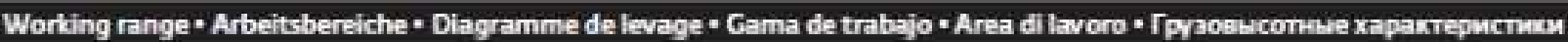

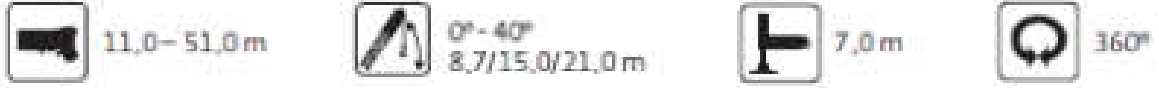

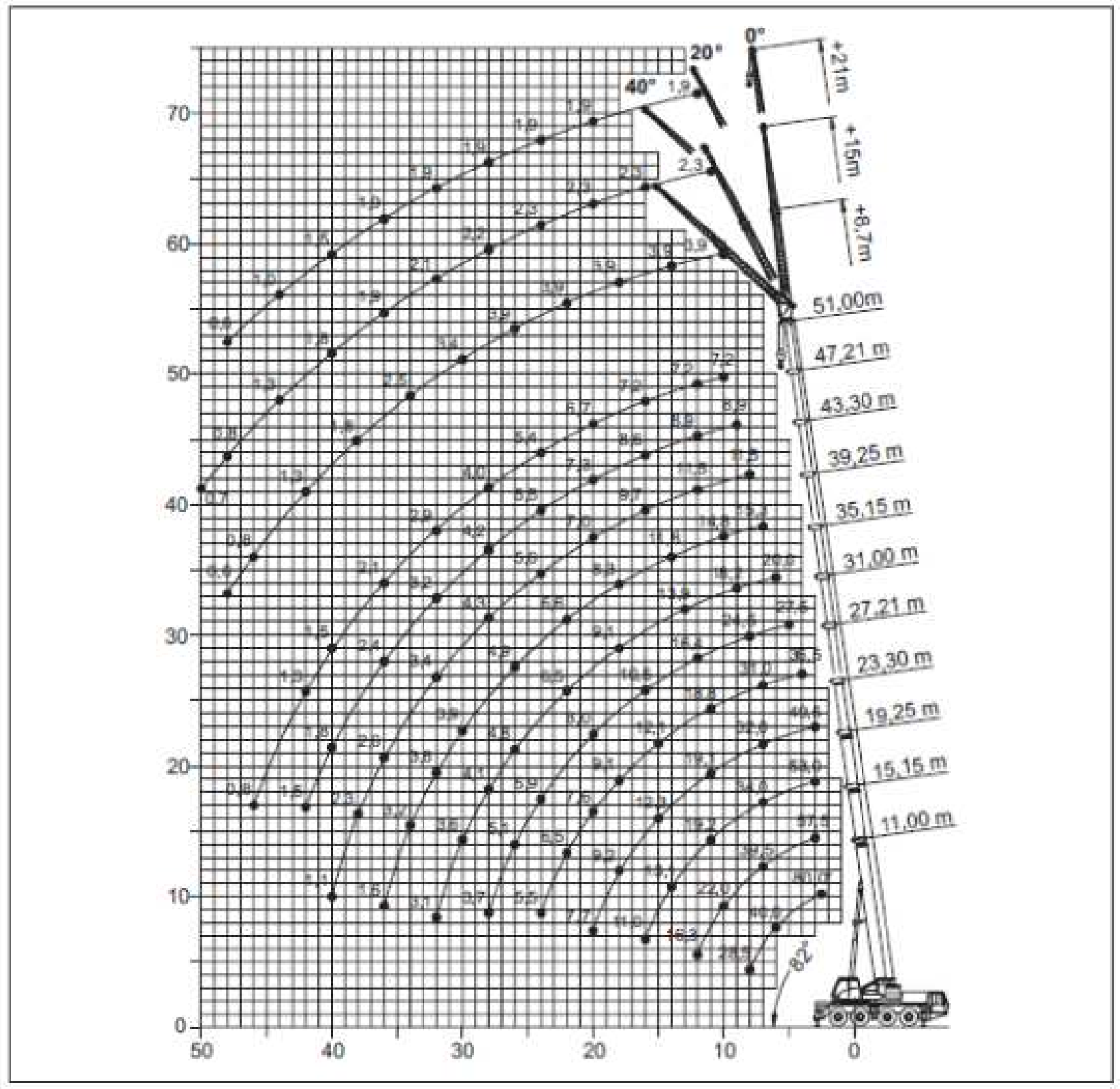

Figura 5.24: Diagrama de la GMK4080 de la página no13 de dicha grúa 
Según obtenemos en el siguiente extracto de la tabla de la grúa GMK4080 (página 14 de las tablas oficiales de Grove), el radio mínimo de trabajo de dicha máquina es de 2,5 metros y con una pluma principal de 11 metros de longitud, la capacidad de la grúa es de 80 toneladas. Corresponde lógicamente la capacidad a radio mínimo de la máquina (80t.) con la capacidad nominal oficial con la que el fabricante define la grúa en el inicio del catálogo de características y tablas de la máquina.

El momento que obtenemos por tanto a radio mínimo es de:

MomRmin $=80 \times 2,5=200 \mathrm{~m} \cdot \mathrm{t}$

Telescopic boom - Teleskopausleger - Flèche principale - Pluma telescópica - Braccio telescopico - Телескопическая стрела

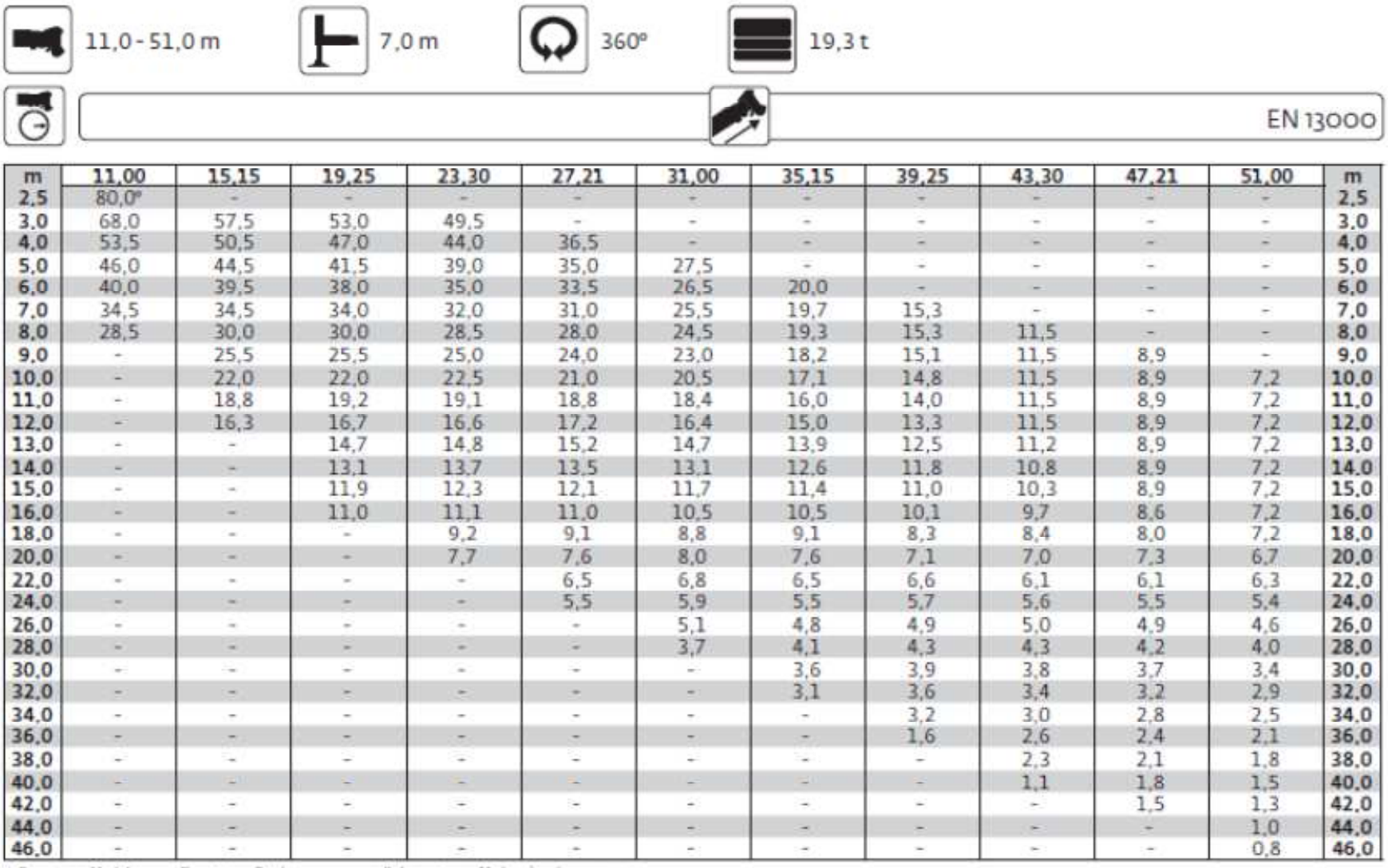

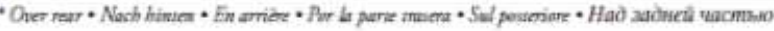

Figura 5.25: Extracto de la página no14 de las tablas oficiales de la GMK4080 
Procedemos de la misma manera para el radio máximo:

En la página no 19 hayamos la configuración que nos permite trabajar a 523 metros de radio con una capacidad de 0,8 toneladas como se puede observar en el siguiente extracto de la tabla:

\begin{tabular}{|c|c|c|c|c|c|c|c|c|c|c|c|}
\hline \multirow{3}{*}{$\begin{array}{l}\mathbf{m} \\
\mathbf{m}\end{array}$} & \multirow{2}{*}{\multicolumn{5}{|c|}{$\begin{array}{l}47.2 \\
15.0\end{array}$}} & \multirow{2}{*}{\multicolumn{5}{|c|}{$\begin{array}{l}51.0 \\
15.0\end{array}$}} & \multirow{3}{*}{$\begin{array}{l}\mathbf{m} \\
\mathbf{m}\end{array}$} \\
\hline & & & 15.0 & & & & & & & & \\
\hline & $0^{\circ}$ & $0^{\circ}-20^{\circ}$ & $20^{\circ}-40^{\circ}$ & $0^{\circ}-20^{\circ}$ & $20^{\circ}-40^{\circ}$ & $0^{\circ}$ & $0^{\circ}-20^{\circ}$ & $20^{\circ}-40^{\circ}$ & $-0^{\circ}-20^{\circ}$ & $20^{\circ}-40^{\circ}$ & \\
\hline 10.0 & 2,7 & - & - & - & - & - & - & - & - & $=$ & 10.0 \\
\hline 11.0 & 2,7 & - & - & - & - & 2,3 & - & - & - & - & 11.0 \\
\hline 12.0 & 2.7 & - & - & - & - & 2,3 & - & - & - & - & 12,0 \\
\hline 13.0 & 2,7 & - & - & - & - & 2,3 & - & - & - & - & 13.0 \\
\hline 14.0 & 2.7 & - & - & - & - & 2,3 & - & - & - & - & 14.0 \\
\hline 15.0 & 2,7 & 2,3 & - & 1,4 & - & 2,3 & - & - & $\therefore$ & - & 15.0 \\
\hline 16.0 & 2.7 & 2.2 & - & 1,3 & - & 2,3 & 2,2 & - & 1,3 & - & 16.0 \\
\hline 18.0 & 2,7 & 2,1 & - & 1,2 & - & 2,3 & 2,1 & - & 1,3 & - & 18.0 \\
\hline 20.0 & 2.6 & 2.0 & 1.7 & 1.2 & 0.9 & 2,3 & 2,0 & 1,6 & 1.2 & 0.9 & 20.0 \\
\hline 22,0 & 2,6 & 2,0 & 1,6 & 1,1 & 0,9 & 2,3 & 1,9 & 1,6 & 1,1 & 0,9 & 22,0 \\
\hline 24.0 & 2.5 & 1.9 & 1,6 & 1.0 & 0.8 & 2,3 & 1,9 & 1,6 & 1,1 & 0.8 & 24.0 \\
\hline 26.0 & 2,4 & 1,8 & 1,6 & 1,0 & 0,8 & 2,3 & 1,8 & 1,6 & 1,0 & 0.8 & 26.0 \\
\hline 28.0 & 2.3 & 1.8 & 1,5 & 0.9 & 0.8 & 2,2 & 1,8 & 1.5 & 1.0 & 0.8 & 28.0 \\
\hline 30.0 & 2,2 & 1,7 & 1,5 & 0,9 & 0,8 & 2.2 & 1,7 & 1,5 & 0,9 & 0,8 & 30,0 \\
\hline 32,0 & 2,1 & 1.7 & 1.5 & 0.9 & 0.8 & 2,1 & 1.7 & 1.5 & 0.9 & 0,8 & 32.0 \\
\hline 34.0 & 2,0 & 1,7 & 1,5 & 0.8 & 0,7 & 2,0 & 1,6 & 1,5 & 0.9 & 0.7 & 34.0 \\
\hline 36.0 & 1.9 & 1.6 & 1.5 & 0.8 & 0.7 & 1,9 & 1.6 & 1.5 & 0.8 & 0.7 & 36.0 \\
\hline 38.0 & 1,9 & 1,6 & 1,5 & 0.8 & 0.7 & 1,9 & 1,6 & 1,4 & 0,8 & 0,7 & 38.0 \\
\hline 40.0 & 1.8 & 1.6 & 1,4 & 0,7 & 0.7 & 1,8 & 1.5 & 1,4 & 0.8 & 0,7 & 40,0 \\
\hline 42,0 & 1,7 & 1,5 & 1,4 & 0.7 & 0,7 & 1,5 & 1,5 & 1,4 & 0,7 & 0.7 & 42.0 \\
\hline 44.0 & 1,5 & 1,5 & 1,4 & 0,7 & 0.7 & 1,3 & 1,3 & 1,4 & 0.7 & 0.7 & 44.0 \\
\hline 46.0 & 1.3 & 1,3 & 1,4 & 0,7 & 0.7 & 1,0 & 1,0 & 1.3 & 0,7 & 0,7 & 46.0 \\
\hline 48.0 & 1,1 & 1,1 & - & 0.7 & 0.7 & 0.8 & 0,8 & 1.0 & 0.7 & 0,7 & 48.0 \\
\hline 50.0 & 0.9 & 0.9 & - & 0,6 & - & 0.7 & 0.7 & - & 0.7 & - & 50.0 \\
\hline 52,0 & 0.8 & 0.8 & - & 0,6 & - & 0,7 & 0,7 & - & 07 & - & 52.0 \\
\hline
\end{tabular}

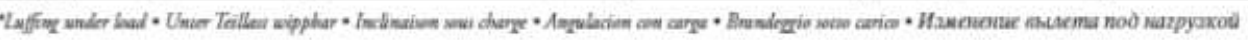

Figura 5.26: Extracto de la página no 19 de las tablas oficiales de la grúa GMK4080

En este caso en momento será:

$\operatorname{MomRmax}=0,8 \times 52=41,6 \mathrm{~m} \cdot \mathrm{t}$

Para un radio de 30 metros, se tiene la máxima capacidad en la misma tabla de la página no14 con pluma principal de 39,25 metros de longitud. Como se puede ver en la tabla ya mencionada, dicha capacidad es de 3,9 toneladas:

En este caso en momento será:

MomR30 $=30 \times 3,9=117 \mathrm{~m} \cdot \mathrm{t}$

El momento Máximo de la grúa GMK4080 de 241,5 m.t $(34,5 \times 7)$ que como vemos es algo superior al obtenido para radio mínimo. 
Vemos por lo tanto que esta grúa telescópica sobre camión tiene su máximo momento (MLM) relativamente cerca de su radio mínimo.

Los resultados de capacidades obtenidos para la grúa CMK4080 se resumen en la siguiente tabla:

\begin{tabular}{|c|c|}
\hline & $\begin{array}{l}\text { Grúa Telescópica } \\
\text { GMK4080 }\end{array}$ \\
\hline Radio minimo & 2,50 \\
\hline ton a Rmin & 80,00 \\
\hline Radio máximo & 52,00 \\
\hline ton a Rmax & 0,80 \\
\hline Radio 30 & 30,00 \\
\hline ton a R30 & 3,90 \\
\hline Mom Rmin & 200,00 \\
\hline Mom R30 & 117,00 \\
\hline Mom Rmax & 41,60 \\
\hline Max load moment & 241,50 \\
\hline
\end{tabular}

Figura 5.27: Tabla resumen de resultados técnicos obtenidos para la grúa GMK4080 


\subsection{7.- Grúa MD3200}

Grúa torre marca Potain (actualmente dentro del grupo Manitowoc) de 80 toneladas de capacidad nominal:

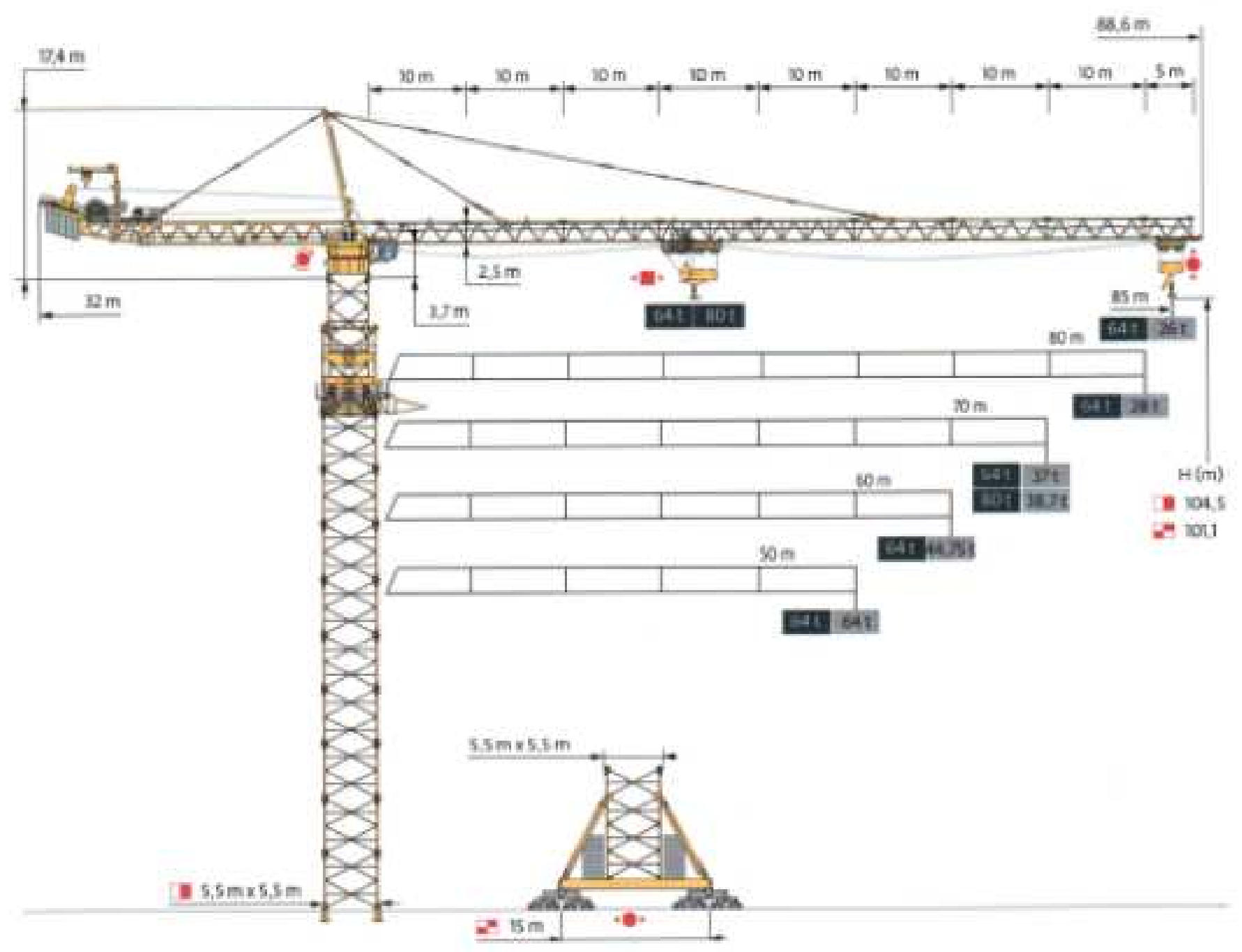

Figura 5.28: Extracto de la página no1 de las tablas oficiales de la grúa MD3200.

Según obtenemos en el siguiente extracto de la tabla de la grúa MD3200 (página no3 de las tablas oficiales de Potain), el radio mínimo de trabajo de dicha máquina es de 6,5 metros y con cualquier pluma principal, la capacidad de la grúa con triple tiro es de 80 toneladas (mantiene dicha capacidad hasta 37 metros de radio con pluma hasta $70 \mathrm{~m}$ ya que al tratarse de una grúa torre nos encontramos en la zona plana de la curva limitada por el tiro). 
Corresponde lógicamente la capacidad a radio mínimo de la máquina (80t.) con la capacidad nominal oficial con la que el fabricante define la grúa en el inicio del catálogo de características y tablas de la máquina.

\section{Courbes de charges / Lastkurven / Load curves / Curvas de cargas / Curve di carico Curvas de carga / Кривые нагрузок.}
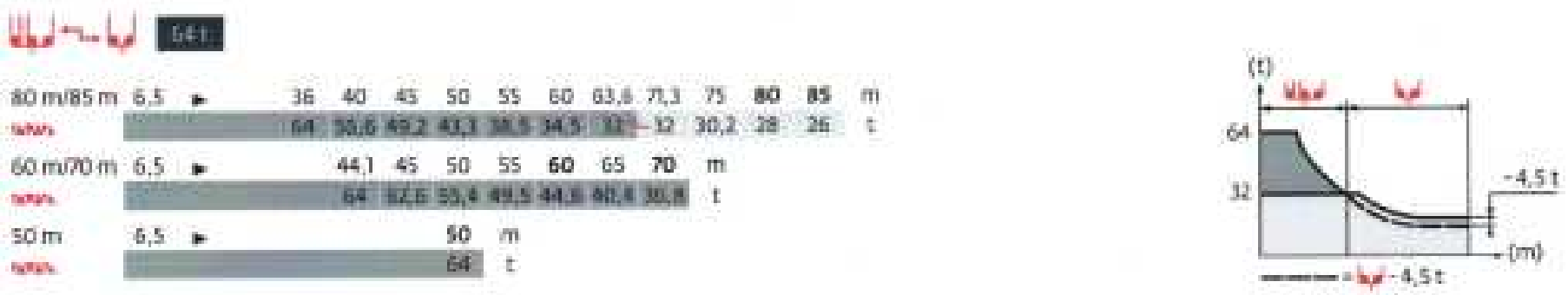

\section{seit}

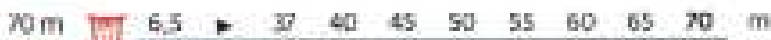

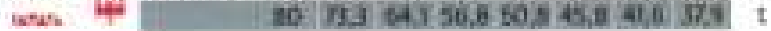

$70 \mathrm{~m}$ \% $6.5 \quad 53,455 \quad 60 \quad 6570 \quad \mathrm{~m}$

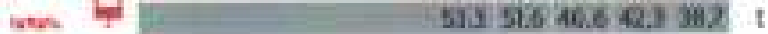

Figura 5.29: Extracto de la página no 3 de las tablas oficiales de la grúa MD3200

El momento que obtenemos por tanto a radio mínimo es de:

MomRmin $=80 \times 6,5=520 \mathrm{~m} . \mathrm{t}$ 
Procedemos de la misma manera para el radio máximo:

En la misma página no 3 hayamos la configuración de pluma de 85 metros que nos permite trabajar a un máximo de 85 metros de radio con una capacidad de 26 toneladas en punta como se puede observar en la tabla anterior.

En este caso en momento será:

MomRmax $=26 \times 85=2.210$ m.t

Para un radio de 30 metros, se tiene la máxima capacidad con pluma 70 metros de longitud. Como se puede ver en la tabla anterior, dicha capacidad es de 80 toneladas ya que estamos en la zona plana de la curva de cargas todavía:

En este caso en momento será:

MomR30 $=30 \times 80=2.400$ m.t

El momento Máximo de la grúa MD3200 es de 2960 m.t ( 80 x 37) que como vemos es algo superior al obtenido para radio $=30$ metros.

En el caso de esta grúa el momento máximo se obtiene con triple tiro y en el radio máximo de la zona plana de la curva de capacidades. Es decir, en el punto en el que cambia la limitación de capacidad por tiro a limitación por vuelco. 
Los resultados de capacidades obtenidos para la grúa MD610 M40 se resumen en la siguiente tabla:

\begin{tabular}{|l|l|}
\hline & Grúa Torre \\
& MD3200 \\
\hline Radio minimo & \\
\hline ton a Rmin & 6,50 \\
\hline Radio máximo & 80,00 \\
\hline ton a Rmax & 85,00 \\
\hline Radio 30 & 26,00 \\
\hline Ton a R30 & $2.960,00$ \\
\hline & \\
\hline Mom Rmin & 30,00 \\
\hline
\end{tabular}

Figura 5.30: Tabla resumen de resultados técnicos obtenidos para la grúa MD3200 
Grúa torre marca Potain (actualmente dentro del grupo Manitowoc) de 40 toneladas de capacidad nominal tal y como indican las últimas cifras de su nombre:

\section{610 M40}

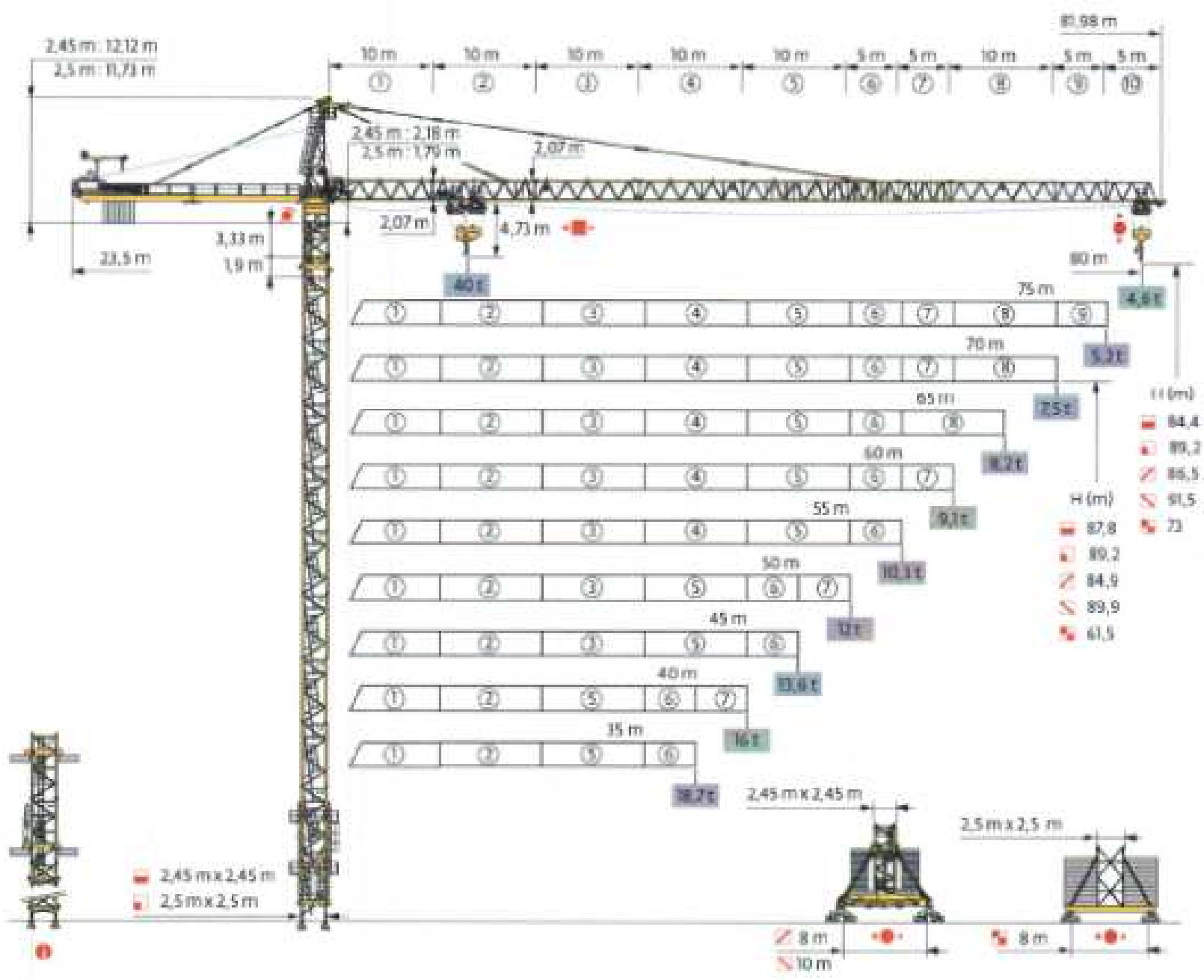

Figura 5.31: Extracto de la página no1 de las tablas oficiales de la grúa MD610 M40

Según obtenemos en el siguiente extracto de la tabla de la grúa MD610 M40 (página no3 de las tablas oficiales de Potain), el radio mínimo de trabajo de dicha máquina es de 3,95 metros y 
con cualquier pluma principal, la capacidad de la grúa con doble tiro es de 40 toneladas (mantiene dicha capacidad hasta 17 metros de radio con plumas cortas ya que al tratarse de una grúa torre nos encontramos en la zona plana de la curva limitada por el tiro).

Corresponde lógicamente la capacidad a radio mínimo de la máquina (40t.) con la capacidad nominal oficial con la que el fabricante define la grúa en el inicio del catálogo de características y tablas de la máquina.

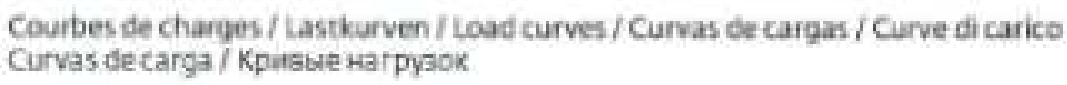

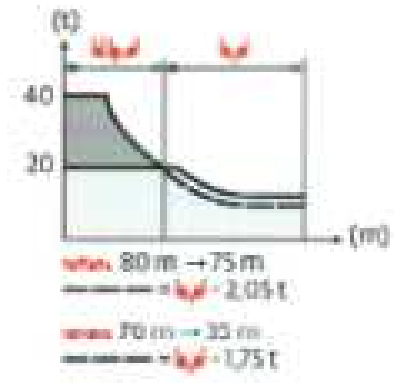

Figura 5.32: Extracto de la página no 3 de las tablas oficiales de la grúa MD610 M40

El momento que obtenemos por tanto a radio mínimo es de:

MomRmin $=40 \times 3,95=158 m \cdot t$

Procedemos de la misma manera para el radio máximo: 
En la misma página no 3 hayamos la configuración de pluma de 80 metros que nos permite trabajar a un máximo de 80 metros de radio con una capacidad de 4,6 toneladas en punta como se puede observar en la tabla anterior.

En este caso en momento será:

MomRmax $=4,6 \times 80=368$ m.t

Para un radio de 30 metros, se tiene la máxima capacidad con plumas de 35 o 40 metros de longitud. Como se puede ver en la tabla anterior, dicha capacidad es de 20,5 toneladas:

En este caso en momento será:

MomR30 $=30 \times 20,5=615 \mathrm{~m} \cdot \mathrm{t}$

El momento Máximo de la grúa MD610 M40 es de 680 m.t que como vemos es algo superior aunque bastante similar al obtenido para radio $=30$ metros .

En el caso de esta grúa el momento máximo se obtiene con doble tiro y en el radio máximo de la zona plana de la curva de capacidades. Es decir, en el punto en el que cambia la limitación de capacidad por tiro a limitación por vuelco. 
Los resultados de capacidades obtenidos para la grúa MD610 M40 se resumen en la siguiente tabla:

\begin{tabular}{|c|c|}
\hline & $\begin{array}{l}\text { Grúa Torre } \\
\text { MD610 } 40\end{array}$ \\
\hline Radio minimo & 3,95 \\
\hline ton a Rmin & 40,00 \\
\hline Radio máximo & 80,00 \\
\hline ton a Rmax & 4,60 \\
\hline Radio 30 & 30,00 \\
\hline ton a R30 & 20,50 \\
\hline Mom Rmin & 158,00 \\
\hline Mom R30 & 615,00 \\
\hline Mom Rmax & 368,00 \\
\hline Max load moment & 680,00 \\
\hline
\end{tabular}

Figura 5.33: Tabla resumen de resultados técnicos obtenidos para la grúa MD610 40 


\subsection{9.- Grúa J52NS}

Grúa torre marca Jaso (actualmente dentro del grupo Manitowoc) de 40 toneladas de capacidad nominal tal y como indican las últimas cifras de su nombre:

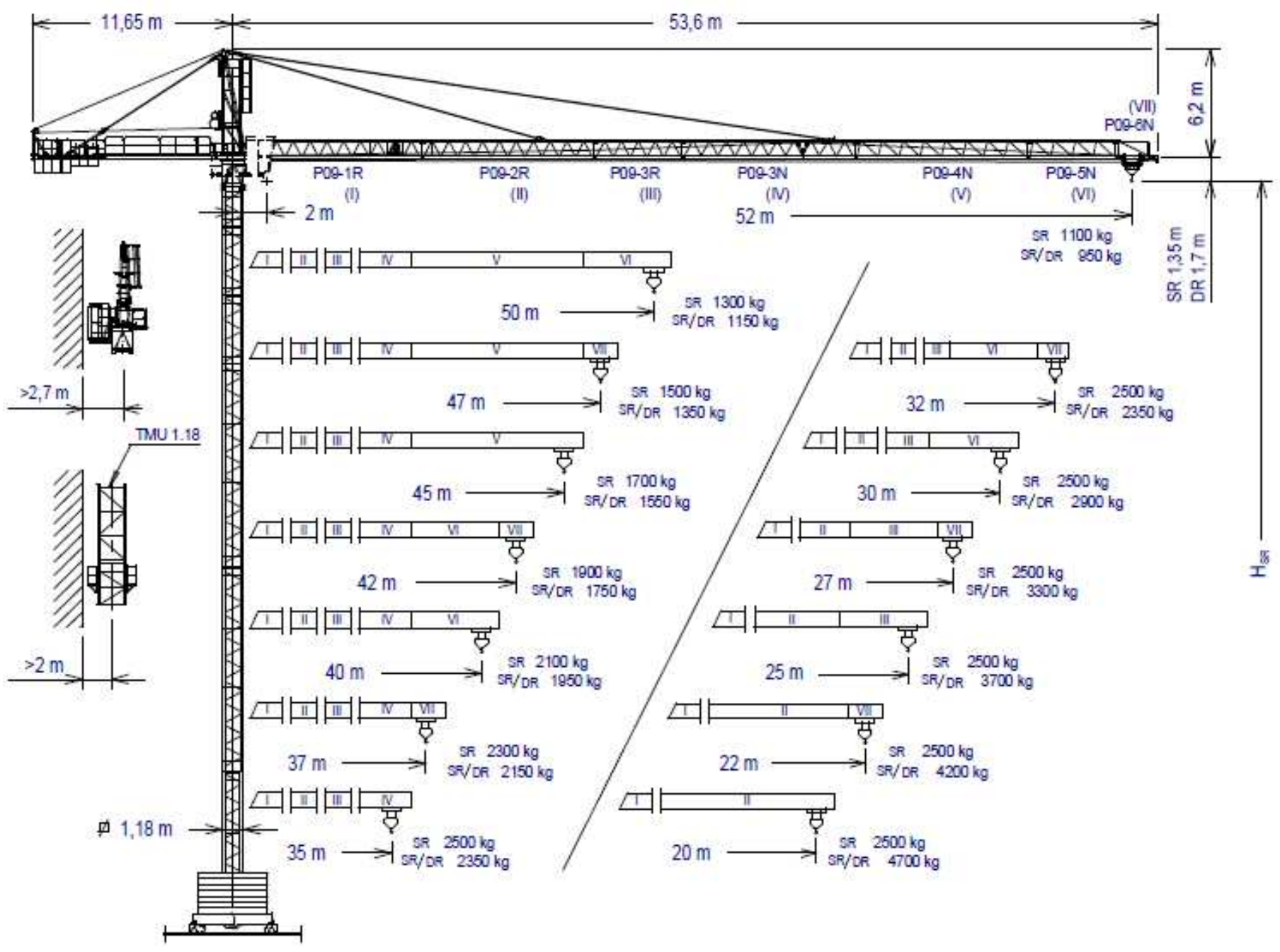

Figura 5.34: Extracto de la página no1 de las tablas oficiales de la grúa J52NS

Según obtenemos en el siguiente extracto de la tabla de la grúa J52NS (página no2 de las tablas oficiales de Jaso), el radio mínimo de trabajo de dicha máquina es de 2 metros y con cualquier pluma principal y doble tiro, la capacidad de la grúa con doble tiro es de 5 toneladas (mantiene dicha capacidad hasta 18,9 metros de radio con plumas de 20 m de longitud que es la mínima ya que al tratarse de una grúa torre nos encontramos en la zona plana de la curva limitada por el tiro). 
Corresponde lógicamente la capacidad a radio mínimo de la máquina (5t.) con la capacidad nominal oficial con la que el fabricante define la grúa en el inicio del catálogo de características y tablas de la máquina.

\begin{tabular}{|c|c|c|c|c|c|c|c|c|c|c|c|c|c|c|c|}
\hline \multicolumn{15}{|c|}{ 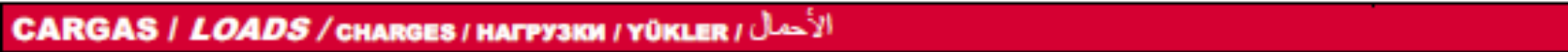 } & \multirow{4}{*}{$\begin{array}{c}\text { J52NS } \\
2 \mathrm{t}-2,5 \mathrm{t} \\
\text { (6..... } \mathrm{m}]\end{array}$} \\
\hline$\frac{b}{d}$ & \multicolumn{2}{|c|}{$\operatorname{SR}(\mathrm{t})$} & \multicolumn{12}{|c|}{ 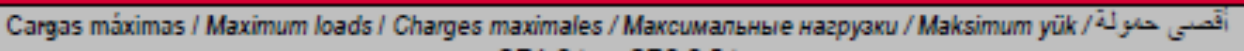 } & \\
\hline$\Delta \Delta$ & \multicolumn{14}{|c|}{ 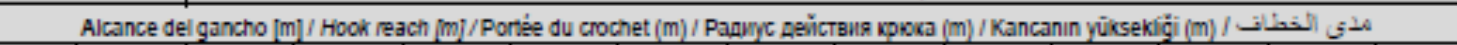 } & \\
\hline$[\mathrm{m}]$ & 52 & 50 & 47 & 45 & 42 & 40 & 37 & 35 & 32 & 30 & 27 & 25 & 22 & 20 & \\
\hline $52 \mathrm{~m}$ & 1,1 & 1,15 & 1,24 & 1,3 & 1,42 & 1,5 & 1,64 & 1,75 & 1,94 & 2,08 & 2,34 & 2,5 & 2,5 & 2,5 & $31,1-25,4$ \\
\hline $50 \mathrm{~m}$ & - & 1,3 & 1,4 & 1,47 & 1,59 & 1,68 & 1,84 & 1,96 & 2,16 & 2,32 & 2,5 & 2,5 & 2,5 & 2,5 & $34,4-28,1$ \\
\hline $47 \mathrm{~m}$ & - & - & 1,5 & 1,57 & 1,71 & 1,81 & 1.97 & 2,09 & 2,31 & 2.48 & 2.5 & 2.5 & 2.5 & 2.5 & $36,5-29,8$ \\
\hline $45 \mathrm{~m}$ & - & - & - & 1,7 & 1,84 & 1,94 & 2.2 & 2,25 & 2,49 & 2,5 & 2,5 & 2.5 & 2,5 & 2,5 & $38,9-31,8$ \\
\hline $42 m$ & - & - & - & - & 1,9 & 2,01 & 2,19 & 2,33 & 2,5 & 2,5 & 2,5 & 2,5 & 2,5 & 2,5 & $40,1-32,8$ \\
\hline $40 \mathrm{~m}$ & - & - & - & - & - & 2,1 & 2,29 & 2,43 & 2,5 & 2,5 & 2,5 & 2,5 & 2,5 & 2,5 & $40-34,2$ \\
\hline $37 \mathrm{~m}$ & - & - & - & - & - & - & 2,3 & 2,44 & 2,5 & 2,5 & 2,5 & 2,5 & 2,5 & 2,5 & $37 \cdot 34,3$ \\
\hline $35 \mathrm{~m}$ & - & - & - & - & - & - & - & 2,5 & 2,5 & 2,5 & 2,5 & 2.5 & 2,5 & 2,5 & 35 \\
\hline $32 \mathrm{~m}$ & - & - & - & - & - & - & - & - & 2,5 & 2,5 & 2,5 & 2.5 & 2,5 & 2,5 & 32 \\
\hline $30 \mathrm{~m}$ & - & - & - & - & - & - & - & - & - & 2,5 & 2,5 & 2,5 & 2,5 & 2,5 & 30 \\
\hline $27 \mathrm{~m}$ & - & - & - & - & - & - & - & - & - & - & 2,5 & 2.5 & 2,5 & 2,5 & 27 \\
\hline $25 \mathrm{~m}$ & - & - & - & - & - & - & - & - & - & - & - & 2.5 & 2,5 & 2,5 & 25 \\
\hline $22 \mathrm{~m}$ & - & - & - & - & - & - & - & - & - & - & - & - & 2,5 & 2,5 & 22 \\
\hline $20 \mathrm{~m}$ & - & - & - & - & - & - & - & - & - & - & - & - & - & 2,5 & 20 \\
\hline
\end{tabular}

\begin{tabular}{|c|c|c|c|c|c|c|c|c|c|c|c|c|c|c|c|c|}
\hline \multirow{3}{*}{$\frac{\mathrm{b} / \mathrm{d}}{\mathrm{D \textrm {m }}]}$} & \multicolumn{2}{|c|}{ SR / DR (t) } & \multicolumn{13}{|c|}{ 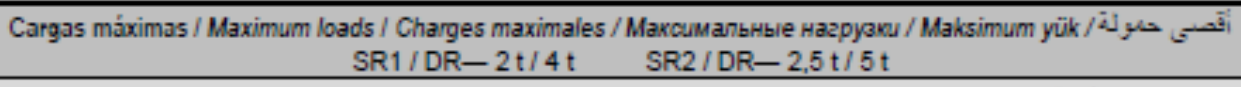 } & \multirow{3}{*}{$\begin{array}{c}\frac{2 t}{4 t}-\frac{2.5 t}{5 t} \\
0 . . .[m]\end{array}$} \\
\hline & \multicolumn{15}{|c|}{ 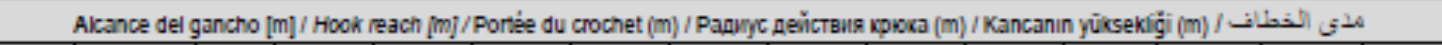 } & \\
\hline & 52 & 50 & 47 & 45 & 42 & 40 & 37 & 35 & 32 & 30 & 27 & 25 & 22 & 20 & 15 & \\
\hline $52 \mathrm{~m}$ & 0,95 & 1,01 & 1,09 & 1,16 & 1,27 & 1,35 & 1,49 & 1,6 & 1,78 & 1,93 & 2,19 & 2,39 & $\frac{2.5}{2, \pi}$ & $\frac{2.5}{3.09}$ & $\frac{2.5}{4.25}$ & $\frac{29,1}{15,9} \cdot \frac{24,1}{129}$ \\
\hline $50 \mathrm{~m}$ & - & 1,15 & 1,25 & 1,32 & 1,44 & 1,53 & 1,69 & 1,81 & 2,01 & 2,17 & 2,45 & $\frac{2.5}{2,69}$ & $\frac{2.5}{3,11}$ & $\frac{2.5}{3,09}$ & $\frac{2.5}{4.74}$ & $\frac{32,2}{17,5}-\frac{26.6}{14,3}$ \\
\hline $47 \mathrm{~m}$ & - & - & 1,35 & 1,42 & 1,55 & 1,65 & 1,62 & 1,94 & 2,16 & 2,33 & $\frac{2.5}{2.64}$ & $\frac{2.5}{2.88}$ & $\frac{2.5}{3,32}$ & $\frac{2,5}{3,7}$ & $\frac{2.5}{5}$ & $\frac{34,2}{18,6}-\frac{28,3}{15,2}$ \\
\hline $45 \mathrm{~m}$ & - & - & - & 1,55 & 1,69 & 1,79 & 1,97 & 2,1 & 2,34 & $\frac{2,5}{2,52}$ & $\frac{2.5}{2.84}$ & $\frac{2.5}{3.1}$ & $\frac{2.5}{3,58}$ & $\frac{2.5}{3,97}$ & $\frac{2.5}{5}$ & $\frac{36,5}{19,9}-\frac{30,2}{16,2}$ \\
\hline $42 \mathrm{~m}$ & - & - & - & - & 1,75 & 1,85 & 2,04 & 2,18 & 2,42 & $\frac{2.5}{2.6}$ & $\frac{2.5}{2.94}$ & $\frac{2.5}{32}$ & $\frac{2.5}{3,69}$ & $\frac{2.5}{4.1}$ & $\frac{2.5}{5}$ & $\frac{37,5}{20,5}-\frac{31,1}{16,7}$ \\
\hline $40 \mathrm{~m}$ & - & - & - & - & - & 1,95 & 2,14 & 2,28 & $\frac{2.5}{2.53}$ & $\frac{2.5}{2,73}$ & $\frac{2.5}{3.07}$ & $\frac{2.5}{3,35}$ & $\frac{2.5}{3,86}$ & $\frac{2.5}{4.29}$ & $\frac{2.5}{5}$ & $\frac{39,2}{21,3}-\frac{324}{174}$ \\
\hline $37 \mathrm{~m}$ & - & - & - & - & - & - & 2,15 & 2,20 & $\frac{2.5}{2.54}$ & $\frac{2,5}{2,74}$ & $\frac{2,5}{3,09}$ & $\frac{2.5}{3,37}$ & $\frac{2.5}{3,68}$ & $\frac{2.5}{4.31}$ & $\frac{2.5}{5}$ & $\frac{37}{21,4}-\frac{325}{17.4}$ \\
\hline $35 \mathrm{~m}$ & - & - & - & - & - & - & - & 2,35 & $\frac{2.5}{2.6}$ & $\frac{2.5}{2,8}$ & $\frac{2.5}{3.16}$ & $\frac{2.5}{3,4}$ & $\frac{2.5}{3,97}$ & $\frac{2.5}{4.40}$ & $\frac{2.5}{5}$ & $\frac{35}{21,8}-\frac{33,1}{17,8}$ \\
\hline $32 \mathrm{~m}$ & - & - & - & - & - & - & - & - & 2,35 & $\frac{2,5}{2,53}$ & $\frac{2,5}{2,55}$ & $\frac{25}{3,11}$ & $\frac{2.5}{3,59}$ & $\frac{2.5}{3,99}$ & $\frac{2.5}{5}$ & $\frac{32}{20}-\frac{30,3}{16,3}$ \\
\hline $30 \mathrm{~m}$ & - & - & - & - & - & - & - & - & - & $\frac{2,5}{2,9}$ & $\frac{2.5}{3.26}$ & $\frac{25}{3,56}$ & $\frac{2.5}{4,09}$ & $\frac{2.5}{4.54}$ & $\frac{2.5}{5}$ & $\frac{30}{22.5} \cdot \frac{30}{18.3}$ \\
\hline $27 \mathrm{~m}$ & - & - & - & - & - & - & - & - & - & - & $\frac{2.5}{3,3}$ & $\frac{2.5}{3,59}$ & $\frac{2.5}{4,14}$ & $\frac{2.5}{4.59}$ & $\frac{2.5}{5}$ & $\frac{27}{22,7} \cdot \frac{27}{18.5}$ \\
\hline $25 \mathrm{~m}$ & - & - & - & - & - & - & - & - & - & - & - & $\frac{2.5}{3.7}$ & $\frac{2.5}{4,25}$ & $\frac{2.5}{4,72}$ & $\frac{2.5}{5}$ & $\frac{25}{23.3}-\frac{25}{19}$ \\
\hline $22 \mathrm{~m}$ & - & - & - & - & - & - & - & - & - & - & - & - & $\frac{2.5}{4.2}$ & $\frac{2.5}{4.67}$ & $\frac{2.5}{5}$ & $\frac{22}{22} \cdot \frac{22}{18,7}$ \\
\hline $20 \mathrm{~m}$ & - & - & - & - & - & - & - & - & - & - & - & - & - & $\frac{2,5}{4,7}$ & $\frac{2,5}{5}$ & $\frac{20}{20} \cdot \frac{20}{18,9}$ \\
\hline
\end{tabular}

Figura 5.35: Extracto de la página no 2 de las tablas oficiales de la grúa J52NS

El momento que obtenemos por tanto a radio mínimo es de:

MomRmin $=5 \times 2=10$ m.t 
Procedemos de la misma manera para el radio máximo:

En la misma página no 2 hayamos la configuración de pluma de 52 metros que nos permite trabajar a un máximo de 52 metros de radio con una capacidad de 1,1 toneladas en punta como se puede observar en la tabla anterior (de simple tiro).

En este caso en momento será:

$\operatorname{MomRmax}=1,1 \times 52=57,2 \mathrm{~m} . \mathrm{t}$

Para un radio de 30 metros, se tiene la máxima capacidad con pluma de 30 metros de longitud y doble tiro. Como se puede ver en la tabla anterior, dicha capacidad es de 2,9 toneladas:

En este caso en momento será:

MomR30 $=30 \times 2,9=87$ m.t

El momento Máximo de la grúa J52NS es de 94,5 m.t $(5 \mathrm{~m} \times 18,9)$ que como vemos es algo superior aunque bastante similar al obtenido para radio $=30$ metros.

En el caso de esta grúa el momento máximo se obtiene con doble tiro y en el radio máximo de la zona plana de la curva de capacidades. Es decir, en el punto en el que cambia la limitación de capacidad por tiro a limitación por vuelco. 
Los resultados de capacidades obtenidos para la grúa J52NS se resumen en la siguiente tabla:

\begin{tabular}{|l|l|}
\hline & Grúa Torre \\
& J52NS \\
\hline Radio minimo & \\
\hline ton a Rmin & 2,00 \\
\hline Radio máximo & 5,00 \\
\hline ton a Rmax & 52,00 \\
\hline Radio 30 & 1,10 \\
\hline Mon a R30 & 54,50 \\
\hline & \\
\hline Mom Rmin & 30,00 \\
\hline
\end{tabular}

Figura 5.36: Tabla resumen de resultados técnicos obtenidos para la grúa J52NS 


\section{3.- ANÁLISIS ECONOMICO FINANCIERO}

Se procede a realizar un estudio económico financiero básico de las máquinas seleccionadas para obtener el coste horario de cada una de ellas (tal y como se ha indicado en la metodología anteriormente).

Como se ha indicado en la metodología, el coste por hora de máquina se va a componer de los siguientes costes:

- Amortización.

- Costes financieros / Intereses.

- Consumos.

- Mantenimiento.

- Coste del operador.

\subsection{1.- Amortización}

El precio de compra de la maquina es como ya hemos dicho complejo de obtener ya que se trata de valores que no se divulgan por motivos comerciales de las empresas fabricantes.

Para este estudio se han obtenido los valores correspondientes a estas máquinas de fuentes de algunas empresas alquiladoras, concretamente una local de ámbito Español y otras de ámbito multinacional.

Lógicamente, dichos precios dependen del poder de compra de cada empresa, no compra igual una empresa que haga una gran cantidad de pedidos de grúas a un fabricante que una que compre una máquina cada varios años. También dependen de la situación del mercado mundial, costes de fabricación en cada momento, etc.

Dichos precios pueden por lo tanto tener ciertas variaciones y se han tomado valores medios para realizar este análisis. Como ya se ha comentado, esto precios de compra de la máquina 
sin embargo no varían tanto como pueda variar el precio de alquiler de la máquina en el mercado. El precio de venta es al fin y al cabo un precio que viene de unos costes de producción y diseño de la máquina que se encuentran dentro de un rango. El precio de alquiler de una máquina es más bien un servicio y por ello depende de muchos más factores incluyendo las posibilidades comerciales de cobrarlo a precios más independientes de sus costes reales.

Además de lo anterior, el precio de venta de las grúas depende enormemente de cómo se compre de completa y los accesorios que se compren. Para este análisis se han considerado precios de venta de grúas bastante completas pero dentro de la normalidad, es decir, sin incluir todos los posibles accesorios disponibles.

Para calcular el coste de amortización, se van a utilizar los procedimientos y valores más habituales en el mercado como son el 15\% de amortización anual, es decir, amortizar la grúa en 6,67 años.

Considerando las 52 semanas del año con 5 días hábiles en general y 10 horas cada día (es un valor habitual de uso diario de las grúas), se obtiene:

$52 \times 5 \times 10$ horas $=2.600$ horas.

Es imposible pensar en una utilización de la máquina del 100\% de las horas. A pesar que en ocasiones hagan horas extras los fines de semana o por las noches, también habrá días festivos, paradas obligatorias por averías, etc. Por ello consideraremos horas útiles a nivel de amortización el $80 \%$ de las horas totales:

$2.600 \times 0,80=2.080$ horas anuales.

Con lo anterior, la repercusión del coste de amortización por hora utilizable de la máquina es igual a:

Precio de compra x 0,15 / 2.080

Los precios medios de las grúas estudiadas, son los siguientes: 
Grúas de Celosía:

LR11350: $14.000 .000 €$

CC2800: 5.000.000€

2200E: $900.000 €$

Grúas telescópicas:

AC700: $4.500 .000 €$

LTM1200: $1.500 .000 €$

GMK4080: 480.000€

Grúas torre:

MD3200: $3.200 .000 €$

MD610 M40: 850.000€

J52NS: $90.000 €$

Y se obtienen los siguientes valores de costes de amortización por hora:

Grúas de Celosía:

LR11350: 1009,62 €/ h

CC2800: $360,58 € / h$

2200E: $64,90 € / h$ 
Grúas telescópicas:

AC700: $324,52 € / h$

LTM1200: 108,17 €/h

GMK4080: $34,62 € / h$

Grúas torre:

MD3200: $230,77 € / h$

MD610 M40: 61,30 € / h

J52NS: $6,49 € / h$ 


\subsection{2.- Costes financieros}

Es necesario repercutir los costes financieros del capital en el coste por hora de la grúa. Cuando las empresas alquiladoras compran sus grúas o incluso cuando las compran clientes finales, ya no se realiza habitualmente mediante el pago de la cantidad total inicial sino que se usan modelos de Renting, leasing, etc. que frecuentemente ofrecen directamente los fabricantes sin necesidad de "acudir al banco" de la empresa alquiladora. Los fabricantes principales son como hemos dicho grandes multinacionales con capacidad financiera importante.

De una manera o de otra, se incurre en unos costes financieros que al final repercuten en el precio hora de la grúa. Para este análisis comparativo, se calcula la repercusión de estos costes financieros mediante los intereses del capital invertido.

Las empresas de grúas en el mundo suelen ser Pymes ya que incluso las mayores empresas que operan a nivel mundial no se pueden considerar grandes multinacionales como lo son sus proveedores, los fabricantes de máquinas.

Se quiere evitar introducir en este análisis presupuestario temas relativos a riesgos puramente financieros como son: el riesgo de liquidez (riesgos de refinanciación en caso de elegir financiar la máquina con un préstamo anual más barato) por lo que se considera un crédito por el periodo de amortización de la máquina; el riesgo de tipo de interés, por lo que se evita un interés variable; o el riesgo de divisa. Se considera que la dirección financiera, banco o leaser ha cubierto dichos riesgos incluyéndolos en el coste de financiación del empresario industrial.

Para dicho crédito se tomará por tanto un tipo de interés fijo para un préstamo a plazo medio a 7 años del $6 \%$ que es razonable en el mercado para este tipo de empresa y plazo. Se pretende también con este valor tener una magnitud que dependa lo menos posible, dentro de lo que cabe, de la coyuntura de un momento muy concreto sino que sea un valor medio aceptable en los últimos tiempos.

Se calcula a continuación el interés total para cada grúa y para el periodo considerado: 
Grúas de Celosía:

Grúa Liebherr LR11350: Total de intereses 2.814.000 Euros según el siguiente cuadro:

\begin{tabular}{|l|c|}
\hline Precio grúa & 14.000 .000 \\
\hline Amortización & $15 \%$ \\
\hline Coste capital (intereses) $\left(^{*}\right)$ & $6 \%$ \\
\hline
\end{tabular}

\begin{tabular}{|c|r|r|r|r|r|}
\hline Ano & Valor inicial & Amortización & Valor contable final & Valor medio & Intereses \\
\hline 1 & 14.000 .000 & 2.100 .000 & 11.900 .000 & 12.950 .000 & 777.000 \\
\hline 2 & 11.900 .000 & 2.100 .000 & 9.800 .000 & 10.850 .000 & 651.000 \\
\hline 3 & 9.800 .000 & 2.100 .000 & 7.700 .000 & 8.750 .000 & 525.000 \\
\hline 4 & 7.700 .000 & 2.100 .000 & 5.600 .000 & 6.650 .000 & 399.000 \\
\hline 5 & 5.600 .000 & 2.100 .000 & 3.500 .000 & 4.550 .000 & 273.000 \\
\hline 6 & 3.500 .000 & 2.100 .000 & 1.400 .000 & 2.450 .000 & 147.000 \\
\hline 7 & 1.400 .000 & 1.400 .000 & - & 700.000 & 42.000 \\
\hline & & & & Total intereses & 2.814 .000 \\
\hline
\end{tabular}

Figura 5.37: Calculo de intereses para la grúa LR11350

Grúa Terex Demag CC2800: Total de intereses 1.005.000 Euros según el siguiente cuadro:

\begin{tabular}{|c|c|c|c|c|c|}
\hline Precio grúa & 5.000 .000 & & & & \\
\hline Amortización & $15 \%$ & & & & \\
\hline Coste capital (intereses) $\left(^{*}\right)$ & $6 \%$ & & & & \\
\hline Ano & Valor inicial & Amortización & Valor contable final & Valor medio & Intereses \\
\hline 1 & 5.000 .000 & 750.000 & 4.250 .000 & 4.625 .000 & 277.500 \\
\hline 2 & 4.250 .000 & 750.000 & 3.500 .000 & 3.875 .000 & 232.500 \\
\hline 3 & 3.500 .000 & 750.000 & 2.750 .000 & 3.125 .000 & 187.500 \\
\hline 4 & 2.750 .000 & 750.000 & 2.000 .000 & 2.375 .000 & 142.500 \\
\hline 5 & 2.000 .000 & 750.000 & 1.250 .000 & 1.625 .000 & 97.500 \\
\hline 6 & 1.250 .000 & 750.000 & 500.000 & 875.000 & 52.500 \\
\hline \multirow[t]{2}{*}{7} & 500.000 & 500.000 & - & 250.000 & 15.000 \\
\hline & & & & Total intereses & 1.005 .000 \\
\hline
\end{tabular}

Figura 5.38: Calculo de intereses para la grúa CC2800 
Grúa Sennebogen 2200E: Total de intereses 180.900 Euros según el siguiente cuadro:

\begin{tabular}{|c|c|c|c|c|c|}
\hline Precio grúa & 900.000 & & & & \\
\hline Amortización & $15 \%$ & & & & \\
\hline Coste capital (intereses) $\left(^{*}\right)$ & $6 \%$ & & & & \\
\hline Ano & Valor inicial & Amortización & Valor contable final & Valor medio & Intereses \\
\hline 1 & 900.000 & 135.000 & 765.000 & 832.500 & 49.950 \\
\hline 2 & 765.000 & 135.000 & 630.000 & 697.500 & 41.850 \\
\hline 3 & 630.000 & 135.000 & 495.000 & 562.500 & 33.750 \\
\hline 4 & 495.000 & 135.000 & 360.000 & 427.500 & 25.650 \\
\hline 5 & 360.000 & 135.000 & 225.000 & 292.500 & 17.550 \\
\hline 6 & 225.000 & 135.000 & 90.000 & 157.500 & 9.450 \\
\hline \multirow[t]{2}{*}{7} & 90.000 & 90.000 & - & 45.000 & 2.700 \\
\hline & & & & Total intereses & 180.900 \\
\hline
\end{tabular}

Figura 5.39: Calculo de intereses para la grúa $2200 E$

Grúa Terex Demag AC700: Total de intereses 904.000 Euros según el siguiente cuadro:

\begin{tabular}{|c|c|c|c|c|c|}
\hline Precio grúa & 4.500 .000 & & & & \\
\hline Amortización & $15 \%$ & & & & \\
\hline Coste capital (intereses) $\left(^{*}\right)$ & $6 \%$ & & & & \\
\hline Ano & Valor inicial & Amortización & Valor contable final & Valor medio & Intereses \\
\hline 1 & 4.500 .000 & 675.000 & 3.825 .000 & 4.162 .500 & 249.750 \\
\hline 2 & 3.825 .000 & 675.000 & 3.150 .000 & 3.487 .500 & 209.250 \\
\hline 3 & 3.150 .000 & 675.000 & 2.475 .000 & 2.812 .500 & 168.750 \\
\hline 4 & 2.475 .000 & 675.000 & 1.800 .000 & 2.137 .500 & 128.250 \\
\hline 5 & 1.800 .000 & 675.000 & 1.125 .000 & 1.462 .500 & 87.750 \\
\hline 6 & 1.125 .000 & 675.000 & 450.000 & 787.500 & 47.250 \\
\hline \multirow[t]{2}{*}{7} & 450.000 & 450.000 & - & 225.000 & 13.500 \\
\hline & & & & Total intereses & 904.500 \\
\hline
\end{tabular}

Figura 5.40: Calculo de intereses para la grúa AC700 
Grúa Liebherr LTM1200: Total de intereses 301.500 según el siguiente cuadro:

\begin{tabular}{|l|c|}
\hline Precio grúa & 1.500 .000 \\
\hline Amortización & $15 \%$ \\
\hline Coste capital (intereses) $\left(^{*}\right)$ & $6 \%$ \\
\hline
\end{tabular}

\begin{tabular}{|c|r|r|r|r|r|}
\hline Ano & Valor inicial & Amortización & Valor contable final & Valor medio & Intereses \\
\hline 1 & 1.500 .000 & 225.000 & 1.275 .000 & 1.387 .500 & 83.250 \\
\hline 2 & 1.275 .000 & 225.000 & 1.050 .000 & 1.162 .500 & 69.750 \\
\hline 3 & 1.050 .000 & 225.000 & 825.000 & 937.500 & 56.250 \\
\hline 4 & 825.000 & 225.000 & 600.000 & 712.500 & 42.750 \\
\hline 5 & 600.000 & 225.000 & 375.000 & 487.500 & 29.250 \\
\hline 6 & 375.000 & 225.000 & 150.000 & 262.500 & 15.750 \\
\hline 7 & 150.000 & 150.000 & - & 75.000 & 4.500 \\
\hline & & & & Total intereses & 301.500 \\
\hline
\end{tabular}

Figura 5.41: Calculo de intereses para la grúa LTM1200

Grúa Grove GMK4080: Total de intereses 96.480 Euros según el siguiente cuadro:

\begin{tabular}{|l|c|}
\hline Precio grúa & 480.000 \\
\hline Amortización & $15 \%$ \\
\hline Coste capital (intereses) $\left(^{*}\right)$ & $6 \%$ \\
\hline
\end{tabular}

\begin{tabular}{|c|r|r|r|r|r|}
\hline Ano & Valor inicial & Amortización & Valor contable final & Valor medio & Intereses \\
\hline 1 & 480.000 & 72.000 & 408.000 & 444.000 & 26.640 \\
\hline 2 & 408.000 & 72.000 & 336.000 & 372.000 & 22.320 \\
\hline 3 & 336.000 & 72.000 & 264.000 & 300.000 & 18.000 \\
\hline 4 & 264.000 & 72.000 & 192.000 & 228.000 & 13.680 \\
\hline 5 & 192.000 & 72.000 & 120.000 & 156.000 & 9.360 \\
\hline 6 & 120.000 & 72.000 & 48.000 & 84.000 & 5.040 \\
\hline 7 & 48.000 & 48.000 & - & 24.000 & 1.440 \\
\hline & & & & Total intereses & 96.480 \\
\hline
\end{tabular}

Figura 5.42: Calculo de intereses para la grúa GMK4080 
Grúa Potain MD3200: Total de intereses 643.200 Euros según el siguiente cuadro:

\begin{tabular}{|c|c|c|c|c|c|}
\hline Precio grúa & 3.200 .000 & & & & \\
\hline Amortización & $15 \%$ & & & & \\
\hline Coste capital (intereses) $\left(^{*}\right)$ & $6 \%$ & & & & \\
\hline Ano & Valor inicial & Amortización & Valor contable final & Valor medio & Intereses \\
\hline 1 & 3.200 .000 & 480.000 & 2.720 .000 & 2.960 .000 & 177.600 \\
\hline 2 & 2.720 .000 & 480.000 & 2.240 .000 & 2.480 .000 & 148.800 \\
\hline 3 & 2.240 .000 & 480.000 & 1.760 .000 & 2.000 .000 & 120.000 \\
\hline 4 & 1.760 .000 & 480.000 & 1.280 .000 & 1.520 .000 & 91.200 \\
\hline 5 & 1.280 .000 & 480.000 & 800.000 & 1.040 .000 & 62.400 \\
\hline 6 & 800.000 & 480.000 & 320.000 & 560.000 & 33.600 \\
\hline 7 & 320.000 & 320.000 & - & 160.000 & 9.600 \\
\hline & & & & Total intereses & 643.200 \\
\hline
\end{tabular}

Figura 5.43: Calculo de intereses para la grúa MD3200

Grúa Potain MD610 M40: Total de intereses 170.850 Euros según el siguiente cuadro:

\begin{tabular}{|c|c|c|c|c|c|}
\hline Precio grúa & 850.000 & & & & \\
\hline Amortización & $15 \%$ & & & & \\
\hline Coste capital (intereses) $\left(^{\star}\right)$ & $6 \%$ & & & & \\
\hline Ano & Valor inicial & Amortización & Valor contable final & Valor medio & Intereses \\
\hline 1 & 850.000 & 127.500 & 722.500 & 786.250 & 47.175 \\
\hline 2 & 722.500 & 127.500 & 595.000 & 658.750 & 39.525 \\
\hline 3 & 595.000 & 127.500 & 467.500 & 531.250 & 31.875 \\
\hline 4 & 467.500 & 127.500 & 340.000 & 403.750 & 24.225 \\
\hline 5 & 340.000 & 127.500 & 212.500 & 276.250 & 16.575 \\
\hline 6 & 212.500 & 127.500 & 85.000 & 148.750 & 8.925 \\
\hline \multirow[t]{2}{*}{7} & 85.000 & 85.000 & - & 42.500 & 2.550 \\
\hline & & & & Total intereses & 170.850 \\
\hline
\end{tabular}

Figura 5.44: Calculo de intereses para la grúa MD610 40 
Grúa Jaso J52NS: Total de intereses 18.090 Euros según el siguiente cuadro:

\begin{tabular}{|c|c|c|c|c|c|}
\hline Precio grúa & 90.000 & & & & \\
\hline Amortización & $15 \%$ & & & & \\
\hline Coste capital (intereses) $\left(^{*}\right)$ & $6 \%$ & & & & \\
\hline Ano & Valor inicial & Amortización & Valor contable final & Valor medio & Intereses \\
\hline 1 & 90.000 & 13.500 & 76.500 & 83.250 & 4.995 \\
\hline 2 & 76.500 & 13.500 & 63.000 & 69.750 & 4.185 \\
\hline 3 & 63.000 & 13.500 & 49.500 & 56.250 & 3.375 \\
\hline 4 & 49.500 & 13.500 & 36.000 & 42.750 & 2.565 \\
\hline 5 & 36.000 & 13.500 & 22.500 & 29.250 & 1.755 \\
\hline 6 & 22.500 & 13.500 & 9.000 & 15.750 & 945 \\
\hline \multirow[t]{2}{*}{7} & 9.000 & 9.000 & - & 4.500 & 270 \\
\hline & & & & Total intereses & 18.090 \\
\hline
\end{tabular}

Figura 5.45 : Calculo de intereses para la grúa J52NS

La distribución de estos costes por hora se realiza de forma uniforme en las horas totales de las máquinas y por lo tanto en las mismas horas consideradas que para las amortizaciones.

Esto implica que las horas totales del periodo de amortización total de cada grúa resulten:

2.080 horas $\times 1 / 0,15=13.867$ horas

Se obtienen los siguientes valores de costes de intereses por hora para cada grúa:

LR11350: $2.814 .000 / 13.867=202,93 € /$ hora

CC2800: $1.005 .000 / 13.867=72,47 € /$ hora

2200E: $180.900 / 13.867=13,05 € /$ hora

AC700: $904.500 / 13.867=95,23 € /$ hora

LTM1200: $301.500 / 13.867=21,74 € /$ hora

GMK4080: $96.480 / 13.867=6,96 € /$ hora

MD3200: $643.200 / 13.867=46,38 € /$ hora

MD610 M40: $170.850 / 13.867=12,32 € /$ hora

J52NS: $18.090 / 13.867=1,30 € /$ hora 


\subsection{3.- Consumos}

Es difícil calcular una utilización media de cualquier grúa y por lo tanto sus consumos ya que habrá momentos en los que esté en obra y otros almacenada esperando trabajo, cuando esté en obra, la variedad también es enorme: en algunas obras la grúa es una máquina a la que hay que "exprimir" y se trata de optimizar al máximo su rendimiento obteniendo el máximo de ciclos posible y hay en obras que se necesita una grúa para izados muy puntuales y la máquina está la mayor parte del tiempo parada esperando las escasas maniobras a realizar.

Por estos motivos, para las grúas con motores diesel (celosía y telescópica) se utilizan en para este análisis datos empíricos de consumo proporcionados por empresas operadoras de dichas máquinas:

LR11350: 18 litros por hora

CC2800: 10 litros por hora

2200E: 5 litros por hora

AC700: 12 litros por hora

LTM1200: 8,3 litros por hora

GMK4080: 6 litros por hora

(En estos valores están todas las horas de parada dentro de las horas "hábiles" de utilización de grúa que se han usado para su amortización)

Utilizando un precio medio del diesel de 1,2€/L:

LR11350: $21,60 € / h$

CC2800: $12,00 € / \mathrm{h}$

2200E: $6,00 € / h$

AC700: $14,40 € / h$

LTM1200: 9,96 €/h 
GMK4080: 7,20 €/h

(Se ha utilizado un precio del diesel de circulación y no industrial ya que en muchos casos la grúa circula y porque se tiende a usar cada vez menos el diesel "rojo")

En el caso de las grúas torre, el consumo fundamental es eléctrico, estimando un coste de 0,12 $€ /$ KWh, y dado que las características de las grúas Potain elegidas indican 200KW para elevación que es su consumo principal, calculamos el consumo que realiza pero teniendo también en cuenta que hay que aplicar el coeficiente reductor ya que cuando la grúa está en obra, no trabaja a toda la potencia constantemente como se ha comentado ya.

Considerando un $80 \%$ de utilización (estancia en obra) y que dentro de ese periodo la grúa está activa un $75 \%$ del tiempo y que su consumo máximo sólo se produce durante el $50 \%$ de su actividad, el coeficiente reductor final será: $0,8 \times 0,75 \times 0,5=0,3$

Y por lo tanto un consumo de $200 \times 0,12 \times 0,3=7,20 € / \mathrm{h}$

Para la grúa Jaso: $34 \times 0,12 \times 0,3=1,22 € / h$

\subsection{4.- Mantenimiento}

En el caso del mantenimiento la solución para la estimación de costes es la obtención de valores empíricos de la realidad.

En este estudio se ha considerado una amortización del $15 \%$ anual por ser de uso frecuente en el sector pero hay que tener en cuenta que es una amortización muy fuerte para los altos precios de esta maquinaria. Debido a esto los costes por hora de esta amortización son elevados pero sin embargo los costes de mantenimiento serán más reducidos ya que la edad de las máquinas en el periodo considerado es reducida lo cual implica que realizando un correcto mantenimiento regular de las máquinas y cuidando los equipos como es debido (misión fundamental del personal y de las empresas propietarias), la probabilidad de ocurrencia de averías en el periodo de amortización es muy reducida. Las pocas averías serán 
frecuentemente por temas de fabricación y estarán cubiertas por la garantía de las máquinas (incluida en el precio de compra).

Se ha consultado como en casos anteriores a empresas de elevación de ámbito internacional y alguna de ámbito nacional y se concluye que se pueden usar los valores medios anuales que dividimos por las 13.867 horas del periodo considerado para obtener los costes horarios:

LR11350: $58.000 € / 13.867$ horas $=4,18 €$

CC2800: $18.000 €$ anuales $/ 13.867$ horas $=1,30 €$

2200E: $11.000 €$ anuales / 13.867 horas $=0,79 €$

AC700: $47.000 €$ anuales $/ 13.867$ horas $=3,38 €$

LTM1200: $25.000 €$ anuales / 13.867 horas $=1,80 €$

GMK4080: $13.000 €$ anuales $/ 13.867$ horas $=0,93 €$

MD3200: $10.000 €$ anuales / 13867 horas $=0,72 €$

MD610 M40: 8.000€ anuales / 13.867 horas $=0,58 €$

J52NS: $3.000 €$ anuales $/ 13.867$ horas $=0,22 €$

Como era de esperar, el mantenimiento más barato es el de la grúa torre y el más caro es el de la telescópica ya que la pluma es más compleja y lleva más mecánica en general (camión de transporte por carretera, etc. 


\subsection{5.- Operador}

Los costes empresa de los operadores de grúas son valores más fáciles de obtener aunque lógicamente varían de una empresa a otra, en función de la cualificación y antigüedad de cada trabajador, en función del país considerado, etc.

Hay que tener en cuenta que los gruistas suelen ser unos trabajadores muy especializados a los que además se les pide mucha movilidad laboral ya que las grúas móviles pueden cambiar de obra frecuentemente. En el caso de las grúas de celosía pueden cambiar fácilmente de Comunidad Autónoma o de país aunque para los tamaños que estamos considerando, rara vez cambian de continente como sería el caso para grúas por encima de las 1200 toneladas aproximadamente.

Estas grúas de muy gran tamaño y capacidad requieren como hemos explicado de una zona geográfica muy grande para que existan los suficientes trabajos que las hagan viables comercialmente y ello implica que el salto de una obra a la siguiente requiera incluso cambiar de continente. Ello repercute también en los sueldos y dietas de los gruistas y finalmente en el coste por hora de la máquina. Si bien es cierto que el coste del gruista es también menor proporcionalmente cuanto más grande es la máquina ya que su sueldo no sube proporcionalmente al precio de la grúa que opera incluso aunque se tenga en cuenta que las grandes grúa suelen llevar como personal permanente 2 o 3 personas en lugar de 1.

Se consideran en este estudio costes medios para España que por otro lado son relativamente similares a los de Europa.

Se ha considerado 1 gruista por cada grúa aunque como hemos señalado la CC2800 es una grúa media que en ocasiones (especialmente con contrapeso superlift, etc.) se opera con una segunda persona como ayudante. 
Los costes empresa medios obtenidos para los gruistas para cada grúa son:

LR11350: 50,00€/hora

CC2800: $45,00 € /$ hora

2200E: $30 € /$ hora

AC700: $40 € /$ hora

LTM1200: 30,00€ / hora

GMK4080: $25 €$ / hora

MD3200: $30 € /$ hora

MD610 M40: 25,00 € / hora

J52NS: $20 € /$ hora 


\subsection{6.- Resumen del análisis económico}

Se adjuntan en las siguientes tablas los datos económicos y financieros obtenidos en los apartados anteriores. Sumando los costes horarios obtenidos para cada máquina obtenemos el coste horario total de cada grúa.

\section{Grúas de Celosía:}

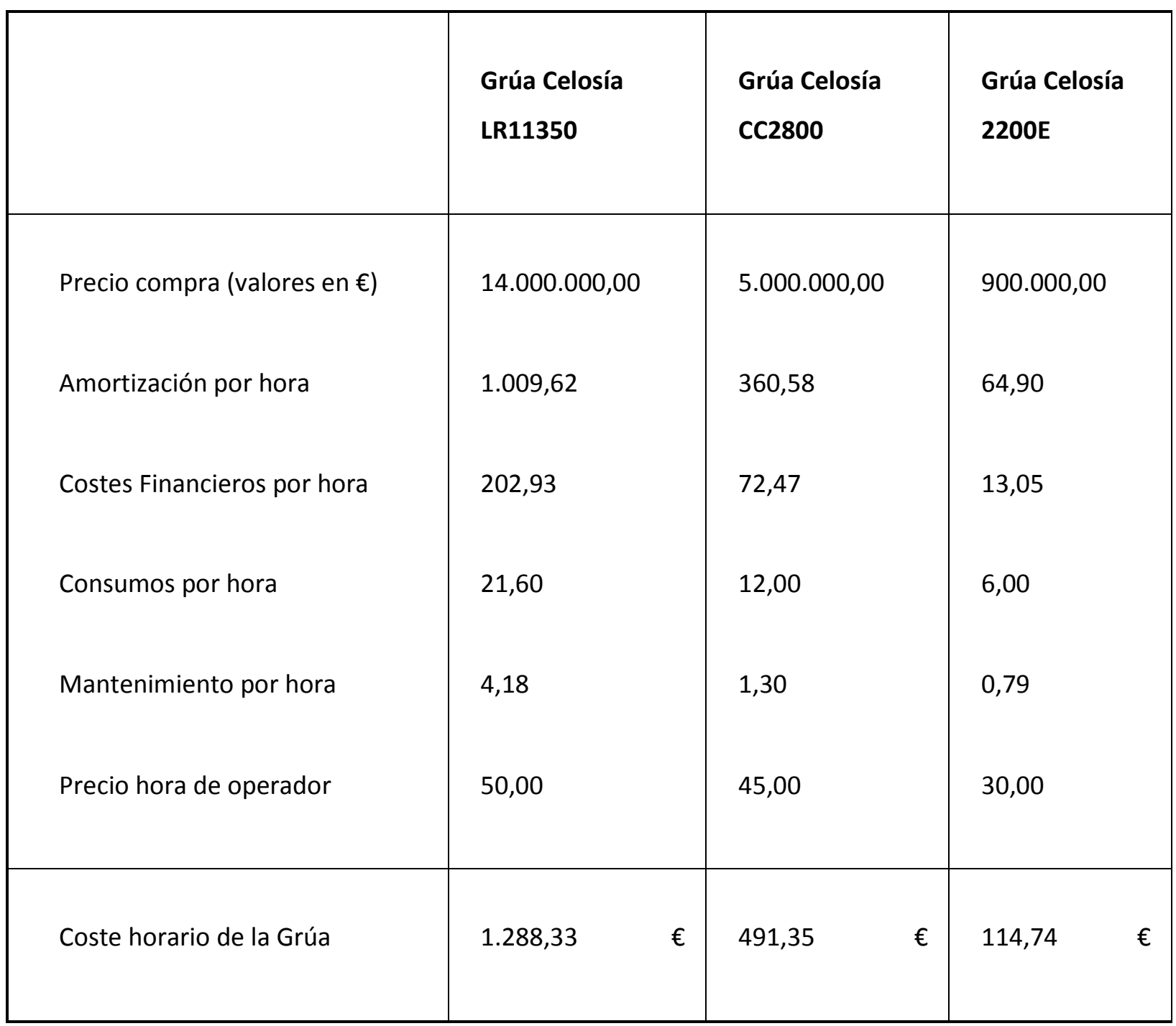

(Valores en Euros)

Figura 5.46: Tabla resumen de resultados económicos obtenidos para las grúas de celosía 
Grúas de Telescópicas:

\begin{tabular}{|c|c|c|c|}
\hline & $\begin{array}{l}\text { Grúa Telescópica } \\
\text { AC700 }\end{array}$ & $\begin{array}{l}\text { Grúa Telescópica } \\
\text { LTM1200 }\end{array}$ & $\begin{array}{l}\text { Grúa Telescópica } \\
\text { GMK1080 }\end{array}$ \\
\hline Precio compra (valores en $€$ ) & $4.500 .000,00$ & $1.500 .000,00$ & $480.000,00$ \\
\hline Amortización por hora & 324,52 & 108,17 & 34,62 \\
\hline Costes Financieros por hora & 95,23 & 21,74 & 6,96 \\
\hline Consumos por hora & 14,40 & 9,96 & 7,20 \\
\hline Mantenimiento por hora & 3,38 & 1,80 & 0,93 \\
\hline Precio hora de operador & 40,00 & 30,00 & 25,00 \\
\hline Coste horario de la Grúa & 477,53 & 171,67 & 74,71 \\
\hline
\end{tabular}

(Valores en Euros)

Figura 5.47: Tabla resumen de resultados económicos obtenidos para las grúas telescópicas 
Grúas de Telescópicas:

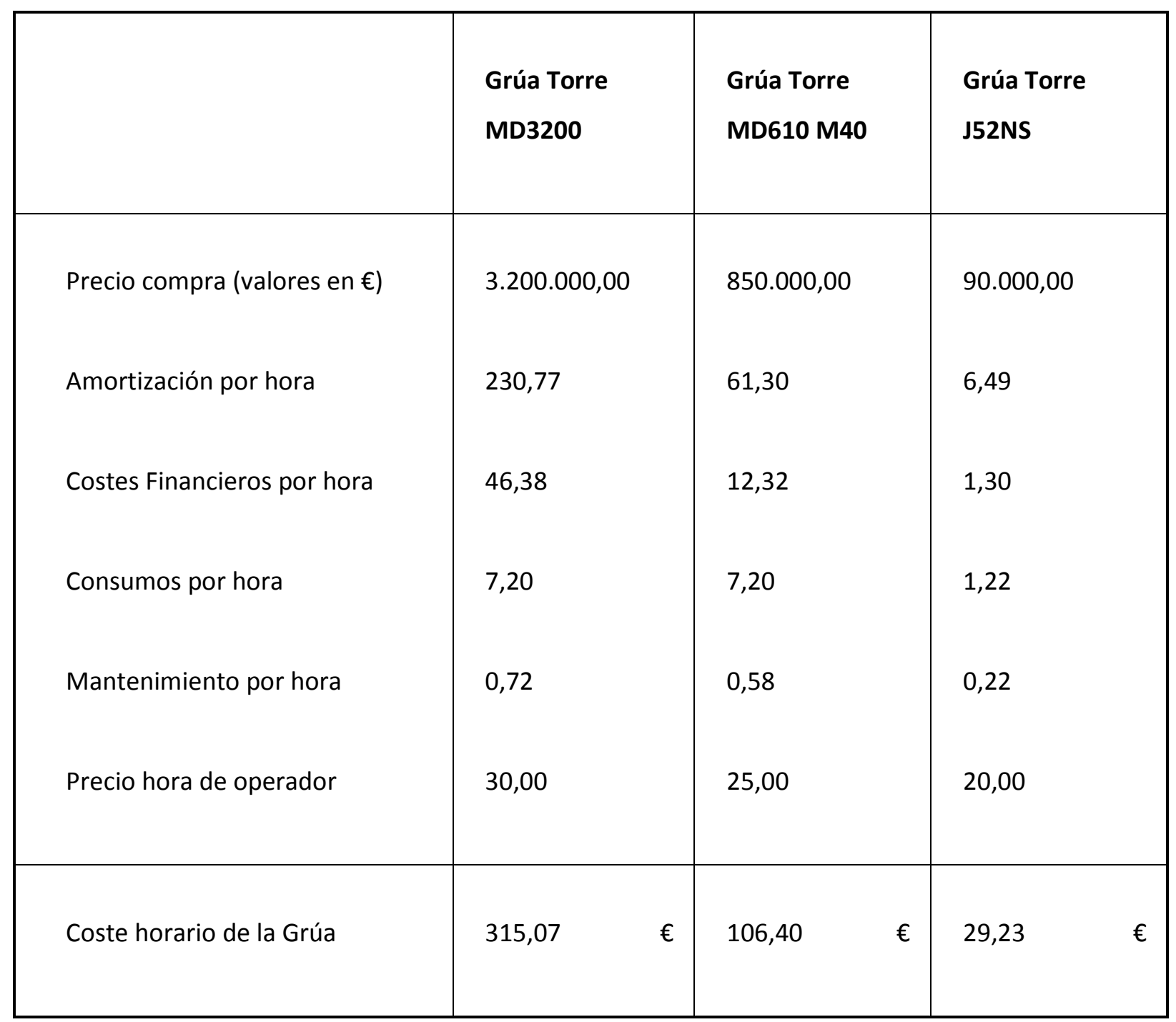

(Valores en Euros)

Figura 5.48: Tabla resumen de resultados económicos obtenidos para las grúas torre 


\section{4.- COMPARATIVA Y ANÁLISIS DE RESULTADOS}

Con todos los resultados obtenidos anteriormente tanto a nivel técnico como económico, se realiza una comparativa con el fin de obtener conclusiones que muestren ventajas e inconvenientes de cada tipo de grúa y también de las variaciones en función de la capacidad de las mismas.

Asimismo permite una reflexión sobre los parámetros que mejor pueden ayudar a evaluar las capacidades reales de las máquinas y ver en qué medida puede afectar todo ello a la investigación y desarrollo de nuevas máquinas en el futuro.

A partir de los datos, se calculan para ello los siguientes ratios y se incluyen también en la tabla:

- Coste horario de la grúa / Capacidad en Toneladas Nominales

- Coste horario de la grúa / Capacidad en máximo momento admisible (MLM, en mt)

Al analizar los resultados es importante tener en cuenta las tipologías de las máquinas y como estas influyen también en ellos.

Se incluye a continuación una tabla con el resumen de los todos datos obtenidos: 
Figura 5.49: Tabla resumen general de resultados obtenidos:

\begin{tabular}{|c|c|c|c|c|c|c|c|c|c|}
\hline & $\begin{array}{l}\text { Grúa Celosía } \\
\text { LR11350 }\end{array}$ & $\begin{array}{l}\text { Grúa Celosía } \\
\text { CC2800 }\end{array}$ & $\begin{array}{l}\text { Grúa Celosía } \\
2200 E\end{array}$ & $\begin{array}{l}\text { Grúa Telescópica } \\
\text { AC700 }\end{array}$ & $\begin{array}{l}\text { Grúa Telescópica } \\
\text { LTM1200 }\end{array}$ & $\begin{array}{l}\text { Grúa Telescópica } \\
\text { GMK1080 }\end{array}$ & $\begin{array}{l}\text { Grúa Torre } \\
\text { MD3200 }\end{array}$ & $\begin{array}{l}\text { Grúa Torre } \\
\text { MD610 M40 }\end{array}$ & $\begin{array}{l}\text { Grúa Torre } \\
\text { J52NS }\end{array}$ \\
\hline Radio minimo & 12,00 & 6,00 & 4,00 & 2,00 & 3,00 & 2,50 & 6,50 & 3,95 & 2,00 \\
\hline ton a Rmin & $1.350,00$ & 600,00 & 80,00 & 700,00 & 200,00 & 80,00 & 80,00 & 40,00 & 5,00 \\
\hline Radio máximo & 132,00 & 142,00 & 58,00 & 110,00 & 80,00 & 52,00 & 85,00 & 80,00 & 52,00 \\
\hline ton a Rmax & 70,00 & 4,00 & 0,60 & 3,80 & 1,30 & 0,80 & 26,00 & 4,60 & 1,10 \\
\hline Radio 30 & 30,00 & 30,00 & 30,00 & 30,00 & 30,00 & 30,00 & 30,00 & 30,00 & 30,00 \\
\hline ton a R30 & 728,00 & 239,00 & 5,20 & 69,50 & 16,60 & 3,90 & 80,00 & 20,50 & 2,90 \\
\hline Mom Rmin & $16.200,00$ & $3.600,00$ & 320,00 & $1.400,00$ & 600,00 & 200,00 & 520,00 & 158,00 & 10,00 \\
\hline Mom R30 & $21.840,00$ & $7.170,00$ & 156,00 & $2.085,00$ & 498,00 & 117,00 & $2.400,00$ & 615,00 & 87,00 \\
\hline Max load moment (MLM) & $22.748,00$ & $7.710,00$ & 320,00 & $2.124,00$ & 657,00 & 241,00 & $2.960,00$ & 680,00 & 94,50 \\
\hline Precio compra (valores en $€$ ) & $14.000 .000,00$ & $5.000 .000,00$ & $900.000,00$ & $4.500 .000,00$ & $1.500 .000,00$ & $480.000,00$ & $3.200 .000,00$ & $850.000,00$ & $90.000,00$ \\
\hline Amortización por hora & $1.009,62$ & 360,58 & 64,90 & 324,52 & 108,17 & 34,62 & 230,77 & 61,30 & 6,49 \\
\hline Costes Financieros por hora & 202,93 & 72,47 & 13,05 & 95,23 & 21,74 & 6,96 & 46,38 & 12,32 & 1,30 \\
\hline Consumos por hora & 21,60 & 12,00 & 6,00 & 14,40 & 9,96 & 7,20 & 7,20 & 7,20 & 1,22 \\
\hline Mantenimiento por hora & 4,18 & 1,30 & 0,79 & 3,38 & 1,80 & 0,93 & 0,72 & 0,58 & 0,22 \\
\hline Precio hora de operador & 50,00 & 45,00 & 30,00 & 40,00 & 30,00 & 25,00 & 30,00 & 25,00 & 20,00 \\
\hline Coste horario de la Grúa & $1.288,33 €$ & $491,35 €$ & $114,74 €$ & $477,53 €$ & $171,67 €$ & $74,71 €$ & $315,07 €$ & $106,40 €$ & $29,23 €$ \\
\hline Ratio Coste horario / Ton nominal & 0,95 & 0,82 & 1,43 & 0,68 & 0,86 & 0,93 & 3,94 & 2,66 & 5,85 \\
\hline Ratio Coste horario / MLM (mt) & 0,06 & 0,06 & 0,36 & 0,22 & 0,26 & 0,31 & 0,11 & 0,16 & 0,31 \\
\hline
\end{tabular}


5.4.1.- Comparativa y análisis de los momentos de vuelco obtenidos y de las capacidades nominales

Hemos obtenido los momentos a radio mínimo (Mom Rmin) que si bien no es un dato muy homogéneo entre las grúas debido a que cada una puede tener un radio mínimo diferente es fundamental al ser el radio cuya capacidad de carga que se usa como Tonelaje nominal de las máquinas definiendo así de cierta manera su capacidad como máquina.

Hemos obtenido los momentos a radio máximo (Mom Rmax), que también es un dato importante en las grúas porque define el alcance y por lo tanto la zona de actuación de cada grúa. Varía también enormemente en función de cada máquina.

Se han considerado y calculado también los momentos a radio $30 \mathrm{~m}$ precisamente para tener un radio de trabajo igual para todas las grúas estudiadas dado que los radios anteriores no coinciden en las máquinas. Si bien tomar el valor de $30 \mathrm{~m}$ es una decisión de este estudio (se podían haber tomado otros valores de la misma manera), se ha escogido este valor por ser intermedio y dentro del alcance de todas las grúas.

Por último el momento máximo de vuelco MLM por sus siglas en inglés (Maximum Load Moment) que es el máximo momento que da la grúa en algún punto de sus tablas. Curiosamente, este valor no se encuentra prácticamente nunca en las tablas ni características de las grúas suministradas por los fabricantes (salvo alguna excepción) y se ha obtenido para este análisis mediante el estudio de cada una de las tablas de capacidades de las grúas buscando en que configuración de montaje y a que radio la grúa daba su máximo momento de vuelco.

Es interesante comparar estos diferentes momentos entre sí y con las toneladas nominales de cada grúa entre otras cosas para poder ver las diferencias entre las distintas máquinas y para ver qué valor nos define mejor la capacidad real de una grúa.

En el gráfico que se incluye a continuación la primera columna en rojo es el MLM y las otras tres son los otros momentos. Se observa que el valor que suele estar más cercano al MLM es el momento a radio 30 metros para casi todas las grúas. 
En ningún caso el Momento a radio máximo es el que está más cercano al MLM. Esto es lógico ya que a partir de ciertos radios, la capacidad decrece muy rápidamente con respecto al aumento de radio.

En tres casos el Momento a radio mínimo es el que está más cercano al valor del MLM:

- La 2200E: la más pequeña de las celosías.

- La LTM1200: la mediana de las telescópicas.

- La GMK4080: La pequeña de las telescópicas.

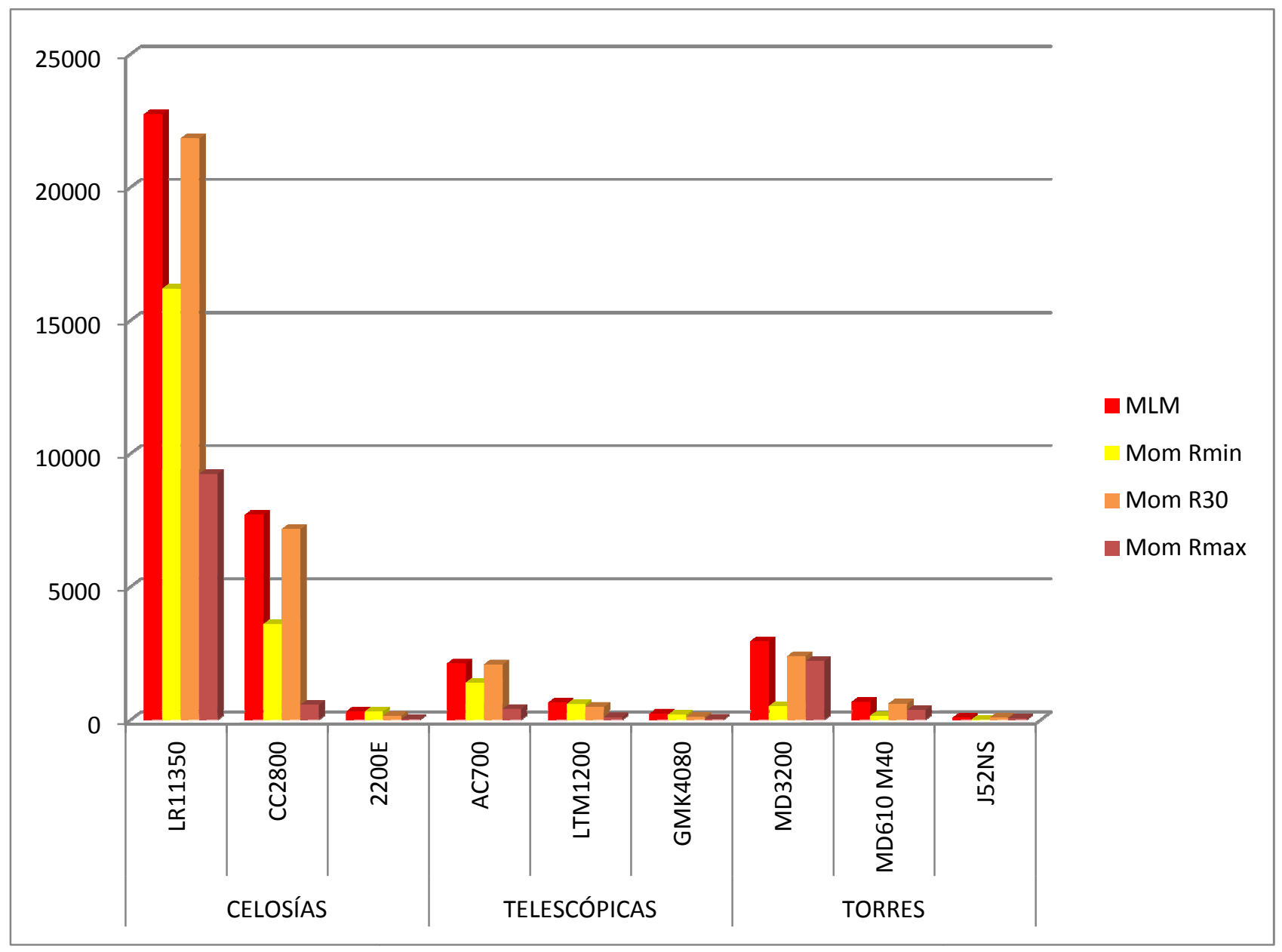

Figura 5.50: Comparativa de los momentos de vuelco obtenidos de las grúas

A nivel general, podemos decir que se observa que tanto las grúas de celosías sobre cadenas como las torres tienen su MLM a radios intermedios.

Las grúas telescópicas sobre camión tienen su MLM cercano al radio mínimo y su valor es similar al Mom Rmin.

Las grúas torre tienen su MLM a radios intermedios. 
Las excepciones a lo anterior son:

- la AC700 que es la telescópica más grande y que es de un tamaño muy importante comportándose a vuelco más parecida a una celosía.

- La 2200E que es la celosía más pequeña y se comporta más como una telescópica lo cual es muy comprensible porque no dispone ni siquiera de contrapeso superlift como el resto de celosías. Precisamente dicho contrapeso es el que mejora considerablemente el momento de vuelco de este tipo de grúas.

La conclusión que se puede obtener a partir de esto es que las grúas de celosía sobre cadenas son mejores a radios medios que las telescópicas. Estas últimas dan sus mejores capacidades de vuelco a radios cortos que precisamente es donde se da el valor de la capacidad nominal de la grúa.

Dicho de otra manera, el nombre o capacidad nominal de una telescópica es mucho más alto con respecto a su capacidad de vuelco que en el caso de una celosía. Factor que beneficia comercialmente a las telescópicas aunque resulta engañoso para un usuario con poca experiencia que compare telescópicas y celosías de capacidades nominales similares a radios medios o largos ya que verá como las capacidades de las telescópicas se reducen drásticamente.

En el siguiente gráfico se han calculado los porcentajes de los momentos Mom Rmin, Mon R30 y MomRmax con respecto al MLM (Maximum Load Moment):

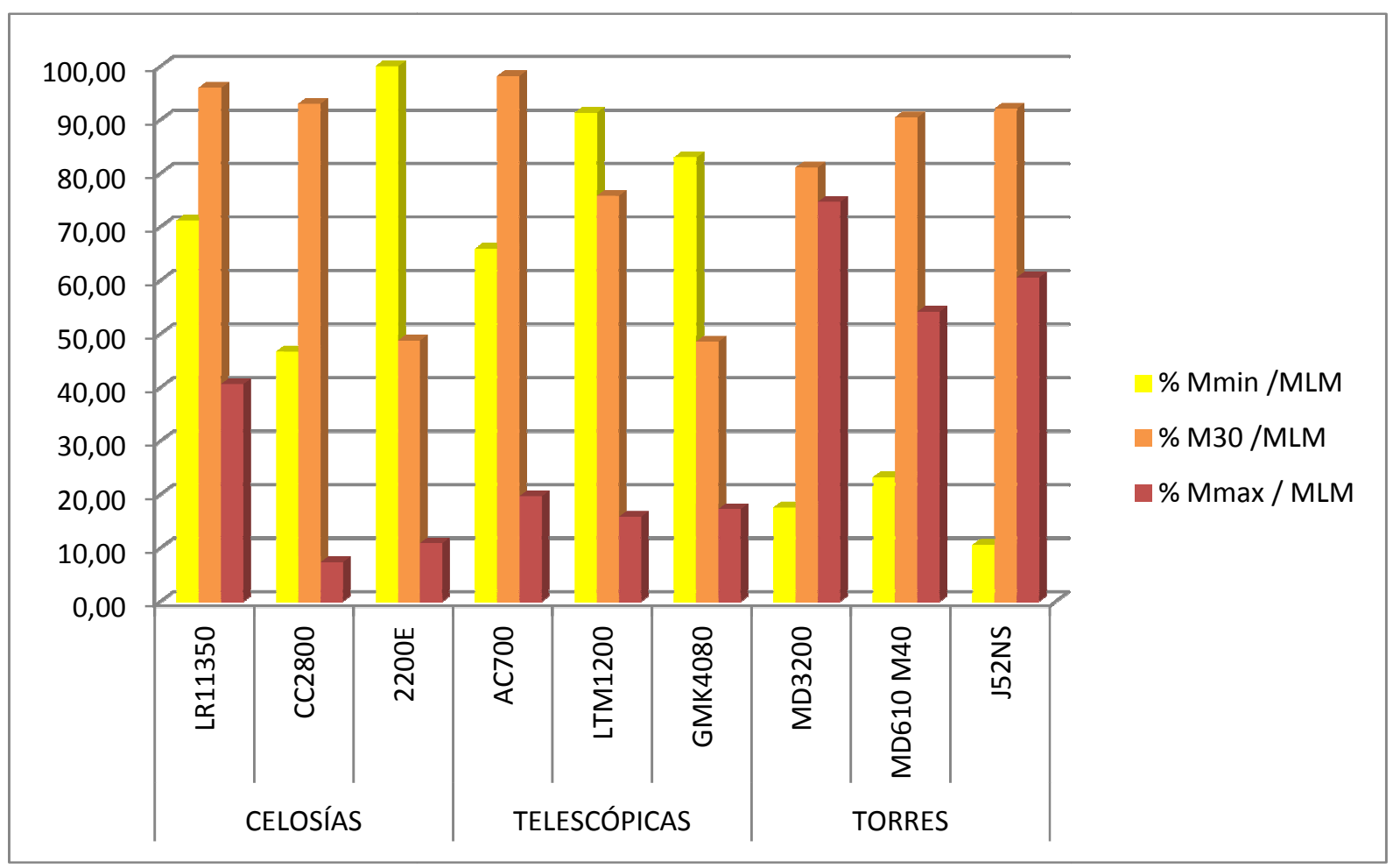

Figura 5.51: Porcentajes de los momentos Mom Rmin, Mon R30 y MomRmax con respecto al MLM (Maximum Load Moment) 
De hecho todas las grúas van perdiendo capacidad en toneladas cuando el radio de trabajo aumenta sin embargo, la comparativa de momentos que se ha realizado permite ver la diferencia que las telescópicas también van perdiendo capacidad de momento de vuelco mientras que las celosías y torres empiezan ganando momento al aumentar el radio de trabajo hasta llegar a su MLM y desde ahí empiezan a perder también capacidad de momento de vuelco.

Este tema es importante porque si bien se viene observando que la denominación de las grúas por su capacidad nominal es bastante deficiente por no mostrar su capacidad real de trabajo, la denominación por momentos, siendo mejor para dar una idea de la capacidad real de las grúas, puede también prestarse a error ya que los usuarios pueden tender a pensar que conociendo el momento de la grúa (dado por su nombre si se usa dicha nomenclatura) pueden conocer prácticamente los valores aproximados de las tablas de carga de la grúa ya que bastaría con dividir el MLM por el radio al cual el usuario quiere trabajar para obtener la capacidad en toneladas de la grúa y esto no es así porque la capacidad a momentos de las grúas no se mantiene constante en función del radio presentando variaciones importantes.

Como se muestra en el gráfico anterior, el momento a radio 30 metros puede llegar a ser menos de la mitad que el MLM pero para el caso de los momentos a radio mínimo y a radio máximo, el valor puede ser incluso inferior al 10\% del MLM.

También se puede observar en el gráfico de la figura № 5.49 que el incremento de los momentos dentro de cada tipología de grúas es importante. En orden de magnitud: 31,3 veces para las grúas torre, 8,8 veces para las telescópicas y 71,1 veces para las celosías. Esto simplemente indica que el rango de capacidades dentro de cada tipología es distinto y centro de las grúas de celosía la diferencia entre las grandes y las pequeñas es enorme mientras que las telescópicas esa variación no es tan importante. Por ello aunque sean de la misma tipología, la diferencia entre la LR11350 que es la celosía grande elegida y la 2200E que es la celosía pequeña es muy importante. Tanto es así que se comportan como máquinas cualitativamente distintas como se ha mencionado anteriormente. La celosía pequeña presenta similitudes importantes con las telescópicas.

En el siguiente gráfico se ha calculado el ratio MLM / toneladas nominales para cada grúa y permite comprobar que las celosías (exceptuando una vez más la pequeña) tienen una capacidad de vuelco muy buena comparada con su capacidad nominal en toneladas mientras que las telescópicas lo tienen muy bajo. 


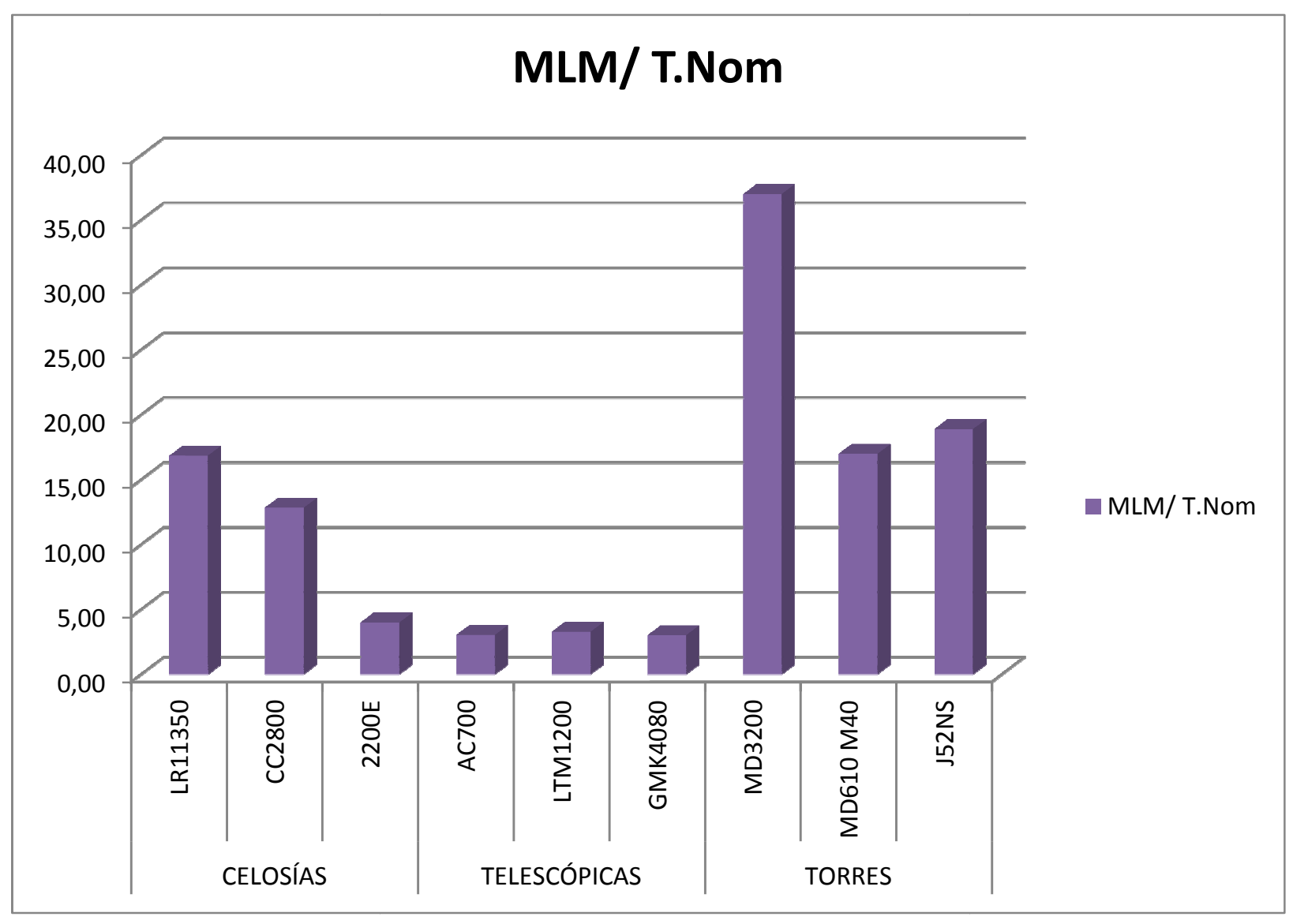

Figura 5.52: Gráfico del ratio MLM / Toneladas nominales.

Sorprende ver en el gráfico anterior el ratio tan bueno de las grúas torre que resulta igual o mejor que el de las celosías. Es lógico ya que las grúas torre tienen los radios cortos muy limitados por su capacidad a rotura del cable y no por su limitación al vuelco que es por tanto mucho más elevada de lo que aparenta. Se puede decir por tanto que las grúas torre se ven también perjudicadas si se usa la capacidad a radio mínimo como definición de su capacidad. De hecho los fabricantes de este tipo de grúa suelen dar muchas veces su capacidad en punta como dato a sus clientes.

Es espectacularmente alto el ratio de la grúa torre grande MD3200. Esto se explica por una excesivamente pequeña capacidad nominal de 80 toneladas para la grúa tan importante que es. Efectivamente, si hablamos de una grúa de 80 toneladas para designar a esta grúa, no nos haremos a la idea de la capacidad tan importante que tiene.

Haciendo una media de este ratio para cada las tres grúas de cada tipología, obtenemos:

Media MLN/T. NOM:

Grúas de celosía: 11,23 
Grúas telescópicas: 3,11

Grúas torre: 24,3

Estos resultados vistos gráficamente:

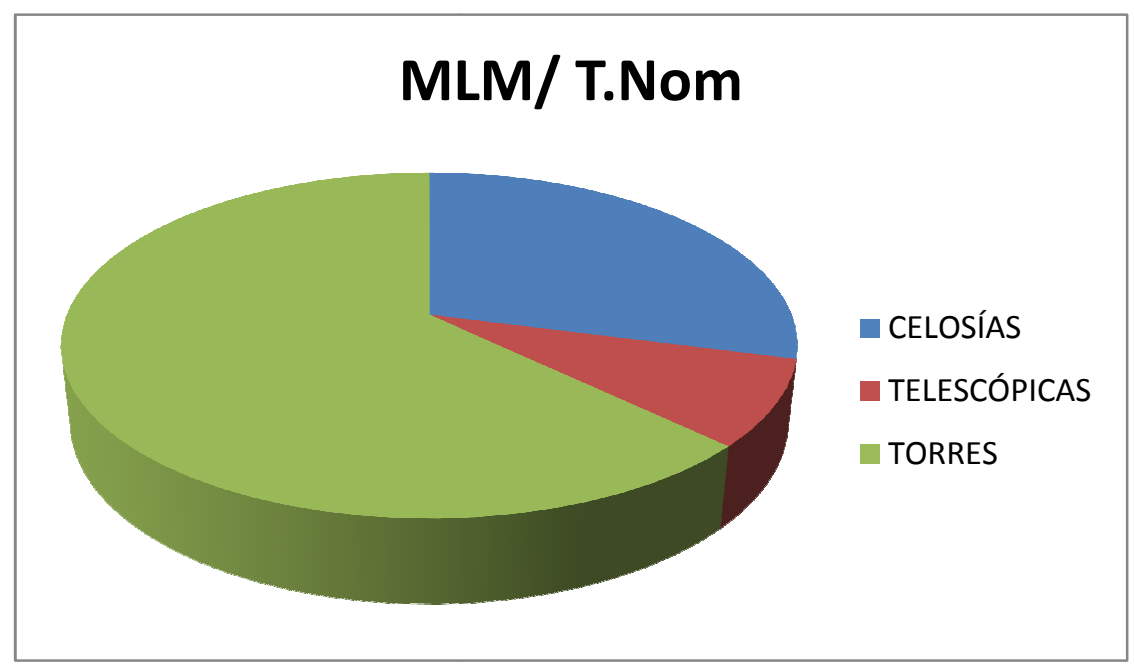

Figura 5.53: Comparativa gráfica de la importancia de los ratios MLM / T.Nom (Maximo momento por Tonelaje nominal de las grúas) según las distintas tipologías de máquinas.

Vemos que en las celosías el momento máximo con respeto a su capacidad nominal es 3,6 veces superior que para las telescópicas.

En el caso de las grúas torre es 7,8 veces superior al de las grúas torre.

Entre grúas de celosía y grúas torre se podría decir que estas medias son también muy diferentes pero observando el gráfico de la figura 5.51 vemos que el ratio en el fondo es bastante similar salvo por las excepciones de la grúa de celosía más pequeña y la torre más grande. 


\subsection{2.- Comparativa y análisis del coste horario de las grúas}

De los valores resumidos en la tabla anterior, se puede observar que como era de esperar los costes por hora de las distintas máquinas son muy diferentes (ver gráfico a continuación que muestra los costes horarios de las tres grúas). Esto no podía ser de otra manera ya que las capacidades y precios de compra son muy distintos.

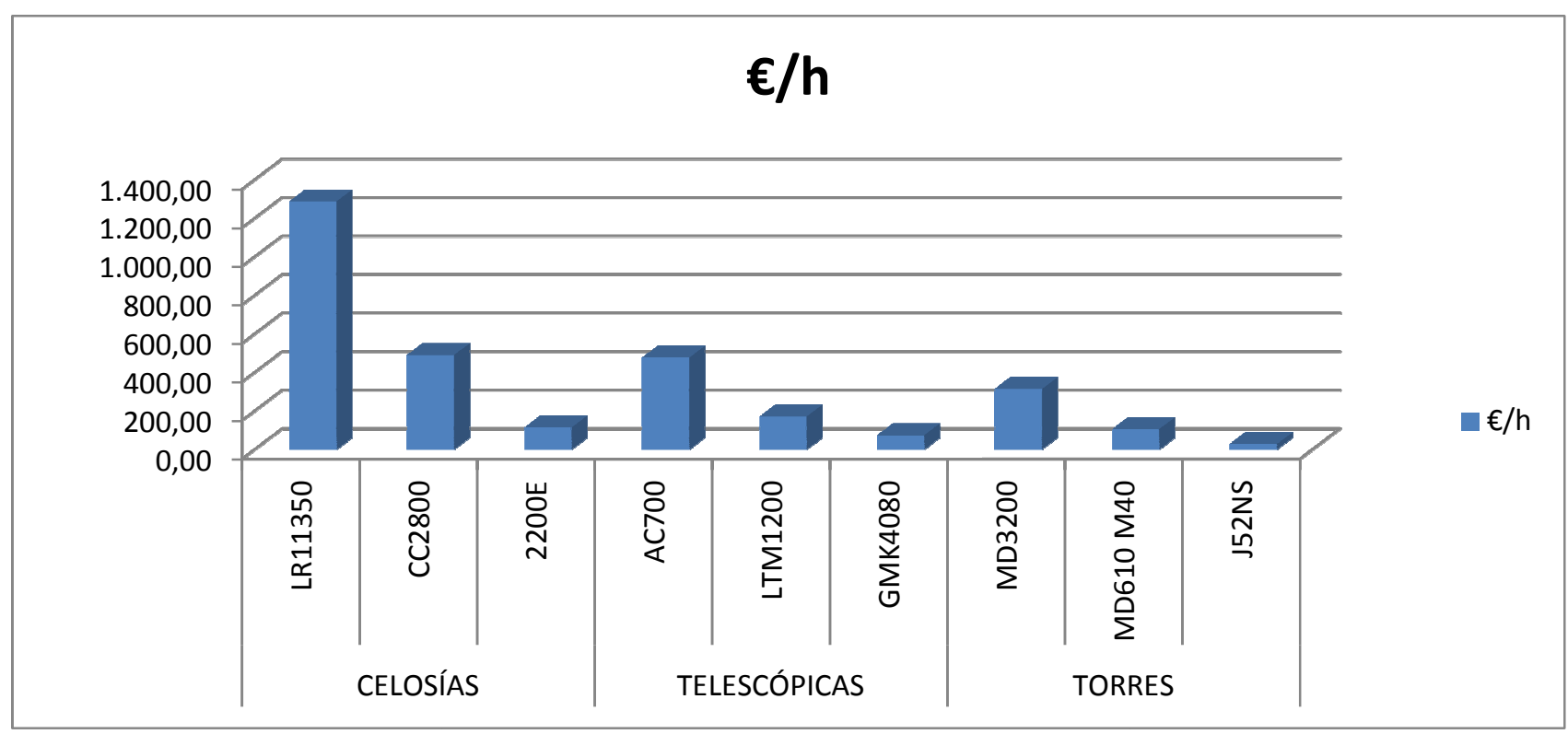

Figura 5.54: Gráfico del coste horario en Euros

Aun así, observando este gráfico solamente, podría parecer a primera vista (ya que estamos comparando rangos de capacidades que no son homogéneos) que las grúas telescópicas son muy interesante ya que su coste es muy reducido comparado con las celosías en general y sin embargo, no es muy superior al de las grúas torre.

Con el coste horario hemos obtenido 2 ratios diferentes:

- Coste horario / Tonelada nominal: que es la forma habitual en el mundo de la construcción de referirse a la grúa y a su "supuesta" capacidad.

- Coste horario / Momento máximo (Maximum Load Moment): que como se ha explicado sería una forma más adecuada de dar una idea realista de la capacidad de una grúa. 
Es necesario hacer el análisis económico de las grúas usando estos ratios para poder comparar los precios en función de las capacidades de las grúas y de esta forma homogeneizar la comparación.

El problema surge de que valor se ha de tomar para definir la capacidad de una grúa ya que como se ha explicado y visto con ejemplos anteriormente, la capacidad nominal, que es el nombre de la grúa que todo el mundo usa y que coincide con su capacidad en toneladas a radio mínimo y con una cierta configuración de montaje, no se corresponde ni es proporcional en la realidad con la capacidad real de esa grúa trabajando a un cierto radio que se aleje del radio mínimo.

El otro valor que se podría utilizar es el Momento máximo de carga MLM (Maximum Load Moment) que puede aguantar la grúa en alguna configuración y radio de la misma donde la grúa ofrece la máxima capacidad ante el momento que le puede producir el vuelco. Como se ha visto anteriormente, el momento de vuelco también varía considerablemente en función del radio de trabajo de la máquina y no es por lo tanto un valor cuya estabilidad le permita definir y dar una idea de la capacidad de carga de la grúa a un determinado radio.

En los siguientes apartado se van a analizar ambos ratios con el fin de compararlos entre si y poder concluir cual de los dos nos ofrece mejores y más reales posibilidades de análisis.

\subsection{3.- Ratio Coste horario por tonelada nominal}

Al realizar la comparativa de las tres grúas con el primer ratio (ver gráfico a continuación de coste horario por tonelada nominal), se observa que las celosías y las telescópicas presentan valores muy similares. Es interesante ver como al dividir por las toneladas nominales, los precios hora de las celosías sobre cadenas y de las telescópicas quedan tan igualados. Si el tonelaje nominal se pudiese considerar como el valor referencia para determinar la capacidad real de una grúa, cosa que hace habitualmente el sector de grúas a nivel mundial pero que se ha cuestionado anteriormente, se podría concluir que las grúas de celosía sobre cadenas y las telescópicas sobre camión, no tienen prácticamente variación de coste en función de su tamaño ni de su tipología. 
Sin embargo, el coste de la grúa torre por hora y tonelada nominal de capacidad resulta elevadísimo lo cual sí que es sorprendente ya que se esperaría un valor bajo de coste de una grúa torre dado que se entiende que son grúas baratas y con muy buenos rendimientos.

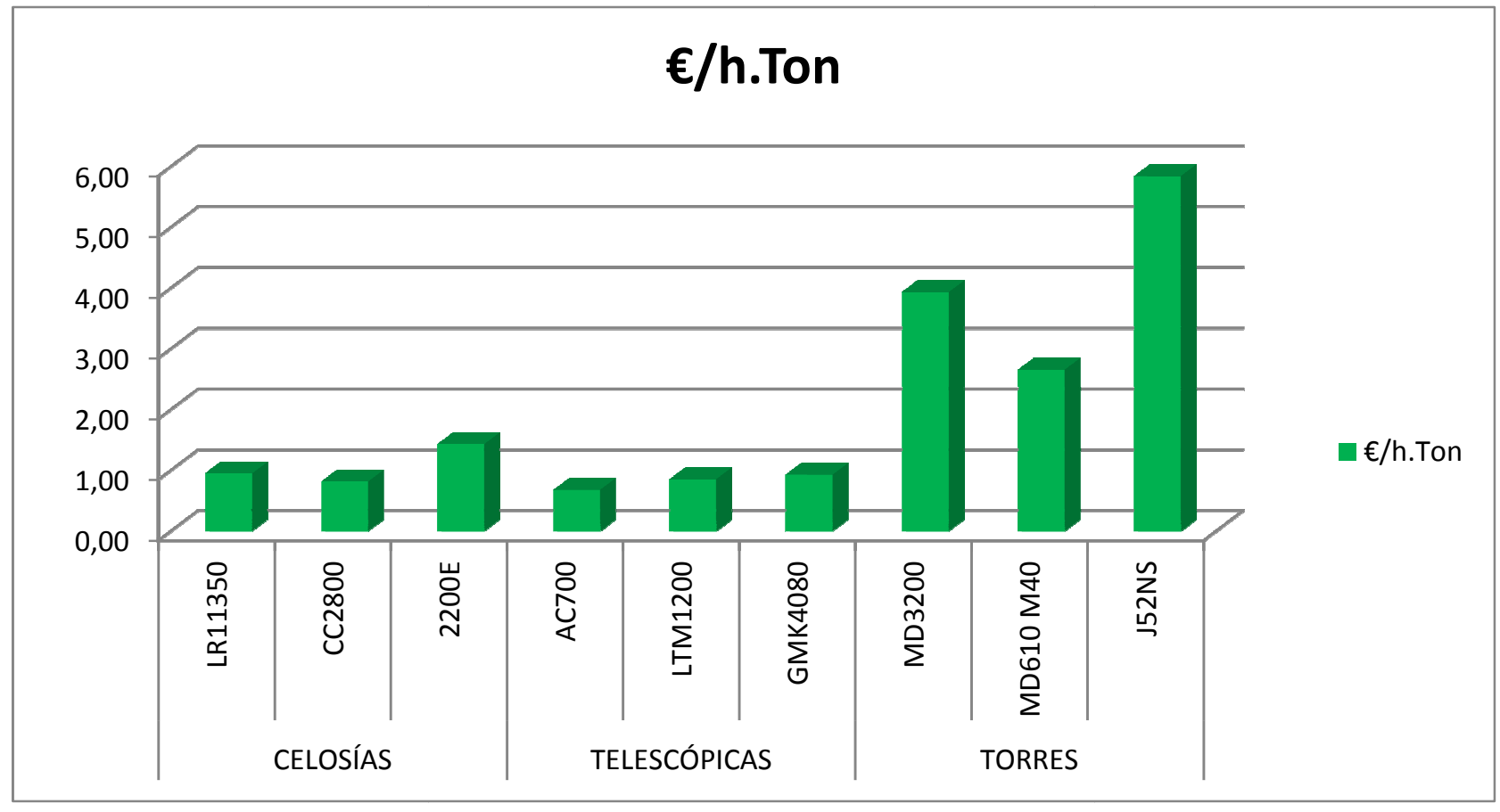

Figura 5.55: Gráfico del ratio coste horario en Euros / Toneladas nominales de la grúa

De acuerdo con estos resultados las grúas de celosía y telescópicas tendrían una rentabilidad similar en función de su capacidad y sin embargo las grúas torre serían poco rentables para las toneladas de capacidad que dan.

Esta posible conclusión no podría sostenerse con un rápido análisis de mercado de la utilización de grúas por tipologías y aunque no es objeto de esta tesis realizar tal análisis de mercado, es conocida la enorme presencia de la grúa torre por su eficiencia en obras de edificación y civiles sobre todo cuando las cargas a izar no son demasiado elevadas.

También es conocida la eficiencia de las grúas de celosía para izados de grandes cargas frente a las telescópicas, no porque sean más baratas comparando dos de la misma capacidad nominal sino porque para realizar un determinado izado de peso importante, la grúa de celosía necesaria será muy probablemente de capacidad nominal mucho menor que la telescópica que sirviera también para ese trabajo. 
La ventaja competitiva de la grúa telescópica no vendrá tanto de su eficiencia para el izado sino de su fácil y rápida movilización a obra cosa que no ocurre con las celosías cuyo transporte es mucho más complejo así como su montaje en obra. No es tampoco objeto de esta tesis entrar en este campo de análisis comercial de las máquinas en función de su tipología ni de parámetros de movilidad y versatilidad ya que se está realizando el análisis en función de sus capacidades de carga para que las grúas han sido diseñadas y construidas.

Por los motivos expuestos realizamos a continuación el análisis del coste pero con otro ratio que usa el MLM (máximo momento admisible).

\subsection{4.- Ratio Coste horario por máximo momento de vuelco (MLM)}

Estas posibles conclusiones que se obtendrían observando los gráficos anteriores a primera vista nos pueden llevar a error por los motivos ya explicados de lo engañoso que puede resultar el utilizar las toneladas nominales como referencia de la capacidad real de una grúa.

Por estos motivos, se ha calculado este segundo ratio comparando esta vez el coste horario de cada máquina con el momento máximo de la grúa cuyas siglas en inglés son MLM (Maximum Load Moment). Aunque cuando se planifica una maniobra con una grúa se intenta lógicamente minimizar el radio para disponer así de la máxima capacidad de la máquina, en la realidad, ya sea por obstáculos de la obra, por las dimensiones de la propia pieza o por otros condicionantes, la mayoría de las maniobras que realizan las grúas no pueden ser a radio mínimo y muy frecuentemente ni siquiera en la zona de las tablas en las que la grúa falla por rotura (de cables, de pluma a compresión, etc.). En la mayoría de las maniobras que se realizan, las grúas están trabajando en la zona de las tablas de capacidad en las que el valor de la capacidad viene limitado por el posible vuelco de la grúa. Dado que la limitación de capacidad por rotura y por vuelco no tienen una relación unívoca entre sí sino que incluso pueden a llegar a ser contraproducentes los aumentos de una para la otra (tal y como ya se ha visto) , parece lógico en un principio que este ratio nos permita obtener conclusiones más acordes con la capacidad real de las grúas. 


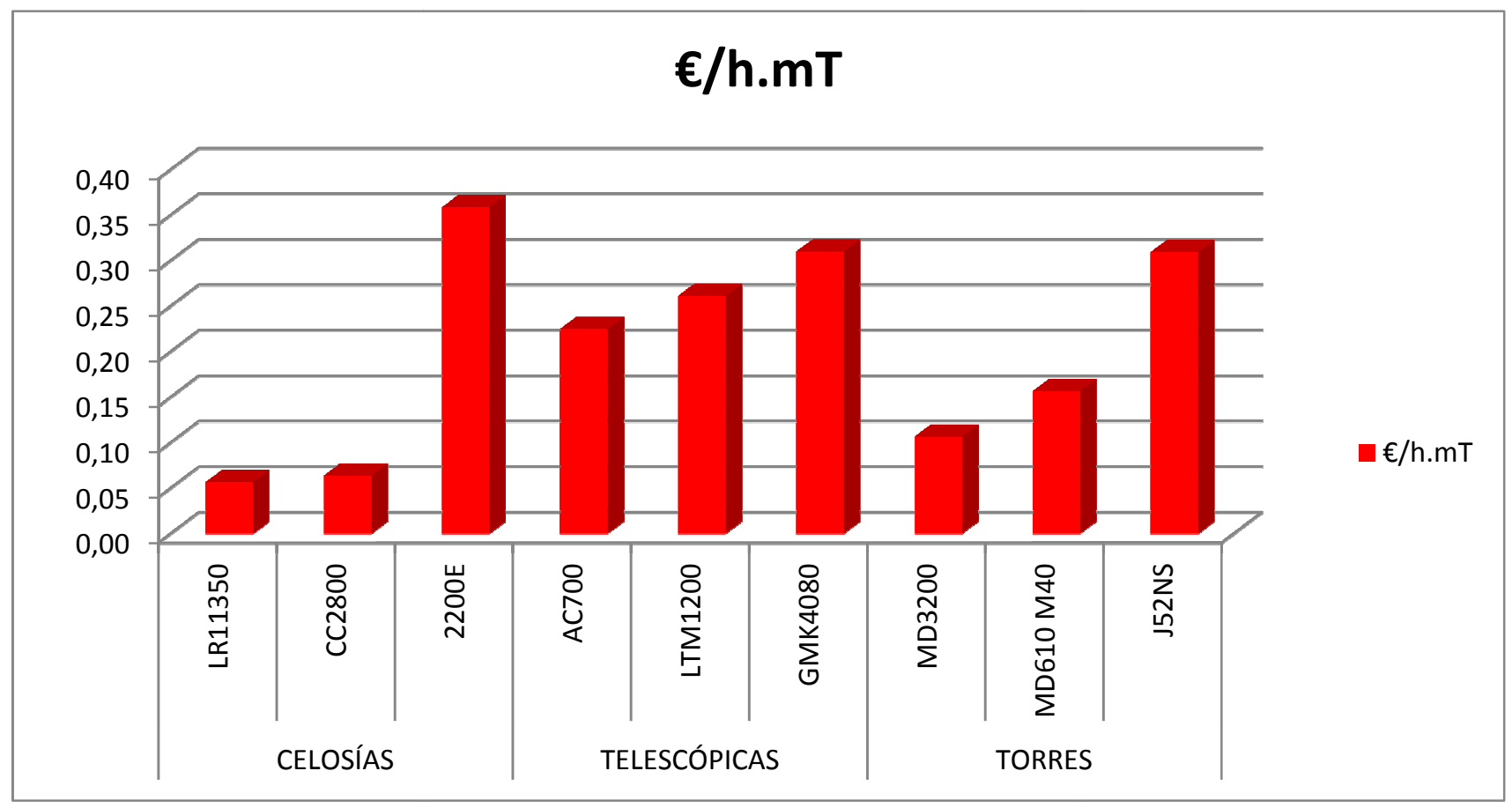

Figura 5.56: Gráfico del ratio coste horario en Euros / MLM (Maximum Load Moment), momento máximo de la grúa.

Este gráfico da muchas posibilidades de análisis de la información porque permite obtener conclusiones con respecto al los tamaños de las grúas pero también con respecto a sus distintas tipologías.

Se observa a simple vista que las grúas de celosía son en principio mucho más baratas que las otras al dividir su coste por su MLM.

Sin embargo resulta chocante el valor que se obtiene de la menor de las celosías que es extremadamente elevado comparado con las otras grúas de su misma tipología. Efectivamente, el valor de 0,36 es 6 veces superior al valor de las otras grúas de celosía. El motivo de esta aparente anomalía se ha empezado a ver anteriormente cuando se han analizado los momentos de las grúas. Hay que recordar que esta grúa de celosía era la única cuyo MLM está más cerca del valor del momento a radio mínimo que del valor del momento a radio 30. Este hecho muestra que, en cuanto a su capacidad de aguantar momentos esta grúa se comporta más como una grúa telescópica que como una celosía. ¿Es esto únicamente debido a su tamaño? La respuesta hay que buscarla en las características y diseño de la propia máquina. Debido a su tamaño, esta máquina no va equipada con un contrapeso superlift como suelen llevar el resto de las celosías. Este hecho de no equipar a las celosías pequeñas de 
superlift es frecuente en casi todos los fabricantes, motivado por el alto coste de dicho contrapeso que al no ser proporcional al tamaño, sería muy caro por debajo de una capacidad.

Parece de todos modos sorprendente que un único accesorio como es el contrapeso, pueda condicionar tanto el momento de vuelco de una grúa pero si se analiza un simple ejemplo de maniobra real como es el de los izados con la grúa CC2800 (grúa muy frecuentemente utilizada para estas maniobras) de los módulos de una central de ciclo combinado, se observa que con la configuración de pluma principal de 84 metros de longitud a 30 metros de radio (que es habitual para poder introducir los módulos de caldera verticales en el edificio de la caldera de recuperación de vapor) la capacidad que se obtiene de las tablas oficiales de Terex Demag es de 50 toneladas. Estos módulos suelen pesar alrededor de las 180 o 190 toneladas con lo cual la maniobra con esta grúa CC2800 sería completamente imposible. Equipando a la misma grúa con contrapeso superlift a 17 metros, con la misma longitud de pluma principal de 84 metros y al mismo radio de trabajo de 30 metros, la capacidad que dan las tablas de Terex Demag es de 223 toneladas. Es decir que el contrapeso de superlift multiplica la capacidad de la CC2800 en este simple ejemplo por 4,46.

Puede haber configuraciones y posiciones en las que este aumento sea mayor o menor a este valor pero lo importante del ejemplo es que no resulta ya sorprendente que la celosía más pequeña de nuestras grúas analizadas presente este valor tan alto de este ratio ya que el orden de magnitud del aumento de capacidad a radios medios que dan el superlift y la diferencia del ratio de esta grúa con las demás celosías son de órdenes de magnitud parecidos.

Todo esto indica que por debajo de un cierto tamaño de grúa de celosía, el precio se dispara con respecto al momento de vuelco admisible y por lo tanto la eficiencia de la grúa se reduce drásticamente. Cosa que por otro lado explica bastante bien el hecho de la falta de grúas de celosías pequeñas en el mercado dejando así la franja de cargas menos pesadas a las telescópicas y las torres. De hecho las celosías pequeñas están en el mercado más dedicadas a otras labores como las obras de cimentaciones que las de maniobras de izados propiamente dichas (esto se explica por las ventajas estructurales que presentan para ese otro tipo de trabajos pero que no es objeto de este estudio).

¿Para qué tamaño de grúas de celosía se produce este salto de eficiencia? Estará lógicamente como se ha visto, relacionado con el tamaño de grúas de celosías a partir del cual empiezan a equiparse con contrapeso superlift y como es sabido, suele estar dicha barrera en las 250 toneladas de capacidad nominal habitualmente. 
Dentro de cada tipología, se observa en el gráfico anterior que cuanto más potente es la grúa, más barata resulta comparándola con su capacidad a momentos. Esto no ocurría sin embargo cuando utilizábamos el ratio de toneladas nominales.

Esta tendencia es importante para futuros diseños de grúas ya que se puede concluir que merece la pena económicamente ir a piezas más grandes y grúas más grandes, no sólo por las ventajas que ofrece muy a menudo la prefabricación y la construcción modular sino por la propia máquina de izado en sí misma.

En el caso de habernos quedado con el análisis del ratio por tonelada nominal, al no haber diferencia de eficiencia en función de la capacidad, se podría concluir que la recomendación de cara a futuros diseños e investigación en la construcción de nuevas grúas y mejoras de las actuales, sería igualmente eficaz dedicar recursos a un tamaño que a otros de celosías y de telescópicas y desde luego no dedicar mucho esfuerzo a las torres. No merecería demasiado la pena intentar construir grúas mucho más grandes que las existentes sino centrase en la mejora y perfeccionamiento los tamaños que se usan.

Esta no es desde luego la tendencia del mercado de grúas de los últimos años en los que se están desarrollando grúas cada vez más grandes y las capacidades se van aumentando en cada feria de maquinaria que tiene el sector (especialmente la Bauma en Munich cada 3 años suele ser el lugar de presentar los nuevos desarrollos de cada fabricante al mundo).

Se dice a veces que estas grandes grúas se diseñan y construyen por capricho o motivos comerciales de tener la grúa más grande del mundo. Si observamos el último gráfico que usa el ratio de momentos, se ve claramente que cuanto mayor es la capacidad más barato es el ratio por MLM y esta estrategia de innovación y desarrollo está plenamente justificada.

Las grúas telescópicas son según este cuadro mucho menos eficientes con respecto a su capacidad a vuelco. ¿Cómo es posible entonces su presencia tan importante en la construcción? El motivo es posiblemente ajeno a la relación coste capacidad objeto de este estudio y se debe probablemente a otros factores como la facilidad de montaje, su gran movilidad o la versatilidad que nos da cada tipo de máquina en obra. Se puede observar también en esta tipología la tendencia de menor coste por tamaño que se contrasta en la realidad y que probablemente explique el auge, evolución y desarrollo de las grúas telescópicas en las últimas décadas y especialmente últimos años 20 o 30 años con excepciones nuevos de modelos grandes de grúas telescópicas como las de 600 y 700 
toneladas o la mayor del mundo de 1.200t (LTM11200) que salió al mercado alrededor de 2010.

Cabe mencionar con respecto a las grúas torre el buen resultado que muestra este ratio de de la MD3200 que es la grande de las grúas torre estudiadas. El MLM que tiene esta grúa es un valor muy alto y como ya se vio al compararlo con el tonelaje nominal, esta grúa es la que presenta mayor diferencia entre ambos. Por ello, estaba tremendamente penalizada al usar el ratio anterior de las toneladas nominales y no se daba la visión real de esta máquina.

Por tipologías, las grúas de celosía dan mucho mejores resultados que las torres y estas a su vez que las telescópicas. Calculando las medias de los ratios anteriores de cada una de las tipologías, queda el siguiente gráfico comparativo:

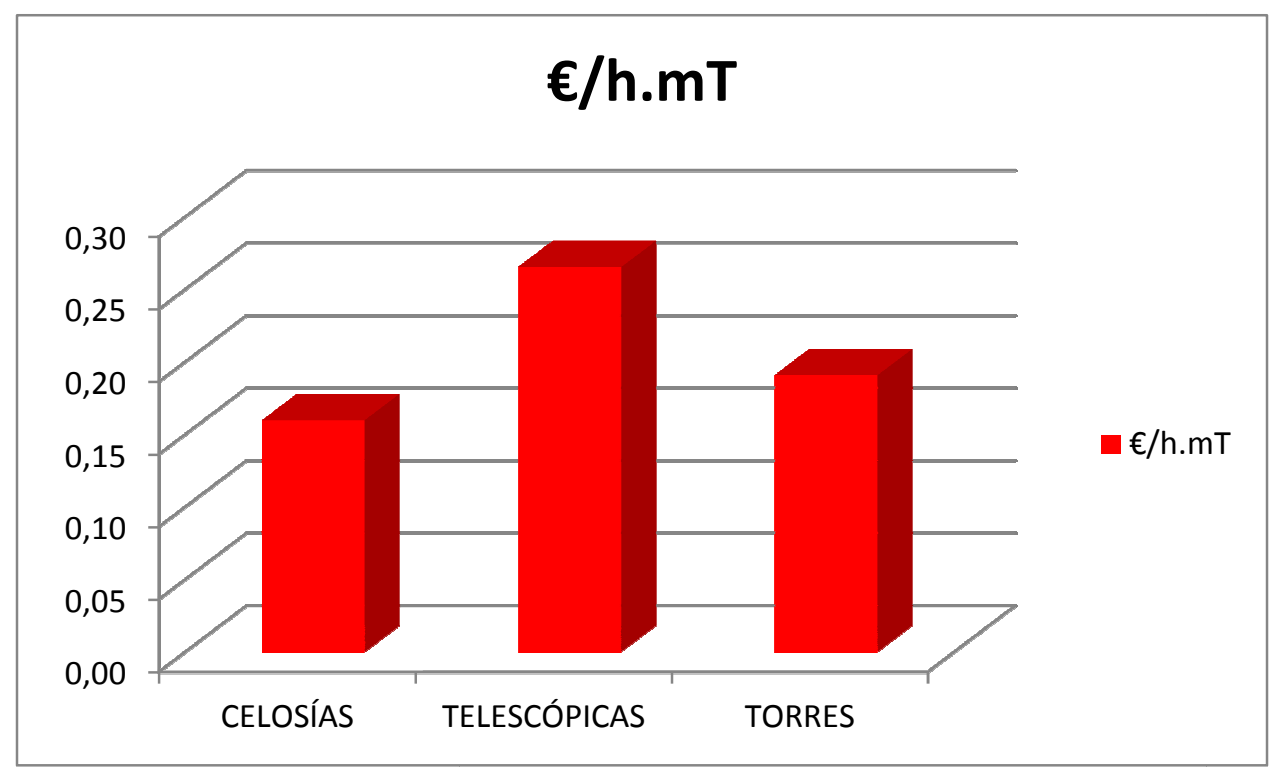

Figura 5.57: Gráfico del ratio coste horario en Euros / MLM (Maximum Load Moment), medias por cada tipología de grúa analizada

Esta comparativa usando el ratio del momento máximo para definir la capacidad de las grúas se ajusta mucho mejor a la realidad de esta maquinaria ya que como se ha explicado y demostrado, el valor del MLM indica mucho mejor la capacidad real de una grúa que las toneladas nominales. Las conclusiones que obtenemos del análisis de este ratio son mucho más solidas que las del ratio de tonelaje a radio corto ya que este último define mal la capacidad de las grúas. 


\section{CONCLUSIONES}

\section{1.- CONCLUSIONES SOBRE EL MÁXIMO MOMENTO ADMISIBLE MLM Y EL TONELAJE NOMINAL}

Los nombres comerciales de las grúas no ayudan en general a entender de qué tipo de máquina se trata ni cuál es su capacidad. La costumbre es definir la capacidad de una grúa por el valor de su tonelaje nominal, es decir las toneladas que aguanta a radio mínimo.

Existe la controversia a nivel mundial de la conveniencia de usar este valor como definición o intentar cambiar la nomenclatura y el valor de capacidad a otro parámetro que defina mejor la capacidad de las grúas como puede ser el momento máximo admisible (MLM por sus siglas en ingles: Maximum Load Moment).

- Al comparar dos grúas de 200 toneladas de capacidad nominal de la misma marca (Liebherr) una telescópica (LTM1200) y otra celosía (LR1200) se obtiene: misma capacidad a radio mínimo, a radio 30 metros, la celosía da 1,52 veces más capacidad que la telescópica y a radio 80 metros la celosía da 3,46 veces más capacidad que la telescópica. Se observa por tanto que el valor de la capacidad nominal presenta seria deficiencias a la hora de definir la capacidad real de las grúas.

- Al comparar el MLM con tonelaje nominal, se ha llegado a la conclusión que la relación entre ambos depende de la tipología de las grúas. Las medias que se han obtenido para este ratio son: 11,23 para las celosías, 3,11 para las telescópicas y 24,3 para las grúas torre. Esto quiere decir que las celosías tienen el ratio 3,6 veces mayor que las telescópicas y las torres 7,8 veces mayor que las telescópicas. 
El utilizar uno de los dos valores para definir la capacidad de las grúas va a beneficiar o perjudicar por lo tanto a ciertas tipologías con respecto a otras. Obviamente, el uso del tonelaje nominal (generalizado hoy en día) beneficia enormemente a las grúas telescópicas.

- Es cierto que la capacidad de la grúa frente al momento de vuelco no sólo no es constante en función de su radio sino que varía hasta un 10\% del valor máximo (MLM) como se ha observado, pero por otro lado, la zona de los valores por vuelco de las tablas de capacidad de las grúas es la más utilizada a la hora de realizar izados y se trabaja poco frecuentemente en la zona de valores limitados por la rotura ya que suelen ser a radio muy corto para la mayoría de las maniobras.

- Por todos estos motivos y como se ha analizado y demostrado, el MLM es un parámetro que define mucho mejor la capacidad de una grúa y la recomendación que se hace como conclusión a esta investigación sería el utilizar una nomenclatura para las grúas que las definiera de la mejor forma posible, es decir tanto en su tipología como en su capacidad.

- Una posible propuesta sería poner unas letras iniciales que indique su tipología tanto en su tipo de pluma (celosía, telescópica, torre horizontal, etc.), como en su tipo de apoyo (Cadenas, camión, ringer, zapata, raíles, etc.). Estas letras estarían seguidas de un valor numérico que sería el valor del MLM.

Tal y como se ha visto a lo largo de esta investigación, esta propuesta presenta dos obstáculos importantes que son en primer lugar la mundialización de este tipo de maquinaria que hace que sea muy difícil cambiar las costumbres establecidas y convencer a empresas fabricantes y usuarias de tantos lugares diferentes. Esto sólo se podría hacer poco a poco y si las grandes empresas empiezan a usar una nomenclatura similar a la propuesta. Esto nos lleva precisamente al segundo obstáculo que puede ser la reticencia de muchos fabricantes a usar un valor que pueda disminuir comercialmente la imagen de su producto. El efecto a la larga, sería que los esfuerzos de investigación y desarrollo se centrarían lógicamente en conseguir mayores MLM para vender mejor la máquina en lugar de intentar conseguir grandes valores de tonelaje a radio corto con configuraciones que muchas veces no se llegan a usar. 
Para actuar a nivel legislativo en esta dirección, se tendría también el problema de no poder llegar a todas partes y no poder obligar a las multinacionales fabricantes. Sin embargo, si sería posible exigir a nivel nacional o europeo la mención visible del MLM en las tablas de características y capacidades de cada grúa que, como se ha explicado, es muy raro y complicado de encontrar o calcular. Esto se hace con muchos productos precisamente para evitar que los consumidores se lleven a engaño sobre sus características o contenidos. Empezar mencionando el MLM puede dar lugar poco a poco a que se extienda la práctica ya que al final se editan las tablas para toda Europa o para todos los países de habla hispana o se cuelgan en internet y la mundialización puede jugar aquí precisamente para que una buena práctica se extienda rápidamente.

\section{2.- CONCLUSIONES CON RESPECTO A LOS TAMAÑOS Y TIPOLOGÍAS DE LAS GRÚAS ANALIZADAS}

- Las diferentes de grúas que se han analizado, no sólo ofrecen diferentes aspectos cualitativos de funcionamiento como son la movilidad, la versatilidad, etc. sino también diferentes rangos de eficiencia dependiendo tanto de su tipología como de su capacidad. Es una evidencia que se había llegado a construir grúas celosías de mayor capacidad que las telescópicas y estás a su vez mayores que las torres. Las grúas record hoy en día son:

- Celosía sobre cadenas: LR13000 de 3.000 toneladas de capacidad nominal.

- Telescópica sobre camión: LTM1200 de 1.200 toneladas de capacidad nominal.

- Torre: Kroll10000 de 240 toneladas de capacidad nominal.

Pero se confirma con este análisis que las grúas de celosía son más eficientes que las torres y estas que las telescópicas ya que el ratio del coste hora con respecto al MLM es un 1,66 veces más elevado para la media de las telescópicas que para la media de las celosías y un 1,39 veces más elevado con respecto a la media de las grúas torre. Cuando comparamos las grúas grandes en lugar de la media de cada tipología, estas cifras aumentan de forma espectacular y son 3,97 y 2,11 veces superiores respectivamente. 
- Dentro de cada una de las tipologías, el aumento de su capacidad (cuando definimos esta con el MLM) da también lugar a mayor eficiencia como se observa con el ratio de coste hora / MLM, llegando a ser la pequeña 6,33 veces más cara que la grande por unidad de MLM para las celosías, 1,38 veces para las telescópicas y 2,91 para las torres.

- Se puede deducir que la innovación será en principio mucho más interesante dirigirla hacia el desarrollo de nuevas grandes grúas dentro de cada tipología. A esto se suma el efecto que en un principio es externo al mundo de las grúas pero que afecta enormemente y que es el aumento de la prefabricación tanto en el mundo de construcción civil como en el de la construcción industrial. En el mundo industrial se observa a nivel mundial la creciente modularización de la construcción que obliga a realizar maniobras con piezas de grandes dimensiones y pesos tanto de transporte de lado a lado del mundo como de izados o colocación en obra. Este fenómeno motivado por distintos factores como pueden ser los plazos de ejecución (permite construir en paralelo módulos en distintos lugares del mundo y luego colocarlos casi simultáneamente en obra), o las dificultades de construcción en algunos destinos de las obras (como puede ser Canadá por el clima o países en vías de desarrollo por la escasez de medios en obra), o el alto coste local en algunas obras (como es el caso de Noruega o Australia) empuja al sector de las grúas a desarrollar nuevos modelos de máquinas con mayores capacidades y se entiende que es una aportación de esta investigación el haber comprobado que el uso de grúas de mayor capacidad implica también una mayor eficiencia económica de la grúa en las obras ya que los ratios de coste horario por capacidad se reducen al aumentar las capacidades de las tres principales tipologías de grúas existentes en el mercado. Efectivamente, en caso de haber obtenido los resultados opuestos (que el coste horario en función del MLM se incrementara al aumentar la capacidad de las grúas, se habría producido un efecto adverso de eficiencia de esta maquinaria al responder a las demandas del mercado. 
- Se ha comprobado que el sector de las grúas y máquinas de elevación tiene una gran capacidad de ingeniería y desarrollo de nuevos productos y, mediante el análisis de casos concretos, se puede concluir que la innovación se produce tanto como respuesta a las necesidades del mercado como por su propio dinamismo interno lanzando nuevos diseños y máquinas que crean su propio mercado, mejoran la eficiencia, e impulsan de esta manera los procedimientos constructivos al ofrecer nuevas posibilidades de izados y maniobras que no se habrían podido ni soñar hasta hace unos pocos años.

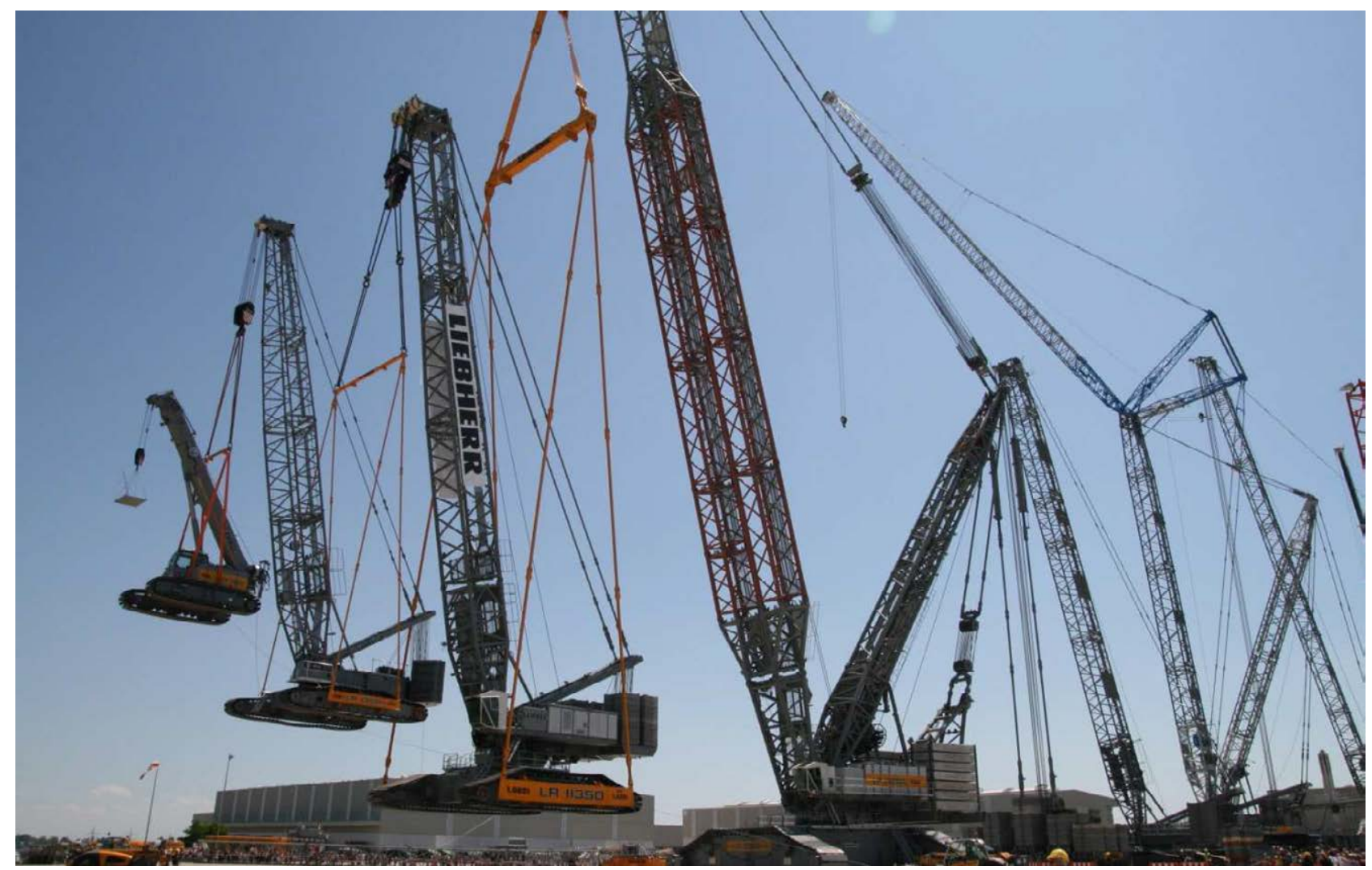




\section{FUTURAS LÍNEAS DE INVESTIGACIÓN}

Tras el análisis técnico financiero de las grúas en función sus costes horarios y de sus capacidades, queda abierta la posibilidad de realizar distintos análisis de otros factores de este tipo de maquinaria que afecten a la eficiencia de las grúas y por lo tanto a su diseño de cara a futuras investigaciones y desarrollos. Estos factores pueden ser:

- Su movilidad, accesorios y alcances: con el impacto que ello tiene en el alcance y la zona de trabajo barrida por la grúa. Las grúas telescópicas son móviles pero trabajan una vez estacionadas y por lo tanto desde posición fija al igual que les ocurre a las grúas torre ancladas sobre zapata o trepantes por una estructura. Las celosías sobre cadenas pueden desplazarse con la carga colgada al igual también puede desplazarse en carga que una grúa torre sobre raíles. Esto hace que su zona de trabajo no se limite al alcance de sus plumas sino a la zona de la obra por la que puedan moverse. Sin embargo son menos móviles que las telescópicas para cambiar de emplazamiento ya que su montaje, desmontaje y porte son más complejos y largos. El uso de accesorios para las grúas como los distintos tipos de plumines o los contrapesos superlift puede también ser como se ha indicado determinante para mejorar los alcances de las grúas y sus posibilidades para resolver problemas concretos de obra.

Este nuevo estudio tendría que considerar más la estrategia de planificación de los recursos de construcción según los distintos tipos de obras: lo que la construcción industrial denomina cada vez más frecuentemente: Constructatibilidad (traducción directa de del término inglés "constructability"), que las características técnicas de la propia máquina que se han considerado en este análisis.

- Su versatilidad o especialización para distintos tipo de obras: Una grúa puede ser muy versátil para adaptarse a distintas tipologías de obras lo cual es positivo a nivel de eficiencia para poder mantener alta su ocupación y amortizarla con mayor facilidad (la grúa torre es quizás el ejemplo más claro de versatilidad) pero en ciertos casos como se ha comentado puede ser ecónomamente más interesante diseñar una grúa específica para un trabajo concreto como es el caso por ejemplo de las grúas portuarias para cargar y descargar 
contenedores a buque. Sólo sirven para ese trabajo concreto y por lo tanto se eliminan capacidades innecesarias para dicho trabajo (en este ejemplo: la capacidad de giro o la capacidad de otras cargas mayores). De esta manera se optimiza y abarata la grúa para ese trabajo concreto a realizar.

- Es difícil decir, llegados a este punto, si el desarrollo de nuevas grúas más grandes (o más especializadas) viene provocado únicamente por la demanda del mercado de dicha maquinaria, porque se diseñan las obras contando con grúas cada vez más grandes.

Se ha demostrado en esta investigación que la mayor capacidad de la grúa mejora su eficiencia al abaratar su coste por capacidad. Este hecho en principio motivaría también a los fabricantes a desarrollar nuevos modelos más grandes para poder competir de forma más eficiente y esta oferta de nuevos productos en el mercado empujaría también a la demanda a usar estos nuevos productos y planificar las futras obras con esta nueva maquinaria.

Sería por lo tanto muy interesante investigar si en el caso de las grúas es la demanda la que empuja a la oferta a innovar, diseñar y construir nuevas máquinas de mayor tamaño o distinta tipología o es oferta la que innova y empuja a la demanda a construir de otra manera al ofrecerle una nueva maquinaria con mayores capacidades. 


\section{BIBLIOGRAFÍA:}

ADAM, Jean Pierre. (1984) La Construction romaine, matériaux et techniques. Paris.

ALBERTI, Leon Battista (1441). Della Tranquillità dell'animo, citado en Brunelleschi's dome (Ross King, 2000).

ARISTÓTELES. (384-322). Ejercicios mecánicos. (Mech. 18, 853a32 - 853b13; atribuido a Aristóteles)

CERVERA VERA, Luis (1996). El manuscrito de Juan de Herrera indebidamente titulado "Architectura e Machinas". Valencia. Ed. Patrimonio Ediciones S.L.

COMITEE FOR EUROPEAN CONSTRUCTION EQUIPMENT. Grúas torre. Mayor seguridad y confort. Con la nueva normativa europea EN 14439. Documento [en línea]: http://www.liebherr.com/CMS/downloads/CC CECE TowerCranes SP.pdf [consulta: 29 octubre 2015]

CONRAD KYESER VON EICHSÄDT. Bellifortis. (manuscrito Ms.2259). Dibujo de "Máquina para perforar tubos en madera". Biblioteca Nacional y Universitaria de Estrasburgo

COVARRUBIAS, Sebastian de. Tesoro de la Lengua Castellana o Española. Según la impresión de 1611, con las adiciones de Benito Remigio Noydens, publicada en 1674. Edición preparada por Martín de Riquer. Barcelona, Editorial Alta Fulla, 1987

ERLANDE-BRANDENBURG, Alain (1994). Quand les cathédrales étaient peintes. Ed. Gallimard. Paris.

ESCUELA BÍBLICA DE JERUSALEN (1975). Biblia de Jerusalén. Versión católica romana. Ed. Editorial Española Desclée de Brouwer, S.A., Bilbao (nueva edición 1976; p15) - Construcción de la Torre de Babel, Génesis 11: 1-9.

FLÓREZ DE LA COLINA, Miguel y FLÓREZ ALÍA, José (2008). Apuntes de sistemas de elevación, grúas. Ed. Publicaciones E.T.S. Ingenieros de Caminos Canales y Puertos de la Universidad Politécnica de Madrid. Madrid. (ISBN: 978-84-7493-391-8)

GONZÁLEZ TASCÓN, Ignacio. (1998). "Los caminos y los puentes". En: Felipe II. Los ingenios y las máquinas. Madrid: Sociedad Estatal para la conmemoración de los centenarios de Felipe II y Carlos V y Ministerio de Fomento, 1998. Catálogo de la exposición, Real jardín Botánico, CSIC, Pabellón de Villanueva.

GONZÁLEZ TASCÓN, Ignacio (2002). "Ingenios, máquinas y grúas". En Artifex: ingeniería romana en España. Madrid: Ministerio de Educación, Cultura y Deporte; Ministerio de Fomento; Fundación Juanelo Turriano, 2002. Catálogo de la exposición, Museo Arqueológico Nacional.

JASO TOWER CRANES. Brochure J 52 NS - Data sheet. http://www.towercranes.net/pdf/Jaso52-NS-Data-Sheet.pdf. [consulta: 29 octubre 2015] 
KING, Ross (2000). Brunelleschi's dome. Ed. Walker Publishing Company, Inc. New York.

LANZ y BETANCOURT (1808). Ensayo sobre la composición de las máquinas. Madrid: Colegio ingenieros de Caminos, Canales y Puertos, Demarcación de Madrid, 1990.

LIEBHERR. Catalogue Liebherr LR 11350 Crawler crane - Data Sheet. Catálogo [en línea]: http://www.liebherr.com/CR/en-GB/products cr.wfw/id-8361-0/measure-metric [consulta: 29 octubre 2015]

LIEBHERR. Catalogue Liebherr LR 1200 Crawler crane - Data Sheet. Catálogo [en línea]: http://www.liebherr.com/CR/en-GB/products cr.wfw/id-1434-0/measure-nonMetric

[consulta: 29 octubre 2015]

MANITOVOC. Catalogue Grove GM 4080-1 All-terrain Crane - Product guide Metric. Catálogo [en línea]: http://www.bigge.com/crane-charts/Grove-GMK4080-1.pdf [consulta: 29 octubre 2015]

MANUSCRITO. "Construcción de la torre de Babel" miniatura del Códice Cod. Bibl.2 5, de la Württembergische Landesbibliothek de Stuttgart.

MINISTERIO DE TRABAJO Y ASUNTOS SOCIALES. NTP 701: Grúas-torre. Recomendaciones de seguridad en su manipulación. Documento [en línea]: http://www.insht.es/InshtWeb/Contenidos/Documentacion/FichasTecnicas/NTP/Ficheros/701 a750/ntp 701.pdf [consulta: 29 octubre 2015]

PSEUDO JUANELO TURRIANO (1564-1579). Los veintiún libros de los ingenios y las máquinas. Manuscritos sig. 3372 a 3376 de la Biblioteca Nacional de Madrid. Madrid: Colegio Oficial de Ingenieros de Caminos, Canales y Puertos de Madrid. Prólogo de Juan Antonio García-Diego (1983). Vol. II, p. 518.

POTAIN, MANITOVOC. Catalogue MD 610 M40. Catálogo [en línea]: https://www.manitowoccranes.com/es-ES/cranes/potain/top-slewing/md/MD-610-M40.

[consulta: 29 octubre 2015]

POTAIN, MANITOVOC. Catalogue MD 3200. Catálogo [en línea]: https://www.manitowoccranes.com/en/cranes/potain/top-slewing/md-maxi/MD-3200.

[consulta: 29 octubre 2015]

REAL ACADEMIA ESPAÑOLA (1977). Diccionario de La Lengua Española. Madrid, Espasa-Calpe S.A., 1977. p. 679 , de la 19a edición.

SCHILLING, Diebold (1484-1485). "Construcción de un puente" en la Crónica privada de Berna denominada "de Spiez". Manuscrito Ms Hist. Helv. I-16, de la sección de Historia suiza de la Burgerbibliothek de Berna, Suiza.

SENNEBOGEN. Brochure 2200 Crawler crane - Data Sheet. Catálogo [en línea]: http://www.sennebogen.com/uploads/tx irdownload/2200 E 02.pdf [consulta: 29 octubre 2015]

SHAPIRA, A., \& GLASCOCK, J. D. (1996). "Culture of using mobile cranes for building construction". Journal of Construction Engineering and Management, 122(4), p. 298-307. 
SHAPIRA, A.; LUCKO, G., \& SCHEXNAYDER, C. J. (2007). "Cranes for building construction projects". Journal of Construction Engineering and Management, 133(9), p. 690-700.

SHAPIRO, L. K.; \& SHAPIRO, H. I. (1988). "Construction cranes”. Scientific American, 258(3), p. 72-79.

TEREX DEMAG Catalogue Terex Demag CC 2800-1 Craw/wer crane - Data Sheet Metric. Catálogo [en línea]:

http://www.terex.com/cranes/en/idc03/groups/webcontent/@web/@cra/documents/web c ontent/ucm02 047783.pdf [consulta: 29 octubre 2015]

TEREX DEMAG Catalogue Terex Demag AC 700 crane - Data Sheet Metric. Catálogo [en línea]: http://www.terex.com/cranes/es/products/allterraincranes/AC700/index.htm [consulta: 29 octubre 2015]

VITRUVIO POLIO, Marco. (MANUSCRITO del Siglo I). De Architectura.

- Los diez libros de Arquitectura. Traducción y comentarios por J. Ortiz y Sanz. Prólogo de D. Rodríguez Ruiz. Ed. Akal. Madrid, 1987.

- Ed. Florencia 1513 en 
ANEXOS: 
ANEXO №1: INSTRUCCIÓN TÉCNICA COMPLEMENTARIA (ITC) “MIEAEM-2" del Reglamento de aparatos de elevación y manutención, referente a grúas torre para obras u otras aplicaciones. REAL DECRETO 836/2003 de 27 de Junio 


\section{Disposición final segunda. Entrada en vigor.}

El presente real decreto entrará en vigor el día siguiente al de su publicación en el "Boletín Oficial del Estadon.

Dado en Madrid, a 4 de julio de 2003.

\section{JUAN CARLOS R.}

La Ministra de Educación, Cultura y Deporte,

PILAR DEL CASTILLO VERA

\section{MINISTERIO DE CIENCIA Y TECNOLOGÍA}

14326 REAL DECRETO 836/2003, de 27 de junio, por el que se se aprueba una nueva Instruc ción técnica complementaria "MIE-AEM-2" del Reglamento de aparatos de elevación y manutención, referente a grúas torre para obras $u$ otras aplicaciones.

La Instrucción técnica complementaria (ITC) "MIE-AEM- $2 n$ del Reglamento de aparatos de elevación y manutención, aprobada por Orden de 28 de junio de 1988, contempla los requisitos constructivos exigibles a las grúas torre desmontables para obra, estableciendo la obligatoriedad de aplicación de la norma UNE 58-101-80, parte I. Asimismo, establece las condiciones aplicables a todas las grúas torre, en cuanto a montaje. utilización e inspecciones periódicas, tanto a las comercializadas de acuerdo con la reglamentación nacional como aquellas que posteriormente han sido fabricadas de acuerdo con el Real Decreto 1435/1992, de 27 de noviembre, modificado por el Real Decreto 56/1995, de 20 de enero de transposición de la Directiva 89/392/CEE del Consejo, sobre máquinas y sus sucesivas modificaciones.

Dada la experiencia adquirida desde la aplicación de la ITC, parece aconsejable revisar ciertos aspectos contemplados en ella, por lo que se modifica la redacción de algunos puntos, se fijan criterios para la realización de las inspecciones y se actualizan las referencias de las normas en ella contempladas.

Asimismo, los reales decretos de transposición de la directiva de máquinas mencionada obligan a introducir algunas modificaciones en el articulado, con el fin de tener en cuenta la existencia de grúas fabricadas y comercializadas de acuerdo con la referida directiva y que, en consecuencia, llevan el marcado "CEn.

Esta disposición ha sido sometida al procedimiento de información en materia de normas y reglamentaciones técnicas y de reglamentos relativos a los servicios de la sociedad de la información, previsto en la Directiva 98/34/CE del Parlamento Europeo y del Consejo, de 22 de junio de 1998, modificada por la Directiva $98 / 48 / C E$, de 20 julio de 1998, así como en el Real Decreto $1337 / 1999$, de 31 de julio, que incorpora estas directivas al ordenamiento jurídico español, y, de acuerdo con lo dispuesto en el artículo 24.1.c) de la Ley 50/1997. de 27 de noviembre, del Gobierno, al trámite de audiencia que en ella se establece, remitiéndose al sector afectado.

Esta disposición se dicta al amparo de lo establecido en el artículo 149.1.13. ${ }^{\circ}$ de la Constitución Española, que atribuye al Estado la competencia para determinar las bases y coordinación de la planificación general de la actividad económica.
En consecuencia, se considera conveniente sustituir el contenido de la Instrucción técnica complementaria (ITC) "MIE-AEM-2n del Reglamento de aparatos de elevación y manutención por un nuevo texto.

En su virtud, a propuesta del Ministro de Ciencia y Tecnología, de acuerdo con el Consejo de Estado y previa deliberación del Consejo de Ministros en su reunión de 27 de junio de 2003 .

\section{DISPONGO:}

Artículo único. Aprobación de la Instrucción técnica complementaria "MIE-AEM-2".

Se aprueba la Instrucción técnica complementaria (ITC) «MIE-AEM-2n del Reglamento de aparatos de elevación y manutención, referente a grúas torre para obras u otras aplicaciones, que se inserta a continuación.

Disposición adicional primera. Reglamentación aplicable.

Los usuarios de las grúas torre que, con anterioridad a la entrada en vigor de este real decreto, hubieran justificado ante el órgano competente de la comunidad autónoma correspondiente el cumplimiento de los requisitos establecidos en la ITC "MIE-AEM-2w, aprobada por Orden de 28 de junio de 1988, podrán seguir utilizándolas siempre que cumplan los requisitos que para su instalación y puesta en servicio se establecen en el artículo 5 de la ITC «MIE-AEM-2n que acompaña a este real decreto y dispongan de la documentación contemplada en los apartados 5 y 6 de la norma UNE 58-101-92. parte 3. y cuyos conceptos se indican a continuación:

a) Manual del fabricante: especificaciones técnicas, instrucciones de instalación y montaje, utilización y mantenimiento, especificación de repuestos.

b) Instrucciones del usuario: instrucciones de instalación, instrucciones de montaje, instrucciones para el trabajo con la grúa, instrucciones de revisión, instrucciones generales de seguridad.

Disposición adicional segunda. Equipos procedentes de la Unión Europea.

Las grúas torre no incluidas en la disposición adicional primera y que hayan sido comercializadas en la Unión Europea con anterioridad al 1 de enero de $1995 \mathrm{sin}$ cumplir con la Directiva 89/392/CEE del Consejo, sobre máquinas, y sus sucesivas modificaciones, podrán ser instaladas y utilizadas en el territorio nacional, si justifican el cumplimiento de los requisitos técnicos indicados en la norma UNE-58-101-92 parte 1, mediante la certificación de un organismo de control autorizado, y si disponen de la documentación indicada en la disposición adicional anterior coincidente con los apartados 5 y 6 de la norma UNE 58-101-92, parte 3.

No obstante lo expresado en el párrafo anterior, se admitirá en el mercado español la instalación y utilización de grúas torre para obras u otras aplicaciones, procedentes de otros Estados miembros de la Unión Europea o fabricadas dentro del Espacio Económico Europeo, que cumplan con sus normas o reglamentaciones nacionales. siempre que por el órgano competente de la comunidad autónoma en que se instale o comercialice por primera vez se reconozca que tienen un nivel de seguridad equivalente al que se establece en esta ITC.

A estos efectos, el procedimiento a seguir será:

a) Certificado expedido por la autoridad competente del país del que proviene la grúa en el que se indique la conformidad de que la grúa en su estado actual continúa cumpliendo con la reglamentación nacional que le era de aplicación en el momento de su fabricación. 
b) Certificado de un organismo de control en el que se indiquen las diferencias entre los requisitos técnicos exigidos en la norma UNE 58-101-92, parte 1, y los exigidos en la reglamentación nacional que era de aplicación a la grúa en el momento de su fabricación. Se especificarán las medidas de seguridad alternativas en la grúa, indicando si, a la vista de dichas alternativas. consideran que tienen un nivel de seguridad equivalente al establecido en esta ITC

c) Elórgano competente de la comunidad autónoma donde se comercialice o se instale por primera vez la grúa, a la vista de la documentación indicada en los dos párrafos anteriores, certuficará el cumplimiento de los requisitos de esta ITC.

Disposición transitoria primera. Operadores de grúas torre.

Los operadores de grúas torre existentes en la actualidad con experiencia demostrada o que dispongan de la formación especifica adecuada deberán obtener el carné de operador de grúa torre a que se refiere el anexo $\mathrm{V}$. en el plazo de tres años desde la entrada en vigor de este real decreto. Las comunidades autónomas que tuvieran regulada la expedición de carnés en esta materia podrán establecer un plazo inferior.

La acreditación de la experiencia estará formada documentalmente por, al menos:

a) Vida laboral del trabajador, expedida por el Instituto Nacional de la Seguridad Social.

b) Certificación de las empresas titulares de las grúas torre, con las que se ejerció la actividad.

Disposición transitoria segunda. Grúas torre en otras apficaciones.

Las grúas incluidas en esta ITC a las que no les era aplicable la Orden de 28 de junio de 1988 , por estar destinadas a otras aplicaciones distintas de las obras. y que se encuentren instaladas con anterioridad a la publicación de este real decreto, deberán ser inspeccionadas por un organismo de control autorizado de acuerdo con los criterios indicados en el apartado B del anexo III. en el plazo de un año desde la entrada en vigor de este real decreto, presentándose informe de inspección al órgano competente de la comunidad autónoma.

Estas grúas deberán cumplir las disposiciones de la ITC "MIE-AEM-2 w adjunta contenidas en el articulo 7 (utilización), articulo 8 (mantenimiento y revisiones) y articulo 10 (inspecciones extraordinarias).

Disposición transitoria tercera. Empresas instaladoras.

Las empresas instaladoras autorizadas que no cum plan con los requisitos que se establecen en el articulo 6 de la ITC deberan adaptarse en el plazo de un año desde la entrada en vigor de este real decreto.

Disposición derogatoria única. Derogación normativa.

A partir de la entrada en vigor de este real decreto. queda derogada la Instrucción técnica complementaria "MIE-AEM-2w, aprobada por Orden del Ministerio de Industria y Energia. de 28 de junio de 1988 , y sus modificaciones.

\section{Disposición final primera. Título competencial.}

Este real decreto se dicta al amparo de lo establecido en el articulo 149.1.13. ${ }^{\text {a }}$ de la Constitución, que atribuye al Estado la competencia para determinar las bases y coordinación de la planificación general de la actividad económica.

\section{Disposición final segunda. Facultades de desarrollo.}

Se faculta al Ministro de Ciencia y Tecnologia a modificar o desarrollar los anexos de este real decreto o introducir otros nuevos, asi como a actualizar periódicamente las normas contempladas en esta ITC, de acuerdo con la evolución de la técnica o cuando dichas normas hayan sido revisadas, anuladas o sustituidas por otras nuevas.

\section{Disposición final tercera. Entrada en vigor.}

El presente real decreto entrará en vigor a los tres meses de su publicación en el "Boletin Oficial del Estadom.

Dado en Madrid, a 27 de junio de 2003. JUAN CARLOS R.

BMrintro de Ciencie y Tecnologia.

JOSEP PIOUE I CAMPS

\section{INSTRUCCION TECNICA COMPLEMENTARIA "MIE-AEM-2: DEL REGLAMENTO DE APARATOS DE ELEVACION Y MANUTENCION REFERENTE A GRUAS TORRE PARA OBRAS U OTRAS APLICACIONES}

\section{Articulo 1. Objeto.}

Esta Instrucción técnica complementaria (ITC) tiene por objeto establecer las prescripciones del Reglamento de aparatos de elevación y manutención, en cuanto se refiere a las condiciones de seguridad exigibles para el montaje y utilización de las gruas torre para obras u otras aplicaciones.

\section{Articulo 2. Definiciones.}

Para la aplicación de esta ITC se tendrán en cuenta las definiciones que figuran en las normas UNE $58-110-90$, 58-104, partes 1 a 5 , y en especial las siguientes:

2.1 Grúa. Aparato de elevación de funcionamiento discontinuo destinado a elevar y distribuir, en el espacio, las cargas suspendidas de un gancho o de cualquier otro accesorio de aprehensión.

2.2 Grúa pluma. Grúa en la que el accesorio de aprehensión está suspendido de la pluma o de un carro que se desplaza a lo largo de ella.

En el primer caso, la distribución de la carga se puede efectuar por variación del ángulo de inclinación de pluma (figura 1 del anexo 1): en el segundo caso, la posición de la pluma suele ser horizontal (figura 2 del anexo I). aunque puede utilizarse inclinado hasta formar un determinado ángulo (figura 3 del anexo I).

2.3 Grúa torre. Grúa pluma orientable en la que el soporte giratorio de la pluma se monta sobre la parte superior de una torre vertical, cuya parte inferior se une a la base de la grúa (figura 4 del anexo I).

2.4 Grùa torre desmontable. Grùa torre, concebida para su utilización en las obras de construcción u otras aplicaciones, disefiada para soportar frecuentes montajes y desmontajes, así como traslados entre distintos emplazamientos.

2.5 Grúa torre autodesplegable. Grúa pluma orientable en la que la pluma se monta sobre la parte superior de una torre vertical orientable, donde su parte inferior se une a la base de la grúa a través de un soporte giratorio y que está provista de los accesorios necesarios para 
permitir un rápido plegado y desplegado de la torre y pluma (figura 5 del anexo 1 ).

2.6 Grúa torre autodesplegable monobloc. Grúa torre autodesplegable cuya torre está constituida por un solo bloque y que no requiere elementos estructurales adicionales para su instalación, que puede ir provista de ruedas para facilitar su desplazamiento.

2.7 Grúa torre desplazable en servicio. Es aquella cuya base está dotada de medios propios de traslación sobre carriles $\mathrm{u}$ otros medios y cuya altura máxima de montaje es tal que sin ningún medio de anclaje adicional sea estable tanto nen servicion como wfuera de servicion para las solicitaciones a las que vaya a estar sometida (figura 6 del anexo I).

2.8 Grúa torre fija (estacionaria). Grúa torre cuya base no posee medios de traslación o que poseyéndolos no son utilizables en el emplazamiento, o aquéllas en que la base es una fundación o cualquier otro conjunto fijo (figura 6 del anexo I).

2.9 Grúa torre trepadora. Grúa torre instalada sobre la estructura de una obra en curso de construcción y que se desplaza de abajo hacia arriba por sus propios medios al ritmo y medida que la construcción progresa (figura 7 del anexo I).

2.10 Emplazamiento de la grúa. Es la zona donde la grúa se ha de situar y por la que, en su caso, se puede desplazar.

2.11 Condición de servicio. Es el conjunto de disposiciones tomadas en la grúa y en sus elementos y mecanismos para que, convenientemente instalada en su emplazamiento, pueda prestar su cometido.

2.12 Condición de fuera de servicio. Es el conjunto de disposiciones tomadas en las grúas y en sus elementos y mecanismos para que, convenientemente ins. talada en su emplazamiento, pueda permanecer estable sin realizar ningun trabajo.

2.13 Grúa instalada. Es la condición en que se encuentra la grúa erigida por completo en su emplazamiento, sometida a las solicitaciones establecidas en las reglas de cálculo para la condición fuera de servicio. pero sin que sea necesario que esté dispuesta para pasar a la condición de servicio.

2.14 Puesta en servicio. Es el conjunto de comprobaciones y maniobras que deben ejecutarse en una grúa instalada para que pueda pasar inmediatamente a la condición de servicio si las circunstancias lo permiten.

2.15 Instalación de la grúa. Es el proceso material de realizar todas las operaciones necesarias para que la grúa quede en la condición de instalada, incluyendo las de ejecución de sus fundaciones y montaje de la grúa. También incluye, en su caso, al conjunto de fundaciones, camino de rodadura y grúa instalada.

2.16 Montaje de la grúa. Es el proceso real de erigir y montar la grúa sobre su emplazamiento y fundaciones, para que pueda prestar su cometido.

2.17 Fabricante. Es la persona fisica o juridica que asume la responsabilidad de su construcción.

2.18 Importador. Es la persona física o juridica que comercializa en el Estado grúas torre fabricadas fuera del Espacio Económico Europeo.

2.19 Usuario. Es la persona fisica o juridica que utiliza la grúa, en calidad de propietario o arrendatario legal, que es responsable de su utilización y custodia, asi como de que se realice el adecuado mantenimiento.

2.20 Empresa instaladora. Es aquella que está autorizada para realizar el montaje y desmontaje de las grúas torre.

2.21 Empresa conservadora. Es aquella que está autorizada para realizar operaciones de mantenimiento periódico y reparaciones en la grúa, distintas de las que pueden corresponder al gruista.
2.22 Gruista u operador de grúa torre. Es la persona física que tiene conocimientos y autorización para manejar y operar directamente la grua.

2.23 Obra. Es la zona localizada de trabajo donde la grúa va a utilizarse en un solo emplazamiento o en varios sucesivos.

2.24 Jefe de obra. Es la persona fisica designada por el usuario como responsable de la obra en que se instale la grúa.

2.25 Propietario. Es la persona física o juridica que ostenta la propiedad legal de la grúa, aunque pueda no usarla por si mismo.

2.26 Arrendatario. Es la persona fisica o juridica que, mediante contrato de arrendamiento, utiliza la grúa.

2.27 Organismo de control autorizado. Entidad acreditada de acuerdo con el Real Decreto 2200/1995, de 28 de diciembre, para la aplicación de esta ITC.

2.28 Arriostramiento. Es la sujeción obligatoria de que se deberá proveer a la grúa cuando ésta supera la altura autoestable definida por el fabricante, para las condiciones de utilización, con el fin de asegurar su estabilidad (figura 8 del anexo l).

2.29 Fundación. Es el elemento a través del cual se transmiten al suelo las acciones de la grúa de acuerdo con las reglas de cálculo.

2.30 Pies, patas, anclajes, garras o zarpas de empotramiento. Elementos mecánicos o estructurales de la grúa que, unidos a la torre, sirven para transmitir las solicitaciones a la fundación.

2.31 Carga nominal. Valor de las cargas indicadas por el fabricante y expresadas en el correspondiente diagrama.

2.32 Carga máxima Valor máximo de la masa a elevar por la grúa según los datos del fabricante.

2.33 Carga en punta. Valor máximo de la masa a elevar por la grúa en su alcance máximo.

2.34 Diagrama de cargas y alcances. Correlación de cargas y alcances para cada longitud de pluma y cada dispositivo de aprehensión expresada gráficamente.

2.35 Momento nominal o par nominal. Momento máximo de la carga admitido por la grua a su altura autoestable.

2.36 Altura bajo gancho. Es la distancia vertical entre el plano de emplazamiento de la grúa y el centro del gancho en su posición más elevada (figura 10 del anexo l).

2.37 Altura de montaje. Es la altura bajo gancho en la posición adoptada.

2.38 Altura autoestable. Es la mayor altura bajo gancho que permite que la grúa sea estable tanto en condición de servicio como fuera de servicio, sin ningún medio adicional de anclaje, para las solicitaciones definidas en las reglas de cálculos vigentes.

2.39 Altura máxima. Es la altura bajo gancho máxima de la grúa que permiten las reglas de cálculo y la disposición de los mecanismos, convenientemente arriostrada.

\section{Articulo 3. Ambito de aplicación.}

Esta ITC es aplicable a todas las grúas torre de más de $15 \mathrm{kN} . \mathrm{m}$ de momento nominal, movidas mecánica. mente, destinadas a la elevación y distribución de materiales, tanto en obras como en otras aplicaciones.

En el anexo I se incluyen las distintas configuraciones de gruaas torre.

\section{Articulo 4. Fabricación y comercialización.}

4.1 Quedan excluidas de la certificación de tipo indicada en el artículo 4 del anexo del Real Decreto $2291 / 1985$, de 8 de noviembre, por el que se apruebs 
el Reglamento de aparatos de elevación y manutención. as gruas torre y sus componentes, objeto de esta ITC. 4.2 No obstante, los fabricantes o, en su caso, los importadores entregarán, junto con cada grúa torre, la declaración "CE" de conformidad prevista en el Real Decreto $1435 / 1992$, de 27 de noviembre, sobre máquinas, modificado por el Real Decreto $56 / 1995$, de 20 de enero, asi como el manual del fabricante y las instrucciones del usuario de acuerdo con lo indicado en los citados reales decretos.

Las instrucciones del usuario deberán ser redactadas al menos en castellano.

4.3 La responsabilidad de la construcción de la grúa torre corresponde al fabricante 0 , en su caso, al importador.

\section{Articulo 5. Instalación y puesta en servicio.}

5.1 Provecto de instalación. $\mathrm{La}$ instalación de los aparatos incluidos en esta ITC requiere la presentación de un proyecto ante el órgano competente de la comu nidad autonoma, suscrito por técnico titulado competente y visado por el colegio oficial al que pertenezco.

En el anexo ll se indica el contenido minimo del proyecto de instalación.

Dicho proyecto se realizará de acuerdo con lo expresado en cuanto a condiciones de instalación en la norma UNE 58-101-92. parte 2 «Aparatos pesados de elevación. Condiciones de resistencia y seguridad en las gruas torre desmontables para obras. Condiciones de instalación y utilización.

La referencis a la imposibilidad de contacto de cualquier parte de la grúa, asi como de las cargas suspen didas, contenida en el segundo párrafo del apartado 4.1 de la norma UNE 58-101-92, parte 2, se entenderá referida en lineas de baja tensión exclusivamente a la imposibilidad de contacto eléctrico.

El plano de emplazamiento y las características de terreno serán facilitados por la dirección facultativa de la obra al técnico que realice el proyecto.

No se exigirá un nuevo proyecto tócnico cuando una misma grúa se desplace dentro de la misma obra y siempre que no se modifiquen sus condiciones de montaje e instalación ni las características del terreno, siendo necesario para la nueva instalación la presentación de los documentos previstos para la puesta en servicio.

En el caso de grúas autodesplegables de tipo monobloc cuyo momento nominal esté comprendido entre $15 \mathrm{kN} . \mathrm{m}$ y $170 \mathrm{kN} . \mathrm{m}$, el proyecto de instalación citado anteriormente podrá ser sustituido por un certificado de instalación emitido y firmado por el técnico títulado com petente de la empresa instaladora y visado por el colegio oficial al que pertenezca (en el anexo $\mathrm{V}$ se incluye el modelo de certificado de instalación de grúa autodesplegable monobloc).

5.2 Los pies de empotramiento y cualquier otro elemento estructural de la grúa que se sustituya estarán fabricados por la misma empresa fabricante de la grúa. y cuando alguno de estos elementos estructurales no sea fabricado por la empresa fabricante de la grúa, deberá certificarse su idoneidad y compatibilidad por un orgarnismo de control autorizado. En este caso, la certificación indicará que el provecto de diseno, los materiales y la fabricación de ese elemento concreto garantizan la capacidad de soportar las solicitaciones de la grúa.

Para ser autorizados por el órgano competente de las comunidades autónomas donde estén establecidos, y poder fabricar los pies de empotramiento o cualquier otro elemento estructural de la grús, estos fabricantes deberán contar como minimo con los medios humanos y materiales que se indican a continuación

a) Disponer en plantilla de un técnico titulado competente. b) Disponer de soldadores y procesos de soldadura homologados por un organismo de control autorizado.

c) Instalaciones y local adecuado a la actividad que se desarrolla.

d) Seguro de responsabilidad civil, aval u otra garantía financiera suscrita con entidad debidamente autorizada, con cobertura mínima por accidente de 1.000 .000 de euros.

Cada tramo de empotramiento, garras o zarpas que se fabrique se identificará con un número $\mathrm{y}$, además de la certificación del organismo de control, se acompaf́ará con el certificado de fabricación expedido por el tecnico titulado competente de la empresa.

Igualmente, en el caso de reparaciones de cualquier elemento estructural de la grúa torre, se emitirá certificación del técnico titulado competente de la empresa.

5.3 Montaje. Las grúas incluidas en esta ITC se montarán de acuerdo con lo que al respecto se indica en la norma UNE 58-101-92, parte 2 "Aparatos pesados de elevación. Condiciones de resistencia y seguridad en las grúas torre desmontables para obras. Condición de instalación y utilizaciónn.

En relación con el apartado 6.1. de dicha norma, se tendrá en cuenta:

a) El montaje será realizado por empresa instaladora autorizada o por el propio fabricante de la grúa.

b) Los montadores que realicen estas operaciones dependerán del técnico competente de la empresa autorizada responsable del montaje, el cual deberá planificar y responsabilizarse del trabajo que se ejecute, extendiendo al efecto los correspondientes certificados de ins. talación. según el modelo que figura en el anexo $\mathrm{V}$

5.4 Instalación de anemómetro. El anemómetro será exigible en las gruas que vayan a instalarse en una zona donde puedan alcanzarse los vientos limite de servicio. Deberá dar un aviso intermitente a la velocidad de viento de $50 \mathrm{~km} / \mathrm{h}$ y continuo a $70 \mathrm{~km} / \mathrm{h}$, parando la señal al dejar la grúa fuera de servicio (en veleta).

5.5 Puesta en servicio. Para la puesta en servicio se presentará ante el órgano competente de la comunidad autónoma la siguiente documentación.

a) Documento firmado por la empresa instaladora y por el usuario, en el que la empresa instaladora acredite que se cumplen las condiciones de instalación de la norma UNE 58-101-92, parte 2. que se ha hecho entrega de la grúa al usuario después de comprobar en presencia de éste $y$ del gruista el correcto funcionamiento de los dispositivos de seguridad y que se ha entregado el manual de instrucciones de utilización.

b) Informe de inspección de la grúa emitido por un organismo de control autorizado en el que se acredite su correcto estado y la idoneidad de la documentación. Para ello se realizara, antes del montaje, una inspección de todos los elementos de la grúa y otra inspección una vez finalizado su montaje. Para ambas inspecciones se tendrán en cuenta los criterios indicados en el anexo III.

En el caso de grủas autodesplegables del tipo monobloc cuyo momento nominal se encuentre comprendido entre $15 \mathrm{kN}$.m y $170 \mathrm{kN}$.m, solamente se realizarán las inspecciones cada dos años, independientemente del número de montajes realizados en dicho periodo.

c) Certificado de instalación emitido por el técnico titulado competente de la empresa instaladora. En el anexo $\mathrm{V}$ se indican los modelos de los certificados de instalación que deben utilizarse para gruas torre desmontables y autodesplegables de tipo monobloc, con la información que como mínimo deben contener dichas certificaciones. 
d) Declaración "CEn de conformidad o, en su caso. certificación del cumplimiento de las disposiciones adicionales primera o segunda de este real decreto.

e) Contrato de mantenimiento.

f) En su caso, certificación de los elementos mecánicos o estructurales incorporados a la grúa.

\section{Articulo 6. Empresas instaladoras.}

Para la inscripción en el registro industrial, las empresas instaladoras deberán acreditar que cumplen con los requisitos exigibles y contar con una plantilla minima de un técnico titulado competente, que será el responsable técnico y además con tres montadores cualificados, de los cuales dos habrán de ser necesariamente mecánicos, y el tercero, eléctrico.

Estas empresas tendrán cubierta su responsabilidad civil con una póliza de seguros, un aval u otra garantia financiera suscrita con entidad debidamente autorizada por una cuantia minima de 600.000 euros, incrementándose anualmente de acuerdo con la variación del indtce oficial de precios de consumo.

\section{Articulo 7. Utilización.}

Las grúas serán manejadas en todo momento por un gruista que reunirá las condiciones fijadas por la norma UNE 58-101-92, parte 2, y estará sometido a las obligaciones que se indican en esta.

La autorización de los gruistas se realizará de acuerdo con los criterios especificados en el anexo VL. El carné expedido de acuerdo con estos criterios tendrá validez en todo el territorio nacional.

El gruista dispondrá del manual de instrucciones de utilización facilitado por la empresa instaladora/conservadora, cuyo contenido se indica en el anexo IV. En todo momento deberá tener accesibles las cargas de comprobación necesarias para verificar el correcto estado de la grúa (cargas nominales máxima y en punta o en la posición más alejada de la carga en la pluma en la obra concreta, así como las del 10 por ciento de dichos valores).

\section{Articulo 8. Mantenimiento y revisiones.}

Las grúas instaladas incluidas en el ámbito de aplit cación de esta ITC y sus accesorios serán revisadas periódicamente al menos cada cuatro meses, de acuerdo con los criterios establecidos en la norma UNE 58-101-92. parte 2.

El usuario deberá suscribir un contrato de mantenimiento con una empresa conservadora autorizada mientras la grúa permanezca instalada.

Las grúas que hayan permanecido en la condición de fuera de servicio durante un período de tiempo superior a tres meses deberán ser revisadas antes de su nueva puesta en servicio.

Estas revisiones podrán efectuarse por el propietario o usuario de la grúa, si se ha demostrado ante el órgano competente de la comunidad autónoma que cumple con las condiciones exigidas a las empresas conservadoras.

Los propietarios o usuarios de las grúas cumplirán lo establecido en el artículo 13 del Reglamento de aparatos de elevación y manutención.

\section{Artículo 9. Empresas conservadoras.}

Las empresas conservadoras cumplirán lo establecido en los artículos 10 y 11 del Reglamento de aparatos de elevación y manutención.

Para su inscripción en el registro industrial, las empresas conservadoras deberán acreditar que cumplen los requisitos exigibles y contar con una plantilla suficiente para atender las instalaciones que tengan contratadas, con un minimo de dos operarios cualificados, en la comunidad autónoma en la que desarrollen las actividades. Estas empresas dispondrán de un local con el equipamiento necesario, aunque el órgano competente de la comunidad autónoma podrá dispensar, por causa justificada, del cumplimiento de estos requisitos.

Estas empresas deberán cubrir su responsabilidad civil de acuerdo con lo indicado en el articulo 6 para las empresas instaladoras.

\section{Artículo 10. Empresa instaladora-conservadora.}

Para la inscripción en el registro industrial de una empresa como instaladora y conservadora, no será necesario suscribir más que una sola póliza por la cuantía indicada, y el personal podrá simultanear ambas funciones.

\section{Articulo 11. Inspecciones extraordinarias.}

Las grúas incluidas en el ámbito de aplicación de esta ITC, cuya instalación se mantenga en el mismo emplazamiento durante un tiempo prolongado, deberán someterse a una inspección extraordinaria cada dos años, contados desde la puesta en servicio.

Estas inspecciones serán realizadas por un organismo de control autorizado, y no será necesario proceder a su desmontaje.

Articulo 12. Modificaciones esenciales en grúas instaladas.

Se consideran modificaciones esenciales de la instalación a que se refiere el articulo 18 del Reglamento de aparatos de elevación y manutención los que afectan a los siguientes extremos:

a) Alcance.

b) Altura de montaje.

c) Diagrama de cargas y aicances.

d) Composiciones del mástil, pluma o contrapluma.

e) Cables (tipo o diámetro).

f) Masas de lastre y de contrapeso.

g) Velocidades.

h) Elementos de seguridad.

Estas modificaciones esenciales requerirán la presentación de la documentación prevista en el artículo 5 para la instalación y puesta en servicio.

No se permitirán modificaciones esenciales no previstas por el fabricante de la grúa. 
Figuras

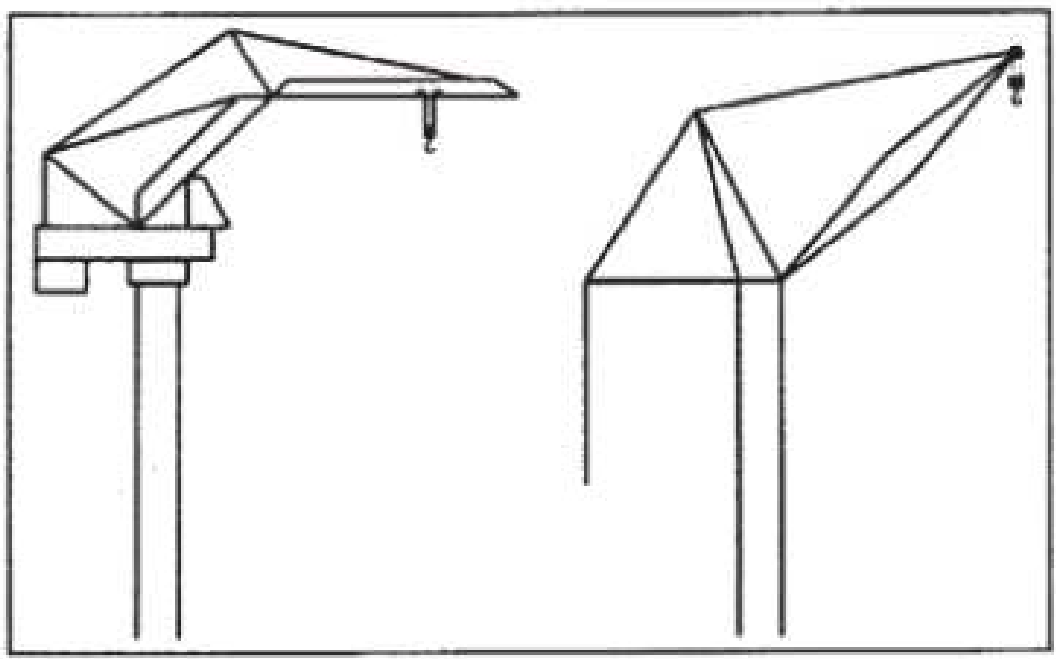

Fig.1

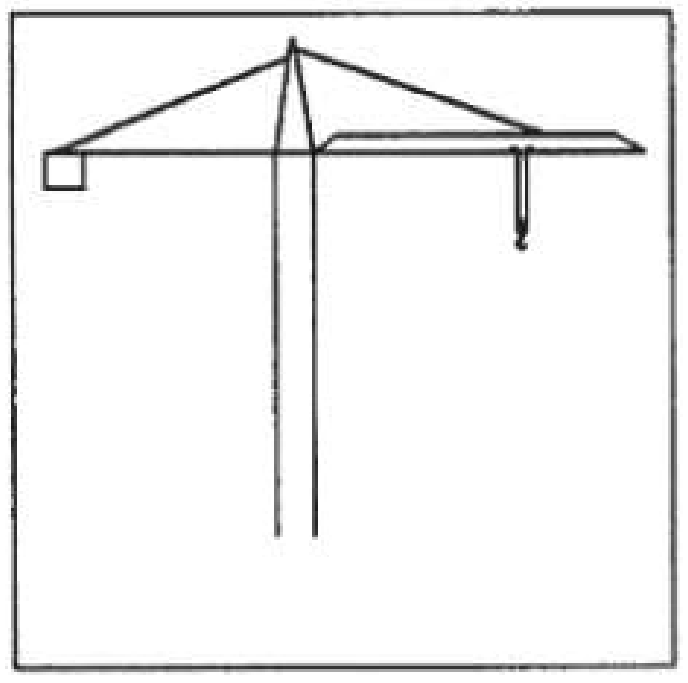

Fig.2

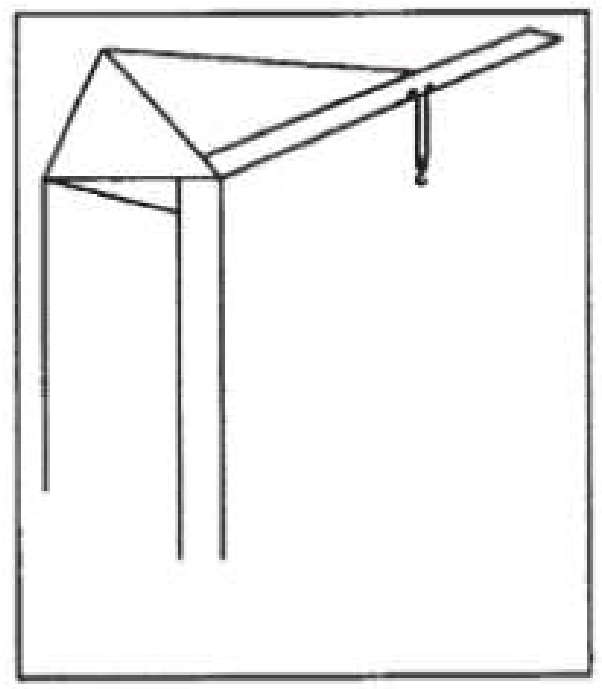

Fig.3 


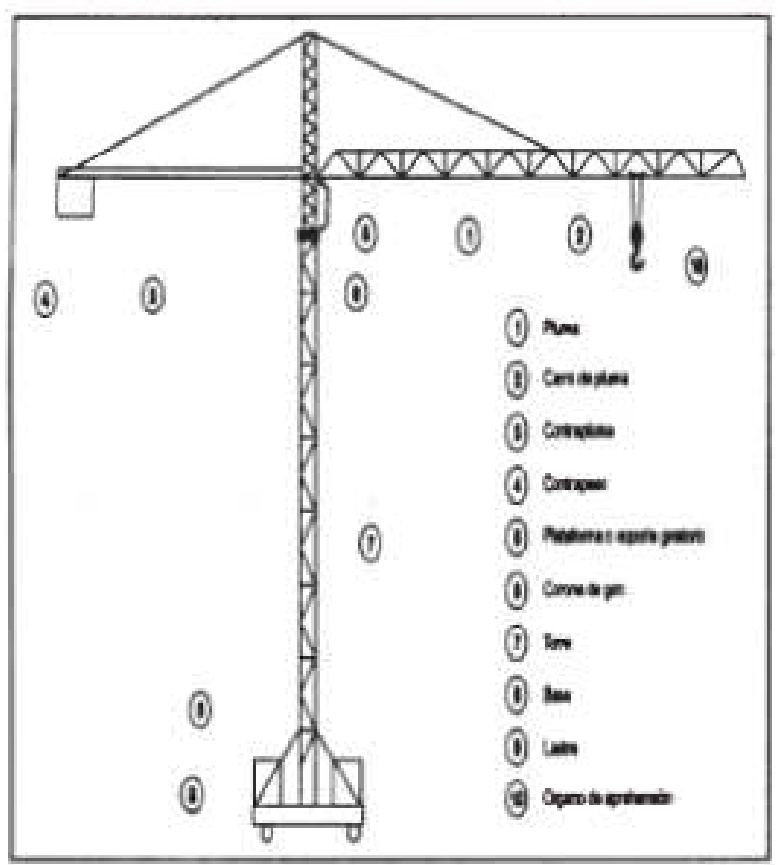

Fig.4

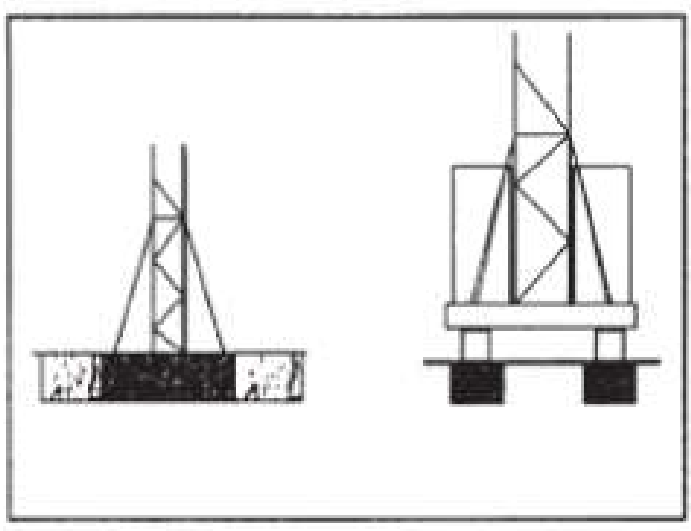

Fig.6

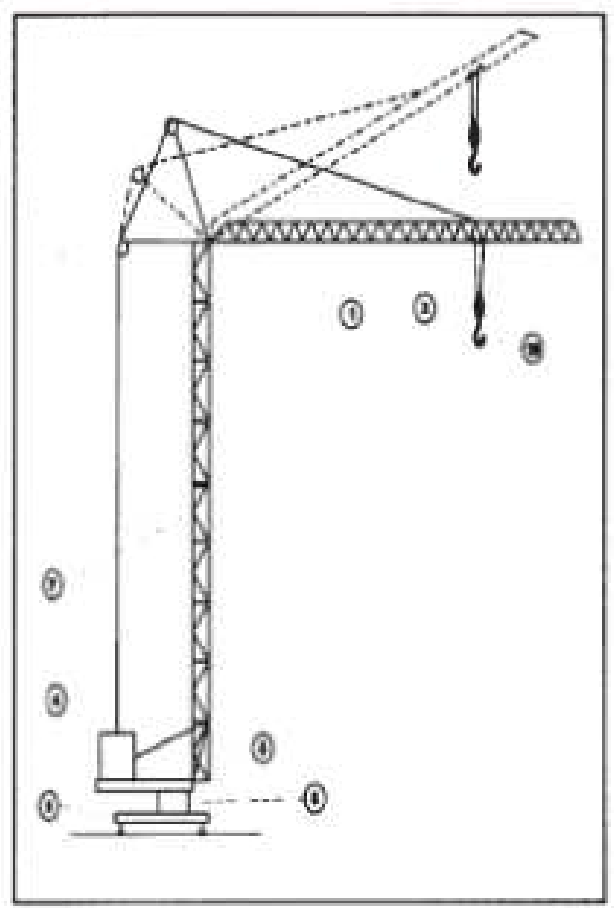

Fig.5

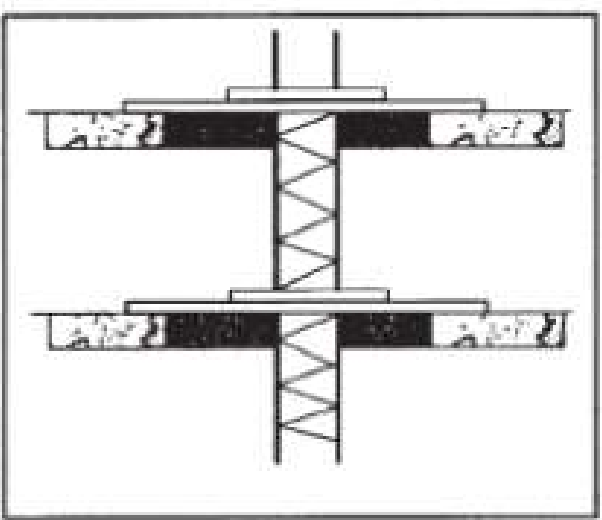

Fig.7 

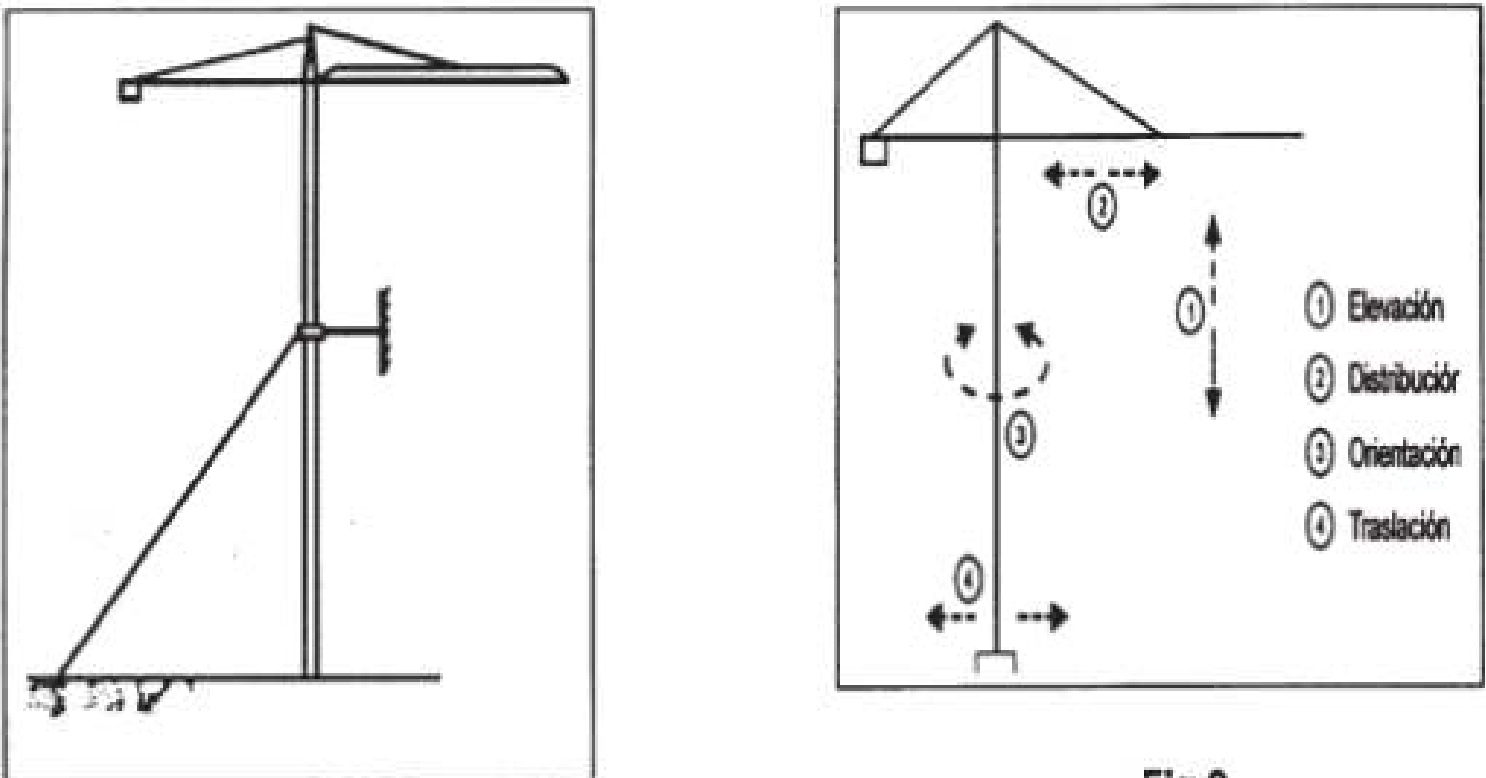

Fig.9

Fig.8

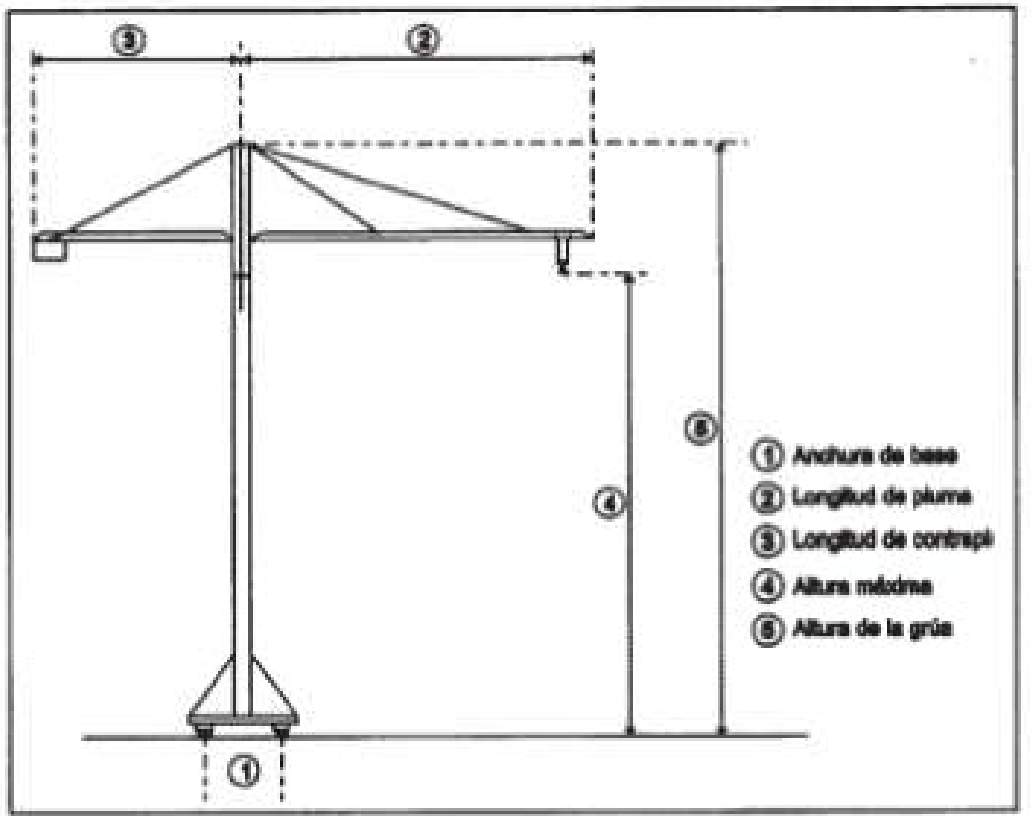

Fig.10 


\section{ANEXO II}

\section{Proyecto de instalación}

El proyecto de instalación deberá incluir como mínimo:

1. Datos generales:

1.1 Empresa usuaria de la grúa torre (usuario): nombre o razón social, NIF/CIF y domicilio a efectos de notificaciones.

1.2 Empresa propietaria de la grúa torre (propietario): nombre o razón social, NIF/CIF y domicilio a efectos de notificaciones.

1.3 Empresa instaladora.

1.4 Empresa conservadora.

1.5 Obra a la que se destina la instalación (definición).

1.6. Situación y emplazamiento de la obra.

1.7 Referencia del anterior montaje de la grúa.

2. Identificación y caracteristicas técnicas de la grúa torre:

2.1 Identificación de la grúa torre (marca, modelo y.$^{\circ}$ de fabricación).

2.2 Características técnicas:

2.2.1 Longitud de pluma $\mathrm{y}$ alcance útil (inicial y final).

2.2.2 Longitud de contrapluma y peso del contrapeso aéreo.

2.2.3 Altura de montaje y altura autoestable.

2.2.4 Arriostramiento, en su caso (definición).

2.2.5 Elevación: tipo de reenvio.

2.2.6 Velocidades de elevación.

2.2.7 Velocidades de giro.

2.2.8 Velocidades de distribución.

2.2.9 Velocidad de traslación.

2.2.10 Cables: diámetro y tipo.

De elevación.

Del carro.

2.2.11 Sistema de rodadura, en su caso (características, definición del carril ...).

2.2.12 Diagrama de cargas y alcances.

2.2.13 Dispositivos de seguridad disponibles (descripción de los limitadores de par de elevación y distribución, de carga máxima, de carrera inicial y final en distribución o vía de traslación, de elevación, de giro, de puesta en veleta, otros).

2.2.14 Instalación eléctrica (potencia máxima, tensión, descripción de las protecciones eléctricas y la puesta a tierra...).

2.2.15 Indicar la ubicación del puesto de mando (botonera, mando por control remoto o cabina).

3. Cálculo de la fundación (análisis del estado de tensiones en el terreno en el caso más desfavorable). 4. Cálculo del arriostramiento, en su caso (según UNE 58-101-92, parte 2, apartado 6.3).

5. Presupuesto (mano de obra de montaje, medios auxiliares...).

6. Conclusiones (cumplimiento de las condiciones de instalación de la norma UNE 58-101-92, parte 2).

7. Documentos anexos:

a) Ficha técnica de la grúa torre.

b) Documentación acreditativa de las caracteristicas del terreno (informe facilitado por la dirección facultativa de la obra) o estudio geotécnico, visados por el correspondiente colegio oficial.
8. Planos:

a) Plano de situación de la obra (con referencias invariables; escala de aproximada 1:10.000 / 1:50.000 en formato A4, a ser posible).

b) Plano del emplazamiento de la grúa torre dentro de la obra con indicación expresa de los obstáculos existentes en el alcance y en las proximidades).

c) Plano de la fundación.

d) Plano del arriostramiento, en su caso.

\section{ANEXO III}

\section{Criterios indicativos para la inspección de grúas torre}

Las inspecciones contemplarán las siguientes comprobaciones:

A. Inspección con la grúa desmontada.

Se realizará una comprobación de la documentación de la instalación y de la grúa:

Proyecto de instalación.

Manual del fabricante.

Certificado de fabricación o Declaración «CE» de conformidad.

Ficha técnica.

Manual de instrucciones de utilización.

Se realizará una inspección ocular de todos los ele. mentos que componen la grúa a ras de suelo, para la comprobación de que los elementos que vayan a instalar estén en correcto estado para resistir las solicitaciones propias del servicio (soldaduras, oxidaciones, grietas, holguras, desgastes, identificación de elementos, etc.).

Los puntos en los que se deberán comprobar posibles deformaciones o anomalias serán:

Estructura y elementos de unión.

Instalación eléctrica.

Protecciones de los órganos móviles, caída de objetos y contrapeso.

Mecanismos (gancho, cables, tambores, poleas).

Dispositivos de seguridad (limitadores y topes).

Indicadores para maniobras (placa fabricación, diagrama, distancias).

De la comprobación se emitirá un informe por ambas partes (inspector y usuario o instalador) donde se anotarán todos aquellos elementos y zonas que presenten deficiencias que deban subsanarse antes del montaje.

Si no presenta deficiencias se podrá realizar el montaje de la grúa para realizar la inspección con la grúa montada. Aquellas grúas que a criterio del O.C.A. presenten dudas razonables sobre su seguridad, para el montaje o para su funcionamiento, deberán ser rechazadas prohibiéndose su instalación. El O.C.A. comunicará al propietario $\mathrm{y}$ al órgano competente de la comunidad autónoma los motivos del rechazo.

B. Inspección con la grúa montada.

Para la realización de la inspección será necesario disponer de los elementos adecuados de protección personal (casco, zapatos de seguridad, arnés de seguridad, etc.). y de los adecuados elementos de comprobación (dinamómetro, cinta métrica, calibre, comprobador de diferenciales, multímetro, telurómetro, etc.). 
Se realizara una inspección de los apartados que se indican a continuación:

\section{Estabilidad}

1.1 Ensayo de carga.

Esta pruoba so realizara para demostrar la aptitud de la grúa y verificar el funcionamiento de los mecanismos y de los frenos de la grûa.

El ensayo se considerara favorable si los elementos concernientes se muestran capaces de cumplir sus funciones y si no aparecen grietas, deformaciones permanentes. cuarteado de la pintura u otro dano que afecte al funcionamionto y a la seguridad do la grùa, así como que ningún acoplamiento aparezca aflojado o danado.

El ensayo se realizará separadamente para cada movimiento de la grúa y para los posibles movimientos simutáneos en las posiciones que impongan la mavor carga a los mocanismos (las comprobaciones con la pluma se realizarán en las cuarto diagonales de la torre, a ser posible). Se realizarán durante al menos una hora, arranques y paradas repetidas do cada movimiento en todo su recorrido útil Se realizarán arranques con la carga suspendida, y no deberán producirso retrocesos de las cargas.

Finalizados los ensayos con las cargas nominales, se comprobara la actuacion de los limitadores de cargas.

Para la realización del ensayo se utilizarán las cargas disponibles en la instaiación (carga máxima, carga on punta y las del 10 por ciento de dichos valores;.

El operador de la grua será el gruista designado por el propietario o arrendatario de la grua

Si existe cabina y se maneja desde ella, deberá disponerse de medios adecuados de comunicacion bidi. reccional entre el inspector y el gruista.

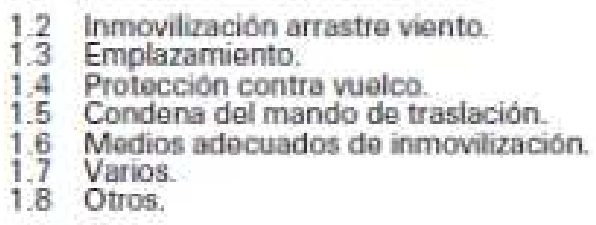

\section{Instalación electrica}

2.1 Emplazamiento instalación eléctrica.

2.2 Interruptor omnipolar y diferencial de $300 \mathrm{~mA}$ en cuadro general de obra

2.3 Armario elóctrico do la grúa.

2.4 Proteccion contra sobreantensidades.

2.5 Interruptores para circuitos auxiliares.

2.6 Estado de contactores.

2.7 Conductores y cables electricos.

2.8 Esfuorzos mocánicos on conductores.

2.9 Protección de los elementos bajo tensión.

210 Botonera de mando.

2.11 Tensión máxima de maniobra.

2.12 interruptor de emergencia.

2.13 Continuidad de las manas.

2.14 Cable de puesta a tierra.

2.15 Material eléctrico adecuado.

2.16 Otros

\section{Cabina y medios de acceso}

3.1 Localización de la cabina.

3.2 Impermeabilidad y resistencia del techo.

3.3 Puesta a tierra.
3.4 Barandillas, rodapies, escalas

3.5 Elementos de sujeción personal. Pluma y contrapluma.

3.6 Materiales de cabina.

3.7 Visibilidad de la cabina.

3.8 Cristales de las cabinas.

3.9 Limpiaparabrisas de cabina.

3.10 Ventilación de la cabina.

3.11 Calefacción de la cabina.

3.12 Dimensiones de la cabina.

3.13 Suelos y plataformas antidestizantes.

3.14 Extintor on cabina.

3.15 Varios.

3.16 Otros.

\section{Protecciones}

4.1 Protección de los órganos móviles.

4.2 Protección del aparejo de poleas.

4.3 Ruedas de traslación con quardarruedas.

4.4 Protección contra caida de objetos y órganos montados sobre vacio.

4.5 Sistema de fijación del contrapeso.

4.6 Otros.

\section{Mecanismos}

5.1 Ganchos.

5.2 Cables

5.3 Tambores.

5.4 Arrollamiento del cable en el tambor.

5.5 Poleas.

5.6 Freno elevación.

5.7 Freno de orientación.

5.8 Freno carro pluma (distribución).

5.9 Freno de traslación.

5.10 Freno de elevación de pluma.

5.11 Varios.

5.12 Otros.

\section{Dispositivos de seguridad}

6.1 Limitader de par de elevación.

6.2 Limitador de par de distribución.

6.3 Limitador de carga máxima.

6.4 Limitador de recorrido de elevación.

6.5 Limitador de alcance máximo y minimo del carro.

6.6 Limitador do traslación por via.

6.7 Limitador de giro.

6.8 Limitador do ángulos superior e inforior.

6.9 Limitador de gran velocidad.

6.10 Dispositivo de puesta on veleta.

6.11 Paragolpes en recorrido del carro de la plums.

6.12 Posibilidad de instalación de anemometro.

6.13 Control de pesos.

6.14 Otros.

\section{Indicaciones para maniobras y placas}

7.1 Identificación y utilización de mandos.

7.2 Placa de fabricación.

7.3 Placa de cargas y alcances.

7.4 Placas de maniobras, utilización y engrase. 
7.5 Placas de distancias en pluma.

7.6 al 7.9 Indicadores de cargas, alcances y par. 7.10 Otros.

\section{Estructura y elementos de unidon}

8.1 Baso y/o tramo de empotramiento.

8.2 Lastre de base.

8.3 Torre.

8.4 Pluma

8.5 Contrapluma

8.6 Contrapeso aêreo

8.7 Torreta portatirantes.

8.8 Tirantes de pluma y contrapluma.

8.9 Carretón de traslación.

8.10 Carro de pluma.

8.11 Plataformas o soporte giratorio.

8.12 Corona de giro y tornillos.

8.13 Tornilleria y bulones.

8.14 Corrosion y pintura.

8.15 Varios

8.16 Otros.

\section{Documentación}

9.1 Manual del fabricante.

92 Manual de instrucciones de utilización.

9.3 Lbro historial de la gruo.

9.4 Certificado de fabricación o Dectaración *CE* de conformidad

9.5 Acreditación del gruista.

9.6 Acreditación del contrato de conservación.

9.7 Otros.

10. Otros

(podrain resenarse otros aspectos de interés)

Con independencia de las comprobaciones y criterios que se han indicado en este anexo III para la realización de las inspecciones de las gruas torre, el grupo de trabajo especifico creado al efecto ha elaborado un manual de inspecciones en el que, de una manera más amplia, se ostablecen los criterios de valoración de dichas inspec. ciones. Dicho manual será distribuido entre los sectores afectados por esta instrucción técnica complementaria. 
ANEXO IV

Manual de instrucciones de utilización

GRÚA TORRE:

MARCA :

MODELO :

TIPO

N. ${ }^{\circ}$ FABRICACION:

ANOO FABRICACION:

FABRICANTE:

DIRECCION:

LOCALIDAD:

C.Postal:

TFNO:

FAX:

e-MAIL:

(Croquis do la grúa con la situación de los dispositivos de seguridad) 


\section{Datos generales.}

\section{PROPIETARIO:}

Dirección :

Localidad :

Tfno.

Fax:

C.Postal:

e-mail:

USUARIO:

Dirección :

Localidad :

Tfno.

Fax:

C.Postal:

e-mail:

OBRA:

Dirección :

Localidad :

EMPRESA CONSERVADORA:

Dirección :

Localidad :

C.Postal:

Tfno.

Fax:

e-mail:

2. Datos técnicos. 
CARACTERISTICAS DE LA GROA

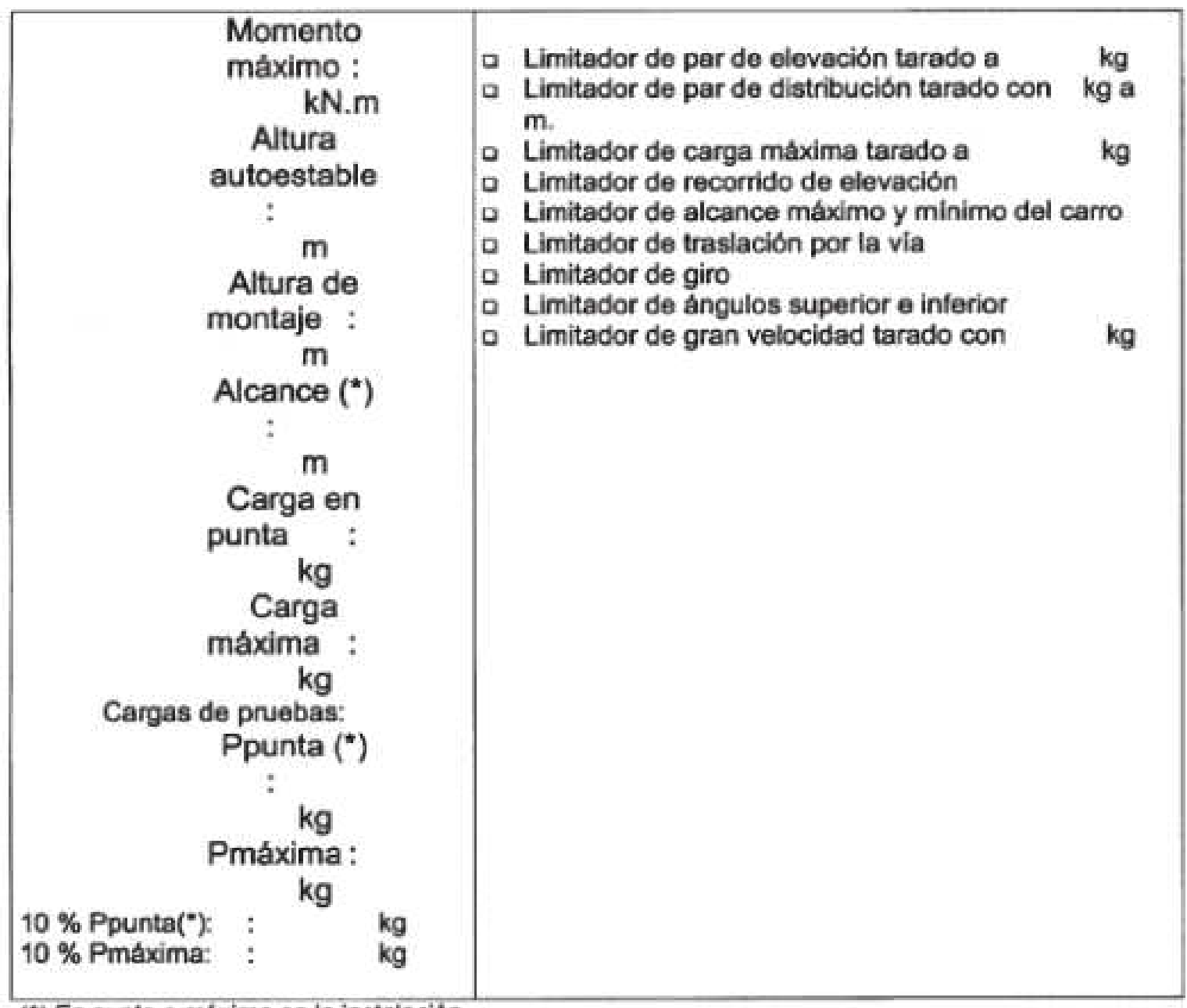

(") En punta o máximo en la instalación.

Se hace entrega de este manual para ser tenido en cuenta en el manejo dlario de la grúa.

Fecha de entrega:

\begin{tabular}{|c|c|c|}
\hline \multicolumn{3}{|c|}{ Recibi: } \\
\hline $\begin{array}{l}\text { El responsable del usuario o jefe de obra: } \\
\text { D. }\end{array}$ & $\begin{array}{lll}\text { El gruista: } \\
\text { DNI: }\end{array}$ & DNI: \\
& & (Firma) \\
\hline
\end{tabular}




\section{Obligaciones del gruista}

Reconocimiento de la vá (si procede).

Verificación del aplomado de la grüa.

Verificación de lastres y contrapesos.

Verificacion de niveles de aceite y conocimionto de

los puntos de engrase.

Comprobación de los mandos en vacio.

Comprobación do la actuación do los dispositivos de seguridad con los pesos tarados.

Correcta puesta fuera de servicio de la grúa.

Comprobación del estado de los cables de acero y accesorios de elevación (eslingas, cadenas. portapa. lets...).

Comunicar al responsable de la obra cualquier anomalia observada en ol funcionamiento de la grua o en las comprobaciones que efectùe, así como la mala sujeción y amarre de las cargas, deteniendo o no poniendo en funcionamiento la grua hasta recibir instrucciones.

\section{Prohibiciones}

Utilizar los elementos de elevación, para hacer trac. ciones oblicuas de cualquier tipo y para arrancar cargas adheridas al suelo o paredes entrelazadas, asi como cualquier otra operación extrana a las propias de manutención de cargas.

Elevar una carga superior a las especificaciones de la grùa, teniendo en cuenta las condiciones de empleo.

Transportar cargas por ancima del porsonal.

Balancear las cargas para depositarlas en puntos a los que no llega normalmente el aparejo de elevación.

Realizar mas de tres rotaciones complotas en el mismo sentido de giro. en el caso de que el mecanismo de elevación no gire con la pluma, con el fin de evitar cualquier torsión excesiva del cable de elevación.

Se prohibe utilizar las gruas para ol transporte de personal.

La zona de trabajo de la grúa, por donde han de pasar las cargas, estará senalizada, impidiendo el paso por ella a toda persona que no sea de la obra y no leve casco de seguridad.

Dejar carga u otros objetos colgando del gancho de la grüa en ausencia del gruista.

\section{Internupción del trabajo}

En caso de vientos fuertes, o de tormenta eléctrica próxima se interrumpirá el trabajo y se tomarán las medidas prescritas por ol fabricante, dejando la grúa on velota y cortando la corriente en el cuadro general de la obra.

\section{Mantenimiento}

Independientemente del mantenimiento que debe realizar la empresa conservadora, el gruista debera realizar periódicamente una serie de controles y verificaciones para el buen funcionamiento de la grùa, debiendo comprobar los cables. gancho, poleas, limitadores. interruptores, cuadro electrico, niveles de aceite, puntos de engrase, etc.

\section{Instrucciones}

Descripción de los mandos y su manejo.

Descripción y forma de electuar la regulación de los frenos.

Funcionamiento de los limitadores y demás dispositivos de seguridad.

Comprobacion de niveles y frecuencia de la reposición o sustitución de lubricantes.

Comprobaciones especiales de mecanismos y elementos estructurales.

Inspección de cables y de sus niveles de aptitud.

Par de apriete de los fornillos.

Maniobras para la puesta fuera de servicio.

Valor del desplome maximo que puede admitirse on el mástil de la grua.

Medidas de actuación en caso de emergencia.

Medidas para ovitar danos on los cables de acero.

Limpieza y conservación de todos los elementos en especial del cuadro eléctrico.

\section{Recomendaciones generales}

No utilizar el dispositivo de parada de emergencia para detener un desplazamiento normal.

Instalar un cercado que impida el acceso a la zona de funcionamiento a las personas no autorizadas.

Utifizar siempre el cable de seguridad cuando se deba trabaiar o desplazarse sobre la pluma o contrapluma.

La velocidad máxima del viento admitida para el trabajo con esta grúa será de $72 \mathrm{~km} / \mathrm{h}$, o la que indique el fabricante, si es menor.

Otras recomendaciones.

\section{Verificaciones y controles}

Deberàn realizarse verificaciones antes del inicio de la jornada de trabajo con la grua y al finalizar la jornada, anotandose las deficiencias detectadas en el parte de control adjunto, solamente ef día en que se produzca la deficiencia, para que el responsabie de la obra lo comtnique a la empresa conservadora. Si no existe ninguna anotación, se entenderá que, realizadas las verificaciones, la grua esta correcta.

\subsection{Verificaciones diarias.}

5.1.1 Al inicio de la jornada de trabajo:

\begin{tabular}{|c|c|}
\hline Contral vasal & Aeastar \\
\hline $\begin{array}{l}\text { Estado correcto de la base de apoyo. } \\
\text { Estado correcto de topes y rampas fin de carrera, si es } \\
\text { grúa con traslación. } \\
\text { Estado correcto del aplomado de la grúa. } \\
\text { No oxistencia de perdida do lastre do baso ni de contrapeso } \\
\text { aéreo. } \\
\text { Correcto estado del cable de alimentación eléctrica al cua- } \\
\text { dro de la grúa. } \\
\text { Correcto estado del cable de puesta a tierra. } \\
\text { Correcto estado de las conexiones a tierra de los ralles, } \\
\text { estructura y cuadro. }\end{array}$ & $\begin{array}{l}\text { Desconectar la puesta on veleta. } \\
\text { Buen funcionamiento del interruptor de puesta en } \\
\text { marcha. } \\
\text { Buen funcionamiento del boton de parada de emer- } \\
\text { gencia. } \\
\text { Buen funcionamiento de los mandos en vacio y de cada } \\
\text { mecanismo. } \\
\text { Buen funcionamiento de los frenos. }\end{array}$ \\
\hline
\end{tabular}




\begin{tabular}{|c|c|}
\hline COMPROBACION DE LOS UIMITAD & S UTILIZANDO LAS CARGAS TARADAS \\
\hline CARGA & \begin{tabular}{|l|} 
RECORRIDO \\
\end{tabular} \\
\hline $\begin{array}{l}\text { - PAR ELEVACION (1,1Ppunta)(*) } \\
\text { kg } \\
\text { - PAR CARRO ADELANTE (dist+10\%) } \\
\text { m kg } \\
\text { - CARGA MAXIMA (1,1Pmáx) } \\
\mathrm{kg} \\
\text { - GRAN VELOCIDAD (1,1 P) } \\
\mathrm{kg}\end{array}$ & $\begin{array}{l}\text { - ALTURA GANCHO (1,5 m del carro) } \\
\text { - CARRO (0,2 m tope delante y atrás) } \\
\text { - TRASLACION VIA (0,5 m entre topes) }\end{array}$ \\
\hline
\end{tabular}

(") En punta o máximo en la instalación.

Nota: Si alqün limitador no funciona ESTA PROHIBIDO TRABAJAR HASTA QUE SE REPARE.

5.1.2. Al final de la jomada de trabajo:

Subir el gancho cerca del limite de subida SIN CARGA. Llevar el carro cerca de la torre.

\begin{tabular}{|l|l|}
\hline \multicolumn{2}{|c|}{ PONER EN VELETA } \\
\hline \multicolumn{1}{|c|}{ Dispositivo manual } & \multicolumn{1}{c|}{ Dlspositivo eléctrico } \\
\hline $\begin{array}{l}\text { Accionar palanca. } \\
\text { Pulsar botón de parada en la botonera. }\end{array}$ & $\begin{array}{l}\text { Poner en veleta. } \\
\text { Pulsar el botón de parada en la botonera }\end{array}$ \\
\hline $\begin{array}{l}\text { Colocar las mordazas de fijación a los carriles. } \\
\text { Cortar la corriente en el cuadro de la grúa y en el cuadro general }\end{array}$ \\
\hline
\end{tabular}

5.1.3. Parte de verificaciones diarias:

\begin{tabular}{|c|c|c|c|c|}
\hline \multirow[b]{2}{*}{ FECHA } & \multirow[b]{2}{*}{$\begin{array}{l}\text { DEFECTO } \\
\text { OBSERVADO }\end{array}$} & \multicolumn{2}{|c|}{ REPARACION DEFECTO } & \multirow{2}{*}{$\begin{array}{c}V^{\circ} B^{\circ} .^{\circ} \\
\text { RESPONSABLE } \\
\text { DE OBRA }\end{array}$} \\
\hline & & FECHA & EMPRESA & \\
\hline & & & & \\
\hline & & & & \\
\hline
\end{tabular}




\subsection{Controles periódicos de grúa torre.}

Deberán realizarse controles cada semana, quincenalmente y mensualmente, anotándose las deficiencias encontradas en el parte de control adjunto, para que el responsable de la obra lo comunique a la empresa conservadora.

PARTE DE CONTROL MENSUAL Grúa marca:

Modelo

N. ${ }^{\circ}$ de fabricacion:

\begin{tabular}{|l|l|}
\hline EMPRESA CONSTRUCTORA: & Fama \\
\hline Responsable de la obra: & \\
\hline D. & Finna \\
\hline Gruista: & \\
D. & \\
\hline
\end{tabular}

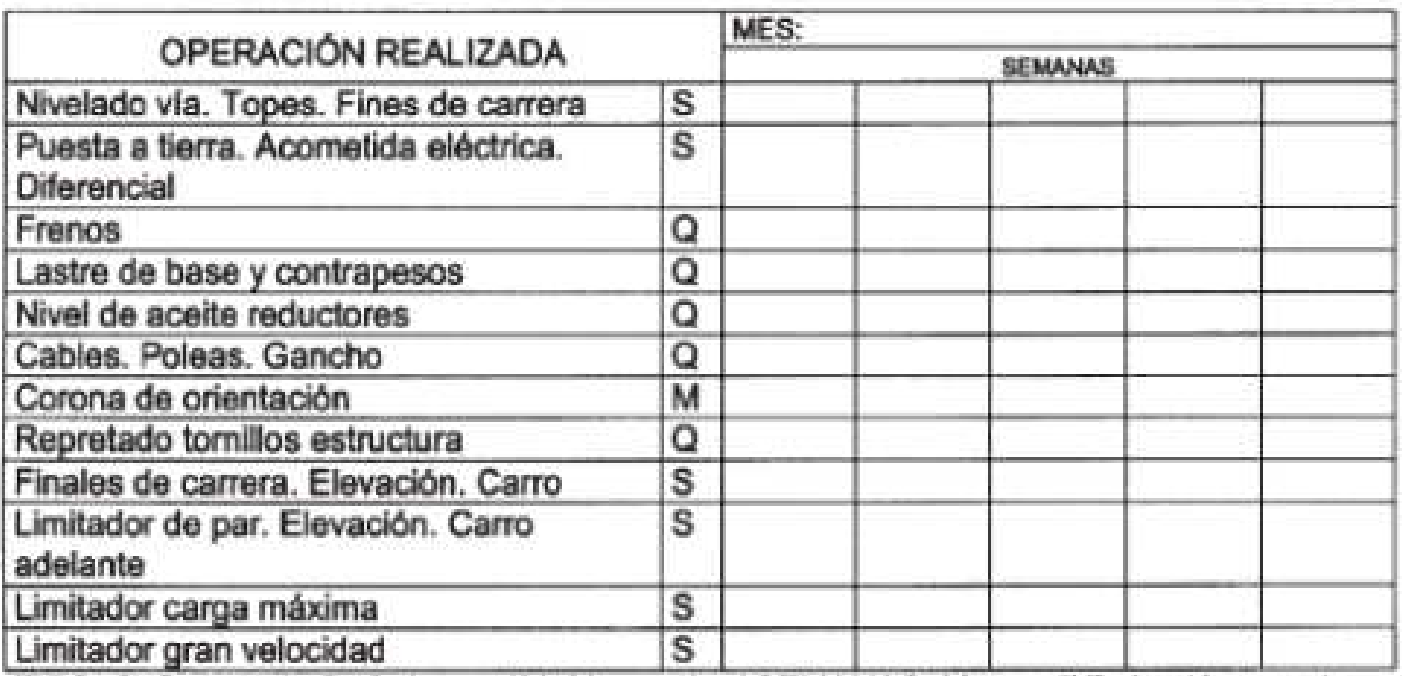

TIPO: S: Semanal Q: QuincenalM: Mensual /SEMANAS: Marcar " $X$ " si está correcto.

OBSERVACIONES:

\begin{tabular}{|l|l|l|}
\hline FECHA & DESCRIPCION & $\begin{array}{c}\text { ENTERNOO } \\
\text { RESPONSABLE } \\
\text { DE UOARA }\end{array}$ \\
\hline & & \\
\hline & & \\
\hline & & \\
\hline & & \\
\hline
\end{tabular}




\section{AVERIAS:}

\begin{tabular}{|l|l|l|l|}
\hline $\begin{array}{l}\text { FECHA } \\
\text { AVISO }\end{array}$ & DESCRIPCION & $\begin{array}{c}\text { PECHA } \\
\text { CORRECCION }\end{array}$ & $\begin{array}{c}\text { ENTERMDO } \\
\text { RESPONSABLE } \\
\text { DE LA DBRA }\end{array}$ \\
\hline & & & \\
\hline & & & \\
\hline & & & \\
\hline & & & \\
\hline & & & \\
\hline
\end{tabular}

NOTA: Deberan inckuirse en el manual de instrucciones de ullizacion todos los partas de control correspondientes mientras permanezca ta grí en esta obre. 


\section{ANEXO V}

\section{Certificado de instalación de grúa torre desmontable para obras u otras apllcaciones}

\section{EXPEDIENTE:}

en el Colegio Oficial de Ingenieros

, coleglado n."

\section{CERTIFICA:}

1. Que la instalación cuyas caracteristicas se indican a continuación:

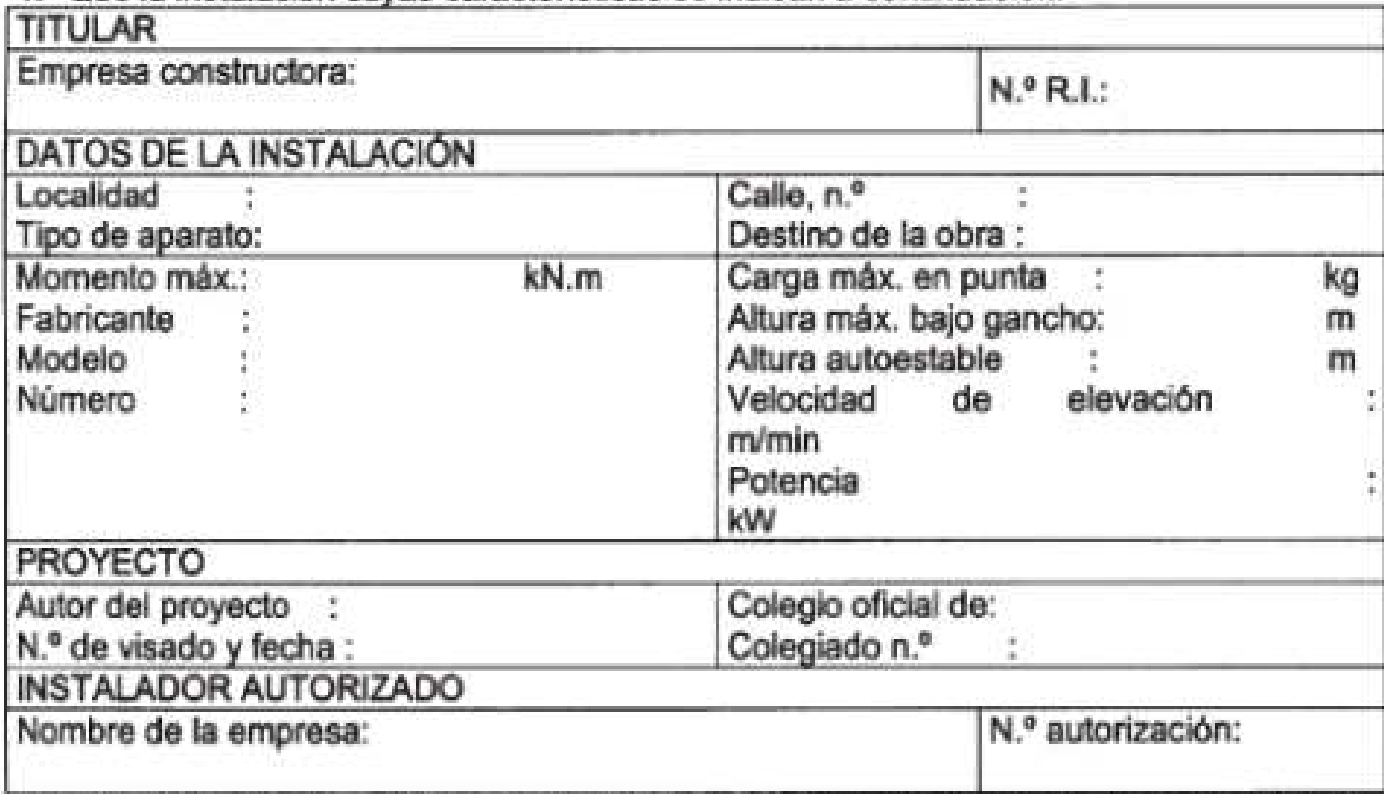

ha sido ejecutada de acuerdo con el proyecto presentado y bajo la dirección técnica del que suscribe, habiéndose finalizado el dla

2. Que la instalación cumple la reglamentacion y normativa siguiente:

Reglamento de aparatos de elevación (Real Decreto 2291/1985, de 8 de noviembre). Instrucción técnica complementaria (ITC) "MIE-AEM-2". Norma UNE 58-101-92, parte 2.

3. Que se han realizado con resultado aceptable las comprobaciones y pruebas necesarias y/o reglamentariamente establecidas.

4. Que se disponen en la instalación de las cargas de comprobación (Pmax., 0.1 Pmax.. Ppunta y 0,1 Ppunta o en la posición más alejada) y se ha entregado el manual de instrucciones de utilización al responsable de la obra D.

5. Que se acompañan los siguientes documentos:

Documento de entrega de la grúa firmado por la empresa instaladora y el usuario. 
Informe de inspección del organismo de control autorizado.

Contrato de conservación con empresa autorizada para todo el tiempo de permanencia de la grúa en el emplazamiento.

Declaración "CE" de conformidad o certificado de fabricación.

Original del certificado de fabricación del tramo de empotramiento, en su caso

Otros:

\section{OBSERVACIONES:}

En ..................................................., a .......... de ...................... de .

(firma del técnico titulado competente de la empresa instaladora)

Visado del colegio oficial: 
CERTIFICADO DE INSTALACION DE GRUA TORRE AUTODESPLEGABLE

(Para grúas tipo monobloc cuyo momento nominal sea superior a $15 \mathrm{kN} . \mathrm{m}$ y no supere los 170 $\mathrm{kN} . \mathrm{m})$

EMPRESA

USUARIA:

DIRECCION

$D E$

LA

INSTALACION:

EMPRESA INSTALADORA:

CARACTERISTICAS DE LA GRÜA:

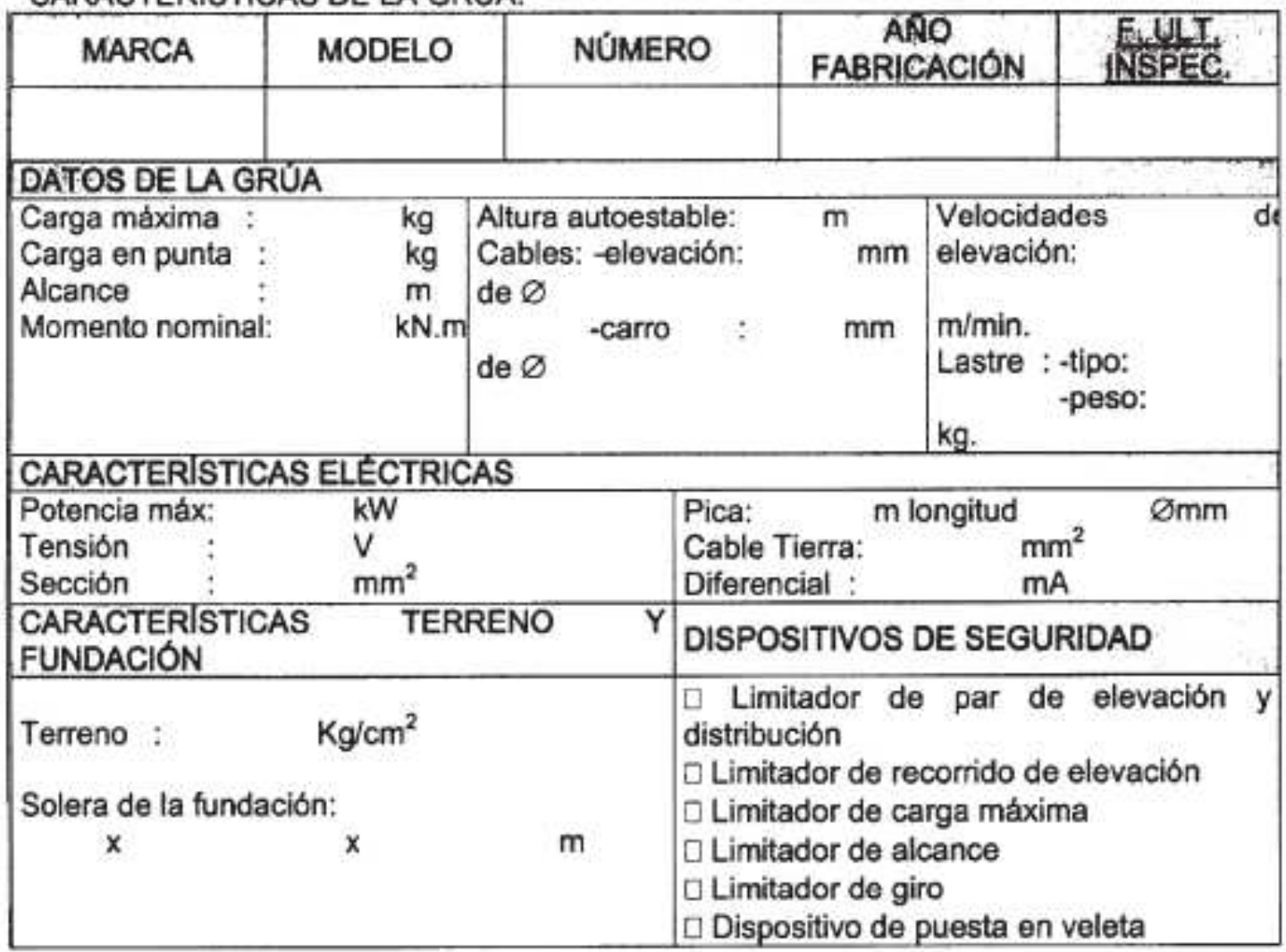

D.

n. 0 del Colegio oficial de.

colegiado de

\section{CERTIFICA:}

1. Que la instalación cumple con la Instrucción técnica complementaria (ITC) "MIE-AEM-2" del Reglamento de aparatos de elevación y manutención. 
2. Que en el área de barrido de la pluma y la carga suspendida, tendra un espacio de seguridad horizontal y vertical, según lo establecido en la Norma UNE 58-101-92, parte 2, en especial a lineas eléctricas.

3. Que se ha realizado la inspección reglamentaria de la grúa por un organismo de control autorizado.

4. Que se disponen de las cargas de comprobación (Pmax., 0,1 Pmax., Ppunta y 0,1 Ppunta o en la posición más alejada) y se ha entregado el manual de instrucciones de utilización al responsable de la obra

D.

En.

a

de de

Visado del colegio oficial instaladora)

(firma del técnico títulado competente de la empresa

ANEXOS:

Ficha técnica de la grúa

Declaración "CE" de conformidad o certificado de fabricación

Planos de situación y de emplazamiento

Informe de inspección de un O.C.A. (última en vigor)

Documento de entrega de la grúa firmado por la empresa instaladora y el usuario.

Contrato de conservación con empresa autorizada, para todo el tiempo de permanencia de la grùa en el emplazamiento.

Otros: 


\section{ANEXO VI \\ Carné de gruista u operador de grúa torre}

1. Objeto y ámbito de aplicación.

Este anexo tiene por objeto regular los requisitos y el procedimiento para la obtención del carné de operador de grúa torre (gruista).

2. Carné de gruista u operador de grúa torre.

El manejo de las grúas torre a las que se refiere esta ITC requerirá la posesión del carné de operador de grúa torre, obtenido de acuerdo con lo senalado en este anexo.

3. Requisitos para la obtención del carné.

La obtención del carné requerirá la concurrencia de los siguientes requisitos:

a) Ser mayor de edad.

b) Estar en posesión de un certificado de estudios primarios.

c) Superar un examen médico sobre agudeza visual, sentido de la orientación, equilibrio y agudeza auditiva $\mathrm{y}$ aptitudes psicológicas.

d) La superacion de un curso teórico-práctico impartido por una entidad acreditada por el órgano competente de la comunidad autónoma donde se realice el curso.

e) La superación de un examen realizado por el órgano competente de la comunidad autónoma donde se ha realizado el curso indicado en el párrafo anterior.

4. Curso teórico-práctico.

4.1 El curso teórico-práctico a que se refiere el párrafo d) del apartado anterior tendrá como mínimo una duración total de 200 horas, repartidas en un módulo teórico de 50 horas y en un módulo práctico de 150 horas, con el siguiente programa:

a) Formación teórica:

Descripción de la grua-torre y componentes (perfiles, cables, lastres, etc.).

Definición de grúa torre desmontable. Clasificación. Composición estructural. Pluma.

Lastres de estabilidad. Contrapesos de equilibrios.

Condiciones que deben cumplir. Masa.

Cables de acero. Manipulación. Engrase. Inspecciones. Sustitución

Emplazamiento de la grúa. Desniveles de base. Via. Proximidad de edificios y lineas eléctricas. Instalaciones con varias grúas. Zona de seguridad. Puesta a tierra. Elementos de seguridad en grúas. Limitadores. Seguridad de momento de par. Seguridad de carga máxima.

Puesta en veleta.

Condiciones de estabilidad en servicio y fuera de servicio.

Arriostramientos rigidos. Arriostramientos elásticos.

Operación y manipulación. Obligaciones y prohibicio-

nes. Conocimiento y caracteristicas. Diagrama de cargas. Cálculo de diagramas.

Mantenimiento y conservación de la grúa torre.

Regulación y puesta en servicio.

Legislación básica: reglamentación y normas UNE.

b) Formación práctica:

Normas de manejo (maniobras permitidas y prohibidas).

Normas de seguridad en el trabajo.

Realización de las comprobaciones diarias y sema-

nales de seguridad y mantenimiento.

Manejo de una grùa torre.

Manejo de una grúa torre autodesplegable.
4.2 Las personas que en el plazo de un ano acre diten experiencia profesional en el manejo de grúa torre por la empresa en que la hubieran adquirido quedarán exceptuadas de la realización del módulo práctico ordinario del curso. La experiencia profesional será justificada mediante acreditación de la empresa y, en dicho supuesto, deberán, adernás, realizar un módulo práctico de 15 horas de duración. No será necesario justificar el apartado 3.b) de este anexo.

5. Entidades reconocidas para impartir cursos.

Podrán ser reconocidas como entidad acreditada para impartir el curso teórico-práctico de operador de grúa torre las entidades que reúnan los siguientes requisitos:

a) Disponer de los medios y recursos mínimos necesarios, personales y materiales (personal competente. locales, elementos de grúas, motores, cables, rodamientos, perfiles, manuales de instalación y mantenimiento, aparatos de medida eléctricos y mecánicos y llaves dinamométricas).

b) Disponer de grúas tipo torre desmontables y autodesplegables, en propiedad o alquiladas, por un periodo minimo equivalente a la duracion del curso a impartir. en correcto funcionamiento y para uso exclusivo de la entidad acreditada.

6. Expedición y validez del carné.

6.1 El carné de gruista u operador de grúa torre será expedido por órgano competente de la comunidad autónoma, una vez acreditado por el solicitante el cumplimiento de los requisitos establecidos en el apartado 3 de este anexo.

6.2 El carné tendrá una validez de cinco anos, trans curridos los cuales podrá ser objeto de renovación por iguales períodos, previa acreditación del requisito establecido en el apartado 3.c) de este anexo.

14327 REAL DECRETO 837/2003, de 27 de junio por el que se aprueba el nuevo texto modificado y refundido de la Instrucción técnics complementaria «MIEAEM-4n del Reglamento de aparatos de elevación y manutención. referente a grúas móviles autopropulsadas.

La experiencia desde la publicación de la Instrucción técnica complementaria (ifC) wMIE-AEM-4n del Reglamento de aparatos de elevación y manutención, refe rente a gruas móviles autopropulsadas usadas, ha llevado a la conveniencia de modificar algunos de sus preceptos, a fin de ponerlos en consonancia con la técnica más actual

El Real Decreto 2370/1996, de 18 de noviembre, por el que se aprueba la instrucción técnica complementaria (ITC) *MIE-AEM-4n del Reglamento de aparatos de elevación y manutención, referente a gruas móviles autopropulsadas usadas, ya recogia en su preámbulo que la presencia, cada vez mayor, de las grúas móviles autopropulsadas con potencial de manipulación de cargas cada vez más importante, es fundamental y posibilita la ejecución de trabajos con una disminución del riesgo de accidente. El desarrollo económico permite que se pueda constatar el gran aumento de las operaciones que se realizan con este tipo de aparatos y su implantación en todos los sectores industriales y de la construcción.

No obstante, aquella ITC solamente establecia criterios mínimos de seguridad, asi como las operaciones de mantenimiento y revisiones $\theta$ inspecciones oficiales, a las que debian someterse las grúas móviles autopropulsadas que constitulan el parque nacional existente 
ANEXO №2: INSTRUCCIÓN TÉCNICA COMPLEMENTARIA (ITC) “MIEAEM-4" del Reglamento de aparatos de elevación y manutención, referente a grúas móviles autopropulsadas. REAL DECRETO 837/2003 de 27 de Junio 


\section{ANEXO VI \\ Carné de gruista u operador de grùa torre}

1. Objeto y ámbito de aplicación.

Este anexo tiene por objeto regular los requisitos y of procedimiento para la obtención del carné de operador de grua torre (gruista).

2. Carné de gruista u operador de grùa torre.

El manejo de las gruas torre a las que se refiere esta ITC requerirá la posesión del carné de operador de grua torre. obtenido de acuerdo con lo senalado en este anexo.

3. Requisitos para la obtención del carnè.

La obtención del carné requerira la concurrencia de los siguientes requisitos:

a) Ser mayor de edad.

b) Estar en posesión de un certificado de estudios primarios,

c) Superar un examen médico sobre agudeza visual, sentido de la orientación, equilibrio y agudeza auditiva y aptitudes psicológicas.

d) La suporación de un curso toórico-práctico impar. tido por una entidad acreditada por el organo competente de la comunidad autónoma donde se realice el curso.

e) La superación de un examen realizado por el órgano competente de la comunidad autónoma donde se ha realizado ol curso indicado on ef párrafo anterior.

\section{Curso teórico-práctico.}

4.1 El curso teorico-práctico a que se refiere el párrafo d) del apartado anterior tendrá, como minimo, una duración total de 200 horas, repartidas en un modulo teorico de 50 horas y en un modulo practico de 150 horas, con el siguiente programa:

a) Formación teorica:

Descripción de la grúa-torre y componentes (perfiles, cables, lastres, etc.)

Definicion de grua torre desmontable. Clasificación.

Composición estructural. Pluma.

Lastres de estabilidad. Contrapesos de equilibrios. Condiciones que deben cumplir. Masa.

Cables de acero. Manipulación. Engrase. Inspecciones. Sustitución.

Emplazamiento de la grùa. Desniveles de base. Via. Proximidad de edificios y lineas electricas. Instalaciones con varias grúas. Zona de seguridad. Puesta a fierra.

Elomentos do seguridad on gruas. Limitadores. Soguridad de momento de par. Seguridad de carga maxima. Puesta en veleta.

Condiciones de estabilidad en servicio y fuera de servicio

Arriostramientos rígidos. Arriostramientos elásticos. Operación y manipulación. Obligaciones y prohibicio nes. Conocimiento y caracteristicas. Diagrama de cargas. Cálculo de diagramas.

Mantonimionto y conservación de la grua torre.

Regulacion y puesta en servicio.

Legislación básica: reglamentación y normas UNE.

b) Formación próctica:

Normas de manejo (maniobras permitidas y prohibidas).

Normas de seguridad en el trabajo.

Realización de las comprobaciones diarias y sema-

nales de soguridad y mantenimiento.

Manejo de una grúa torre.

Manejo de una grúa torre autodesplegable.
42 Las personas que en el plazo de un ano acrediten experiencia profesional en el manejo de grùa torre por la empresa en que la hubieran adquirido quedarán exceptuadas de la realización dol módulo práctico ordinario del curso. La experiencia profesional será justificada mediante acreditación de la empresa y, en dicho supuesto, deberán, además, realizar un módúlo práctico de 15 horas de duracion. No será necesario justificar el apartado 3.b) de este anexo.

5. Entidades reconocidas para impartir cursos.

Podrăn ser reconocidas como entidad acreditada para impartir el curso teórico-práctico de operador do grüa torre las entidades que reunan los siguientes requisitos.

a) Disponer de los medios y recursos minimos nece sarios, personiles y materiales (personal competente. locales, elementos de gruas, motores, cables, rodamientos, perfiles, manuales de instalación y mantenimiento aparatos de medida eléctricos y mecánicos y flaves dinamometricas).

b) Disponer de gruas tipo torre desmontables y auto desplegables, en propiedad o alquiladas, por un periodo minimo equivalente a la duración del curso a impartir. en correcto funcionamiento y para uso exclusivo de la entidad acreditada.

6. Expedición y validez del carné.

6.1 El carné de gruista u operador de grùa torre será expedido por órgano competente de la comunidad autónoma, una vez acreditado por el solicitante el cumplimiento de los requisitos establecidos en el apartado 3 de este anexo.

6.2 El carné tendrá una validez do cinco anos, transcurridos los cuales podra ser objeto de renovación por iguales periodos, previa acreditación del requisito establecido en el apartado 3.c) de este anexo.

14327 REAL DECRETO 837/2003, de 27 de junio. por el que se aprueba el nuevo texto modificado y refundido de la Instrucción técnica complementaria = MIEAEM-4. dd Reglamen to de aparatos de elevación y manutencion referante a grüas móviles autopropulsadas.

La experiencia desde la publicaciön de la instrucción técrica complementaria (IfC) aMIE-AEM-4a del Reglamento de aparatos de elovación y manutención, referente a gruas móviles autopropulsadas usadas, ha llevado a la conveniencia de modificar algunos de sus preceptos, a fin de ponerlos en consonancia con la técnica más actual.

E Real Decreto 2370/1996, de 18 de noviembre. por el quo se aprueba la Instrucción tecnica complo. mentaria (ITC) nMIE-AEM-4n del Reglamento de aparatos de elevación y manutención. referente a gruas móviles autopropulsadas usadas, ya recogis en su proambulo que la presencia, cada vez mayor, de las gruas móviles autopropulsadas con potencial de manipulación de cargas cada vez más importante, es fundamental y posibilita la ejecución de trabajos con una disminucion del riesgo de accidente. E desarrollo económico permite que se pueda constatar al gran aumento de las oporaciones que se realizan con este tipo de aparatos y su implan tación en todos los sectores industriales y de la cons trucción.

No obstante, aquella ITC solamente establecia crite. rios minimas de seguridad asi como las operaciones de mantenimiento $y$ revisiones e inspecciones oficiales. a las que deblan someterse las grúas móviles autopropulsadas que constitulan el parque nacional existente 
con anterioridad, excluyendo expresamente a aquellas fabricadas de acuerdo con el Real Decreto 1435/1992. de 27 de noviembre sobre máquinas, modificado por el Real Decreto 56/1995, de 20 de enero (en adelante Real Decreto 1435/1992, sobre máquinas).

La experiencia que la puesta en vigor de la ITC AMIE-AEM-4 w ha supuesto para la seguridad del sector ha demostrado la importancia de que ésta incluya tambión a las gruas fabricadas con los criterios fijados por el Real Decreto 1435/1992, sobre máquinas, en lo refe rente a las condiciones de utilización mantenimiento y revisiones e inspecciones oficiales.

La inclusion de estas condiciones de utilización, mantenimionto y revisiones o inspeccionos oficiales no llevi consigo ninguna contradiccion con las directrices de la Unión Europea, toda vez que aborda la seguridad de los equipos después de su puesta en el mercado, y per. mite faciliter el seguimiento de sus condiciones de seguridad más allá del propio mantenimiento preventivo fija. do en las instrucciones dictadas por los fabricantes de estos equipos.

El parque nacional actual, on un acolorado proceso de modernización. lleva a la desaparición de fa actual MIE-AEM-4 w, que se manifiesta obsoleta en cuanto a sus prescripciones de diseno y fabricación creandose un vacio legal en el sector, no cubierto por las disposiciones vigentes en el marco de la seguridad de máquinas, y que con esta modificación se pretende corregir.

Asimismo, la creciente utilización en labores cada vez más complojas o importantes lleva a la necosidad de fyar unas condiciones minimas que han de reunir los opersdores de estas gruas móviles autopropulsadas.

Por otra parte, la ampliación del ámbito de aplicación a todas las grúas móviles autopropulsadas, incluso para las nuevas en cuanto a los aspoctos de utilización, man. tenimiento y revisiones e inspecciones oficiales, es una razón que, mejor que disponer la modificación de ar. ticulos determinados de la repetida instrucción, aconseja proceder a la aprobación de un nuevo texto revisado do la ITC -ME.AFM-4n del Reglamento de aparatos de elevación y manutencion, referente a gruas moviles auto. propulsadas.

Esta disposición ha sido sometida al trámite de audiencia establecido en el articulo $24.1 . \mathrm{c}$ ) de la Ley 50/1997, de 27 de noviembre, y ha cumplido el tramite de comunicacion establecido por el Real Decre. to $1337 / 1999$, de 31 de julio, a los efectos de dar cumplimiento a lo dispuesto en la Directiva 98/34/CE dol Parlamento Europeo y del Consejo. de 22 de junio de 1998, modificada por la Directiva 98/48/CE del ParIomento Europeo y del Consejo, de 20 de julio de 1998.

En su virtud, a propuesta del Ministro de Ciencia y Tecnologia, de acuerdo con el Consejo de Estado y previa deliberación del Consejo de Ministros en su reunión del dia 27 de junio de 2003 .

\section{DISPONGO:}

Articulo ùnico. Aprobación de la instrucción técnica complementaria «MIE-AEM-4w.

Se aprueba el nuevo texto revisado y modificado de la Instrucción técnica complementaria =MIE-AEM-4s del Proglamento de aparatos de olevación y manutención referente a gruas moviles autopropulsadas.

Disposición transitoria ünica. Gruistas.

Las personas que en el plazo de seis moses dosde la entrada en vigor de esta disposición acrediten experiencia profesional en ef manejo de grùas moviles autopropulsadas durante un minimo de 12 meses continuos
- 18 meses discontinuos, siompre dentro de los cinco anos anteriores a la entrada en vigor de esta norma. quedarán exceptuadas de la reafización del módulo prác tico del curso de la categoria correspondiente a la carga nominal de la grùa móvil autopropulsada cuyo manejo se acredite asi como dol requisito de poseer el titulo de estudios primarios que con caracter general se solicita en el apartado 3.a) del anexo Vil de la IfC.

La acroditación de experiencis estara formada docu. mentaimente por, al menos:

a) Vida laboral del trabajador, oxpedida por el Instituto Nacional de la Seguridad Social.

b) Certificacion de las empresas titulares de las. gruas móviles autopropulsadas, con las que se ejorcio la actividad o, en su caso, por la correspondiente sociedad estatal de estiba y desestiba

Disposición derogatoria única. Derogación normativa.

Queda derogada la instrucción técnica complementaria wMIE-AEM-4 - del Reglamento de aparatos de elevación y manutencion, referente a grùas moviles autopropulsadas usadas, aprobada por el Real Decreto 2370/1996, de 18 de noviembre.

\section{Disposicion final primera. Habilitación normativa.}

Este real decreto se dicta al amparo de lo establecido en el articulo $149.113^{\text {" }}$ de la Constitución espanola. que atribuyo al Estado la competoncia para doterminar las bases y coordinacion de la planificación general de la actividad economica.

\section{Disposición final segunda. Entrada en vigor.}

El presente real decreto entrará en vigor a los tres meses de su publicación en el *Boletin Oficial del Estadow, excepto to indicado en el apartado 8 do la ITC. que será exigible a partir de los dos anos de la publicación de esta disposición en ol -Boletín Oficial del Estadois.

Dado en Madrid, a 27 de junio de 2003.

JUAN CARLOS R.

E) Ministro do Ciencia y Tecnologia.

JOSEP PICUE I CANPS

\section{INSTRUCCION TECNICA COMPLEMENTARIA (ITC) MIE.AEM-41, REFERENTE A GRUAS MOVILES AUTO- PROPULSADAS}

\section{Ambito de aplicación}

Esta ITC so aplica a todas las grùas móviles auto propulsadas que obedezcan a la definición del apartio. do 2 A.1.

No obstante lo antorior, las disposicionos de esta ITC referentes a las normas de seguridad referidas al diseno no serán de aplicación a las grúas móviles autopropulsadas que hayan sido comercializadas de acuerdo con las disposiciones del Real Decreto $1435 / 1992$, sobre máquinas.

Esta ITC no será de aplicación a las gruas porticos que se desplacen sobre neumáticos o sobre carriles, ni a las grùs autocargantes.

\section{Definiciones}

A efectos de esta ITC, se entiende por:

A. Definiciones generales.

1. Grûa móvil autopropulsada: aparato de elevación de funcionamiento discontinuo, destinado a elevar $y$ dis- 
tribuir en el espacio cargas suspendidas de un gancho - cualquier otro accesorio de aprehensión, dotado de medios de propulsión y conduccion propios o que formen parte de un conjunto con dichos medios que posibilitan su desplazamiento por vías públicas o terrenos.

2. Grúa autocargante: aparato de elevación de funcionamiento discontinuo instalado sobre vehiculos aptos para transportar materiales y que se utilizan exclusivamente para su carga y descarga.

3. Empresa alquiladora: es todo titular (como propietario, arrendador financiero o similar) de gruas móviles que efectúa el arrendamiento de éstas con operador. mediante las condiciones generales de contratación, debidamente registradas.

4. Empresa arrendataria: es todo usuario de grúas móviles alquiladas a un tercero (empresa alquiladora) con operador.

\section{B. Definiciones de componentes.}

1. Aparejo: sistema de poleas y de cables destinado a hacer variar las fuerzas y las velocidades.

2. Base de grúa dispositivo que soporta la estructura de la grúa. Dispone de sistemas propios de propulsión para poderse trasladar mediante ruedas, cadenas u otros sistemas.

3. Cabina: habitáculo destinado al manejo y/o conducción de la grúa y que alberga a los mandos y al operador.

4 Contrapeso: masa fijada sobre la estructura de la grúa para ayudar a equilibrar las acciones de la carga.

5. Corona de orientación: elementos destinados a transmitir los esfuerzos (momento de carga, fuerzas horizontales y verticales) de la estructura giratoria a la base de la grúa y que es accionado por el mecanismo de orientación de la estructura giratoria.

6. Dispositivo de puesta en veleta o giro libre: sistema que asegura la libre orientación de la estructura giratoria ante la acción del viento en la condición de fuera de servicio. Se puede utilizar, asimismo, para la autoalineación vertical de la pluma con la carga, antes de comenzar la maniobra de izado.

7. Estabilizadores: dispositivos destinados a aumentar y/o asegurar la base de apoyo de una grúa en posición de trabajo.

8. Estructura giratoria: estructura orientable capaz de soportar la pluma, contrapeso y todos los mecanismos de accionamiento de la grua. No aloja necesariamente a los mecanismos de traslado de la grúa.

9. Final de carrera de órgano de aprehensión: dispositivo de seguridad que impide que el organo de aprehensión se halle muy próximo a la cabeza de la pluma o plumin.

10. Indicador del ángulo de pluma: dispositivo que permite la lectura, desde la cabina del operador, del ánguo de inclinación de la pluma en cada momentó.

11. Indicador de carga en gancho: dispositivo que permite la lectura, desde la cabina del operador, de la carga que soporta el órgano de aprehensión en cada momento.

12. Indicador de longitud de pluma: dispositivo que permite la lectura, desde la cabina del operador, de la ongitud de pluma en cada momento para aquellas grúas equipadas con pluma telescópica.

13. Indicador de momento de carga: dispositivo automático de seguridad que detecta para cada posición de trabajo la carga máxima que se puede manipular.

14. Limitador de cargas: dispositivo automático de seguridad que detecta para cada posición de trabajo la carga máxima que se puede manipular, cortando el movimiento ascendente del mecanismo de elevación y aquellos movimientos que supongan aumentar los máxi- mos momentos de carga prefijados en el correspondiente diagrama de cargas.

15. Mecanismos de elevación: mecanismo que sirve para elevar y bajar la carga en la grúa y en el que el esfuerzo es transmitido por un elemento flexible (cable) desde un tambor motor.

16. Mecanismos de extensión de la pluma: mecanismos que sirven para variar el alcance y la altura de elevación por variación de la longitud de la pluma telescópica.

17. Mecanismo de inclinación de la pluma: mecanismo que sirve para variar el alcance y la altura de elevación por variación del ángulo de inclinación de la pluma.

18. Mecanismo de orientación: mecanismo que asegura la rotación en un plano horizontal de la estructura giratoria de la grúa.

19. Organo de aprehensión: dispositivo (gancho, cuchara, electroimán, etc.). que sirve para suspender, coger o soportar la carga.

20. Pluma: componente estructural de la grúa capaz de soportar el órgano de aprehensión cargado, asegurando el alcance y la altura de elevación solícitados.

21. Suplemento de apoyo: elementos que son capaces de transmitir al suelo las acciones de la grúa.

\section{Velocidad de los movimientos.}

1. Velocidad máxima de elevación y descenso de la carga, Vn: velocidad controlada vertical de la carga elevada en régimen establecido.

2. Velocidad de giro, W: velocidad angular de la rotación de la estructura giratoria de una grúa en régimen establecido. Se determina para el máximo alcance de carga, instalada la grúa sobre un emplazamiento horizontal y con una velocidad del viento, a una altura de 10 metros, inferior a 3 metros/segundo.

3. Velocidad de traslación. $V_{k}$ velocidad de desplazamiento de la grúa en el régimen establecido. Se determina con el aparato en carga y desplazándose sobre una via o una superficie horizontal, y con una velocidad de viento, a una altura de 10 metros, inferior a $3 \mathrm{me}$ tros/segundo.

4. Velocidad de variación del alcance. V. (por ele vación y descenso de la pluma): velocidad medida del desplazamiento horizontal de la carga en el régimen establecido. Se determinan en la carrera de elevación de la pluma a partir de su alcance máximo, hasta su alcance minimo, o viceversa, estando la grúa instalada sobre un terreno horizontal y con una velocidad de viento que no sobrepase, a 10 metros de altura, 3 metros/segundo.

5. Tiempo de elevación de pluma, $t_{2}$ - tiempo mínimo necesario para elevar la pluma desde su posición de alcance maximo a la de alcance mínimo. Se determina realizando la operación de elevación de la pluma estando la grúa instalada sobre un terreno horizontal y con una velocidad de viento que no sobrepase, a 10 metros de altura, 3 metros/segundo.

6 Tiempo de telescopado de pluma, t- tiempo nece sario para pasar de la posición de pluma totalmente recogida a totalmente extendida. Se determina realizando la operación de telescopado estando la pluma en su ángulo máximo de inclinación, estando la grúa instalada sobre un terreno horizontal y con una velocidad de viento que no sobrepase, a 10 metros de altura, 3 metros/se gundo.

\section{Parametros relacionados con la base}

1. Via (k): distancia horizontal entre los ejes de carriles o de las ruedas del tren de rodadura, medida transversalmente al eje longitudinal de desplazamiento. 
2. Distancia entre ejes (B): distancia entre los ejes del tren de rodadura, medida paralelamente at eje longitudinat de desplazamiento.

3. Peso por eje (GE): peso que soporta sobre la totalidad de las ruedas acopladas a un eje.

4. Distancia entre ejes de estabilizadores (Bo): distancia entre los ejes verticales de los apoyos de los estabilizadores, medida según el oje longitudinal de despla. zamiento de la grúa.

5. Amplitud de los estabilizadores (Ko): distancia máxima entre los ejes verticales de los apoyos de los estabilizadores, medida transversalmente al eje longitudinal de desplazamiento do la gróa.

6. Pendiente superable (i): pendiente maxima. expresada en porcentaje, que la grúa puede superar

7 Contarno de apoyo: contorno formado por la proyección sobre el suelo de las lineas que unen los ejes vorticales de los elementos de apovo de la grùa.

8. Radio de la circunferencia del espacio del borde interior ( $\mathrm{Rk}$ ) radio de la circunferencia interior medida sobre un plano vortical tangente al punto mas exterior que describe la rueda de menor radio, cuando la grua ofectua la curva de menor radio (vóase esquema de apartado 10).

9. Radio de la circunferencia del espacio del borde exterior (entre bordillos) (R). radio de la circunterencia medida sobre un plano de la circunferencia medida sobre un plano vertical tangente al punto más exterior dol nou. mático cuando la grùa esta efectuando su curva de menor radio. Es igual al radio de la circunferencia de giro mas el ancho total del neumático en ese plano (véase esquema del apartado 10)

10. Radio de la circunferencia del especio del giro (entre paredes) (Ro): radio de la circunferencia que abarca los puntos más exteriores de proyección de la grúa. mientras osta ofectùa su curva de menor radio (vóase esquema).

11. Velocidad de desplazamiento en ruta, Vo: velocidad maxima de desplazamiento de la grua en orden de marcha, accionada por sus propios medios.

\section{E. Pardmotros generales.}

1. Clasificación de ta grûa y sus mecanismos: de acuerdo con la norma UNE 58-531-89.

2. Zona de proximidad espacio de seguridad que precisa la grúa durante su fase de trabajo.

\section{F. Parámetros dimensionales.}

1. Alcance o radio, L' distancia horizontal entre el eje de orientación de la parte giratoria y el eje vertical de elevación, estando el aparato de elevación instalado sobre un emplazamiento horizontal.

2 Alcance a partir dol gje de vueico, A distancia horizontal entre el eje de vueico y el eje vertical del elemento de aprehensión sin carga, estando el aparato de elevación instalado sobre un emplazamiento horizontal.

3. Amplitud do alcance: distancia horizontal ontre los ejes verticales de las posiciones extremas del elemento de aprohensión para unis determinada longitud de pluma. A la posicion extrema más proxima al eje de giro se le denomina alcance minimo; a la más alejada, alcanco maximo.

4. Longitud de pluma es, para cada configuración. la distancia expresada en metros entre el eje del giro vortical de la pluma y el eje de las poleas de izado de carga.

5. Longitud de plumin: es, para cada configuración, la distancia expresada en metros entre el punto de fijación a la pluma y el eje de sus poleas de izado de carga 6. Angulo de la pluma es el formado por el eje longitudinal de la pluma con el plano horizontal.
7. Angulo del plumin: es el formado entre el eje longitudinal del plumin y el eje longitudinal de la pluma que lo soporta

8. Zona de barrido trasero, r. radio máximo de la parte giratoria de la grua en el lado opuesto a la pluma.

9. Alture de elovación $\mathrm{H}$ distancia vertical entre el nivel de apovo de la grúa y el dispositivo de aprehensión cuando 65 te 50 encuentra on la posición más elovada de trabajo:

a) Para ganchos y horquillas, la modida se toma a su superticie de apoyo.

b) Para otros dispositivos de aprehensión la medida se toma a su punto mas bajo (en posición cerrada).

La altura de elevación se tomara sin carga y con la grüa instalada sobre un torreno horizontal.

10. Profundidad de descenso, $\mathrm{h}$; distancia vertical entre el nivel de apoyo de la grúa y el dispositivo de aprehension, estando este en su posición de trabajo más baja:

a) Para ganchos y horquillas, la medida se toma a su superticie de apoyo.

b) Para los otros dispositivos de aprehensión. ta medida se toma a su punto más bajo (en posición cerrada).

La profundidad de descenso se tomara sin carga y con la grùa instalada sobre un terreno horizontal.

11 Amplitud de elevación. D: distancia vertical entre la posición de trabajo superior e inferior del dispositivo de aprehensión.

\section{G. Parametros de carga.}

1. Momento de carga $\mathrm{M}=\mathrm{L} \cdot \mathrm{Q}$. producto de la carga nominal correspondiente (Q) por su radio o alcance (L)

2. Momento de vuelco MA $=\mathrm{A} \cdot \mathrm{Q}$. producto de la carga nominal correspondiente (a) por la distancia de su proyección af eje de vuelco (A).

3. Masa nota, Gk: masa de la grùa sin contraposos. carburante, lubricante $y$ agua.

4. Masa total Go: masa total de la grúa en orden de marcha, con contrapesos. carburante, lubricante y agua.

5. Carga sobre un apoyo, p. valor de la carga máxima vertical transmitida a través de un apoyo al camino de rodadura o al suelo.

6. Diaprama do cargas y alcances: correlación de cargas y alcances para cada longitud de pluma y configuracion de trabajo:

7. Cargas sobre estabilizadores diagrama de cargas que expresa las diferentes capacidades de elevación cuando la grua trabaja firmemonte apoyada sobre los estabilizadores y debidamente nivelada.

8. Cargas sobre ruedas: diagrama de cargas que expresa las diferentes capacidades de elevación cuando la grúa trabaja apoyada únicamente sobre las ruedas de desplazamiento de la base.

9. Cargas en $360^{\circ}$. diagrama de cargas sobre estobilizadores o sobre ruedas referido a la zona de trabajo en giro total de la estructura de $360^{\circ}$.

10. Cargas sobre el lateral: diagrama sobre estabilizadores o sobre ruedas reforido a la zona de trabajo que determine el fabricante, con la pluma orientada hacia los dos laterales de la base de la grúa.

11. Cargas por detras: diagrama de cargas sobre estabilizadores o sobre ruedas referido a la zona de trabajo que dotermine ol fabricanto, con la pluma orientada hacia la parte posterior de la base de la grúa según el sentido de marcha.

12. Cargas por delante: diagrama de cargas sobre estabilizadores o sobre ruedas reterido a la zona de tra- 
bajo que determine el fabricante, con la pluma orientada hacia la parte anterior de la base de la grúa según el sentido de marcha.

13. Coeficiente de estabilidad es la relacion, expresada on tanto por ciento, ontro las capacidades de carga de un diagrama y las que produciria el equilibrio inestable de la máquina.

H. Criterios de clasificacion.

1. Clasificación de las grúas segùn sea la base sobre la que va montada:

a) Montada sobre ruedas: aquella cuya base esta equipada de ruedas para su desplazamiento, que puede ser de desplazamiento räpido, todoterreno o mixta (desplazamiento rápido todoterreno).

b) Montada sobre cadenas: aquolla cuya base esta equipada de cadenas para su desplazamiento.

c) Montada sobre bases especiales: aquella cuya base está equipada para su desplazamiento de otros distintos de ruedas o cadenas.

2. Clasificación de las grúas según su estructura:

a) De estructura giratoria aquella cuya estructura superior completa, incluida pluma y equipo de mando, gira sobre su base.

b) De pluma giratoria: aquella cuya estructura superior, incluida la pluma, sin equipo de mando, gira sobre su base.

c) De pluma fija: aquella cuya estructura superior, incluida la pluma, os fija rospocto a su base.

d) Grua articulada: aquella cuya estructura superior incluida la pluma, es fija respecto a una base articulada

3. Clasificación de las grúas según los tipos de plumas:

a) Pluma de longitud fija pluma de longitud de funcionamionto fija que puede variarse con la incorporación o eliminacion de elementos, pero no puede modificarse durante el ciclo de trabajo

b) Pluma de celosia: pluma de longitud fija de estructura de tipo de celosia.

c) Pluma telescópica: formada por varias secciones que permiten variar su longitud por un procedimiento tolescopico.

d) Pluma sobre mástit montaje compuesto de una pluma dispuesta en, o cerca de. la cabeza de un másti vertical o casi vertical.

4. Clasificación segûn los equipos especiales:

a) Plumines:

1." Fijo: es una extension en la extremidad superion de la pluma o cerca de ella para dotarla de una longitud suplementaria de pluma. compuesto de una o varias secciones.

2. Abatible es una extensión on la extremidad superior de la pluma o cerca de ella para dotarla de una longitud suplementaria de pluma, compuesto de una o varias secciones, que se articula para permitir su giro en el plano vertical.

b) Otros equipos: son aquellos que unidos a la grũe aumentan sus capacidades y/o prestaciones.

Nota: en anexo V se muestran ejemplos de las distintas configuraciones de grúas móviles autopropulsadas.

\section{Requisitos}

Las grúas moviles autopropulsadas objeto de esta ITC deberán cumplir con las normas de seguridad que se indican en el anexo $\mathrm{l}$.

\section{Procedimiento}

1. Antes de que se realice la primera utilizacion de la grúa móvil autopropulsada, a partir de la entrada en vigor de esta ITC, su titular doberá presentar por dupt. cado, ante el organo competente de la comunidad autonoma en que radique su domicilio sociat una declaración de adecuación individualizada del parque de gruas moviles autopropulsadas que integren la empresa.

Estas declaraciones de adecuación, en el caso de grúas que no están en posesión del marcado «CEs, confondràn como minimo la información indicadas on el anexo II, incluyendo para el resto de las grúas únicamente los púrrafos a) y b) dol sonalado anoxo II $\mathrm{y}$ la declaración aCEi de conformidad.

2. El órgano competente de dicha comunidad autonoma registrara la declaración "CEu de conformidad o la declaración de adecuación de cada grúa, asignándole un numero en el Registro de aparatos do elovación (grüas: móviles autopropulsadas) sellando una copia en la que so incluirá of numero de registro asignado, copia que devolvera a la empresa propietaria, la cual deberá conservarla para las posteriores inspecciones perídicas u otras comprobaciones que fuesen pertinentes.

En el caso de que el titular de la grúa móvil autopropulsada realice el cambio de su domicilio social a otra comunidad autónoma, deberá proceder al registro de las máquinas en la comunidad autónoma corrospondiente al nuevo domiclio, pudiendo recabar los datos registrales que fueron la base del primer registro, que se respetarán en su integridad.

3. La fecha de la declaración eCE - de conformidad - de fabricación que figure en la declaración de ade. cuación en su caso, constituirá la fecha de inicio a tener on cuenta para la realización do las inspeccionos oficiales en los plazos que se fijan en el apartado 6.

\section{Mantenimiento y revisiones}

Las gruas móviles autopropulsadas objeto de esta ITC seran revisadas de acuerdo con to establecido por el fabricante de la grúa movil o de los conjuntos incorporados a ésta, en los manuales especificos para revisión y mantenimiento, cumpliendo lo ostablecido en ol capi. tulo 5 de la norma UNE 58-508-78.

E mantenimiento y revisiones de las grùas seràn res. ponsabilidad del propietario.

Las revisionos se efoctuarán por las empresas conser. vadoras que cumplan lo establecido en los articulos 10 y 12 del Reglamento de aparatos de elevación y mant tencion.

Dichas empresas conservadoras deberán contar en su plantilla y a jornada completa, en la comunidad auto. noma en que desarrollen sus actividades, como minimo, con un operario cualificado por cada 30 gruas o fracción a conservar, de los cuales al menos uno dispondrá de carno de operador de grua móvil autopropulsada correspondiente a la categoria de las gruas a conservar. Estas empresas deberản inscribirse en el Registro de establecimientos industriales, y dispondrän de local con equiparniento necesario

La responsabilidad civil de aquéllas deberá estar cubierta mediante una poliza de seguros que cubra el riesgo derivado de sus actuaciones, o mediante aval u otra garantia suficiente contratada con entidad debidamente autorizada. con una cobertura minima, por siniestro de 1.000 .000 de euros, la cual será revisada anuat. mente de acuerdo con las revisiones del indice de precios de consurno publicado por el instituto Nacional do Estadistica para dicho periodo. 
Las revisiones que doba efoctuar la empresa conservadora se realizarán, como minimo, cada seis meses, con forme a las proscripciones de ta norma UNE 58-508-78, y debera quedar reflejado of rosultado de esta revision en el libro historial de la grúa móvil autopropulsada.

\section{Inspecciones oficiales}

Poriodicidad. Las grùas objoto do esta ITC serán ins. peccionadas periodicamente con los plazos indicados a continuación:

a) Gruas hasta seis anos de antiguedad: cada tres anos.

b) Gruas de más do seis y hasta 10 anos de antiguedad. cada dos anos.

c) Grúas de más de 10 anos de antiguedad o que no acrediten la fecha de fabricación cada ano.

La antiguedad se computará de acuerdo con lo dispuesto en el apartado 4.3

Estas inspecciones serán realizadas por un organismo do control, facultado para la aplicación dol Reglamento de aparatos de elevación y manutencion. Un ejemplar del acta de inspección se entregará al propietario, y otro sera remitido al organo competente de la comunidad autónoma en que esté inscrita la empresa.

En las inspecciones oficiales se deberán controlar los conceptos que figuran en el anexo IV.

Todo ello, sin periuicio de las que pudieran corresponder con arreglo a su categoría como vehículo.

Toda grùa movil autopropulsada. conforme con las prescripciones establecidas en esta ITC, deberá colocar on parte facilmente visible de la cabina de la grùa, y bajo la responsabilidad det organismo de control que realice la inspeccion, una placa adhesiva de color verde. de $105=74 \mathrm{~mm}$, cuyo modelo se adjunta en el anexo Vili, en la que figuren los siguientes datos:

Nombre de la comunidad autonoma

IT G A.

RAE-4: 0001 (con numeración correlativa corrospondiente al R.A.E-4 de cada comunidad autonoma)

$\mathrm{N}^{\circ}$ de serie (o en su caso del bastidor).

Fecha de la proxima inspección: antes de: XXXXXXXX (mes y ano).

\section{Historial de la grùa}

1. El propietario o la emprese alquiladora tondrá a disposicion del organo competente de la comunidad autónoma o del organismo de control el historial en el que haga constar todas las incidencias derivadas de ta utifización o conservación de la grua, tales como:

a) Identificación de la grüa.

b) Sustitución o reparación de motores.

c) Sustitución o reparación de mecanismos o componentes hidraulicos.

d) Sustitución o reparacion de elementos estructurales.

e) Inspecciones oficiales de base.

f) Inspecciones oficiales de la estructura.

g) Revisiones.

1) Modificaciones de las caracteristicas de fa grúa

i) Accidentes ocurridos en la utilización de la grúa

i) Sustitución de cables de elevación.

En el anexo VI figuran los modelos, a titulo orientativo. para la formalización de dicho historial.

\section{Operador de grúa móvil autopropulsada}

Para el correcto montaje y manejo de las grúas móviles autopropulsadas, la persona que trabaja con olla debera contar con carné oficial de operador de grùa movil autopropulsada, expedido con las condiciones que 5 senalan en ol angxo VII y qug tendrá carácter nacional, todo ello con independencia de que en el caso de que ademés sea el conductor del vehiculo deba cumplir las disposiciones vigentes sobre la matoria.

En todo casó, el manejo de la grùa móvil autopropulsada se realizará bajo la dirección y supervisión del director de la obra o actividad o la persona designada por él con caracter previo al inicio de las operaciones.

Corresponderá al operador de la empresa alquiladora - titular de la grua las operaciones de montaje y de manejo de esta, y especialmente:

a) En ol montajo

La conducción de la grúa móvil.

La instalación y comprobación del funcionamionto del indicador de capacidad/limitador de capacidad, asl como de todos los dispositivos de seguridad de la grúa.

El emplazamiento de la grua a partí de los datos sobre resistencia del terreno, pesos, balance de cargas y distancias, alturas y profundidades a operar durante las maniobras, debidamente aportadas por el arrendatario.

La colocación y comprobación de las placas de apoyo y de los gatos de apoyo.

b) En el manojo:

La conducción de la grúa móvil.

Conocer las instrucciones dol fabricante para las operaciones de elevacion y mantenimiento de la grua.

La aplicación de la información contenida en registros y tablas de cargas relativas al rango de usos y de un uso seguro de la grüa.

Comprobar el funcionamionto dol limitador do cargas y del indicador de cargas.

El uso correcto y seguro de los gatos de apoyo y de la colocación de las placas de apovo de éstos.

El funcionamiento de la grúa, teniendo en cuenta los afectos del viento y otros efectos climáticos sobre la carga y sobre la grua.

Iqualmente, y en ol marco de operaciones y responsabilidad del operador de grua movil autopropulsada. y de los distintos agentes que actúan en el conjunto de operaciones de montaje y manejo de las gruas y preparacion de los trabajos que se deban efectuar, sera responsabilidad de la empresa usuaria de la grúa movi autopropulsada, especialmente:

La elección de la grúa de/con la capacidad adecuada a/para los servicios que se solicitan.

La designación del jefe de la maniobra, responsable de la supervisión y dirección de la maniobra.

La eliminación de obstáculos que impliquen riesgos. incluidas las fineas eléctricas de alta y baja tensión con conductores dosnudos, o, en casio de sor imposibie 54 eliminacion, la toma de las medidas preventivas oportunas.

La comprobación de que of terreno sobre ol que va a trabajar y circular la grúa tenga la resistencia suficiente. Ejecutar, con personas debidamente formadas, las tecnicas y labores de estrobaje y senalización.

\section{ANEXO 1}

\section{Normas de seguridad}

Las grùas a que se refiere esta ITC cumplirán con las normas y disposiciones que a continuación se especifican y que afectan al diseno y fabricación de todos aquellos componentes y mecanismos que están directamento relacionados con las condiciones de resistencia 
y seguridad. Su clasificación, a estos ofoctos, se realizara conforme a la norma UNE 58-531-89.

Notas la clasificación general de los aperatos de elevación, entre los que se encuentran los incluidos en esta ITC, esta contemplada en la norma UNE 58-112/1-91.

\section{Equipo hidradilico (vease UNE 58-506-78)}

Los cilindros hidráulicos do extensión a inclinación de pluma y los verticales de los gatos estabilizadores deberán ir provistos de válvulas de retención que eviten su recogida accidental on caso de rotura o averla en las tuberias flexibles de conexion

En el circuito de giro deberá instalarse un sistema de frenado que amortigge la parada dol movimiento de giro y evite, asimismo los esluerzos laterales que accidentaimente pueden producirse.

\section{Cables}

Se cumplira con to especificado en las normas UNE58-120/1-91. UNE58-120/2-91 y UNE58-111-91

\section{Ganchos}

En la norma UNE 58-515-82 se define su modo de sujeción, forma y utilización.

Asimismo, todo gancho debe llevar incorporado el correspondiente cierre de seguridad que impida la salida de los cables.

\section{Contrapesos}

Aquellas grùas en que sea necesaria la utilizacion de un contrapeso constituido en uno o varios bloques desmontables dispondrän de las fijaciones necesarias del contrapeso a la estructura para evitar desprendimiento.

\section{Cabina de mando}

Las cabinas seràn de construcción corrada y se ins. talarán de modo que el operador tenga durante las maniobras el mavor campo de visibilidad posible, tanto en las puertas de accoso como en los laterales $y$ ventanas.

Las cabinas estarán provistas de accesos fáciles y seguros desde el suelo, y en su interior se instalarár diagramas de cargas y alcances, rotulos $\theta$ indicativos necesarios para la correcta identificación de todos los mandos e iluminacion.

\section{Corona de orientacion}

Las coronas de orientación que se instalen en las gruas moviles autopropulsadas, así como los sistomas utílzados para su unión a las partes de aquellas (base y estructural, serán de capacidad suficiente para resistir los esfuerzos producidos por al funcionamiento de la grúa.

En cualquior caso, y siompre que sea posible, debera asegurarse el acceso de los utiles necesarios para verificar 0 , en su caso, aplicar los pares de aprietes que corrospondan a la calidad de la tornilloria establecido por el fabricante de la corona.

\section{Otros elementos de segunidad}

Las grûas móvilos autopropulsadas, cuya puosta on el mercado no se haya hecho de conformidad con io senalado en el Reat Decreto 1435/1992. sobre máquinas, deberán estar provistas $y$ en corrocto funcionamien- to, como minimo, de los olementos de seguridad siguien tes, además de los indicados anteriormente:

a) Grùas de hasta 80 toneladas o de longitud de pluma con o sin plumín menor o igual de 60 metros.

Final de carrera del órgano de aprehensión. Indicador del ângulo de pluma.

Limitador de cargas

b) Grùas de más de 80 toneladas o de longitud de pluma con o sin plumin mayor de 60 metros:

Final de cartora del organo de aprehension. indicador del ângulo de pluma.

Indicador de carga en ganchos o indicador de momento de cargas

Limitador de cargas.

\section{Letreros e indicativos}

Todos los letroros, indicativos, avisos e instrucciones. tanto interiores como exteriores, que figuren en las gruas objeto de esta ITC, deberán estar redactados, al menos, en castellano.

\section{ANEXO $\|$}

\section{Declaración de adecuación}

La declaración de adecuación de la grùa autopropulsada a que se refiere el apartado 4 de esta ITC contendrá. como minimo, lo siguiente:

a) Nombre y dirección del propietario de la grúa, o de su representante legal.

b) Datos identificativos de la grúa (marca, tipo. número de serie, etc), acompanada por las descripciones. planos, fotografias, otc, necosarios para definirla.

c) Certificado de adecuación de la grúa a las pres. cripciones técnicas correspondientes del anexo L firmado por el organismo de control, con indicación de las soluciones adoptadas para su cumplimiento.

d) Manual de instrucciones de la grúa.

\section{ANEXO III}

\section{Relación de normas UNE necesarias para el cumplimiento de la ITC}

Este anexo tiene por objeto relacionar todas aquellas normas UNE que son necesarias para dar cumplimiento a lo especificado on osta ITC.

\begin{tabular}{|c|c|}
\hline Cosign nemina URA & Tam \\
\hline $58-111-91$ & $\begin{array}{l}\text { Cables para aparatos de olevación. } \\
\text { Criterios de examen y de sustitucion de } \\
\text { los cables. }\end{array}$ \\
\hline $58-112 / 1-91$ & Grúas y aparatos de elevación. \\
\hline $58-120 / 1-91$ & $\begin{array}{l}\text { Gruas y aparatos de elevación. } \\
\text { Selocción de cables. Parte 1; genera- } \\
\text { lidades. }\end{array}$ \\
\hline $58-120 / 2-91$ & $\begin{array}{l}\text { Grúas y aparatos de elevación. } \\
\text { Selección de cables. Parte } 2 \text { gruas movi- } \\
\text { les. Coeficiente de utilización. }\end{array}$ \\
\hline $\begin{array}{l}58-506-78 \\
58-508-78\end{array}$ & $\begin{array}{l}\text { Grúas móviles. Equipo hidráulico. } \\
\text { Instrucciones de servicio para manejo y }\end{array}$ \\
\hline $\begin{array}{l}58-515-82 \\
58-531-89\end{array}$ & $\begin{array}{l}\text { Ganchos do olovación. Nomonclatura. } \\
\text { Aparatos de elevación. Clasiticación. } \\
\text { Grúas móviles. }\end{array}$ \\
\hline
\end{tabular}




\section{ANEXO IV Ficha de inspecciones oficiales}

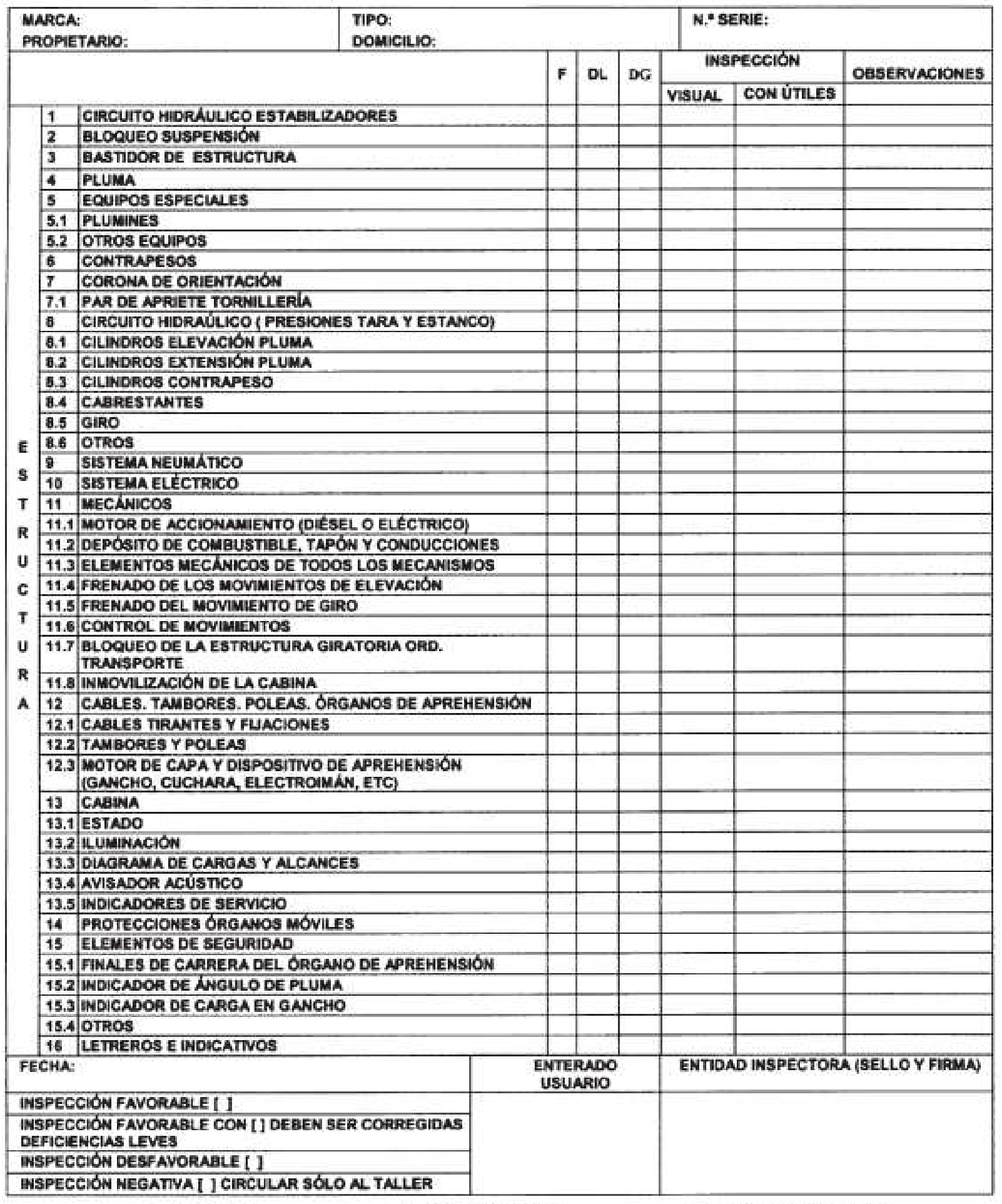

$$
F=\text { FAVORABLE }
$$


ANEXO V Ejemplos de las distintas configuraciones de grúas móviles autopropulsadas
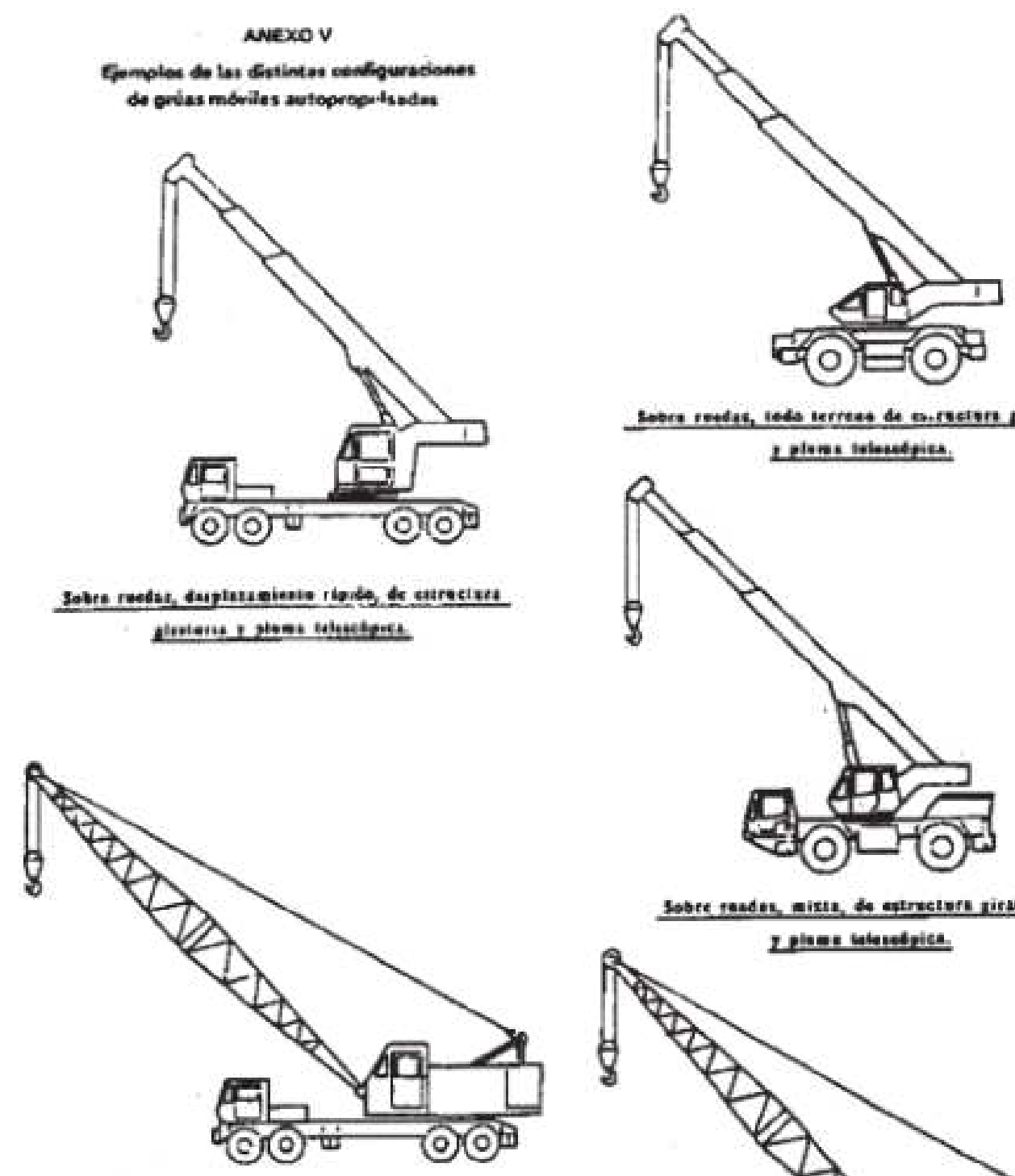

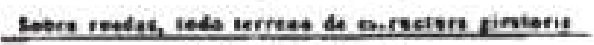
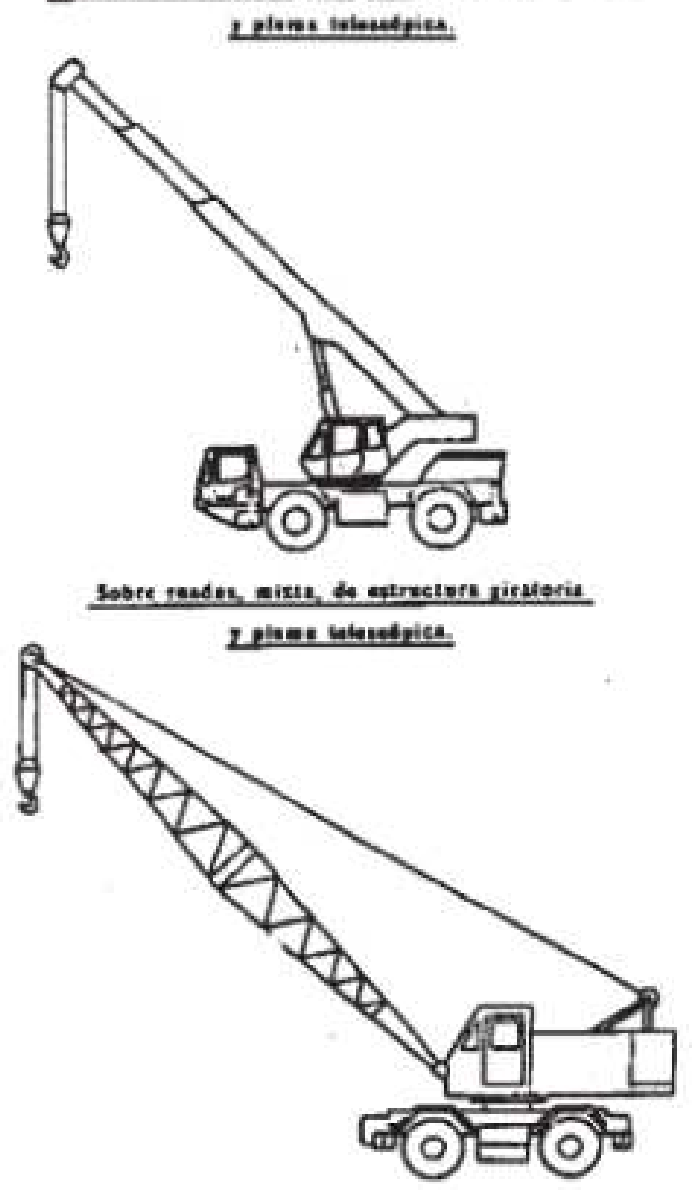

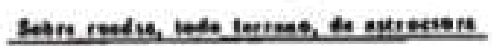

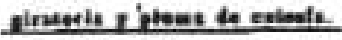




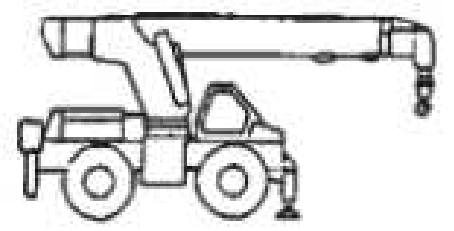

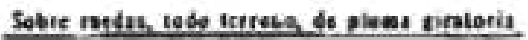
1 bestetess.

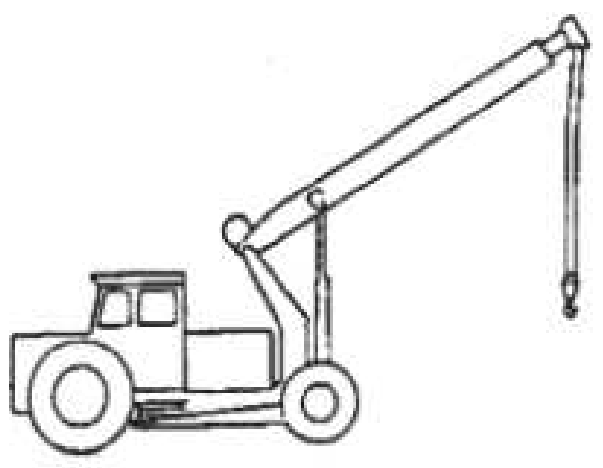

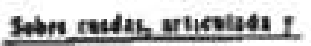

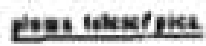

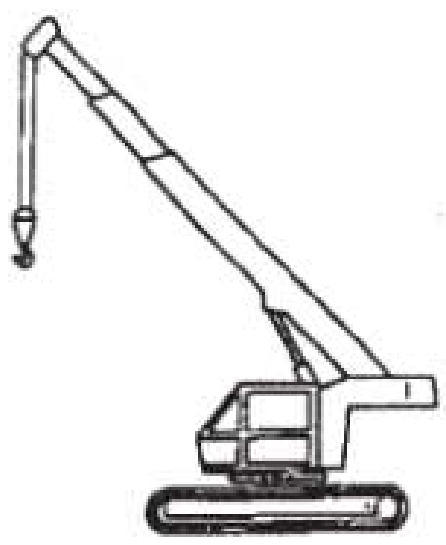

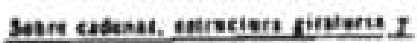
tanas colucteries.

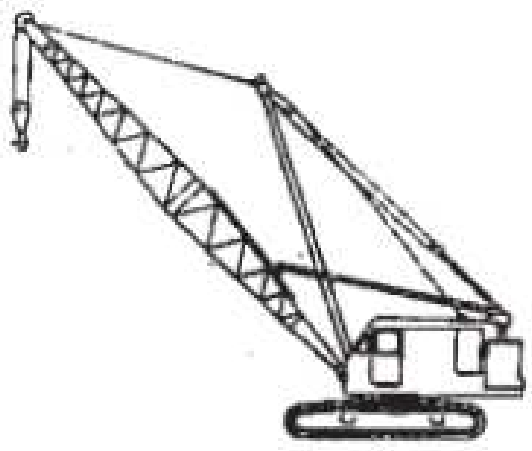

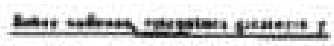
Leternathis.

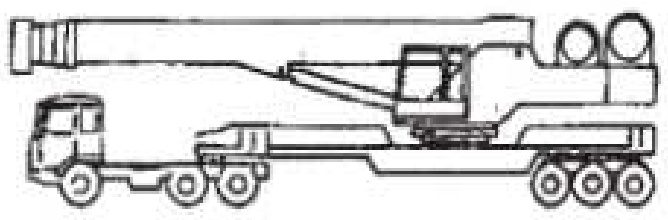

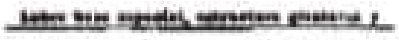

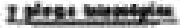

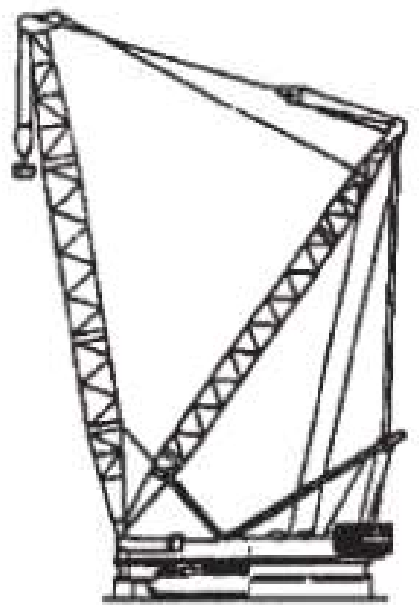

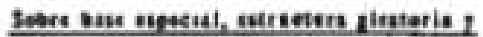

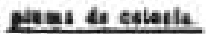




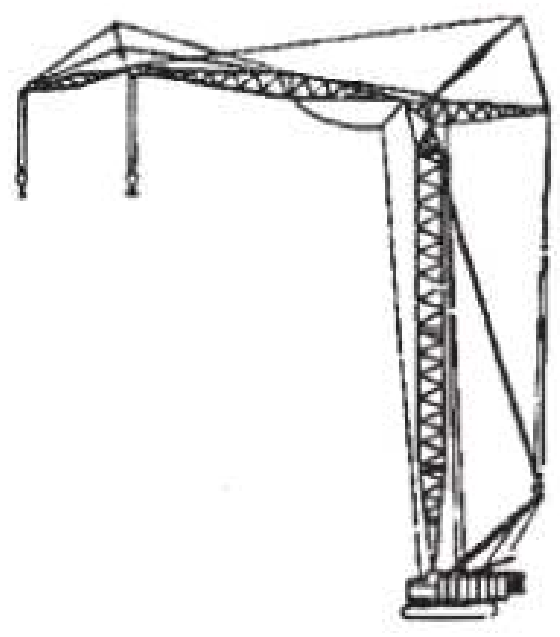

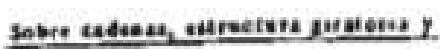
phes sober intuli.

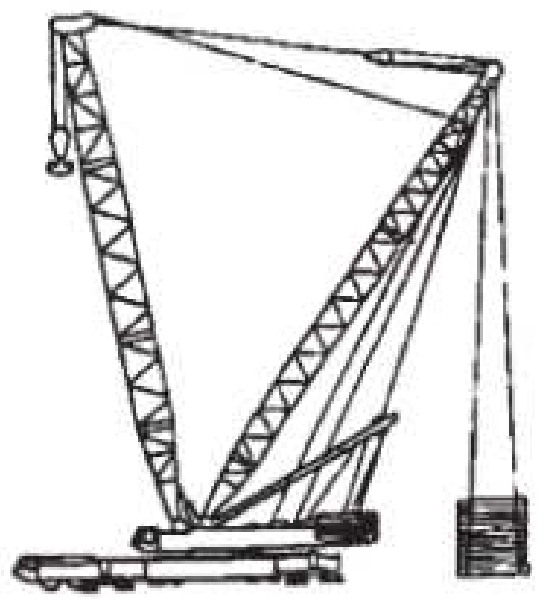

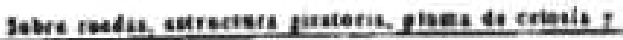
staip especial.

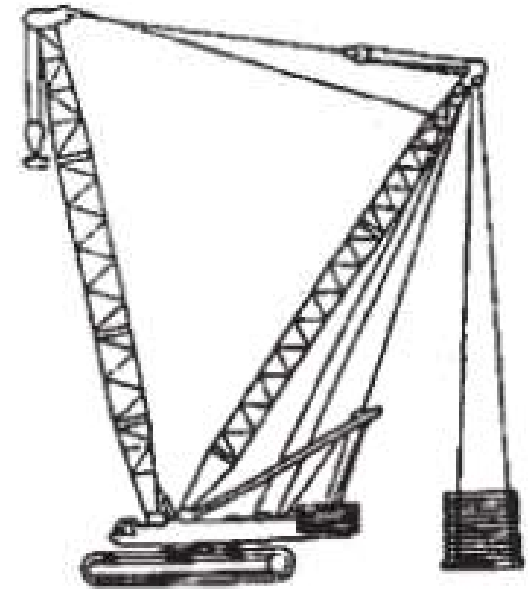

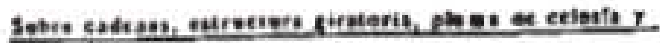
orese stpesint.

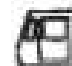

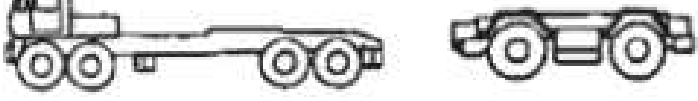

Ban teres indet.

nove sober roden.

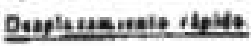
Tede numes.

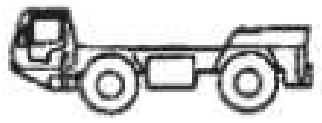

neer nobar reades. Mats

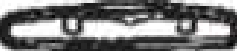

Des tetresceters

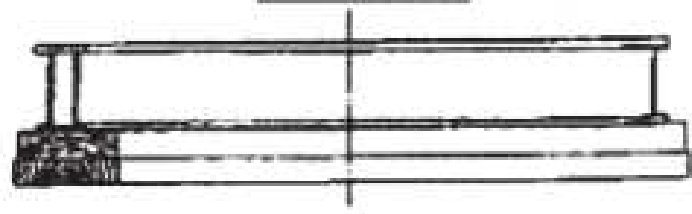

Eapesenerial 

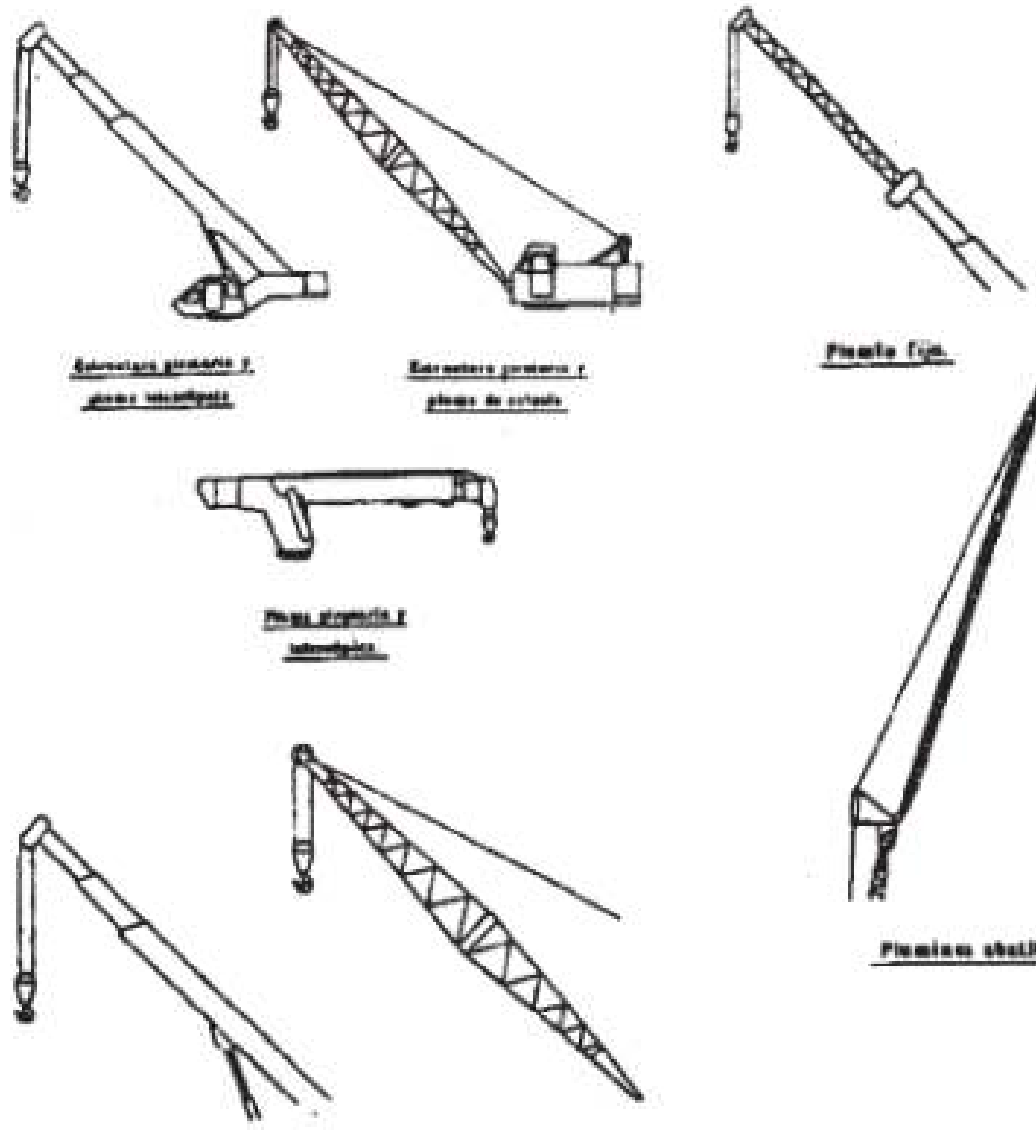

netefise
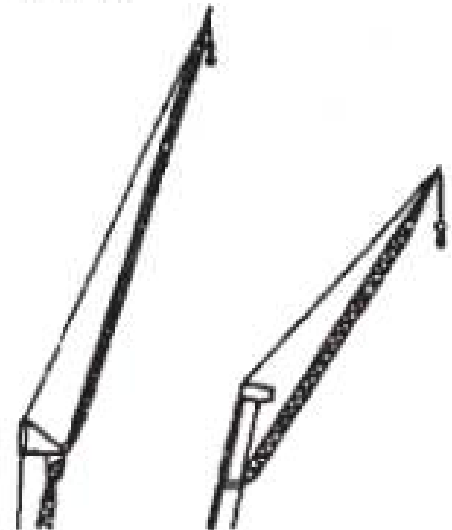

mencendests

mose teteds.

Preseines watians.
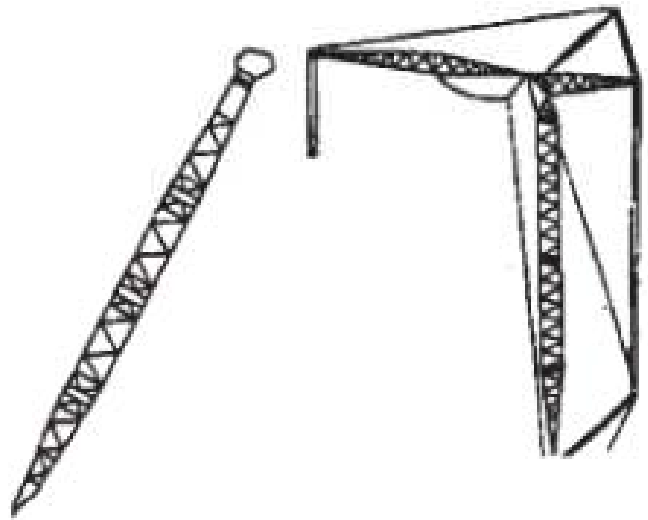

nate a wested in

Detpentase 
ANEXO VI

Libro historial de la grúa

1. Identificación de la grúa:

\begin{tabular}{|c|c|}
\hline Grúa n. ${ }^{\circ} \ldots$. & Propietario: \\
\hline Marca....... : & \\
\hline $\begin{array}{l}\text { Tipo. ........ . } \\
\text { N. }{ }^{0} \text { de serie. . } \\
\text { Matricula . . : }\end{array}$ & Domicilio: \\
\hline
\end{tabular}

2.1. Registro de inspecciones oficiales de la base:

\begin{tabular}{|c|c|c|c|c|}
\hline \multicolumn{5}{|c|}{ INSPECCIONES OFICIALES DE LA BASE } \\
\hline FECHA & TIPO & $\begin{array}{c}\text { ENTIDAD } \\
\text { INSPECTORA } \\
\text { (O.C.A.) }\end{array}$ & $\begin{array}{c}\text { RESULTADO } \\
\text { (Firma y sello dol } \\
\text { O.C.A.) }\end{array}$ & $\begin{array}{c}\text { PROXIMA } \\
\text { REVISION }\end{array}$ \\
\hline & & & & \\
\hline & & & & \\
\hline & & & & \\
\hline & & & & \\
\hline & & & & \\
\hline & & & & \\
\hline & & & & \\
\hline & & & & \\
\hline
\end{tabular}

2.2. Registro de inspecciones oficiales de la estructura:

\begin{tabular}{|c|c|c|c|c|}
\hline \multicolumn{5}{|c|}{ INSPECCIONES OFICIALES DE LA ESTRUCTURA } \\
\hline FECHA & TIPO & $\begin{array}{c}\text { ENTIDAD } \\
\text { INSPECTORA } \\
\text { (O.C.A.) }\end{array}$ & $\begin{array}{c}\text { RESULTADO } \\
\text { (Firma y sello del } \\
\text { O.C.A.) }\end{array}$ & $\begin{array}{c}\text { PROXIMA } \\
\text { REVISION }\end{array}$ \\
\hline & & & & \\
\hline & & & & \\
\hline & & & & \\
\hline & & & & \\
\hline & & & & \\
\hline & & & & \\
\hline & & & & \\
\hline & & & & \\
\hline
\end{tabular}


3. Registro de revisiones técnicas periódicas:

\begin{tabular}{|l|l|l|l|}
\hline \multicolumn{5}{|c|}{ REVISIONES TÉCNICAS PERIODICAS } \\
\hline FECHA & CONCEPTO & $\begin{array}{c}\text { EMPRESA } \\
\text { MANTENEDORA }\end{array}$ & RESULTADO \\
\hline & & & \\
\hline & & & \\
\hline & & & \\
\hline & & & \\
\hline & & & \\
\hline & & & \\
\hline & & & \\
\hline
\end{tabular}

4. Registro de reparaciones realizadas:

\begin{tabular}{|c|c|c|}
\hline \multicolumn{3}{|c|}{ REPARACIONES REALIZADAS O PIEZAS SUSTITUIDAS } \\
\hline FECHA & $\begin{array}{c}\text { TIPO DE REPARACION ON O } \\
\text { TIPO DE SUSTITUCION }\end{array}$ & $\begin{array}{c}\text { EMPRESA } \\
\text { MANTENEDORA }\end{array}$ \\
\hline & & \\
\hline & & \\
\hline & & \\
\hline & & \\
\hline & & \\
\hline & & \\
\hline & & \\
\hline & & \\
\hline
\end{tabular}

5. Registro de accidentes:

\begin{tabular}{|l|c|}
\hline \multicolumn{2}{|c|}{ ACCIDENTES } \\
\hline FECHA & DESCRIPCION \\
\hline & \\
\hline & \\
\hline & \\
\hline & \\
\hline & \\
\hline & \\
\hline & \\
\hline & \\
\hline & \\
\hline
\end{tabular}




\section{ANEXO VII}

\section{Carné de operador de grúa móvil autopropulsada}

\section{Objeto y ambito de aplicacion}

Este anexo tiene por objeto el regular los requisitos y el procedimiento para la obtención del carné de operador de grúa móvil autopropulsada.

\section{Carné de operador de grúa móvil autopropulsada}

Para el montaje y manejo de las grúas móviles autopropulsadas a las que se refiere estra ITC, se exigirá la posesión del camé de operador de grúa móvil autopropulsada de, al menos, categoría igual o superior a la correspondiente a su carga nominal, obtenido de acuerdo con lo senalado en este anexo.

El carné que se establece se delimita en las siguientes categorias

Categoria A: habilita a su titular para el montaje y manejo de grúas móviles autopropulsadas de hasta $130 \mathrm{t}$ de carga nominal, inclusive.

Categoría B: habilita a su titular para el montaje y manejo de grúas móviles autopropulsadas de más de 130 t de carga nominal.

\section{Requisitos para la obtención del carné}

La obtención del carné requerirá la concurrencia de los siguientes requisitos:

a) Estar en posesión del título de estudios primarios. b) Tener cumplidos 18 anos en el momento de realizar la solicitud del curso que se cita en el párrafo c).

c) La superación de un curso teórico-práctico impartido por una entidad acreditada por el organo competente de la comunidad autónoma.

d) La superación de un examen teórico-práctico realizado por el órgano competente de la comunidad autónoma en la que radique la entidad que impartió el curso.

e) Superar un examen médico, psicotécnico y físico. especifico para este tipo de actividades, que incluye examen sobre agudeza visual, sentido de la orientación, equilibrio y agudeza auditiva.

\section{Curso teónicopráctico}

El curso a que se refiere el párrafo c) del apartado anterior estará compuesto por un módulo de formación teórica y un módulo de formación práctica, con la duración y contenido, de acuerdo con la categoria, siguientes:

a) Duración:

\begin{tabular}{|c|c|c|c|}
\hline Categoris & $\begin{array}{c}\text { Formadion 1patica } \\
\text { (heras) }\end{array}$ & $\begin{array}{c}\text { Farmocion pristica } \\
\text { (thoras) }\end{array}$ & $\begin{array}{c}\text { Formeoden tots } \\
\text { (horas) }\end{array}$ \\
\hline $\begin{array}{l}\mathrm{A} \\
\mathrm{B}\end{array}$ & $\begin{array}{c}75 \\
150\end{array}$ & $\begin{array}{l}225 \\
300\end{array}$ & $\begin{array}{l}300 \\
450\end{array}$ \\
\hline
\end{tabular}

A estos efectos, a los titulares de carné de operador de grúa móvil autopropulsada de categorla A, para acceder a un carné de categoría B, se les computará como tiempo efectuado en la formación teórica y práctica el senalado para la categoría A, debiendo realizar el periodo restante de formación práctica con grúas móviles autopropulsadas de carga nominal comprendida en la categoria B.

\section{b) Formación teórica:}

Reglamentación aplicable (Reglamento de aparatos de elevación y manutención, ITC aMIE-AEM-4 " y normas UNE).

Descripción de la grúa móvil autopropulsada y componentes (pluma, plumin, estabilizadores, cabina y accesos, ganchos, cables, etc.). Funcionamiento general.

Tipos de grúa móvil autopropulsada. Clasificación. Diferencias entre grúas telescópicas y de celosía.

Nociones de resistencia de materiales (fuerzas, momentos, estabilidad). Centro de gravedad Momento de vuelco. Cálculo de pesos. Soldaduras. Perfiles (ant gulares, cuadrados, redondos)

Nociones de electricidad (efectos, protecciones).

Nociones de mantenimiento. Niveles de aceite y agua. Presión de los neumáticos. Equipos de inyección y bombas. Sistemas de funcionamiento mecánico, eléctrico o hidráulico. Sistemas de refrigeración. lubricación y frenos.

Elementos de seguridad de las grúas móviles autopropulsadas (indicador y limitador de carga, indicador de radio, limitadores de movimientos, etc.). Coeficientes de seguridad.

Montaje y desmontaje de las grúas móviles autopropulsadas. Mecanismos de extensión de la pluma. Procedimientos de montajes especiales (grúas de celosía, plumines, etc.).

Emplazamiento de la grúa en la zona de trabajo (visión general del entorno, taludes, líneas eléctricas, conducciones subterráneas, resistencia del terreno, etc.).

Utiles de enganche: elección del método más apropiado, conservación y mantenimiento (estrobos de acero, cadenas, eslingas de poliéster, grilleteș). Revisiones y marcaje. Formas de estrobar la carga. Útiles especiales (balancines).

Operaciones normales con la grúa (estrobaje, nivelación, interpretación de diagramas de cargas, senales, etc.). Maniobras prohibidas.

Operaciones especiales con la grúa (pilotaje, elevación de una carga con más de una grúa, desplazamientos con la grúa totalmente montada y desplegada, elevación de una carga sin estabilizadores, derribo y demolición con bola). Precauciones en interiores.

Operaciones de grúas con peligros próximos (taludes. lineas eléctricas aereas, aeropuertos, ferrocarril, carreteras, plantas de proceso industrial, etc.)

Verificaciones diarias, semanales y semestrales. Mantenimiento y conservación de la grúa móvil autopropulsada (sistema de elevación y vehiculo). Inspecciones de los cables de acero y sustitución. Comprobación del sistema hidráulico y válvulas anti-retomo.

Deberes y responsabilidades del operador de grúa móvil autopropulsada, del eganchador o estrobador y del jefe de la maniobra.

Prevención de riesgos laborales: seguridad en servicio Seguridad con viento Senalización. Desplazamiento con cargas. Control de las medidas de seguridad. Equipos de trabajo.

\section{c) Formación práctica:}

Toma de contacto con la grúa. Explicar puesta en funcionamiento para operar desde la estructura. Movimientos desde la estructura giratoria en vacio y con carga.

Normas de manejo (maniobras permitidas y prohibidas). Senales.

Realización de las comprobaciones diarias y semanales de seguridad.

Operaciones con los sistemas de seguridad, Utilización del sistema de control electrónico de la grúa (wordenador de a bordow). 
Mantenimiento de la grủa: diferentes puntos de engrase, verificación de niveles de aceite, limpieza, etc.

Ejercicios para estabilizar la grúa en diferentes tipos de terreno. Desplazamiento de grúa desplegada con carga y en vacio.

Montaje de plumin y su utilización.

Adiestramiento en el manejo con carga: simulación de montaje de grúa torre, tumbar o levantar silo de cemento, hormigonar con caidero, descarga de palés de ladrillo, etc

Prácticas de eslingaje: reconocimiento de los diferentes tipos de estrobos, eslingas, grilletes, cadenas, ganchos, y su utilizacion correcta.

Conducción en carretera: puertos de montana, pendientes y rampas prolongadas, etc.

Conducción atodoterrenon: utilización de reductoras $\mathrm{y}$ bloqueos.

Reconocimiento de diferentes tipos de terreno.

Normas de seguridad en el trabajo.

\section{Entidades reconocidas para impartir cursos}

El órgano competente de la comunidad autónoma podrá reconocer como entidad acreditada para dar el curso téorico-práctico de operador de grúa móvil autopropulsada a las entidades que reúnan los siguientes requisitos:

5.1 Disponer de los medios y recursos minimos necesarios, personales y materiales (personal, locales y medios técnicos auxiliares), que como mínimo serán:

a) Personal:

Director del curso: ingeniero superior o técnico con experiencia acreditada en el sector.
Profesorado para formación teórica: ingeniero superior o técnico con experiencia acreditada en el sector. Profesorado para formación práctica: oficial cualificado con experiencia acreditada de al menos tres anos en el sector.

b) Instalaciones:

Local independiente con capacidad y mobiliario suficiente para impartir la formación teórica.

Espacio adecuado para impartir la formación práctica.

c) Medios técnicos auxiliares:

Elementos de grúas, motores, cables, rodamientos, manuales de mantenimiento, aparatos de medida eléctricos y mecánicos y llaves dinamométricas.

5.2 Disponer de grúas autopropulsadas, con una antiguedad máxima de seis anos, en funcionamiento y para uso exclusivo de la entidad acreditada, durante el curso.

5.3 Acreditar el programa de desarrollo del curso, con detalle de contenidos, distribución de tiempos y profesorado.

\section{Expedición y validez del carne}

6.1 El carné de operador de grúa móvil autopropulsada será expedido por el órgano competente de la comunidad autonoma, una vez acreditado por el solicitante el cumplimiento de los requisitos establecidos en el apartado 3 de este anexo.

6.2 El carné tendrá una validez de cinco anos, transcurridos los cuales podrá ser objeto de renovación por periodos quinquenales, previa acreditación del requisito establecido en el apartado 3.1.e) de este anexo. 


\section{ANEXO VIII}

Modelo de placa adhesiva (dimensiones 105x74 mm)

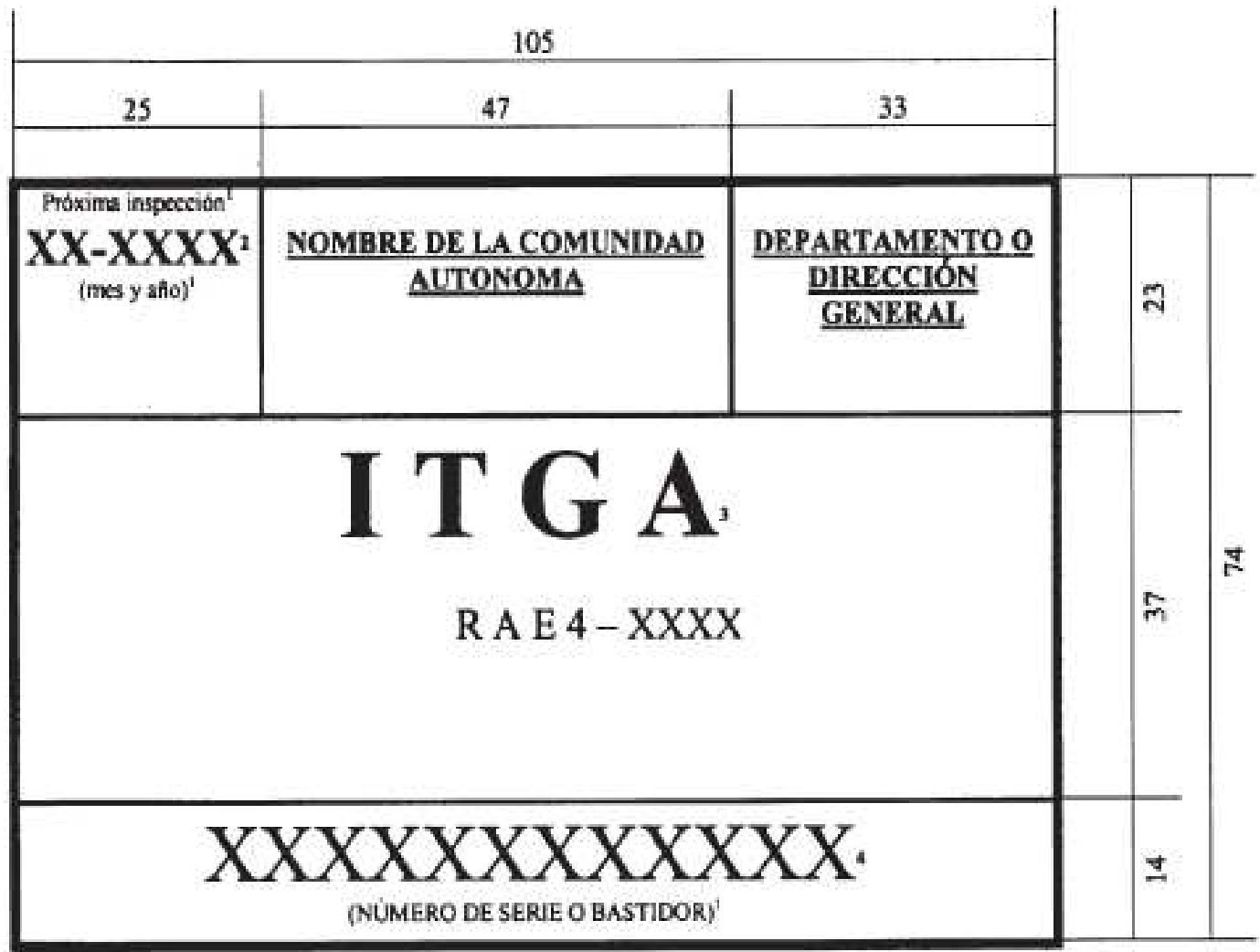

Tamaño de las letras:

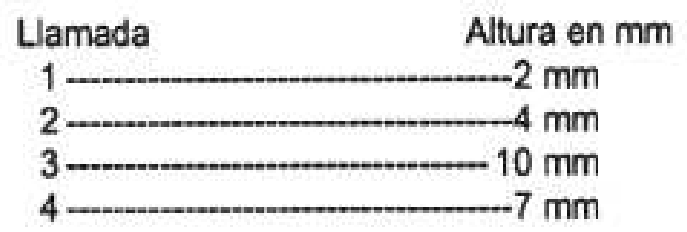

